Universidade de São Paulo

Escola de Engenharia de São Carlos

Departamento de Engenharia de Estruturas

\title{
ANÁLISE TEÓRICA E EXPERIMENTAL DE TRELIÇAS METÁLICAS ESPACIAIS CONSTITUÍDAS POR BARRAS COM EXTREMIDADES ESTAMPADAS
}

\section{CARLOS HENRIQUE MAIOLA}

Dissertação apresentada à Escola de Engenharia de São Carlos da Universidade de São Paulo, como parte dos requisitos para obtenção do Título de Mestre em Engenharia de Estruturas

ORIENTADOR: Prof. Dr. Maximiliano Malite 
CHass. KESE- EESC

Cutt.

Tombo

$5 / 51034356$

Ficha catalográfica preparada pela Seção de Tratamento da Informação do Serviço de Biblioteca - EESC/USP

Maiola, Carlos Henrique
Análise teórica e experimental de treliças metálicas
espaciais constituídas por barras com extremidades
estampadas / Carlos Henrique Maiola. -- são Carlos,
1999.
Dissertação (Mestrado) -- Escola de Engenharia de
São Carlos-Universidade de São Paulo, 1999.
Area: Engenharia de Estruturas.
Orientador: Prof. Dr. Maximiliano Malite.
1. Estruturas metálicas. 2. Estruturas de aço.
3. Estruturas espaciais. 4. Treliças espaciais.
Instabilidade. I. Título.




\section{FOLHA DE APROVACÃO}

\section{Candidato: Engenheiro CARLOS HENRIQUE MAIOLA}

Dissertação defendida e aprovada em 25-03-1999 pela Comissão Julgadora:

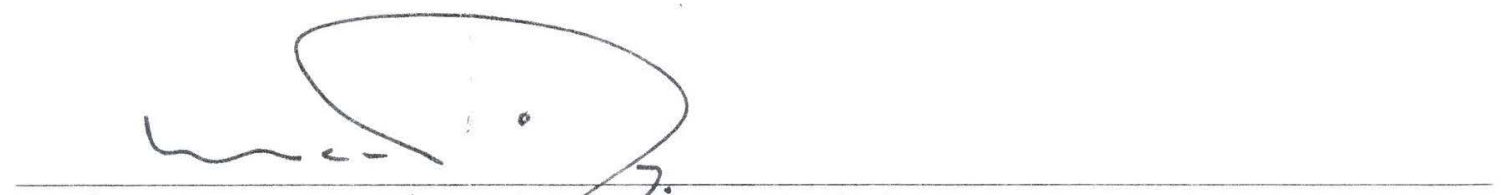

Prof. Doutor MAXIMILIANO MÁLITE (Orientador)

(Escola de Engenharia de Săo Carlos - Universidade de São Paulo)

Prof. Doutor ROBERTO MARTINS GONÇALVES

(Escola de Engenharia dê São Carlos - Universidade de São Paulo)

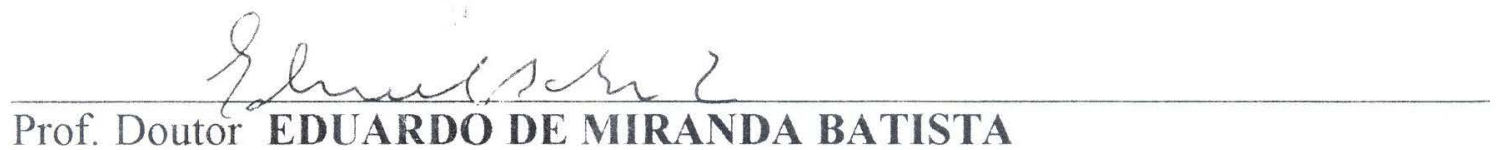

(Universidade Federal do Rio de Janeiro - UFRJ)

Prof. Titular CARLITO CALIL JUNIOR

Coordenador da Área de Engenharia de Estruturas

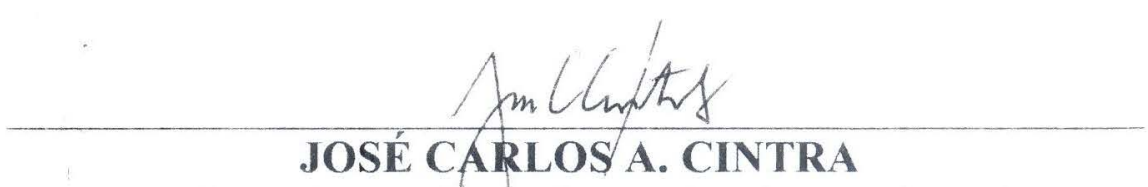

Presidente da Comissã̃o de Pós-Graduação da EESC 
Ao Deus Poderoso, o qual me conduz pelo caminho da vida entre flores e pedras, nas quais muitas vezes tropeço, mas Ele sempre me estende a mão.

Àqueles que são responsáveis pelo que sou, meus pais, Dorival e Terezinha, que espero um dia alcança-los em graça e sabedoria.

$\mathcal{A}$ minha querida irmã, Carla.

À minfia amada Mi, pela compreensão, carintio e disposição em acompantiar-me por esse processo de nossas vidas. 


\section{Agradecimentos}

Ao Professor Dr. Maximiliano Malite, pela orientação e amizade em todos os momentos.

Aos Professores Drs. Roberto e Jairo, pelo apoio.

Aos colegas do Departamento de Estruturas, pelo companheirismo e amizade.

Aos amigos, Pr. Jarbas e Luci, pelo apoio e amizade.

Às secretárias do Departamento de Estruturas, às funcionárias da Biblioteca e aos funcionários do Laboratório de Estruturas pela constante disposição em ajudar-me.

À ALUSUD, pela doação da estruturas ensaiadas.

À FAPESP, pelo apoio financeiro. 


\section{SUMÁRIO}

LISTA DE FIGURAS.......................................................................

LISTA DE TABELAS........................................................................

LISTA DE SÍMBOLOS...................................................................... vi

RESUMO

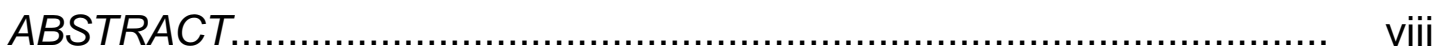

CAPÍTULO 1 - INTRODUÇÃO......................................................... 01

CAPÍTULO 2 - REVISÃO BIBLIOGRÁFICA.......................................... 06

2.1 - Aspectos gerais..................................................... 06

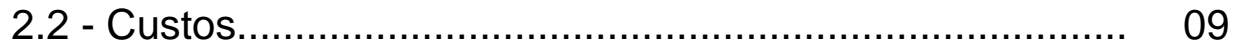

2.3 - Análise estrutural..................................................... 12

2.4 - Instabilidade das treliças espaciais.............................. 15

2.5 - Fatores que influenciam na resistência......................... 16

2.6 - Ensaio de barras isoladas.......................................... 19

2.6.1 - Descrição dos elementos ensaiados.................... 20

2.6.2 - Ensaio das barras............................................... 22

2.6.3 - Análise teórica................................................. 26

2.6.4 - Comentários sobre os ensaios de barra isolada... $\quad 30$

CAPÍTULO 3 - ANÁLISE EXPERIMENTAL........................................... 32

3.1 - Descrição dos protótipos............................................... 33

3.2 - Estrutura de reação e aplicação de força....................... 37

3.3 - Montagem dos protótipos............................................. 39

3.4 - Equipamentos utilizados............................................. 40

3.4.1 - Posicionamento da instrumentação....................... 42

3.5 - Procedimento de ensaio dos protótipos......................... 50 
CAPÍTULO 4 - ANÁLISE NUMÉRICA............................................... 51

4.1 - Elementos finitos utilizados......................................... 52

4.2 - Descrição da modelação............................................. 55

4.2.1 - Modelação como treliça ideal............................... 55

4.2.2 - Modelação dos protótipos com nó típico.............. 56

4.2.3 - Modelação do protótipo com nó de aço................ 58

4.2.4 - Modelação do protótipo com sistema misto de conexão....................................................... 59

4.2.5 - Compatibilizações de deslocamentos e rotações. $\quad 60$

CAPÍTULO 5 - RESULTADOS E DISCUSSÕES.................................... 62

5.1 - Resultados da análise numérica....................................... 62

5.2 - Resultados da análise experimental.............................. $\quad 74$

5.2.1 - Ensaio de tração................................................ 74

5.2.2 - Ensaio de compressão....................................... $\quad 79$

5.2.3 - Ensaio dos protótipos........................................ 82

5.2.3.1 - Modos de falha....................................... 82

5.2.3.2 - Deslocamentos...................................... $\quad 85$

5.2.3.3 - Deformações........................................... 90

CAPÍTULO 6 - CONCLUSÕES............................................................. 100

$\begin{array}{ll}\text { BIBLIOGRAFIA } & 105\end{array}$

APENDICE A - Planilha dos resultados dos ensaios dos protótipos PROT 1 a PROT 4 


\section{LISTA DE FIGURAS}

FIGURA 1.1 - Nó típico................................................................. 03

FIGURA 1.2 - Nó de aço................................................................. 03

FIGURA 1.3 - Vista geral do protótipo PROT 1 ……......................... 04

FIGURA 2.1 - Graham Bell e o que seria a primeira estrutura espacial 07

FIGURA 2.2 - Sistemas de nós comerciais mais conhecidos................ 08

FIGURA 2.3 - Sistema de conexão MERO.......................................... 09

FIGURA 2.4 - Representação do sistema CATRUS............................ 10

FIGURA 2.5 - Dispositivos de nó analisados neste trabalho. Extraído do catálogo ALUSUD............................................... 11

FIGURA 2.6 - Representação do nó WACO, DE MARTINO (1992)...... 12

FIGURA 2.7 - Relação força $x$ deformação idealizada por MADI \& EL-TAYEM (1994)............................................... 14

FIGURA 2.8 - Detalhe das extremidades das barras ensaiadas........... 21

FIGURA 2.9 - Vista geral do ensaio de barra isolada e detalhe dos apoios................................................................. 22

FIGURA 2.10 - Gráfico -Força x Deslocamento (Extrem. tipo A - $\lambda=60$ ).. 24

FIGURA 2.11 - Gráfico -Força x Deslocamento (Extrem. tipo A - $\lambda=100$ ) 24

FIGURA 2.12 - Gráfico -Força x Deslocamento (Extrem. tipo A - $\lambda=140$ ) 24

FIGURA 2.13 - Gráfico -Força x Deslocamento (Extrem. tipo B - $\lambda=60$ ).. 24

FIGURA 2.14 - Gráfico -Força x Deslocamento (Extrem. tipo B - $\lambda=100$ ) 24

FIGURA 2.15 - Gráfico -Força x Deslocamento (Extrem. tipo B - $\lambda=140$ ) 24

FIGURA 2.16 - Gráfico -Força x Deslocamento (Extrem. tipo C - $\lambda=60$ ). 25

FIGURA 2.17 -Gráfico -Força x Deslocamento (Extrem. tipo C - $\lambda=100$ ) 25

FIGURA 2.18 -Gráfico -Força x Deslocamento (Extrem. tipo C - $\lambda=140$ ) 25

FIGURA 2.19 - Gráfico - Força x Deformação (Extrem. tipo A - $\lambda=100$ ).. 25

FIGURA 2.20 - Gráfico - Força x Deformação (Extrem. tipo $B-\lambda=100)$.. 25

FIGURA 2.21 - Gráfico - Força x Deformação (Extrem. tipo $C$ - $\lambda=100$ ).. 25

FIGURA 2.22 - Força x Deslocamento relativo (Extrem. tipo C - $\lambda=140$ ) 25

FIGURA 2.23 - Força $x$ Deslocamento relativo (Extrem. tipo $C$ - $\lambda=100$ ) 25

FIGURA 2.24 - Força $x$ Deslocamento relativo (Extrem. tipo $C-\lambda=60$ ).. 25

FIGURA 2.25 - Momentos de inércia para os três tipos de extremidade. 28 
FIGURA 2.26 - Curvas de resistência à compressão e resultados experimentais.

FIGURA 3.1 - Esquema geral dos protótipos.

FIGURA 3.2 - Disposição dos nós do protótipo com sistema misto de conexão.

FIGURA 3.3 - Detalhe do nó típico...

FIGURA 3.4 - Detalhe do nó de aço.

FIGURA 3.5 - Vista geral e detalhe do sistema de apoio.

FIGURA 3.6 - Vista geral das estruturas de reação para a aplicação de força....

FIGURA 3.7 - Montagem do protótipo no piso do laboratório..................

FIGURA 3.8 - Preparação para o içamento do protótipo.........................

FIGURA 3.9 - Esquema geral do ensaio: aplicação de forças..

FIGURA 3.10 - Detalhe do sistema de aplicação de forças e do nó de aço fabricado para ancoragem da cordoalha.

FIGURA 3.11 - Detalhe dos transdutores de deslocamento.

FIGURA 3.12 - Detalhe da instrumentação com extensômetros elétricos

FIGURA 3.13 - Posicionamento das células de carga.

FIGURA 3.14 - Posicionamento da instrumentação do PROT 1...............

FIGURA 3.15 - Posicionamento da instrumentação do PROT 2...............

FIGURA 3.16 - Posicionamento da instrumentação do PROT 3..............

FIGURA 3.17 - Posicionamento da instrumentação do PROT 4.............

FIGURA 4.1 - Modelo constitutivo do material adotado para a análise numérica.

FIGURA 4.2 - Elemento finito BEAM 24: representação esquemática..

FIGURA 4.3 - Elemento finito SHELL 43: representação esquemática.

52

53

54

FIGURA 4.4 - Modelação da região amassada da barra utilizando o elemento BEAM 24.

FIGURA 4.5 - Barra modelada com elemento BEAM 24 (com variação de inércia).

FIGURA 4.6 - Detalhe do nó da estrutura modelada ( $1^{a}$ hipótese).........

FIGURA 4.7 - Modelação do nó típico com elemento de casca SHELL 43.

FIGURA 4.8 - Deslocamentos verticais teóricos e experimentais. SOUZA (1998).

FIGURA 4.9 - Modelação do nó de aço com elemento de casca SHELL 43.

FIGURA 4.10 - Compatibilização dos deslocamentos e rotações entre os elementos barra-chapa (nó típico).

FIGURA 4.11 - Compatibilização dos deslocamentos e rotações entre os elementos barra-chapa (nó de aço).

FIGURA 5.1 - Esforços no protótipo para uma força de $1 \mathrm{kN}$ por ponto (análise linear elástica).

FIGURA 5.2 - Deslocamento vertical do nó central (PROT 1 - análise numérica).

FIGURA 5.3 - Deformações da diagonal de apoio (PROT 1 - análise numérica)

FIGURA 5.4 - Deformação da barra do banzo superior (PROT 1 análise numérica) 
FIGURA 5.5 - Deslocamento vertical do nó central (PROT 2 - análise numérica).

FIGURA 5.6 - Deformações da diagonal de apoio (PROT 2 - análise numérica).

FIGURA 5.7 - Deformação da barra do banzo superior (PROT 2 análise numérica).

FIGURA 5.8 - Deslocamento vertical do nó central (PROT 3 - análise numérica).

FIGURA 5.9 - Deformações da diagonal de apoio (PROT 3 - análise numérica)

FIGURA 5.10 - Deformação da barra do banzo superior (PROT 3 análise numérica).

FIGURA 5.11 - Deslocamento vertical do nó central (PROT 4 - análise numérica).

FIGURA 5.12 - Deformações da diagonal de apoio (PROT 4 - análise numérica).

FIGURA 5.13 - Deformação da barra do banzo superior (PROT 4 análise numérica).

FIGURA 5.14 - Extração e dimensões dos corpos-de-prova (ensaio de tração)

FIGURA 5.15 - Corpo-de-prova retirado da região da costura................ 75

FIGURA 5.16 - Vista geral do ensaio de tração do aço........................ 76

FIGURA 5.17 - Corpos-de-prova dos ensaios de compressão.............. 79

FIGURA 5.18 - Vista geral do ensaio de compressão......................... 80

FIGURA 5.19 - Tensão x deformação, ensaio de compressão (PROT 1/2)

FIGURA 5.20 - Tensão x deformação, ensaio de compressão (PROT 3/4).

FIGURA 5.21 - Rotação do nó junto ao vértice C (PROT 1) ................... 83

FIGURA 5.22 - Rotação do nó junto ao vértice D (PROT 1)................... 83

FIGURA 5.23 - Flexão de extremidade da barra do banzo superior (PROT 1)

FIGURA 5.24 - Flambagem de duas barras do banzo superior do PROT 3.

FIGURA 5.25 - Flambagem de uma barra do banzo superior do PROT 4

FIGURA 5.26 - Deslocamentos de apoio do PROT 2.

FIGURA 5.27 - Deslocamento vertical do nó central do PROT1 (experimental).

FIGURA 5.28 - Deslocamentos dos nós do banzo superior junto aos vértices (PROT 3).

FIGURA 5.29 - Deslocamento vertical do nó central (PROT 1 x PROT

2).

FIGURA 5.30 - Deslocamento vertical do nó central (PROT $1 \mathrm{x}$ PROT 3 x PROT 4)

FIGURA 5.31 - Deformações da diagonal de apoio do vértice A (PROT 1). 
FIGURA 5.32 - Deformações de uma barra do banzo superior junto ao vértice A (PROT 1)................................................ 91

FIGURA 5.33 - Deformação média de uma barra do banzo superior

junto ao vértice A (PROT 1).......................................... vértice $D$ (PROT 1).

FIGURA 5.35 - Deformações médias das barras comprimidas junto ao vértice $B$ (PROT 2)

FIGURA 5.36 - Deformações médias das barras comprimidas junto ao vértice $D(P R O T 3)$

FIGURA 5.37 - Deformações médias das barras comprimidas junto ao vértice $D$ (PROT 4).

FIGURA 5.38 - Distribuição de tensões nas extremidades estampadas das barras componentes do nó típico. VENDRAME (1999).

FIGURA 5.39 - Deformações médias da diagonal de apoio do vértice A (PROT 2)

FIGURA 5.40 - Deformações médias da barra do banzo superior junto ao vértice $A$ (PROT 2)

FIGURA 5.41 - Deformações médias da diagonal de apoio do vértice A (PROT 3)

FIGURA 5.42 - Deformações médias da barra do banzo superior junto ao vértice $A$ (PROT 3 )

FIGURA 5.43 - Posicionamento da instrumentação nas extremidades das barras do vértice $A$ do PROT 4

FIGURA 5.44 - Deformações da extremidade da diagonal de apoio do vértice A (seção 1 -PROT 4)...

FIGURA 5.45 - Deformações da extremidade da diagonal de apoio do vértice $A$ (seção 2 -PROT 4)

FIGURA 5.46 - Deformações médias da diagonal de apoio vértice $A$ (PROT 4)

FIGURA 5.47 - Deformações médias do banzo superior direito do vértice $A$ (PROT 4). 


\section{LISTA DE TABELAS}

TABELA 2.1 - Resultados dos ensaios de compressão nas barras...... 23

TABELA 2.2 - Resultados teóricos - extremidade tipo P....................... 29

TABELA 2.3 - Resultados teóricos - extremidade tipo T........................ 29

TABELA 2.4 - Resultados teóricos - extremidade tipo N....................... 29

TABELA 3.1 - Dimensões e esbeltez para as barras componentes dos protótipos..................................................... 34

TABELA 3.2 - Descrição dos protótipos ensaiados.............................. 34

$\begin{array}{lllll}\text { TABELA } & 3.3 & - & \text { Legenda } & \text { da } \\ 45\end{array}$

instrumentação.

TABELA 5.1 - Deslocamentos verticais teóricos para análise linear..... 62

TABELA 5.2 - Propriedades geométricas, esbeltez e resistência ao escoamento das barras analisadas.............................. 64

$\begin{array}{llll}\text { TABELA } 5.3 & \text { - Resistência a compressão das barras mais solicitadas.. } \quad 65\end{array}$

TABELA 5.4 - Estimativa de força última total................................... 65

$\begin{array}{cl}\text { TABELA 5.5 } & \text { - Resultados do ensaio de tração do aço (PROT } 1 \mathrm{e} \\ & \text { PROT }\end{array}$

2)

TABELA 5.6 - Resultados do ensaio de tração do aço (PROT 3 e PROT $\quad 78$ 4).

TABELA 5.7 - Dimensões das amostras para o ensaio de 79 compressão

TABELA 5.8 - Resultados dos ensaios de compressão......................... $\quad 80$

TABELA 5.9 - Deslocamentos de serviço dos protótipos...................... $\quad 90$

TABELA 6.1 - Deslocamentos de serviço dos protótipos....................... 102

TABELA 6.1 - Forças últimas teóricas e experimentais.......................... 103 


\section{LISTA DE SÍMBOLOS}

\section{Romanos maiúsculos}
A - Alongamento na ruptura
$A_{g} \quad$ - Área bruta da seção transversal
E - Módulo de elasticidade
I - Momento de inércia
K - Parâmetro utilizado no cálculo do comprimento de flambagem
L $\quad$ - Comprimento em geral
$\mathrm{N}_{\mathrm{cr}} \quad$ - Força normal crítica de flambagem elástica
$\mathrm{N}_{\mathrm{cr}}{ }^{*} \quad$ - Força normal crítica de flambagem elástica calculada admitindo-se a variação de inércia
$\mathrm{N}_{\mathrm{n}} \quad$ - Resistência nominal à força normal
$\mathrm{N}_{\mathrm{n}}{ }^{*}$ - Resistência nominal à força normal calculada admitindo-se a variação de inércia
$F_{y} \quad$ - Força correspondente ao escoamento no ensaio de tração
$F_{\max }$ - Força máxima do ensaio de tração
$\mathrm{P}_{\mathrm{u}} \quad$ - Forças últimas de ensaio

\section{Romanos minúsculos}

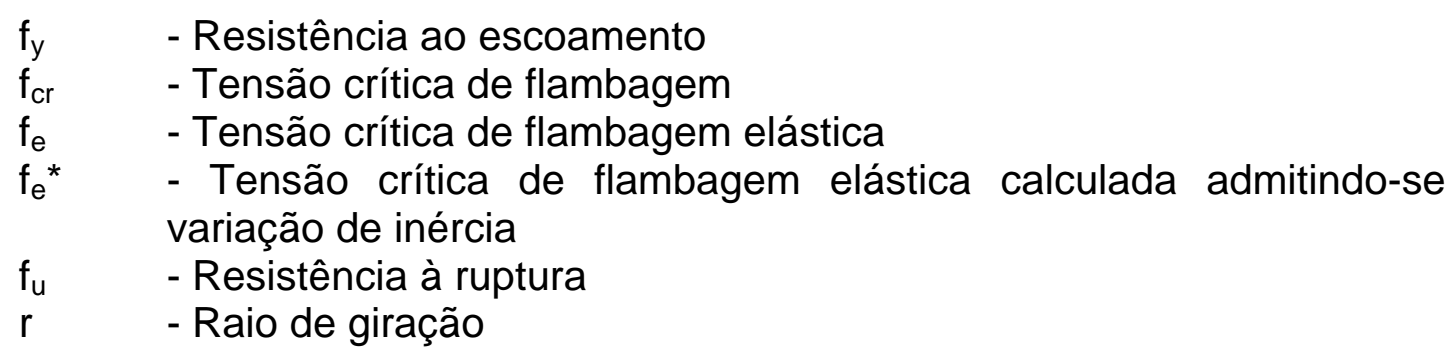

\section{Gregos}

$\beta_{1} \quad$ - Parâmetro de flambagem local (EUROCODE)

$\chi \quad$ - Parâmetro de flambagem global (EUROCODE)

$\delta \quad$ - Deslocamento

$\delta_{\mathrm{x}} \quad$ - Deslocamento na direção $\mathrm{x}$ (local)

$\varepsilon \quad$ - Deformação

$\phi \quad$ - Diâmetro

$\lambda \quad$ - Parâmetro de esbeltez

$\bar{\lambda} \quad$ - Parâmetro de esbeltez reduzido

$\bar{\lambda}^{*} \quad$ - Parâmetro de esbeltez reduzido calculado admitindo-se variação de inércia

$\mu \quad$ - Micro

$\rho \quad$-Parâmetro de flambagem global 


\title{
RESUMO
}

\begin{abstract}
MAIOLA, C.H. Análise teórica e experimental de treliças metálicas espaciais constituídas por barras com extremidades estampadas. São Carlos, 1999. Dissertação (Mestrado) - Escola de Engenharia de São Carlos, Universidade de São Paulo.
\end{abstract}

No Brasil é comum a utilização de barras tubulares com extremidades estampadas na confecção das treliças metálicas espaciais, uma vez que representam uma significativa redução de custos, quando comparado a sistemas mais elaborados, devido a sua simplicidade de fabricação e montagem, entretanto trata-se aparentemente de um sistema precário do ponto de vista estrutural, merecendo estudos que estabeleçam critérios para uma utilização segura. Neste trabalho são apresentadas análises teóricas e experimentais destas estruturas, onde foi analisada a situação construtiva usual de treliça com nós típicos (extremidade das barras estampadas, sobrepostas e unidas por um único parafuso), e com nós de aço (sistema de conexão formado por uma peça com aletas de aço soldadas).

Os resultados experimentais foram obtidos em ensaios de quatro protótipos que simulam um trecho de treliça espacial, constituídos por uma malha quadrada sobre quadrada, composta de nove módulos piramidais de $2,5 \times 2,5 \times 1,5(\mathrm{~m})$, totalizando uma estrutura com dimensões iguais a $7,5 \times 7,5 \times 1,5(\mathrm{~m})$, apoiada por colunas nos vértices, permitindo comparar a rigidez, o modo de falha e a resistência entre estes protótipos.

A análise teórica dos protótipos foi feita admitindo-se os casos de linearidade e também de não linearidade física e geométrica, levando-se em consideração a variação de inércia das barras junto aos nós.

Palavras-chave: estruturas metálicas, estruturas de aço, estruturas espaciais, treliças espaciais, instabilidade. 


\begin{abstract}
MAIOLA, C.H. Theorical and experimental analysis of space steel structures composed of bars with stamping extremities. São Carlos, 1999. Dissertação (Mestrado) - Escola de Engenharia de São Carlos, Universidade de São Paulo.
\end{abstract}

In Brazil the use of tubular bars with stamping extremities is common in space steel structures, as it means a significant reduction of cost, when caompared with more elaborete system, due to its simplicity of manufacture and assembly. However it is apparently an uncertain system from a structural point of view, which requires studies establishing safe utilization criteria. This paper presents theorical and experimental analysis of this structures. The usual constructive situation of space structure with 'nós típicos' (bars with flattened ends, superposed and connected by a unique bolt), and 'nós de aço' (connection system formed by a piece with steel fin welded) was studied.

The experimental results were obtained in tests of four prototypes which simulated a section of space structure composed of a mesh squareon-square, with nine $2.5 \times 2.5 \times 1.5(\mathrm{~m})$ pyramidal modules, totaliing a structure with $7.5 \times 7.5 \times 1.5(\mathrm{~m})$ dimensions, supported by columns in their vertices, permiting to compare the stiffness, the failure manner and the resistance of this_prototypes.

The theorical analysis of prototypes was carried out by assuming the cases of linearity and physical and geometric non-linearity, taking into consideration the variation of stiffness of the bars next to the nodes.

Keywords: Steel structures, space structures, space trusses, instability 


\section{INTRODUÇÃO:}

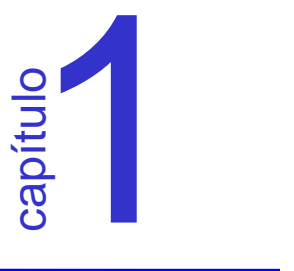

Treliça metálica espacial é um sistema estrutural com aplicações das mais diversas, no entanto, a utilização predominante desta está, sem dúvida, nas coberturas em que se exige grandes vãos livres. Esta estrutura pode ser definida como um reticulado espacial constituído por barras não coplanares, conectadas umas as outras por dispositivos que tecnicamente são chamados de nós, apresentando similaridade nas dimensões de barras e com uma geometria repetitiva.

A utilização das treliças espaciais está em contínuo crescimento, devido principalmente a sua intrínseca leveza e aparência agradável. Associados a este crescimento, alguns problemas estruturais relativos a este sistema vêm ocorrendo, tendo-se observado casos de colapso parcial ou até mesmo total destas estruturas, constituindo assim um grande risco à sociedade. Dentre alguns dos mais recentes problemas envolvendo estruturas deste tipo, cita-se o ocorrido na cobertura do Centro de Convenções de Manaus (110m de vão), onde o colapso global da estrutura foi observado alguns dias após a colocação das telhas e na ausência de ação do vento.

No Brasil, é comum a utilização de barras de seção tubular circular com extremidades estampadas na confecção das treliças metálicas espaciais, gerando uma variação de inércia na região próxima aos nós da estrutura, tendo por sistema de conexão os denominados "nó típico" e "nó de aço". Isto ocorre por serem soluções relativamente simples e baratas, 
entretanto merecedoras de estudos que estabeleçam critérios para a sua utilização.

A análise convencional destas estruturas pressupõe um conjunto de barras interligadas, considerando as ligações como pontos nodais, idealizando-se o seu comportamento como nós rotulados e sem excentricidade, configurando um modelo de treliça ideal. Entretanto estudos e pesquisas têm demonstrado a inadequação desta abordagem analítica, uma vez que vários fatores influenciam o comportamento destas estruturas de uma maneira global.

É importante ressaltar que as hipóteses de cálculo assumidas para os detalhes de ligações de uso comum, não reproduzem bem o comportamento destas. Por outro lado, não existem estudos que expliquem detalhadamente o comportamento das ligações na estrutura, apesar destas serem um dos fatores que influenciam no seu comportamento global além de contribuir significativamente no custo total da estrutura.

Tendo em vista a carência de estudos sobre o comportamento e a ocorrência de problemas com estas estruturas, foi que a partir de 1995, a Área de Estruturas Metálicas do Departamento de Engenharia de Estruturas da EESC-USP, deu início aos estudos de Treliças Metálicas Espaciais dando ênfase aos sistemas mais utilizados no Brasil.

Uma primeira etapa destes estudos, consistiu em ensaios de compressão axial de barras isoladas de aço e alumínio, com variação de inércia nas extremidades, utilizadas na confecção destas treliças. Para alguns detalhes de extremidade analisados, foi observada uma significativa redução da força normal crítica, tomando-se como parâmetro o valor calculado sem admitir a variação de inércia [GONÇALVES et al. (1996), MALITE et al. (1997), SÁLES et al. (1996a) e SÁLES et al. (1996b)].

Vale salientar que o estudo desenvolvido nesta etapa consistiu simplesmente na análise de barras isoladas, visando comparar 0 desempenho dos diversos detalhes de extremidade (estampagem), os quais não permitem fazer extrapolações para barras componentes de uma treliça espacial, tendo em vista que o comportamento de uma barra isolada é 
conseqüência de condições de contorno que são diferentes das apresentadas pela mesma barra inserida na estrutura.

Portanto, dando prosseguimento à esta linha de pesquisa, é que este trabalho se insere tendo por objetivo o estudo do comportamento estrutural de treliças metálicas espaciais, com ênfase em dois sistemas muito utilizados no Brasil, ou seja, treliças espaciais constituídas por barras de extremidade estampadas e tendo por sistemas de conexão os denominados "nó típico" (figura 1.1) e "nó de aço" (figura 1.2), apresentando análises teórica e experimental de protótipos.

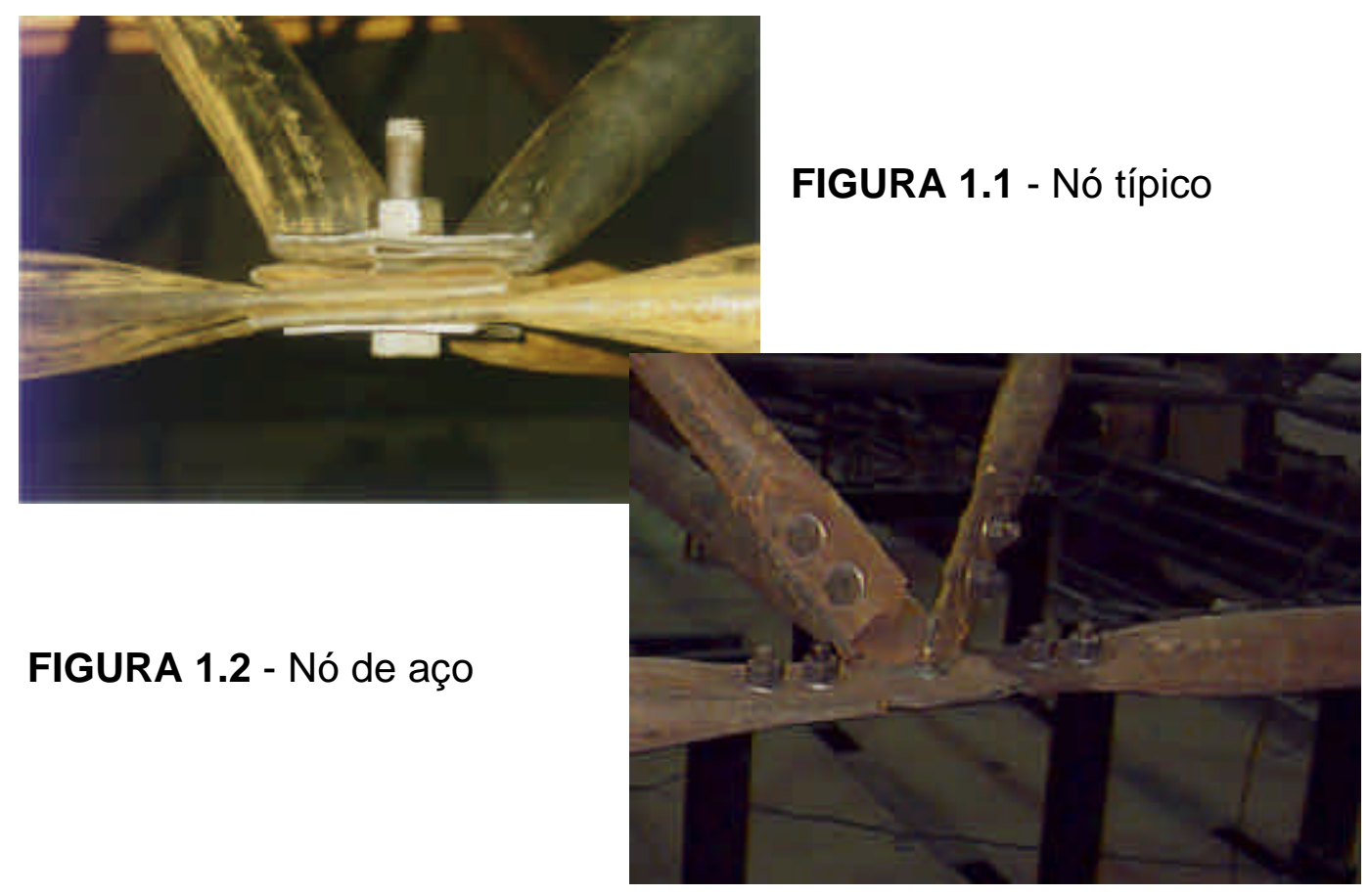

Os resultados experimentais foram obtidos em ensaios de quatro protótipos, denominados de PROT1 a PROT4, os quais simulavam um trecho de treliça espacial, constituído por uma malha quadrada-sobrequadrada, composta de nove módulos piramidais de 2,5 × 2,5 x 1,5(m), totalizando uma estrutura com dimensões 7,5 x 7,5 x 1,5(m), apoiada por colunas nos seus vértices (figura 1.3). 


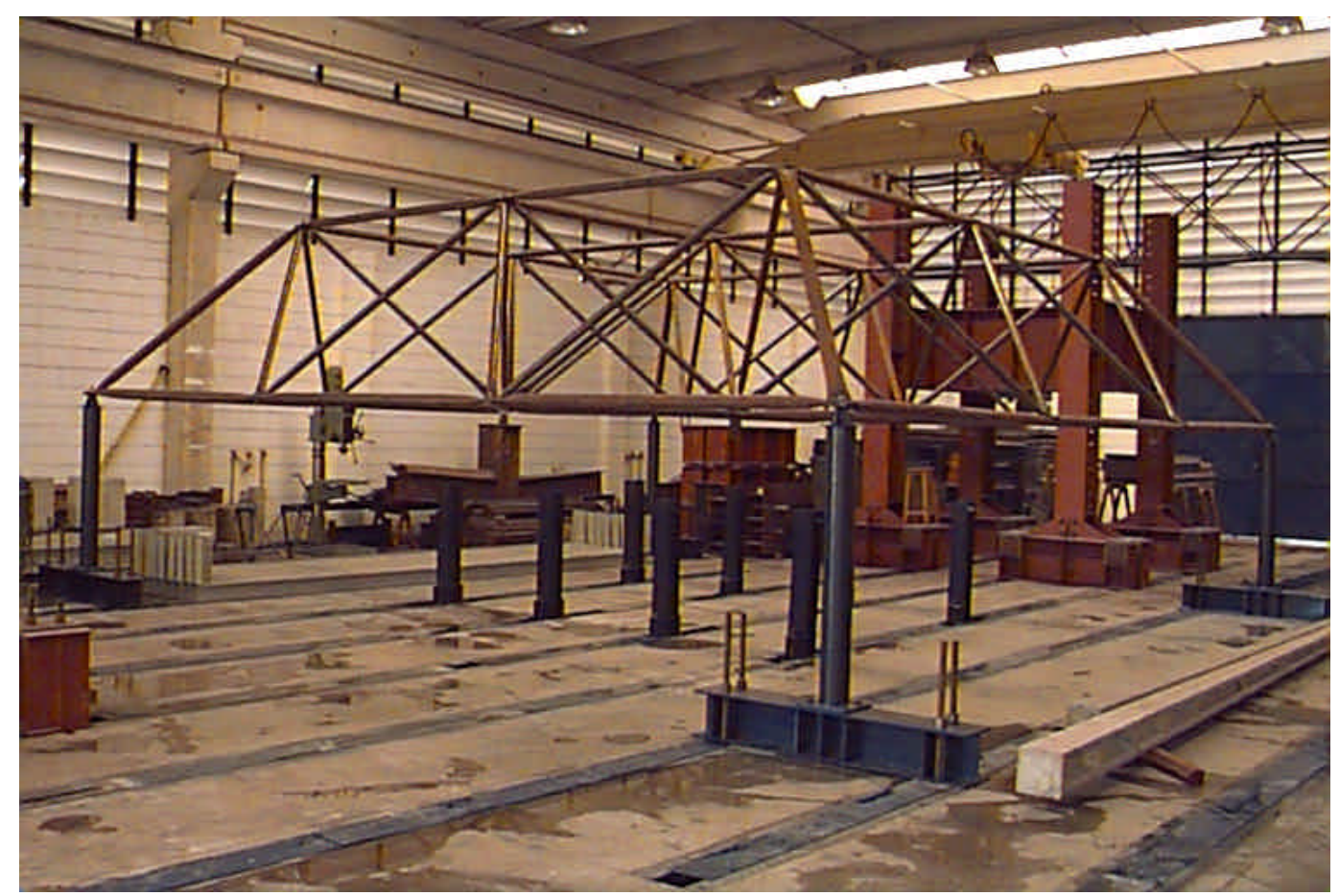

FIGURA 1.3 - Vista geral do protótipo PROT 1

Os protótipos PROT1 e PROT2 foram constituídos totalmente por nós típicos, diferenciados apenas pela dimensão das diagonais de apoio, já o PROT3 foi constituído totalmente por nós de aço e finalmente para o PROT4 optou-se por uma configuração mista do sistema de conexão (nós típicos e nós de aço).

A análise teórica dos protótipos foi feita com o auxílio do programa computacional ANSYS, admitindo-se os casos de linearidade e também de não linearidade física e geométrica, levando-se em consideração na modelação a variação de inércia das seções transversais das barras na região próxima os nós da estrutura.

Como ponto de partida para o desenvolvimento deste trabalho, o capítulo 2 apresenta a revisão bibliográfica sobre o assunto, contendo alguns dados gerais sobre a estrutura em questão, considerações sobre a análise estrutural e um breve comentário sobre o ensaio de barras isoladas com variação de inércia submetidas à compressão axial.

O capítulo 3 trata da análise experimental, trazendo a descrição dos ensaios propriamente dito, apresentando informações relativas ao 
procedimento de ensaio, equipamentos, estruturas de reação, aparelhos de apoio e instrumentação.

Os detalhes referentes à análise numérica dos protótipos são apresentados no capítulo 4, abordando a discretização da malha de elementos finitos, incluindo a variação de inércia das extremidades das barras, as condições de contorno impostas, bem como o carregamento.

No capítulo 5 são apresentados os resultados e discussões, com o objetivo de comparar os resultados teóricos e experimentais, e de verificar a influência dos parâmetros analisados (sistema de conexão utilizado). Finalmente no capítulo 6 são apresentadas as conclusões do trabalho. Como complementação são apresentadas planilhas com os resultados da análises experimentais em forma de Apêndices. 


\section{1 - ASPECTOS GERAIS}

Embora a maioria das estruturas metálicas sejam reticulados espaciais, o termo 'treliça espacial' é usualmente aplicado para as estruturas tridimensionais constituídas por barras não coplanares, conectadas umas as outras por dispositivos tecnicamente chamados de nós, apresentando similaridade nas dimensões das barras e com uma geometria repetitiva.

Experimentos relacionados a este tipo de estrutura iniciaram-se no ano de 1907 com Alexander Graham Bell produzindo uma estrutura tridimensional composta de barras de igual comprimento, conectadas por nós simples, idênticos para toda a estrutura, sendo ele o primeiro engenheiro a mostrar como este sistema é simples e fácil de montar, resultando uma estrutura leve e com grande resistência (figura 2.1). Graham Bell chamou também atenção para a economia que poderia advir da industrialização e pré-fabricação deste sistema (MAKOWSKI 1981). 


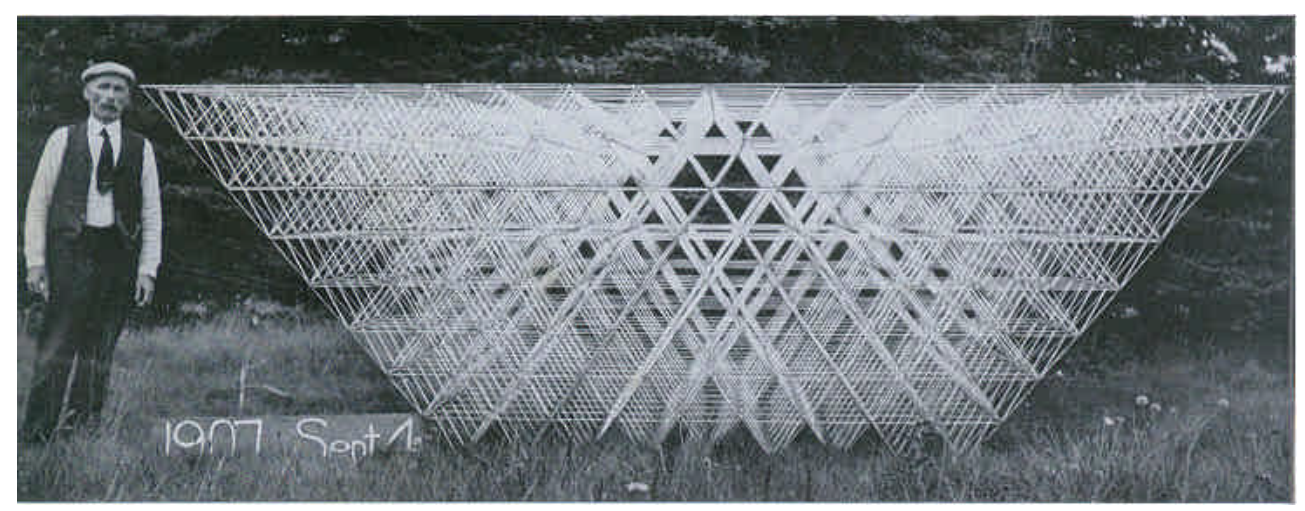

FIGURA 2.1 - Graham Bell e o que seria a primeira estrutura espacial.

Passadas nove décadas desde a primeira estrutura espacial construída por Graham Bell, tem-se observado um crescente interesse por esta forma de construção, com aplicação em grandes coberturas de estádios, espaços públicos, hangares, coberturas de piscinas, ginásios de esportes, e muitas outras construções; entretanto, no geral, a existência das treliças espaciais no mercado de estruturas de grandes coberturas não vem sendo significativamente expressiva, e o número de suas aplicações é relativamente pequeno e não reflete seus importantes méritos construtivos (EL-SHEIKH \& EL-BAKRY 1996).

Nas últimas décadas, dezenas de sistemas de treliças espaciais surgiram, muitas das quais não tiveram grande sucesso comercial, principalmente pela complexidade dos seus sistemas de conexão. Dos sistemas em uso hoje em dia pode-se destacar o sistema alemão MERO (figura 2.2a), que depois de muitos anos de desenvolvimento teve sua aplicação difundida em 1957 no "International Building Exhibition" em Berlim. Nos anos 50 os sistemas de maior destaque foram os TRIODETIC (figura 2.2b) e UNISTRUT (figura 2.2c). Dos mais recentes, merece destaque 0 sistema britânico NODUS (figura 2.2d) ( CODD et al. 1984). 


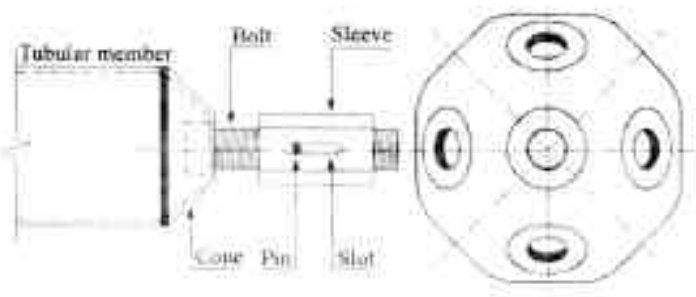

a) MERO

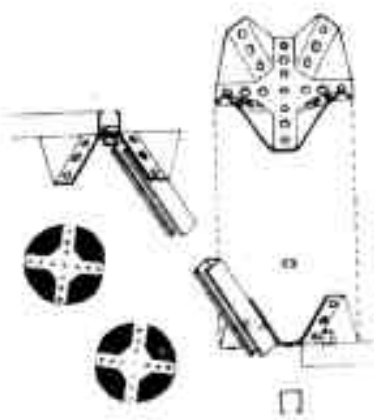

c) UNISTRUT

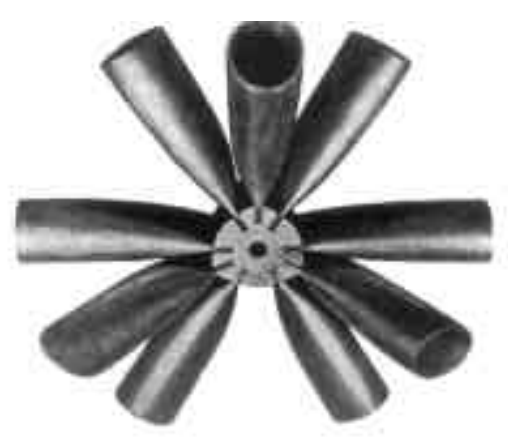

b) TRIODETIC

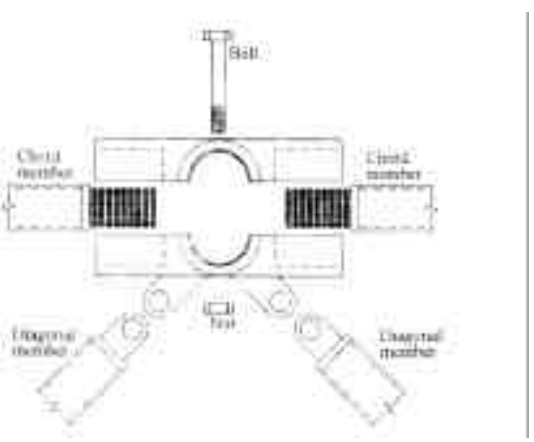

d) NODUS

FIGURA 2.2- Sistema de nós comerciais mais conhecidos.

Quanto a aceitação destas estruturas pode-se dizer que, antes do advento dos computadores pessoais se tornarem comuns nos escritórios de cálculo, havia uma resistência, de certo modo justificada por parte dos engenheiros, em relação ao uso das treliças espaciais, pois a análise destas estruturas (determinação dos deslocamentos e esforços nas barras), era muito trabalhosa, devido a sua grande hiperestaticidade, necessitando recorrer a modelos aproximados e em geral não muito adequados, como o da analogia de placas, por exemplo. Hoje em dia esta análise é facilitada pelos inúmeros programas computacionais de análise estrutural disponíveis.

Entretanto deve-se ter cuidado quanto a utilização de sistemas de treliça espacial já existentes no mercado ou que venham a aparecer, sem se conhecer o seu real comportamento estrutural, pois do ponto de vista estrutural, o bom senso e confiança por parte do projetista não são sempre suficientes, sendo necessária em determinados casos uma simulação numérica sofisticada, e um programa de ensaios em modelos e até mesmo 
protótipos para se constatar a confiabilidade estrutural do sistema (CARAMELLI 1993).

\section{2 - CUSTOS}

As treliças espaciais constituem uma solução extremamente adequada para as coberturas de grandes áreas abertas com poucos pontos de apoios intermediários, sendo a sua aparência agradável, dispensando em alguns casos a colocação de forros, o que muitas vezes é a principal justificativa para o seu emprego.

Pode-se citar também outras vantagens deste sistema construtivo, como a sua leveza, facilidade de fabricação e montagem, além da adequada flexibilidade para cobrir áreas irregulares e colocação dos apoios.

Como pode ser visto, muitos dos sistemas de treliças espaciais possuem características construtivas favoráveis que podem reduzir os seus custos, entretanto, a adoção de sofisticados e caros dispositivos de nó, acabam resultando em uma significativa elevação destes, colocando-as, em relação aos custos, em um nível superior ao encontrado para as outras alternativas de sistemas estruturais planos. A figura 2.3 ilustra o dispositivo de nó e a extremidade de uma barra relativa ao sistema MERO (EL-SHEIKH \& EL-BAKRY 1996), onde pode-se observar a sua complexidade de fabricação.

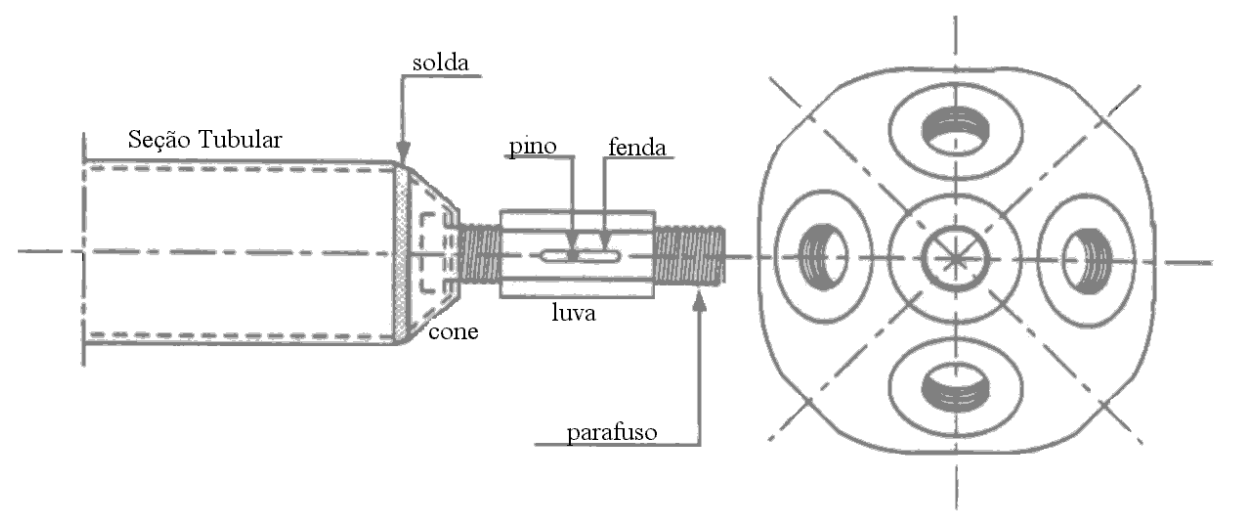

nó MERO com 18 furos

FIGURA 2.3 - Sistema de conexão MERO. 
Portanto pode-se dizer que uma das principais causas, para que hoje em dia o mercado de grandes coberturas apresente "resistência" em aceitar este tipo de estrutura, é o seu elevado custo de produção. Para ser econômica, uma treliça espacial deve permitir ao máximo a sua industrialização, com fácil fabricação de barras, as quais permitam facilmente obter variações de comprimento e resistência dos elementos. Nós simples, eficientes e baratos são essenciais (MAKOWSKI 1981a).

Tentativas foram feitas no passado para produzir novos sistemas de treliças espaciais que pudessem ser bem sucedidos com relação aos custos e comportamento estrutural, mas não prejudicando os usuais méritos construtivos desta estrutura. Ao invés de utilizar dispositivos especiais para conexão das barras, alguns desses sistemas empregam barras contínuas que se cruzam e são conectadas às diagonais utilizando parafusos. Exemplos deste grupo que não necessitam de um dispositivo pré-fabricado são os sistemas CATRUS (EL-SHEIKH \& EL-BAKRY 1996) figura $2.4 \mathrm{e}$ HALLEY (CODD et al. 1984).
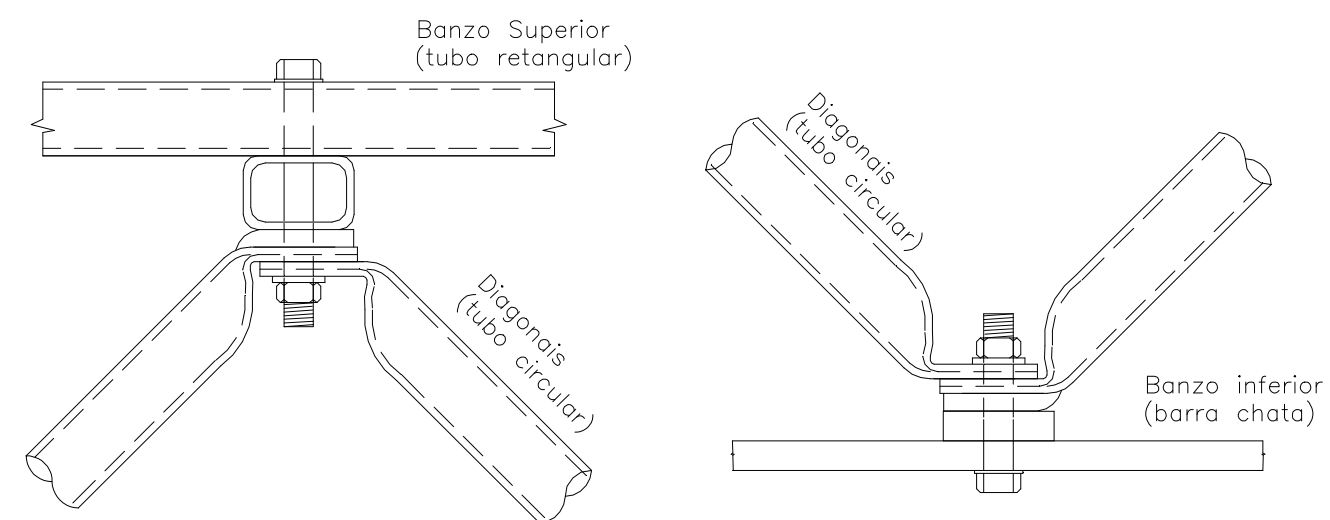

FIGURA 2.4 - Representação do sistema CATRUS

Estes sistemas são baseados em um nó simples que necessita de poucas furações e parafusos, permitindo o uso de barras mais eficientes nos banzos (por serem contínuas), e estando mais flexíveis com relação à orientação de suas barras diagonais. No entanto pode-se notar, no sistema CATRUS as significativas excentricidades no nó, contribuindo para a rotação do conjunto e facilitando a formação de rótulas plásticas. 
Um dos sistemas apresentados nesta pesquisa se enquadra nessa simplicidade, exigindo reduzida furação e consequentemente poucos parafusos, sendo de fácil montagem, não exigindo a pré-fabricação do dispositivo de conexão, é o caso do nó típico (figura 2.5a). Quanto ao nó de aço (figura 2.5b), este dispositivo de conexão é de simples concepção, entretanto, exige maior trabalho para a sua execução, pois é constituído de chapas de aço soldadas, o que eleva o seu custo final.

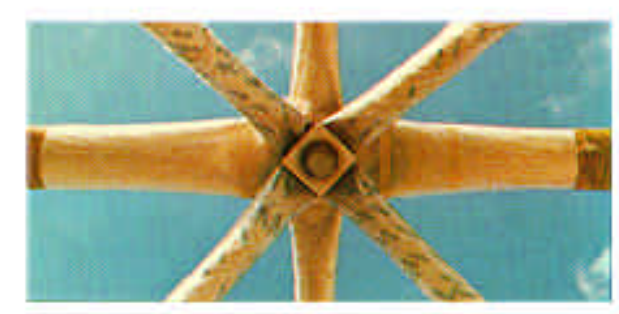

a) NÓ TÍPICO

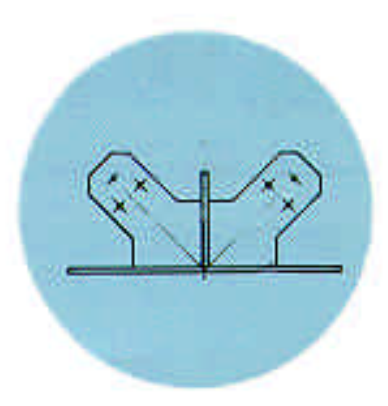

b) NÓ DE AÇO

FIGURA 2.5. - Dispositivos de nó analisados neste trabalho. Extraído do catálogo ALUSUD.

Outro sistema que compartilha desta filosofia, e se assemelha ao nó típico, seria o denominado WACO (DE MARTINO 1992), se diferenciando do nó típico apenas por utilizar quatro parafusos para sua fixação (figura 2.6), o que deve conferir maior rigidez que a apresentada pelo nó típico. 


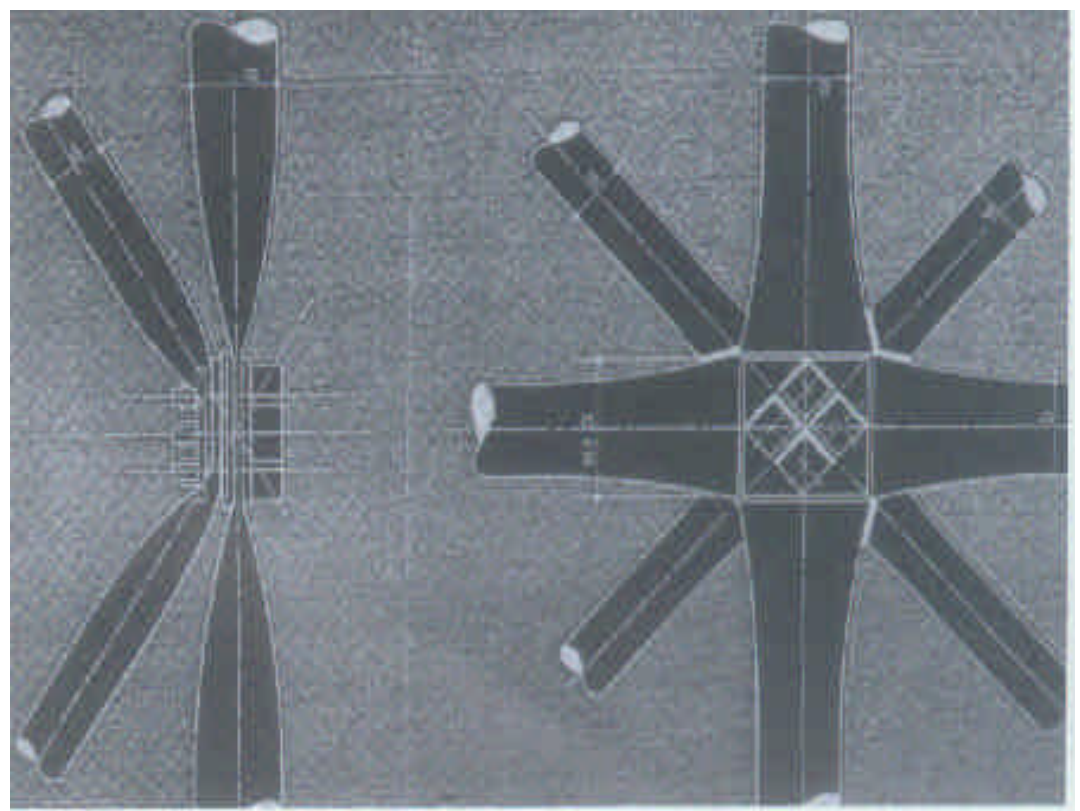

FIGURA 2.6 - Representação do nó WACO, DE MARTINO(1992).

\section{3 - ANÁLISE ESTRUTURAL}

Nos últimos anos, projeto e a construção das treliças metálicas espaciais têm despertado o interesse de muitos pesquisadores em diversos países, os quais têm publicado resultados teóricos e experimentais sobre a investigação do comportamento estrutural de diversos sistemas, envolvendo análises não lineares e modelagens específicas da região nodal. Entretanto o que se observa na prática de projetos, por simplicidade, é a adoção de análise linear elástica, sem a preocupação de se considerar as características da região nodal (excentricidades, variações de inércia, tipo de ligação, etc...) o que, dependendo do sistema, não corresponde a um modelo teórico adequado.

Para pequenos deslocamentos e baixas solicitações (solicitações de serviço), o comportamento esperado da estrutura é, de fato, linear. Entretanto, dependendo das características da região nodal, a resposta da estrutura só poderá ser avaliada adequadamente quando se considera as não linearidades física e ou geométrica (HILL et al. 1989).

A seguir apresenta-se uma breve descrição a respeito das análises linear e não linear das treliças espaciais. 
- Análise linear: Para a análise linear o valor último da solicitação em uma barra é definido como sua resistência à compressão ou resistência à tração. Carregamentos excêntricos, variações de temperatura, tensões residuais, esforços oriundos da montagem e içamento da estrutura, variação da inércia das barras, e a configuração do sistema de conexão também podem influenciar a resposta da estrutura. $\mathrm{Na}$ análise linear elástica, somente alguns destes fatores citados anteriormente, como os esforços oriundos da montagem e içamento ou os efeitos da temperatura podem ser aproximados e tratados como "pseudo-cargas" (MALLA \& SERRETTE 1996).

- Análise não linear: Refere-se às não linearidades física, geométrica ou ambas. Em particular para as treliças espaciais, é interessante considerar a não linearidade geométrica da estrutura, pois os efeitos desta (deslocamentos e rotações) podem acarretar significativas alterações na sua resposta. Imperfeições geométricas tais como diminuição da seção das barras e excentricidades do carregamento, tendem a diminuir a resistência global da treliça. FATHELBAD (1997) apresenta informações sobre os efeitos da não linearidade das conexões das treliças espaciais.

A não linearidade geométrica está associada ao equilíbrio de um sistema estrutural na posição deformada. A consideração da não-linearidade geométrica se faz necessária quando a configuração deformada da estrutura é significativamente diferente da configuração inicial (grandes deslocamentos).

A não linearidade física corresponde ao comportamento não linear da relação tensão $x$ deformação do material. Portanto para se realizar uma análise não-linear física, é necessário idealizar um modelo constitutivo (tensão $x$ deformação) para o material em questão.

Para MADI \& EL-TAYEM (1994), a formulação proposta para a idealização da relação força x deformação é representada na figura 2.7. 


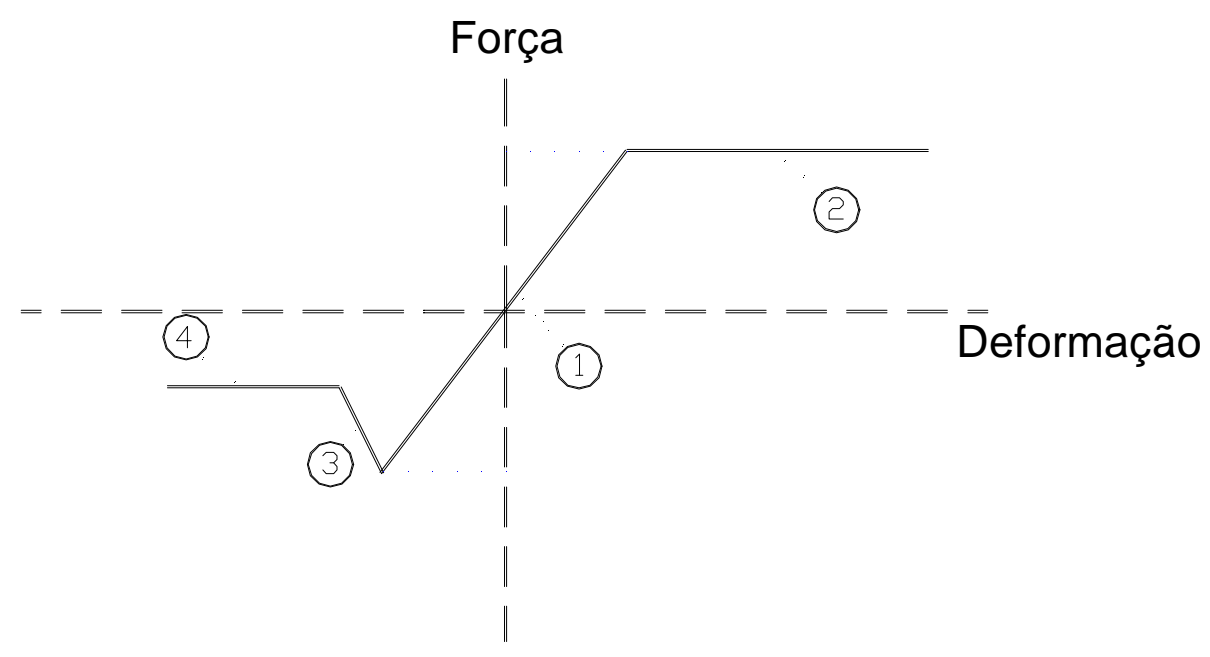

FIGURA 2.7 - Relação força x deformação idealizada por MADI \& EL-TAYEM (1994).

Na figura 2.7, pode-se observar que no trecho referente à tração o material se comporta como sendo elastoplástico perfeito com uma região elástica linear (trecho 1), e logo em seguida apresentando um patamar referente a fase de plastificação do material (escoamento - trecho 2). Para o trecho relativo à compressão, primeiramente tem-se uma fase elástica do material (trecho 1 relativo a compressão), seguida de uma fase onde após atingida a força limite, a resistência do elemento decresce linearmente, para em seguida ser admitida uma resistência residual (trechos 3 e 4 respectivamente).

Para os elementos tracionados o diagrama tensão $\mathrm{x}$ deformação é facilmente obtido por um ensaio de tração, mas para os elementos comprimidos é relativamente complicado equacionar este comportamento, pois deve-se considerar as instabilidades, a qual depende, além das características do material, da esbeltez e das condições de vinculação (SOUZA 1998). 


\section{4 - INSTABILIDADE DAS TRELIÇAS ESPACIAIS}

Estruturas deste tipo apresentam usualmente uma elevada hiperestaticidade, e consequentemente têm um grande número de barras redundantes (entre $15 \%$ a $25 \%$ do total). Com isto, parece que alguns projetistas têm, talvez equivocadamente, acreditado que esta inerente redundância providenciava uma elevada segurança contra o colapso, e que por esta razão o cálculo de uma treliça espacial segura seria um processo que requer somente uma análise linear padrão seguida de um dimensionamento das barras (EL-SHEIKH \& McCONNEL 1993).

Devido a esta elevada hiperestaticidade, é assumido que caso alguma barra atinja o colapso, esta redundância estática provoque uma redistribuição de esforços e consequentemente uma acomodação da estrutura.

Entretanto pesquisas como a de MURTHA-SMITH (1988) mostram que o colapso progressivo pode ocorrer, partindo da perda de estabilidade de um dos elementos. Quando um elemento comprimido atinge o colapso, ocorre uma maior redistribuição dos esforços, o qual causará uma sobrecarga nas barras adjacentes, levando-as também ao colapso, e assim sucessivamente, caracterizando um mecanismo de colapso progressivo.

EL-SHEIKH \& McCONNEL (1993) também alerta para o fato de que as treliças espaciais podem atingir o colapso de uma maneira frágil e instável, na qual a flambagem de uma barra pode disparar um colapso progressivo de toda a estrutura, na qual barras próximas a ela falham sucessivamente em rápida seqüência. Além deste há muitos outros trabalhos que alertam para a forma de colapso frágil e progressivo demonstrada por este tipo de estrutura.

Para analisar o modo de colapso progressivo das estruturas espaciais, MURTHA-SMITH (1988) desenvolveu um método que avalia o efeito que a perda de um dos elementos pode provocar no comportamento global da estrutura.

O método consiste na análise de modelos de treliça espacial, dos quais são removidos diferentes elementos. Constatou-se que a retirada de 
um elemento compromete a segurança de uma grande quantidade de elementos remanescentes, principalmente se o elemento retirado for uma das diagonais de apoio ou algum banzo da região central. Neste estudo o fator de segurança dos elementos remanescentes foi avaliado usando análise linear e não linear, para o qual, no caso mais crítico de elementos removidos, a estrutura apresentou um fator de segurança de apenas $6 \%$.

\section{5 - FATORES QUE INFLUENCIAM NA RESISTÊNCIA}

Trabalhos experimentais como o desenvolvido por SCHMIDT et al.(1976) indicam que a força calculada para falha da estrutura pode não ser alcançada na realidade. Esta redução na resistência é atribuída à influência da distribuição da força inicial no interior da treliça, ou seja, a variação da real distribuição de forças das treliças espaciais contrapondo aquelas determinadas pela análise teórica convencional. Esta variação surge devido ao elevado grau de hiperestaticidade da estrutura provocando a diferenciação no caminhamento das forças entre as barras. Outros fatores que podem contribuir para esta redução seriam: as imperfeições da geometria das barras, a resistência última do material e a presença de tensões residuais, podendo estas serem sobrepostas com as variações causadas na montagem, pelos procedimentos de içamento e possíveis escorregamentos das conexões (para o caso de ligações por atrito) quando a estrutura é solicitada.

$\mathrm{Na}$ prática, as barras estruturais sempre tem alguma imperfeição geométrica inicial, excentricidades das extremidades, e seus sistemas de conexão têm alguma flexibilidade. Estes fatores podem influenciar significativamente o comportamento da treliça espacial. Em geral, imperfeições nas estruturas não podem ser determinadas corretamente, mas seus efeitos podem ser expressivos. A influência global das imperfeições no comportamento das estruturas espaciais foi discutida por SCHMIDT et al. (1976) e por SADIC \& ABATAN (1993). 
A instabilidade rotacional das conexões é outro fator que pode influenciar no comportamento da treliça, esta pode ser causada pela redução da rigidez da barra junto a estas, ações de forças excêntricas, ou forças desbalanceadas que chegam a estas conexões. A flexibilidade da própria conexão também afeta a sua estabilidade rotacional. Por causa da característica do sistema de conexão de uma treliça espacial, a de se ter muitos elementos de barra chegando, excessivas deformações destes sistemas, ou sua instabilidade resultam em uma expressiva redução na resistência da estrutura.

Outro fator que pode influenciar no comportamento da treliça espacial é o posicionamento dos seus apoios. Isto foi comprovado na pesquisa feita por Salajegheh (MAKOWSKI 1981), o qual estudou o efeito de diferentes condições de apoio na resposta de uma treliça espacial de configuração quadrada-sobre-quadrada.

Experimentos em modelos bem como em protótipos, mostram que a rigidez das conexões alteram a distribuição de tensão em somente 10 a $15 \%$, entretanto, restrições impostas nos apoios da estrutura podem ter uma influência mais expressiva, o que foi comprovado por Salajegheh realizando análises puramente computacionais e assumindo que a estrutura era constituída de elementos de mesma seção transversal sob a ação de uma força uniformemente distribuída aplicada em toda a malha, com restrições nos deslocamentos dos apoios da estrutura nas direções horizontais, além da vertical.

Para estas condições ele chegou às seguintes conclusões:

- As forças no banzo superior foram menores e mais igualmente distribuídas, mas a mudança no banzo inferior não foi significativa, sendo que para este caso os apoios se encontravam no banzo superior.

- Os deslocamentos foram afetados consideravelmente pela restrição horizontal, no caso considerado os deslocamentos foram $70 \%$ menores que no caso onde somente haviam restrições verticais; 
- A análise mostrou também que as reações horizontais são apreciáveis e para resistir a elas, precauções especiais devem ser tomadas na construção dos apoios.

Os trabalhos apresentados por MURTHA-SMITH (1988), MURTHASMITH \& LEARY (1993), analisaram o comportamento de treliças espaciais, utilizando a metodologia de retirada de um dos elementos da estrutura, mas variando alguns parâmetros de influência, como quantidade e localização dos apoios, relação vão/tamanho do módulo, relação altura/vão, relação entre maior e menor vão.

Dos parâmetros anteriormente citados, a localização dos apoios teve maior influência no comportamento das treliças espaciais, e sobretudo na propagação da ruína, tendo como pior situação aquela em que os apoios são posicionados nos vértices de uma treliça espacial.

O modelo adotado para cálculo analítico pode contribuir também com a diferença de resultados em relação à análise experimental. Um exemplo disto seria a estimativa do parâmetro efetivo de flambagem "K" fundamental para a determinação da resistência à compressão. Idealmente, a restrição ao giro das extremidades das barras está compreendida entre as situações de giro livre (rótula) e giro impedido (engaste). Elementos com as extremidades apresentando variação de inércia junto aos nós, tem 0 parâmetro efetivo de flambagem (K) próximo do que o correspondente ao caso de barras com extremidades rotuladas. Já elementos com seções completas tem um valor menor para "K" (particularmente aqueles com as extremidades soldadas), e elementos com as extremidades apenas reduzidas apresentam o valor de "K" entre esses dois últimos. Na publicação de MALLA \& SERRETTE (1996), são citados os pesquisadores Madi e ElTayem, os quais sugerem alguns valores para os parâmetros efetivo de flambagem, para cada um das configurações de extremidades comentadas anteriormente, que são os seguintes:

- barras sem variação de inércia nas extremidades (extremidades soldadas) $\quad \Rightarrow \mathrm{k}=0,70$ 
- barras com seção reduzida nas extremidades

(sistema MERO figura 2.3) $\quad \Rightarrow \mathrm{k}=0,90$

- barras com extremidades amassadas

(nós típicos e de aço figura 2.5) $\Rightarrow \mathrm{k}=0,95$

\section{6 - ENSAIO DE BARRAS ISOLADAS}

Neste item são apresentados e discutidos os resultados da análise teórica e experimental de barras de seção tubular com extremidades estampadas (amassadas), submetidas à compressão axial, barras estas amplamente utilizadas nas treliças metálicas espaciais, uma vez que representam uma significativa economia global devido a simplicidade dos nós

Os resultados dos ensaios aqui mostrados foram extraídos do relatório técnico de SALES et al (1996 b). Análises e discussões podem ser encontrados nos trabalhos de GONÇALVES et al. (1996), MAGALHÃES (1996), MALITE et al. (1997), e SOUZA (1998).

Inicialmente, vale salientar que a estampagem da extremidade destas barras leva à uma redução significativa da rigidez à flexão nesta região, o que implica numa redução da sua resistência à compressão. Nos projetos de treliças espaciais, este efeito não é geralmente considerado, o que pode conduzir à uma situação muito desfavorável e portanto contrária à segurança.

O objetivo principal da análise experimental foi comparar o desempenho estrutural de diversos detalhes de estampagem, mediante 0 ensaio de compressão axial de barras isoladas.

Os resultados teóricos da força normal crítica, nas várias barras, foram obtidos através das recomendações das normas AISI/LRFD (1991) e EUROCODE (1992), sendo que o EUROCODE prevê, para barras sujeitas a variação de inércia ao longo do comprimento, uma correção no valor da esbeltez reduzida $\bar{\lambda}$, introduzindo o valor da tensão crítica de flambagem elástica corrigido, ou seja, calculado admitindo-se a variação de inércia. 


\subsection{1 - Descrição dos elementos ensaiados}

Foram ensaiadas 27 barras de seção transversal $\phi 88 \times 2,65(\mathrm{~mm})$, formadas a frio, em aço USI-SAC 41. Os valores convencionais das propriedades mecânicas deste aço, na condição virgem, estão listados a seguir.

\begin{tabular}{ll|}
\hline Resistência ao escoamento: & $\mathrm{f}_{\mathrm{y}}=245 \mathrm{MPa}$ \\
Resistência à tração: & $\mathrm{f}_{\mathrm{u}}=402 / 510 \mathrm{MPa}$ \\
Alongamento na ruptura: & $\mathrm{A}=25 \%$ \\
Módulo de elasticidade: & $\mathrm{E}=205.000 \mathrm{MPa}$ \\
\hline
\end{tabular}

Nota: bobina laminada a quente

As 27 barras ensaiadas foram classificadas em função do seu comprimento teórico, aqui definido como a distância entre as faces externas dos aparelhos de apoio, e do detalhe da estampagem, como apresentado a seguir.

Série $E$ (E1 a $E 9)$ - comprimento teórico igual a $4.200 \mathrm{~mm}(\lambda=140)$

Série $F(F 1$ a F9) - comprimento teórico igual a $3.000 \mathrm{~mm}(\lambda=100)$

Série G (G1 a G9) - comprimento teórico igual a $1.800 \mathrm{~mm}(\lambda=60)$

1 a 3 - estampagem padrão (reta) $\rightarrow$ modelo $P$

4 a 6 - estampagem tradicional $\rightarrow$ modelo $T$

7 a 9 - estampagem nova $\rightarrow$ modelo $\mathrm{N}$

A figura 2.8 indica as dimensões e a geometria das extremidades dos protótipos ensaiados. 

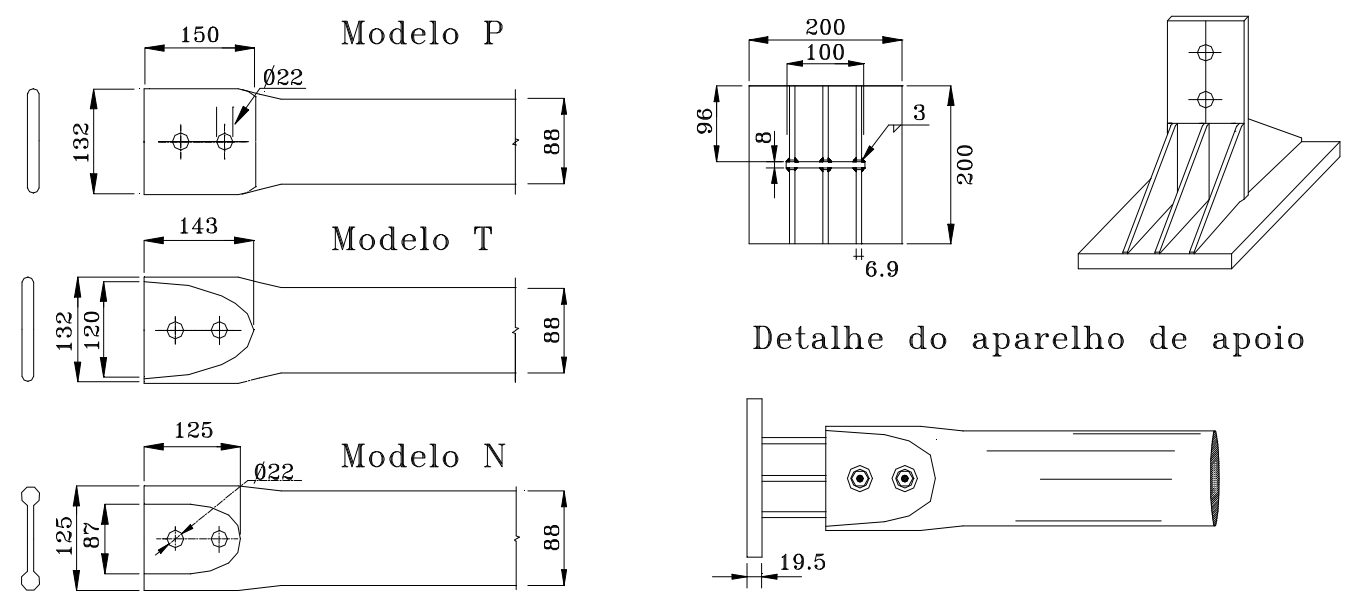

Detalhe do aparelho de apoio

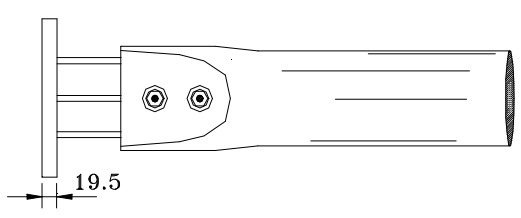

NOTA: dimensões em $\underline{\mathrm{mm}}$

FIGURA 2.8 - Detalhe das extremidades das barras ensaiadas.

A denominação das estampagens apresentadas anteriormente, é utilizada no âmbito do Laboratório de Estruturas da EESC-USP , podendo haver outras nomenclaturas para as mesmas em outras referências.

As 27 barras foram ensaiadas à compressão axial, na posição horizontal (figura 2.9), onde numa extremidade o aparelho de apoio foi simplesmente apoiado na estrutura de reação (superfície plana) denominado de apoio 2 e na outra extremidade, apoiado junto à uma superfície esférica acoplada à célula de carga (apoio 1).

A medição de deformação específica foi feita por quatro extensômetros elétricos uniaxiais (strain gages) posicionados na seção transversal central de cada barra, com o propósito principal de observar a evolução da flexão em todas as etapas do ensaio.

Para a medição de deslocamentos os instrumentos utilizados nestes ensaios foram: 8 transdutores de deslocamento posicionados ao longo da barra (5 na direção de menor inércia: nas extremidades, no meio do comprimento e à cada quarto do comprimento; e 3 transdutores na direção ortogonal a esta: nas extremidades e no meio do comprimento), obtendo 
assim os deslocamentos transversais ao eixo longitudinal em vários pontos da barra.

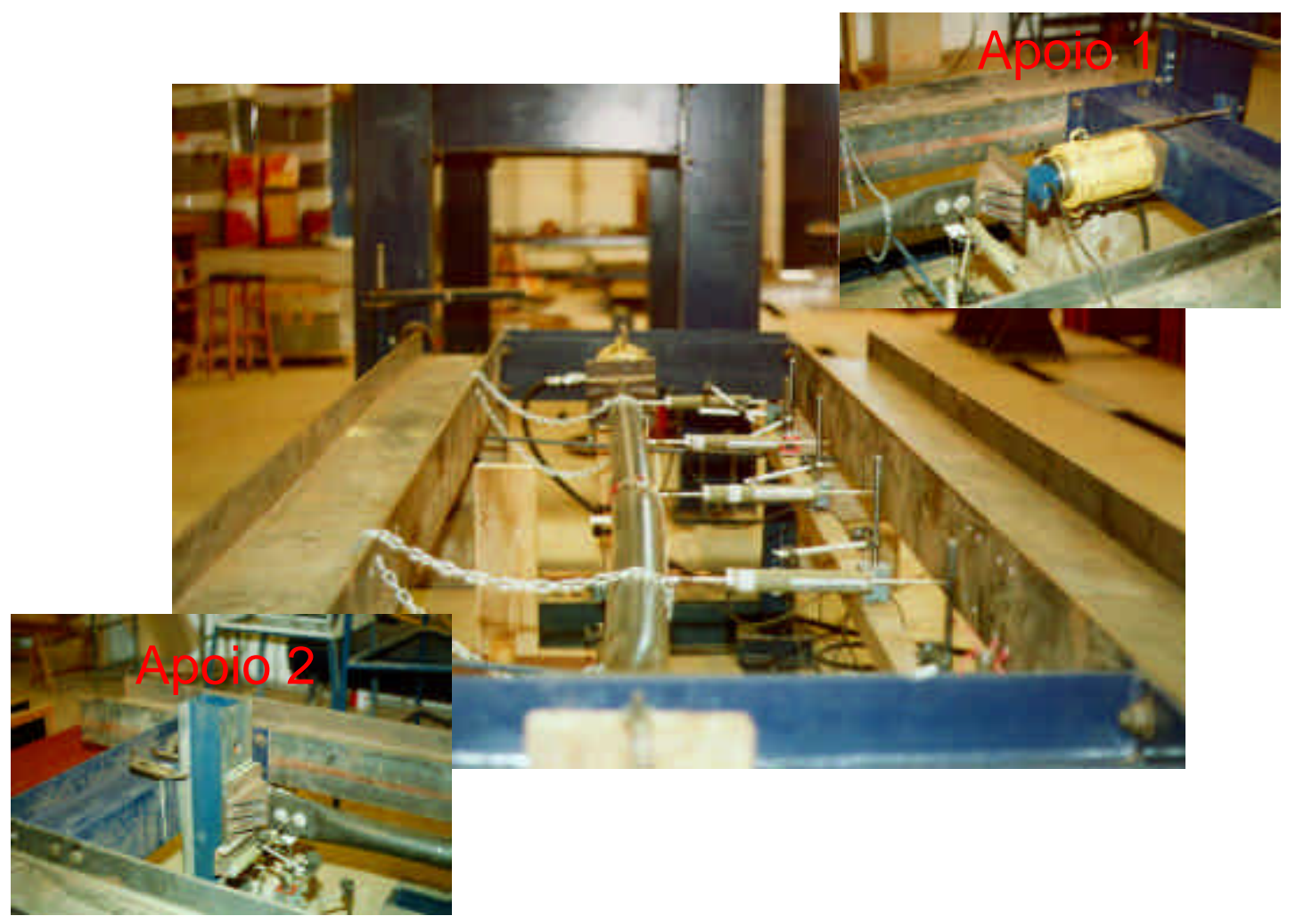

FIGURA 2.9 - Vista geral do ensaio de barra isolada e detalhe dos apoios

\subsection{2 - Ensaio das Barras}

A tabela 2.1 apresenta as máximas forças aplicadas (forças últimas de ensaio) para os 27 protótipos ensaiados, as quais foram assumidas como a força normal crítica. 
TABELA 2.1 - Resultados dos ensaios de compressão nas barras

\begin{tabular}{|c|c|c|c|}
\hline SÉRIE & ESTAMPAGEM & BARRA & $\begin{array}{c}\mathrm{P}_{\mathrm{u}}(\mathrm{kN}) \\
\text { experimental }\end{array}$ \\
\hline \multirow{9}{*}{$\begin{array}{c}\mathbf{E} \\
\lambda=140\end{array}$} & $\mathrm{P}$ & E1 & 75 \\
\hline & $\mathrm{P}$ & E2 & 74 \\
\hline & $\mathrm{P}$ & E3 & 74 \\
\hline & $\mathrm{T}$ & E4 & 76 \\
\hline & $\mathrm{T}$ & E5 & 82 \\
\hline & $\mathrm{T}$ & E6 & 65 \\
\hline & $\mathrm{N}$ & E7 & 70 \\
\hline & $\mathrm{N}$ & E8 & 70 \\
\hline & $\mathrm{N}$ & E9 & 69 \\
\hline & & & \\
\hline \multirow{9}{*}{$\begin{array}{c}\mathbf{F} \\
\lambda=100\end{array}$} & $P$ & $\mathrm{~F} 1$ & 108 \\
\hline & $\mathrm{P}$ & $\mathrm{F} 2$ & 115 \\
\hline & $\mathrm{P}$ & F3 & 101 \\
\hline & $\mathrm{T}$ & $\mathrm{F} 4$ & 125 \\
\hline & $\mathrm{T}$ & $\mathrm{F} 5$ & 115 \\
\hline & $\mathrm{T}$ & F6 & 123 \\
\hline & $\mathrm{N}$ & F7 & 130 \\
\hline & $\mathrm{N}$ & F8 & 139 \\
\hline & $\mathrm{N}$ & F9 & 123 \\
\hline \multirow{9}{*}{$\begin{array}{c}\mathbf{G} \\
\lambda=60\end{array}$} & $P$ & G1 & 124 \\
\hline & $\mathrm{P}$ & G2 & 105 \\
\hline & $P$ & G3 & 100 \\
\hline & $\mathrm{T}$ & G4 & 123 \\
\hline & $\mathrm{T}$ & G5 & 178 \\
\hline & $\mathrm{T}$ & G6 & 154 \\
\hline & $\mathrm{N}$ & G7 & 135 \\
\hline & $\mathrm{N}$ & G8 & 159 \\
\hline & $\mathrm{N}$ & G9 & 145 \\
\hline
\end{tabular}

$$
\begin{aligned}
& \text { Legenda: } \\
& \mathrm{P}=\text { padrão (reta) } \quad \mathrm{T}=\text { tradicional } \quad \mathrm{N}=\text { nova }
\end{aligned}
$$

O modo de colapso para todos os protótipos ensaiados, correspondeu à formação de rótulas plásticas na extremidade da barra junto ao apoio 1, em relação ao eixo de menor inércia. Estas rótulas ocorreram sempre no apoio 1 , pois o apoio 2 apresentava-se restrito parcialmente à rotação. 
Alguns resultados obtidos nos ensaios são apresentados a seguir, na forma de gráficos (figuras 2.10 a 2.24), tomando-se as barras representativas de cada série.

- Força x deslocamento transversal em três pontos ao longo do comprimento da barra.

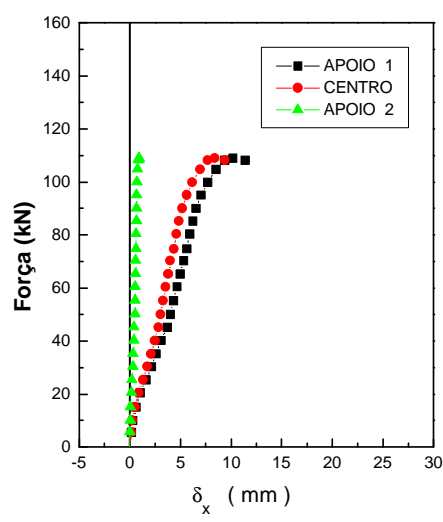

FIGURA 2.10

Gráfico - Força x Desloc. (Extrem. Tipo A - $\lambda=60$ )

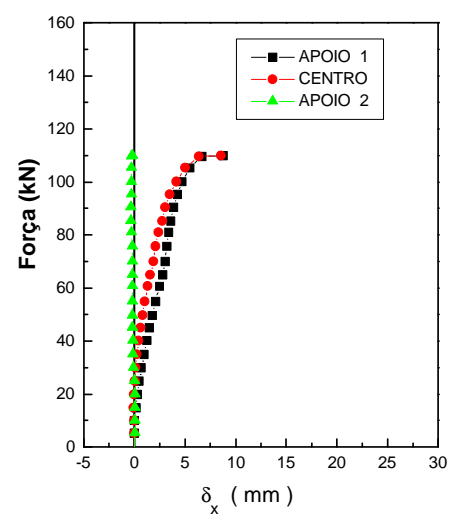

FIGURA 2.11

Gráfico - Força x Desloc. (Extrem. Tipo A - $\lambda=100$ )

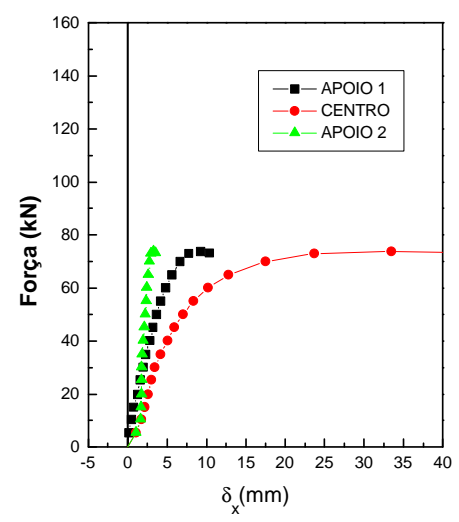

FIGURA 2.12 Gráfico - Força x Desloc. (Extrem. Tipo A $-\lambda=140$ )

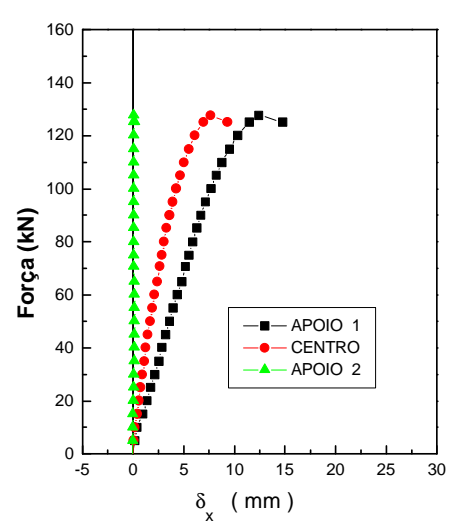

FIGURA 2.13

Gráfico - Força x Desloc. (Extrem. Tipo B $-\lambda=60$ )

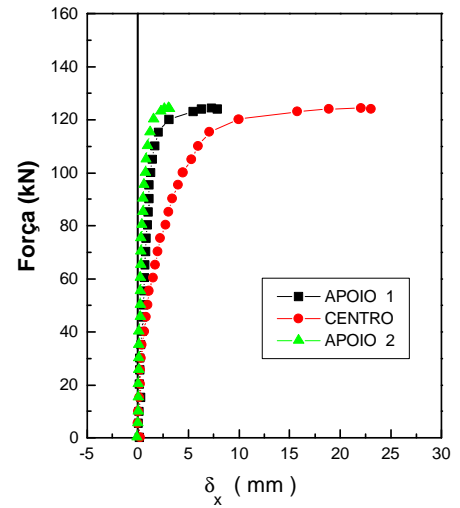

FIGURA 2.14 Gráfico - Força x Desloc. (Extrem. Tipo B - $\lambda=100$ )

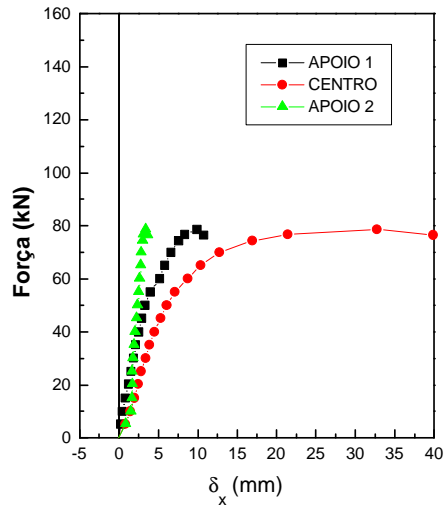

FIGURA 2.15 Gráfico - Força x Desloc. (Extrem. Tipo B - $\lambda=140$ ) 


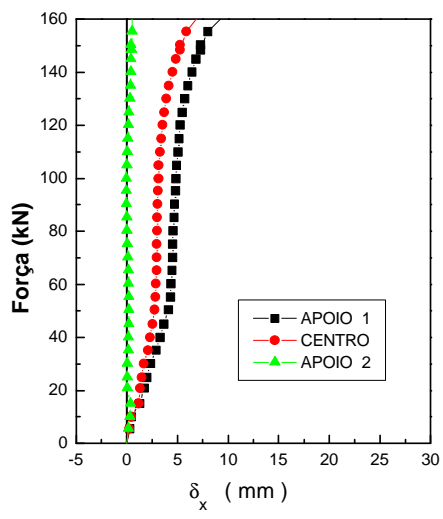

FIGURA 2.16

Gráfico - Forçax Desloc. (Extrem. Tipo $C-\lambda=60$ )

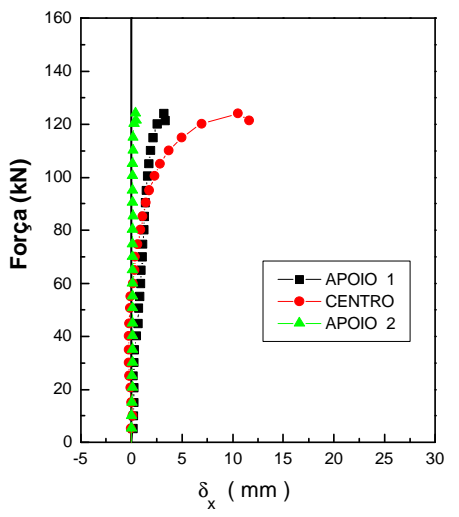

FIGURA 2.17

Gráfico - Força $\times$ Desloc. (Extrem. Tipo $C-\lambda=100$ )

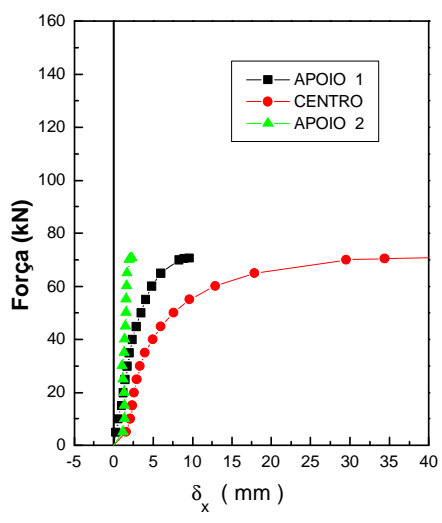

FIGURA 2.18

Gráfico - Force x Displac. (Extrem. Tipo C - $\lambda=140$ )

- Força $x$ deformação da seção transversal central.

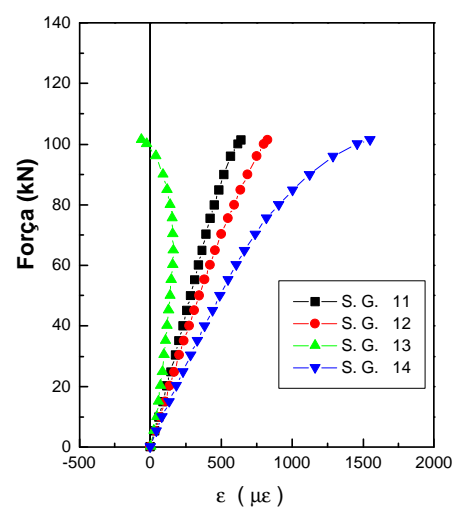

FIGURA 2.19

Gráfico - Força $x$ deform. (Extrem. Tipo $A-\lambda=100$ )

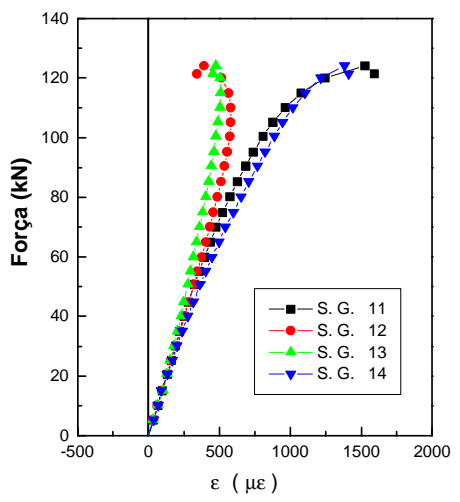

FIGURA 2.21

FIGURA 2.20

Gráfico - Força $\times$ Deform. Gráfico - Força $\times$ Deform. (Extrem. Tipo $B-\lambda=100) \quad$ (Extrem. Tipo $C-\lambda=100$ )

- Evolução dos deslocamentos em algumas etapas de carregamento.

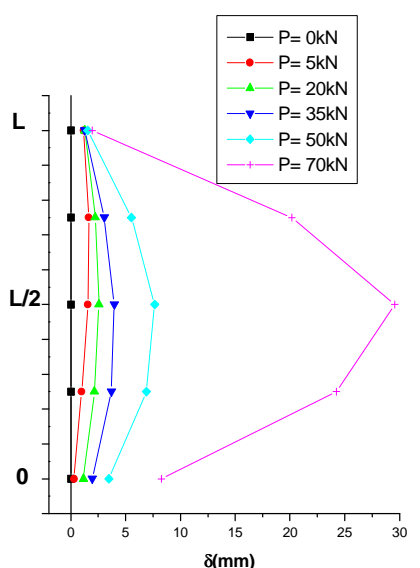

FIGURA 2.22

Força $\times$ Desloc. relativo (Extrem. Tipo C $-\lambda=140$ )

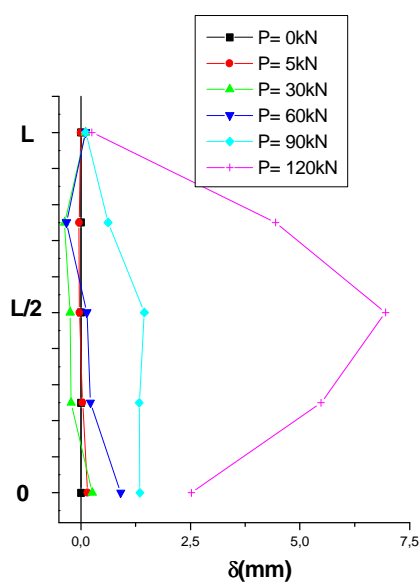

FIGURA 2.23

Força $x$ Desloc. relativo (Extrem. Tipo $C-\lambda=100$ )

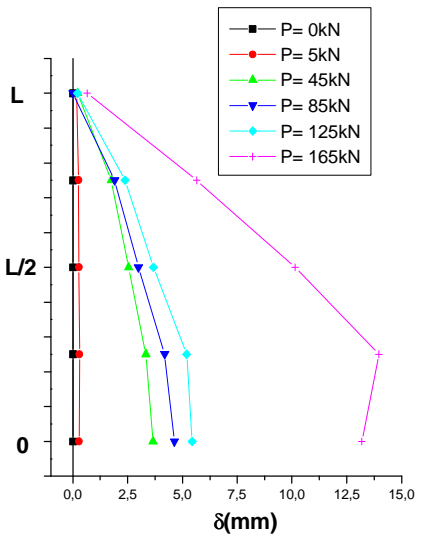

FIGURA 2.24

Força $x$ Desloc. relativo (Extrem. Tipo $C-\lambda=60$ ) 
As figuras 2.22, 2.23 e 2.24 apresentam os deslocamentos obtidos nas etapas indicadas de carregamento, tomando-se os cinco transdutores posicionados na direção de menor inércia. Através deles pode-se notar o significativo deslocamento do ponto posicionado junto ao apoio $1(\mathrm{y}=0)$ e 0 pequeno deslocamento do ponto oposto, posicionado junto ao apoio $2(y=L)$. Esta diferença pode ser atribuída à formação da rótula plástica junto ao apoio 1, a qual induziu ao giro e conseqüentemente ao deslocamento transversal.

\subsection{3 - Análise teórica}

Este item não tem por objetivo a discussão de conceitos teóricos relativos à instabilidade de barras e às curvas de resistência a compressão adotadas pelas normas, limitando-se entretanto a fazer comparações entre os resultados obtidos nos ensaios e os calculados com base nas recomendações de normas técnicas.

Os valores da força última obtida nos ensaios das 27 barras estão resumidos na tabela 2.1 apresentada anteriormente. Os valores teóricos da força última (carga crítica de flambagem) foram calculados com base nos seguintes parâmetros:

Propriedades geométricas da seção: tubo $\phi 88$ × 2,65 (mm):

Área bruta: $A_{g}=7,3 \mathrm{~cm}^{2}$

Raio de giração: $r=3,0 \mathrm{~cm}$

Módulo de elasticidade:

$$
\begin{aligned}
& E=205.000 \mathrm{MPa} \text { (valor convencional) } \\
& E \cong 200.000 \mathrm{MPa} \text { (valor experimental) }
\end{aligned}
$$

Resistência ao escoamento:

$$
\begin{aligned}
& \mathrm{f}_{\mathrm{y}}=245 \mathrm{MPa} \text { (convencional - aço virgem) } \\
& \mathrm{f}_{\mathrm{y}}=412 \mathrm{MPa} \text { (valor experimental médio - tubo) }
\end{aligned}
$$


Obs.: os valores de $\mathrm{E}$ e fy experimentais, foram obtidos através de ensaios de tração em corpos-de-prova extraídos de tubos. As dimensões destes e a metodologia de ensaio à tração seguiram as determinações da ASTM A370-92.

O quadro seguinte contém as expressões para cálculo da tensão crítica de flambagem segundo o AISI/LRFD (1991) (única curva) e o EUROCODE (1992) (múltiplas curvas).

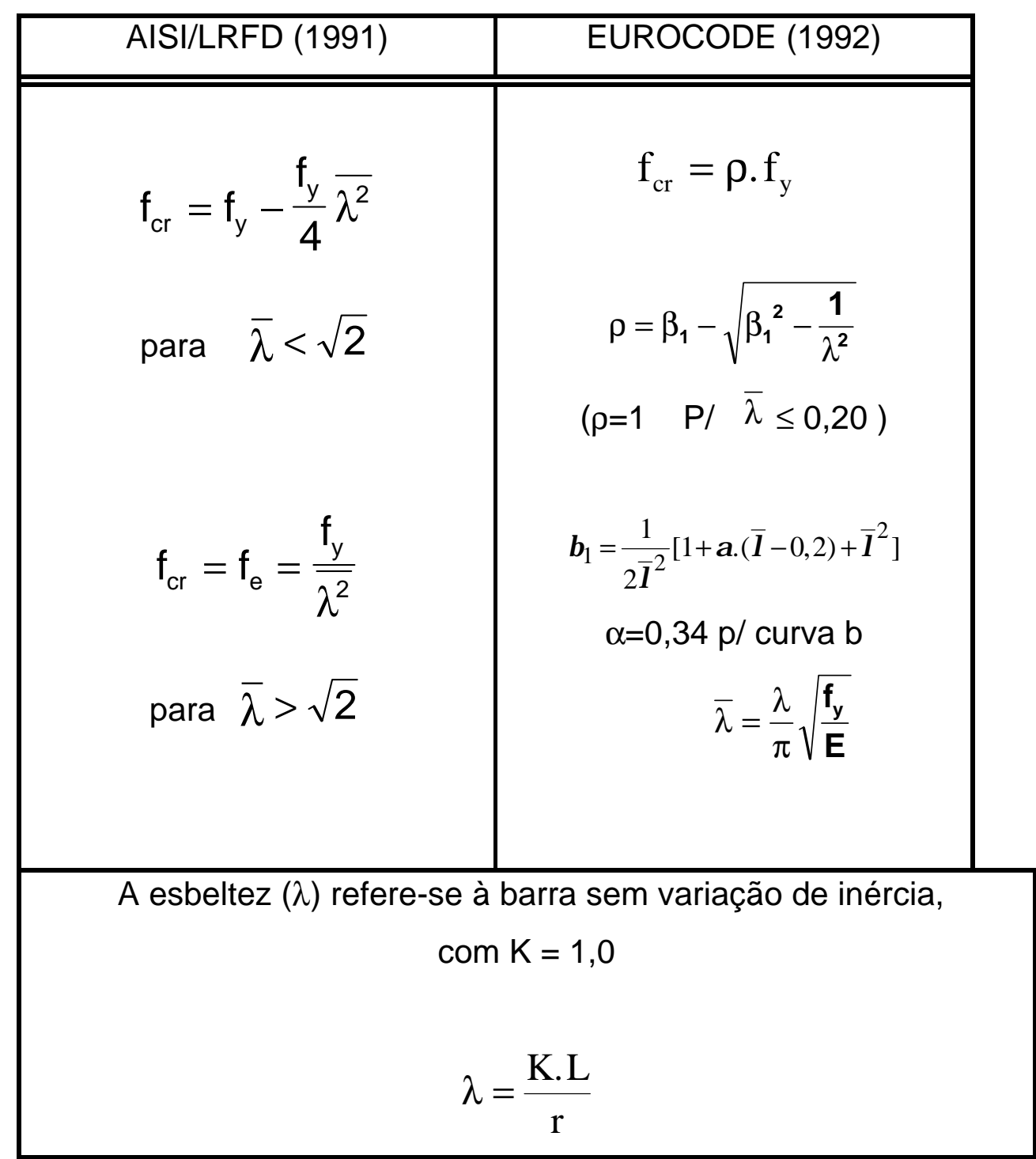

O AISI/LRFD (1991) não faz referência aos casos de barras com variação de inércia, já o EUROCODE (1992) explicita que nos casos de barras com variação de inércia a esbeltez reduzida deve ser corrigida 
tomando-se a tensão crítica de flambagem elástica calculada admitindo-se a variação de inércia. Neste trabalho, este mesmo conceito foi também empregado no cálculo da tensão crítica de flambagem segundo o AISI/LRFD.

$$
\bar{\lambda}^{*}=\sqrt{\frac{\mathrm{f}_{\mathrm{y}}}{\mathrm{f}_{\mathrm{e}}^{*}}}
$$

onde

$\lambda^{*}=$ esbeltez reduzida corrigida

$\mathrm{f}_{\mathrm{y}}=$ resistências ao escoamento do aço

$\mathrm{f}_{\mathrm{e}}{ }^{*}=$ tensão crítica de flambagem elástica calculada admitindo-se variação de inércia

O programa computacional LUSAS ${ }^{\star}$ foi utilizado para a determinação dos valores de $\mathrm{f}_{\mathrm{e}}{ }^{*}$ dos protótipos. Os valores de momento de inércia para os três tipos de extremidade estão apresentados na Figura 2.25:
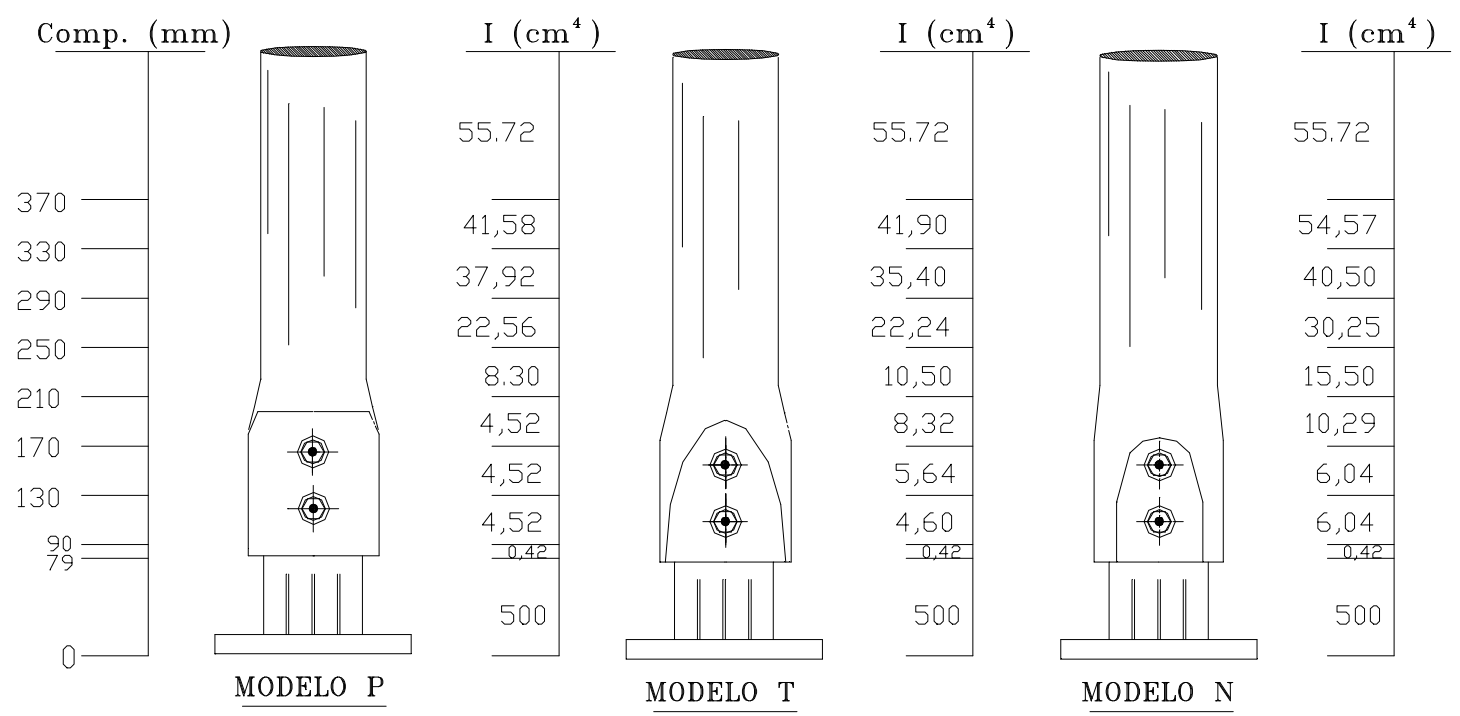

Figura 2.25 - Momentos de inércia para os três tipos de extremidades

\footnotetext{
${ }^{*}$ LUSAS $\Rightarrow$ Finite Element Analysis (FEA), Revision 11, Surrey - U.K. 1996.
} 
As tabelas 2.2 a 2.4 seguintes apresentam um resumo dos resultados obtidos, onde os valores teóricos foram obtidos com base no EUROCODE curva b, com $f_{y}=41,2 k N \mathrm{~cm}^{2}$.

TABELA 2.2 - Resultados teóricos - extremidade tipo P

\begin{tabular}{|l|c|c|c|c|c|c|c|c|c|}
\hline$\lambda$ & $\begin{array}{l}\mathrm{f}_{\mathrm{e}} \\
\left(\mathrm{kN} / \mathrm{cm}^{2}\right)\end{array}$ & $\begin{array}{l}\mathrm{f}_{\mathrm{e}}^{*} \\
\left(\mathrm{kN} / \mathrm{cm}^{2}\right)\end{array}$ & $\bar{\lambda}=\sqrt{\frac{f_{y}}{f_{e}}}$ & $\lambda^{*}=\sqrt{\frac{f_{y}}{f_{e}^{*}}}$ & $\begin{array}{c}N_{n} \\
(\mathrm{kN})\end{array}$ & $\begin{array}{c}\mathrm{N}_{\mathrm{n}}^{*} \\
(\mathrm{kN})\end{array}$ & $\begin{array}{c}\text { Exper. } \\
N_{n, t} \\
(\mathrm{kN})\end{array}$ & $\frac{\mathrm{N}_{\mathrm{n}, \mathrm{t}}}{\mathrm{N}_{\mathrm{n}}}$ & $\frac{\mathrm{N}_{\mathrm{n}, \mathrm{t}}}{\mathrm{N}_{\mathrm{n}}^{*}}$ \\
\hline 60 & 54,83 & 27,73 & 0,867 & 1,219 & 206,6 & 140,7 & 110,0 & 0,53 & 0,78 \\
\hline 100 & 19,74 & 14,89 & 1,445 & 1,663 & 109,3 & 86,8 & 108,0 & 0,98 & 1,24 \\
\hline 140 & 10,07 & 8,89 & 2,023 & 2,153 & 61,7 & 55,2 & 74,0 & 1,20 & 1,34 \\
\hline
\end{tabular}

TABELA 2.3 - Resultados teóricos - extremidade tipo T

\begin{tabular}{|c|c|c|c|c|c|c|c|c|c|}
\hline$\lambda$ & $\begin{array}{c}\mathrm{f}_{\mathrm{e}} \\
\left(\mathrm{kN} / \mathrm{cm}^{2}\right)\end{array}$ & $\begin{array}{c}\mathrm{f}_{\mathrm{e}}^{*} \\
\left(\mathrm{kN} / \mathrm{cm}^{2}\right)\end{array}$ & $\bar{\lambda}=\sqrt{\frac{f_{\mathrm{y}}}{\mathrm{f}_{\mathrm{e}}}}$ & $\bar{\lambda}^{*}=\sqrt{\frac{\mathrm{f}_{\mathrm{y}}}{\mathrm{f}_{\mathrm{e}}^{*}}}$ & $\begin{array}{c}\mathrm{N}_{\mathrm{n}} \\
(\mathrm{kN})\end{array}$ & $\begin{array}{c}\mathrm{N}_{\mathrm{n}}^{*} \\
(\mathrm{kN})\end{array}$ & $\begin{array}{c}\text { Exper. } \\
\mathrm{N}_{\mathrm{n}, \mathrm{t}} \\
(\mathrm{kN})\end{array}$ & $\frac{\mathrm{N}_{\mathrm{n}, \mathrm{t}}}{\mathrm{N}_{\mathrm{n}}}$ & $\frac{\mathrm{N}_{\mathrm{n}, \mathrm{t}}}{\mathrm{N}_{\mathrm{n}}^{*}}$ \\
\hline 60 & 54,83 & 34,03 & 0,867 & 1,100 & 206,6 & 160,9 & 152,0 & 0,70 & 0,94 \\
\hline 100 & 19,74 & 15,75 & 1,445 & 1,617 & 109,3 & 90,9 & 121,0 & 1,11 & 1,33 \\
\hline 140 & 10,07 & 9,17 & 2,023 & 2,120 & 61,7 & 56,8 & 74,0 & 1,20 & 1,30 \\
\hline
\end{tabular}

TABELA 2.4 - Resultados teóricos - extremidade tipo N

\begin{tabular}{|r|r|r|r|r|r|r|r|r|r|}
\hline$\lambda$ & $\begin{array}{l}f_{e} \\
\left(\mathrm{kN} / \mathrm{cm}^{2}\right)\end{array}$ & $\begin{array}{l}\mathrm{f}_{\mathrm{e}}^{*} \\
\left(\mathrm{kN} / \mathrm{cm}^{2}\right)\end{array}$ & $\bar{\lambda}=\sqrt{\frac{f_{y}}{f_{e}}}$ & $\lambda^{*}=\sqrt{\frac{f_{y}}{f_{e}^{*}}}$ & $\begin{array}{c}N_{n} \\
(k N)\end{array}$ & $\begin{array}{c}N_{n}^{*} \\
(k N)\end{array}$ & $\begin{array}{c}\text { Exper. } \\
N_{n, t} \\
(k N)\end{array}$ & $\frac{N_{n, t}}{N_{n}}$ & $\frac{N_{n, t}}{N_{n}^{*}}$ \\
\hline 60 & 54,83 & 36,02 & 0,867 & 1,069 & 206,6 & 166,5 & 146,0 & 0,71 & 0,88 \\
\hline 100 & 19,74 & 15,97 & 1,445 & 1,606 & 109,3 & 92,0 & 131,0 & 1,20 & 1,42 \\
\hline 140 & 10,07 & 9,14 & 2,023 & 2,123 & 61,7 & 56,7 & 70,0 & 1,13 & 1,23 \\
\hline
\end{tabular}

$\left({ }^{*}\right)$ significa valor corrigido, ou seja, calculado admitindo-se variação de inércia

$\lambda=$ esbeltez

$\bar{\lambda}=$ esbeltez reduzida

$\mathrm{f}_{\mathrm{e}}=$ tensão crítica de flambagem elástica

$\mathrm{N}_{\mathrm{n}}=$ resistência nominal à compressão 
A figura 2.26 apresenta as curvas de flambagem teóricas das normas do AISI/LRFD (1991) e EUROCEDE (1992) - curva b, assim como os valores experimentais referentes aos 27 protótipos ensaiados. $O$ limite de escoamento $f_{y}=24,5 \mathrm{kN} / \mathrm{cm}^{2}$ corresponde ao valor convencional do aço virgem (USI-SAC 41) e $\mathrm{f}_{\mathrm{y}}=41,2 \mathrm{kN} / \mathrm{cm}^{2}$ corresponde ao valor médio obtido nos ensaios de tração dos corpos-de-prova extraídos dos tubos.

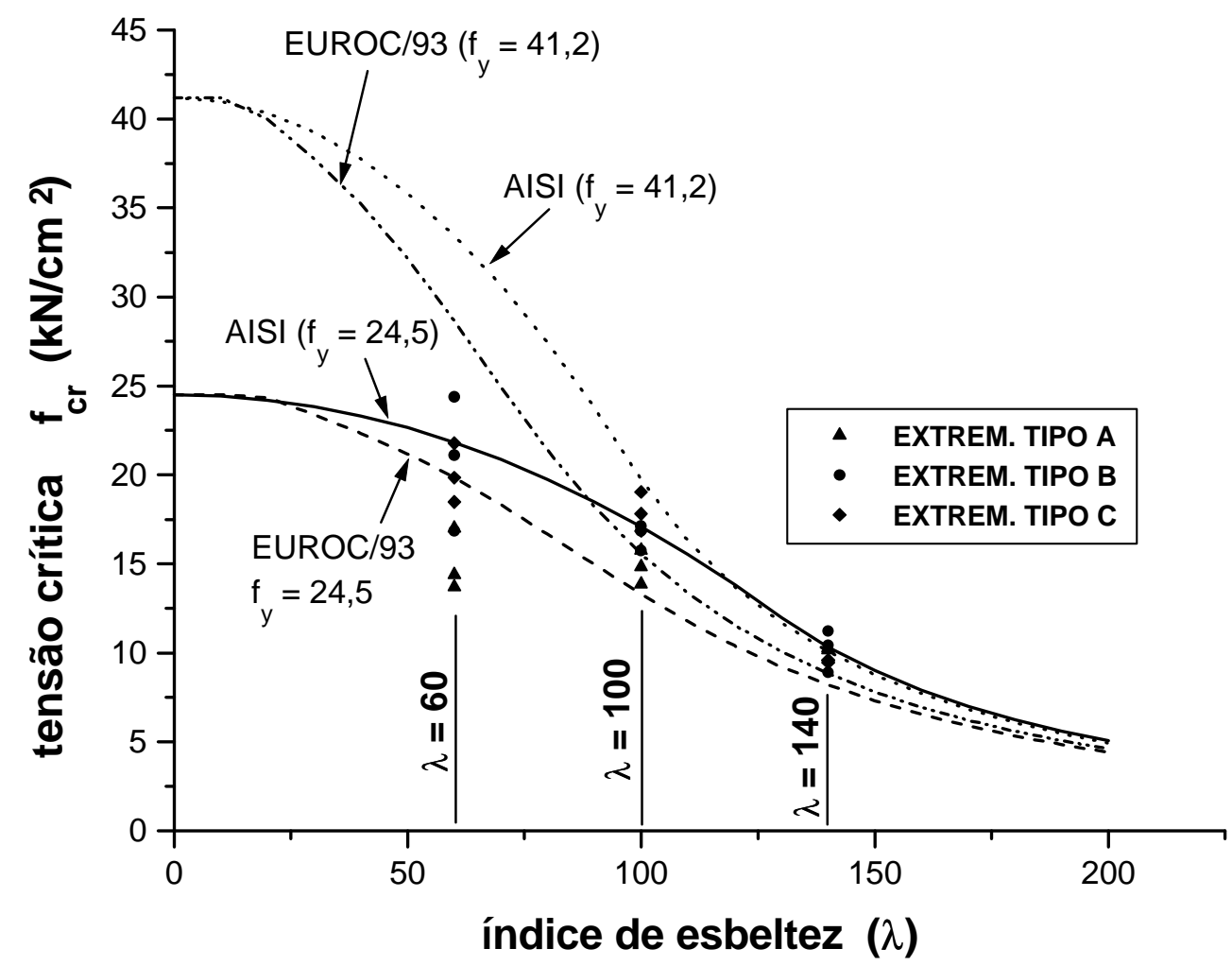

FIGURA 2.26 - Curvas de resistência à compressão e resultados experimentais

\subsection{4 - Comentários sobre os ensaios de barra isolada}

A análise experimental desenvolvida correspondeu a ensaios de compressão axial em barras isoladas, cujo objetivo básico foi o de comparar o desempenho estrutural de barras de aço com extremidades estampadas, variando-se o detalhe da estampagem, aqui denominadas $P, T$ e $\mathrm{N}$ e a 
esbeltez das barras, tomando-se os valores $\lambda=60$ (baixa esbeltez), $\lambda=100$ (média esbeltez) e $\lambda=140$ (esbelta).

Nos ensaios das barras, quanto menor a esbeltez maior a dispersão dos valores da força última, fato este proveniente da maior influência do detalhe de extremidade e das imprecisões inerentes ao ensaio de barra isolada. Para $\lambda=100$ e 60 , as estampagens tipo $T$ e $N$ se mostraram ligeiramente mais eficientes que a usual estampagem reta (tipo $\mathrm{P}$ ), fato não observado nos protótipos com $\lambda=140$, uma vez que, neste caso, a influência da extremidade não é significativa. É possível visualizar melhor tais conclusões observando-se a figura 2.26 apresentada anteriormente.

Comparando-se os valores experimentais com os teóricos, calculados conforme a norma do AISI/LRFD (1991)e EUROCODE(1992), observa-se que para os protótipos com $\lambda=140$, o valor médio experimental coincide com o valor teórico. Para os protótipos com $\lambda=100$, o valor médio experimental coincide com 0 valor teórico admitindo-se 0 limite de escoamento convencional do aço e não o valor obtido da caracterização. Para os protótipos com $\lambda=60$, das nove barras ensaiadas apenas duas apresentaram força última igual ou superior ao valor teórico admitindo-se o limite de escoamento convencional do aço, o que reforça a influência da variação de inércia no comportamento da barra.

É importante lembrar que os valores teóricos foram calculados admitindo-se a condição de apoios articulados, ou seja, $\mathrm{KL}=\mathrm{L}$, sendo que nos ensaios uma das extremidades da barra foi apoiada diretamente na estrutura de reação, ou seja, em superfície plana, o que significa alguma restrição ao giro. 


\section{ANÁLISE EXPERIMENTAL}

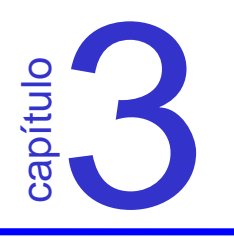

A análise experimental é vital para o entendimento do comportamento estrutural das treliças espaciais em estudo, isto devido as suas características particulares, como extremidades estampadas das barras e sistemas de conexão específicos, as quais dificultam a simulação numérica, servindo a análise experimental como modo de aferição das hipóteses teóricas adotadas.

Uma primeira etapa dos estudos relativos ao comportamento destas estruturas, realizados pela Área de Estruturas Metálicas do Departamento de Engenharia de Estruturas da EESC-USP, consistiu em ensaios de compressão axial de barras isoladas de aço e alumínio, com variação de inércia nas extremidades, barras estas utilizadas na confecção destas estruturas.

Portanto dando prosseguimento a estes estudos, foi proposto este programa experimental, o qual consistiu no ensaio de quatro protótipos de treliça espacial, tendo por objetivos avaliar o comportamento global da estrutura constituída por dois sistemas usuais de conexão (nó típico e nó de aço).

Neste capítulo serão descritos os procedimentos empregados para a realização dos ensaios, incluindo a descrição dos equipamentos utilizados, estruturas de reação, aparelhos de apoio e a instrumentação. 


\subsection{Descrição dos protótipos}

Os protótipos ensaiados simulavam um trecho de treliça espacial, apresentado em sua elevação duas camadas ou banzos, dispostos de forma paralela e plana, formando uma malha quadrada-sobre-quadrada, gerando

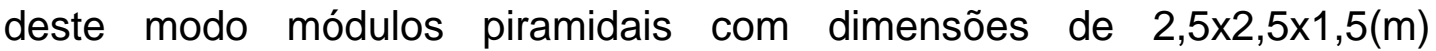
totalizando nove módulos, formando portanto uma estrutura de $7,5 \times 7,5 \times 1,5(m)$. A geometria e dimensões desta são apresentadas na Figura 3.1 .

- Pontos de aplicação de força
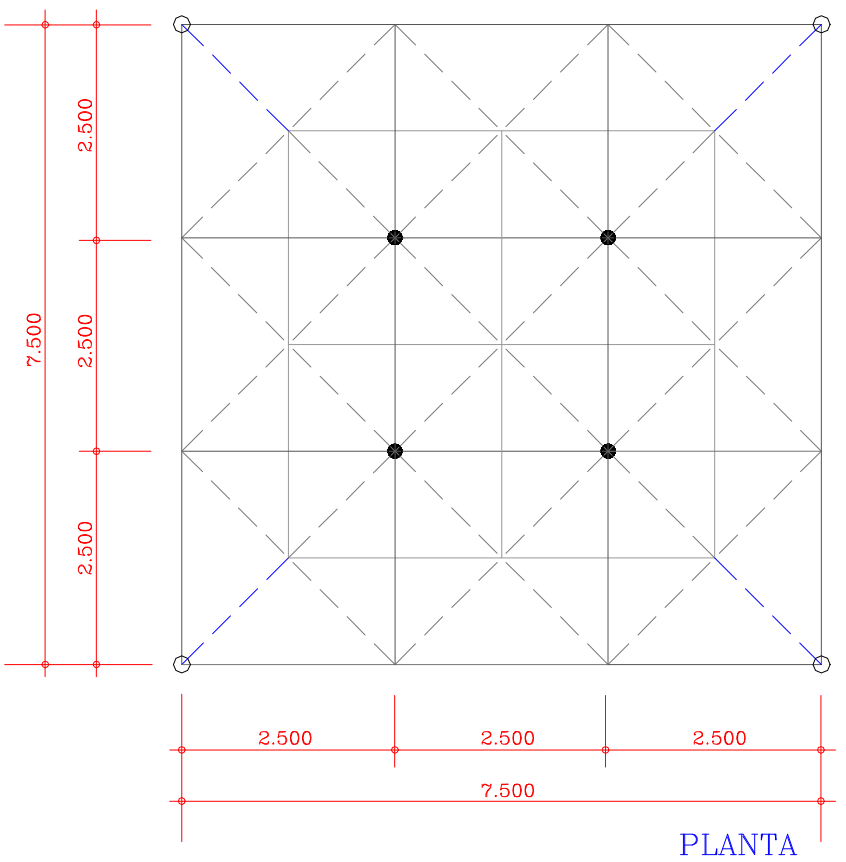

PLANTA

Bamzo superior

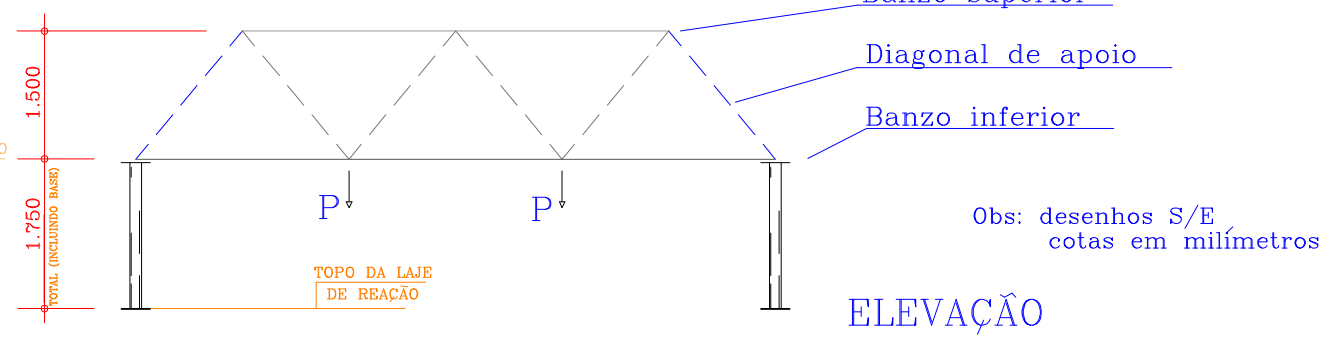

FIGURA 3.1 Esquema geral dos protótipos. 
Os protótipos foram constituídos por barras de aço de seção tubular circular, com extremidades estampadas, apoiadas nos vértices por colunas tubulares de aço $\phi 114 \times 7,11$ (mm). As dimensões e esbeltez são apresentadas na tabela 3.1 .

TABELA 3.1 - Dimensões e esbeltez para as barras componentes dos protótipos

\begin{tabular}{|c|c|c|c|}
\hline Posição da barra & seção $(\mathrm{mm})$ & Comp. $(\mathrm{mm})$ & Esbeltez \\
\hline Banzos & $\phi 76 \times 2,0$ & 2500 & 95,4 \\
\hline \multirow{2}{*}{$\begin{array}{c}\text { Diagonais } \\
\text { de apoio }\end{array}$} & $\phi 76 \times 2,0$ & 2318 & 88,5 \\
\cline { 2 - 4 } & $\phi 88 \times 2,65$ & 2318 & 76,7 \\
\hline Demais diagonais & $\phi 60 \times 2,0$ & 2318 & 112,5 \\
\hline
\end{tabular}

Os comprimentos são os teóricos das barras.

Os protótipos ensaiados diferem entre si apenas nas dimensões das diagonais de apoio, e nos seus sistemas de ligações, a tabela 3.2 a seguir caracteriza estas diferenças. As outras características são comuns a todos.

TABELA 3.2 - Descrição dos protótipos ensaiados.

\begin{tabular}{|c|c|c|}
\hline Protótipo & Detalhe dos nós & Diagonais de apoio \\
\hline PROT $1^{(1)}$ & nós típicos & (ب88x2,65(mm) \\
\hline PROT $2^{(2)}$ & nós típicos & $\phi 76 \times 2,0(\mathrm{~mm})$ \\
\hline PROT 3 & nós de aço & $\phi 88 \times 2,65(\mathrm{~mm})$ \\
\hline PROT 4 & sistema misto & $\phi 88 \times 2,65(\mathrm{~mm})$ \\
\hline
\end{tabular}

O sistema misto de nós empregado no protótipo PROT 4, refere-se ao emprego de nós típicos e de aço no mesmo protótipo, com os primeiros posicionados nas ligações menos solicitadas e o segundo nas mais solicitadas, respeitando os aspectos construtivos. 


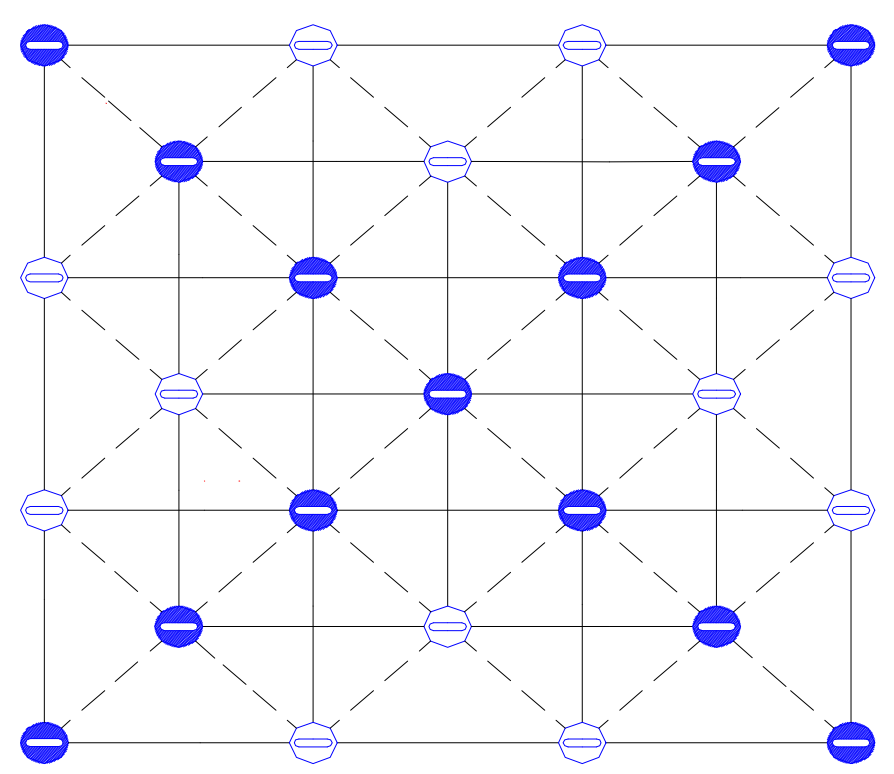

Legenda:

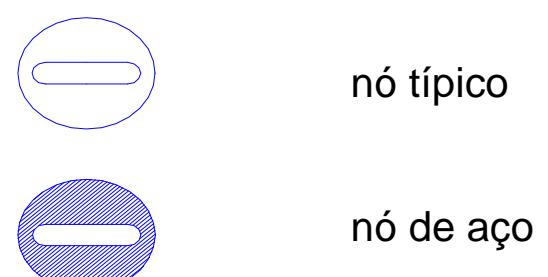

FIGURA 3.2 - Disposição dos nós do protótipo com sistema misto de conexão

A seguir são detalhados os dois sistemas de conexão utilizados nos protótipos.

Nó típico:

É representado pela sobreposição das extremidades estampadas das barras que compõem a estrutura, unidas por apenas um parafuso. Este é o mais comum dos sistemas de ligação encontrados no Brasil sendo também o que merece maior atenção quanto ao seu comportamento estrutural, devido a pouca rigidez conferida a este pela variação de inércia das extremidades amassadas das barras que o compõem, pelas excentricidades 
e também pela utilização de apenas um parafuso na união das barras (figura 3.3).

Esta rigidez é melhorada por medidas tomadas na montagem, como a utilização de arruelas quadradas confinando as extremidades dos tubos e também com o aperto adequado dos parafusos com torque controlado.
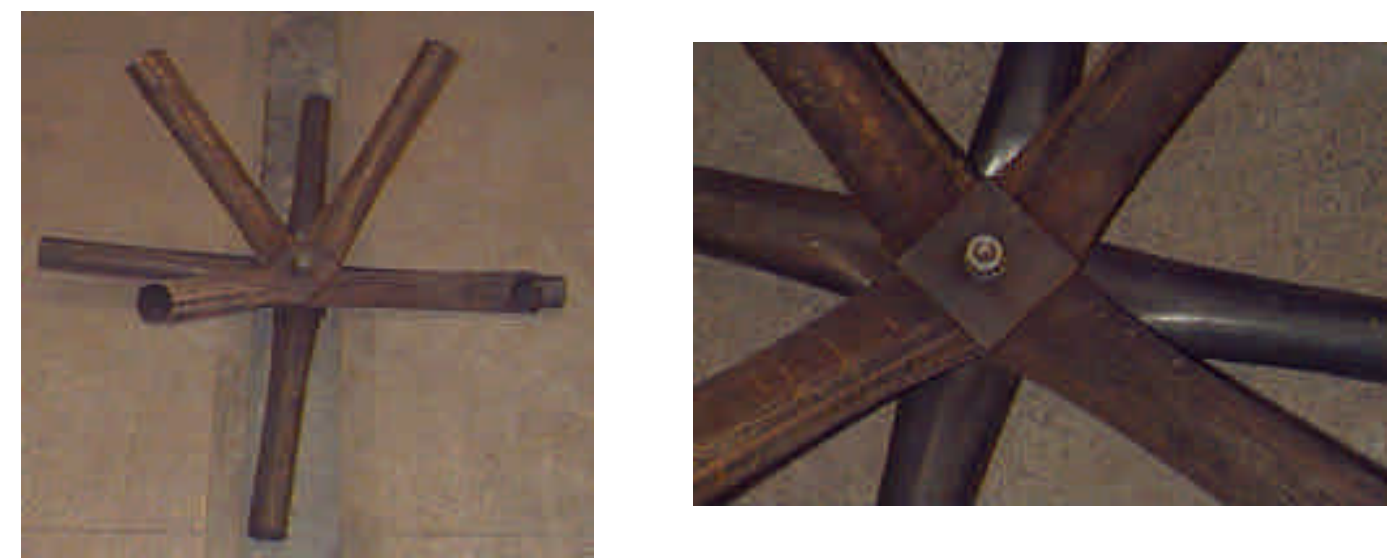

FIGURA 3.3 - Detalhe do nó típico

Nó de aço:

Formado por chapas de aço soldadas em forma de aletas, nas quais as extremidades amassadas das barras são encaixadas e parafusadas, como mostrado na figura 3.4. Este nó apresenta melhor desempenho estrutural do que o anterior, não existindo teoricamente excentricidades, uma vez que as barras concorrem para um único ponto, e também por ser este mais rígido que o nó típico. 


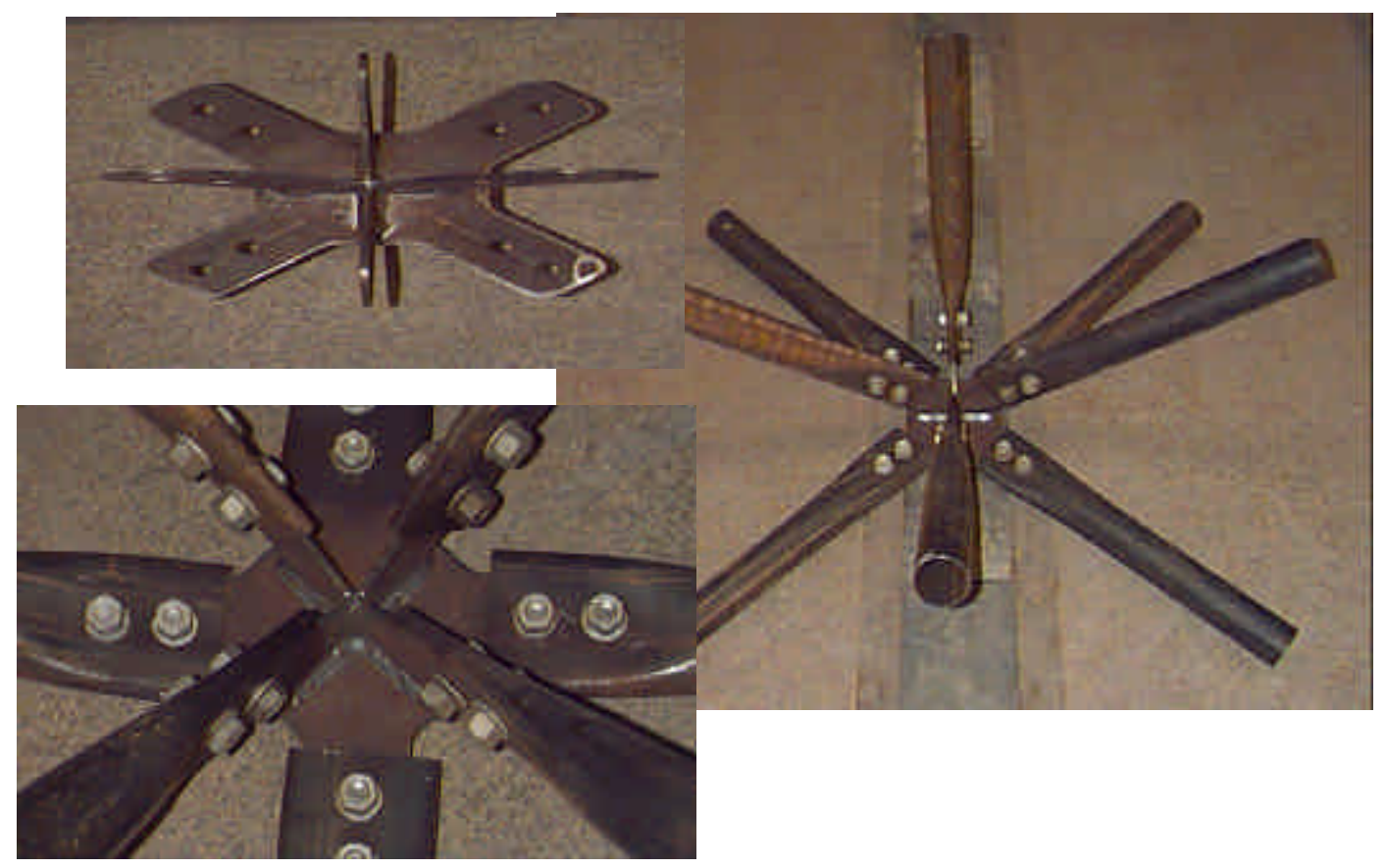

FIGURA 3.4 - Detalhe do nó de aço.

\section{2 - Estrutura de reação e aplicação de força}

Os quatro protótipos foram apoiados em seus vértices do banzo inferior, em colunas tubulares de aço com seção $\phi 168 \times 7,11(\mathrm{~mm})$, as quais tinham a sua extremidade inferior fixada a um segmento de perfil soldado que por sua vez era fixado à laje de reação do Laboratório de Estruturas.
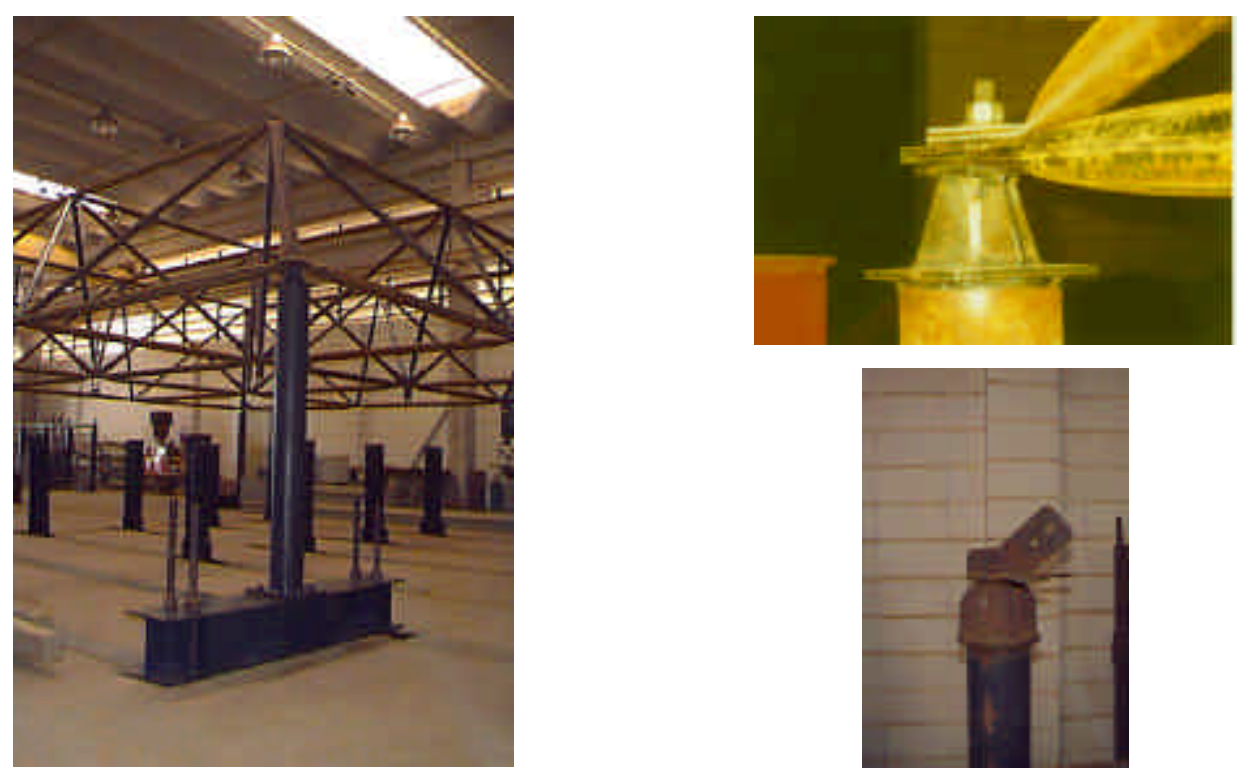

FIGURA 3.5 - Vista geral e detalhe do sistema de apoio 
$\mathrm{Na}$ extremidade superior das colunas de apoio foram soldados dispositivos de fixação para os diferentes tipos de nós empregados: para as estruturas cuja ligação com o apoio se dava por meio de nós típicos, esta era formada por um parafuso tendo em sua base uma chapa de reforço, já no caso de ligação com o nó de aço o topo da coluna era constituído por chapas de aço soldadas similar ao próprio nó de aço.

Sob os protótipos foram montados quatro estruturas de ancoragem para a aplicação de força, fixadas a laje de reação, como pode ser visto na figura 3.6.

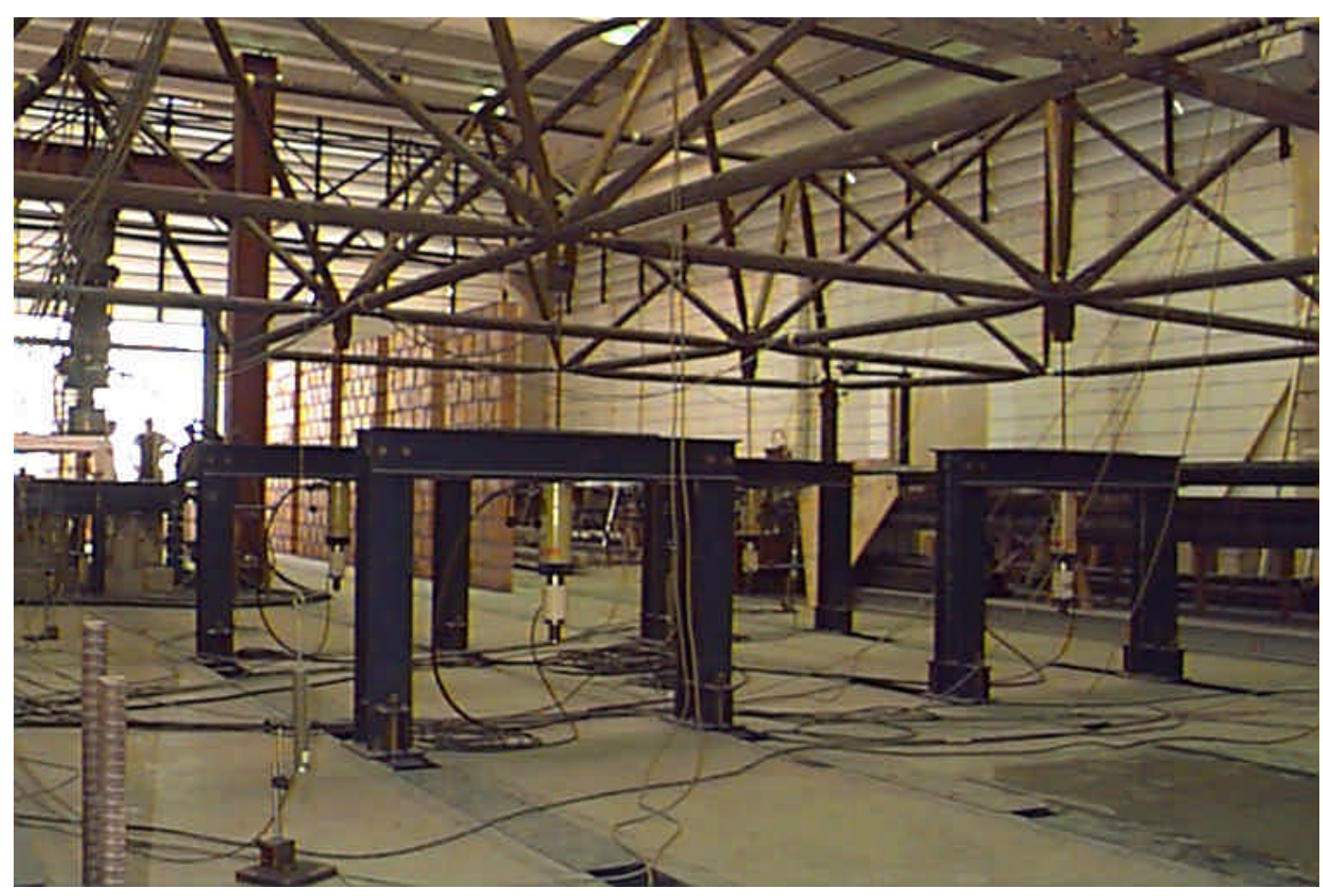

FIGURA 3.6 - Vista geral das estruturas de reação para aplicação de força 


\section{3 - Montagem dos protótipos}

A execução dos protótipos foi realizada pela ALUSUD - Eng. e Ind. de Construções Espaciais Ltda, empresa com larga experiência na fabricação e montagem de treliças espaciais.

A montagem consistiu no posicionamento e conexão das barras ainda no piso do laboratório, para em seguida efetuar o içamento do protótipo já montado (técnica denominada "lift slab"), fixando-o nas colunas de apoio. Os protótipos foram montados no galpão de ensaios do Laboratório de Estruturas da EESC/USP, e o içamento foi feito com o auxílio da ponte rolante sendo a estrutura içada pelo seu nó central localizado no banzo superior.

A figura 3.7 mostra um protótipo em fase de montagem, e a figura 3.8 mostra o protótipo montado e pronto para o içamento.

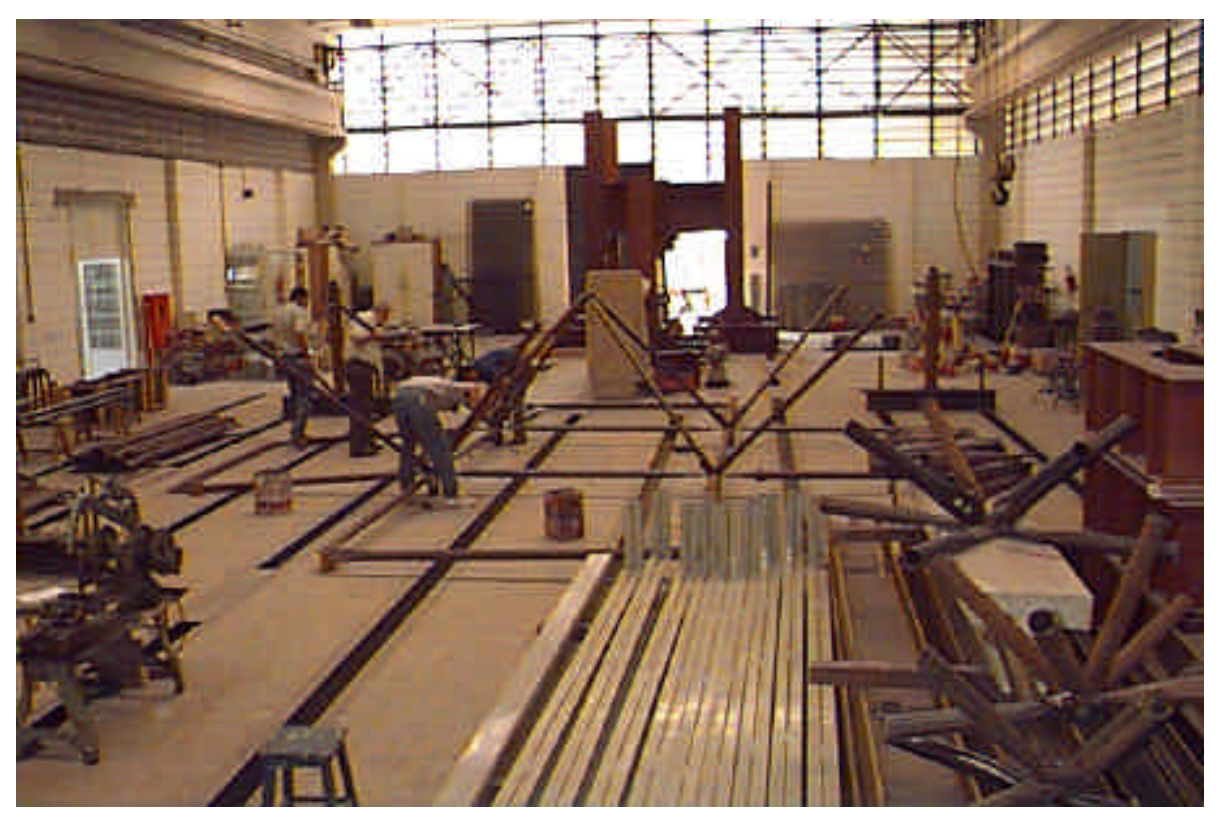

FIGURA 3.7 - Montagem do protótipo no piso do Laboratório 


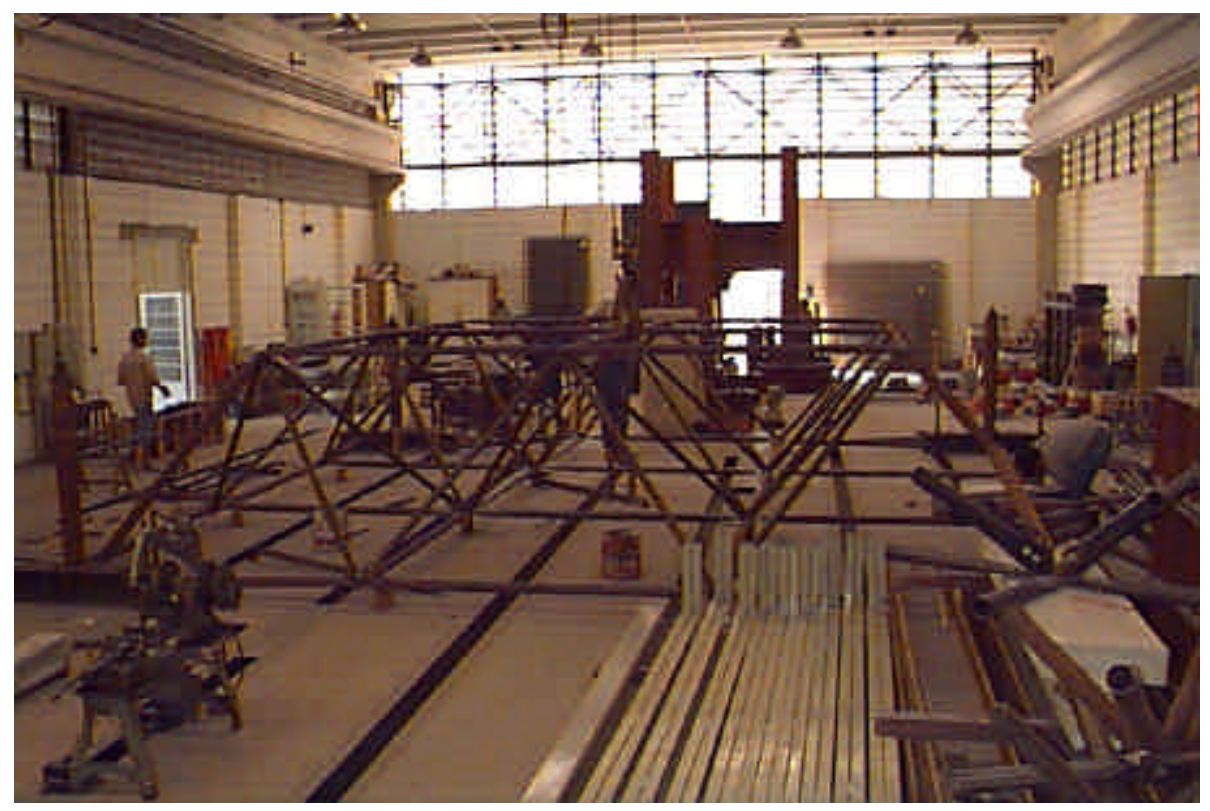

FIGURA 3.8 - Preparação para o içamento do protótipo

$\mathrm{Na}$ fase de montagem os parafusos foram apertados com chave normal, atingindo portanto a condição de pré-torque. Após o posicionamento da estrutura nas colunas de apoio, foi efetuado o aperto final nos parafusos, com aplicação de torque controlado por um torquímetro de estalo, seguindo para tanto os critérios empregados pela empresa ALUSUD, os quais correspondem a aplicar $70 \%$ da força de protensão mínima recomendada pela norma NBR 8800 (1986).

\section{4 - Equipamentos utilizados}

Para a aplicação do carregamento utilizou-se quatro atuadores hidráulicos de haste vazada, da marca Enerpac, com capacidade nominal de $300 \mathrm{kN}$, como a força foi aplicada para baixo, esta foi transmitida dos atuadores para a estrutura por meios de cordoalhas de aço que eram ancoradas nos quatros nós internos do banzo inferior da estrutura, especialmente fabricados para este fim (figura 3.9 e 3.10).

A ancoragem na outra extremidade da cordoalha foi feita na extremidade inferior da célula de carga que também tinha seu corpo vazado e se encontrava rosqueada na face inferior do atuador hidráulico. A 
ancoragem da cordoalha, tanto no nó da estrutura como na célula de carga foi feita por cunhas de ancoragem.

O acionamento dos atuadores hidráulicos foi feito por apenas uma bomba hidráulica elétrica a óleo. Para se obter uma distribuição uniforme de pressão nos quatro atuadores foi utilizada uma válvula de conexões múltiplas.

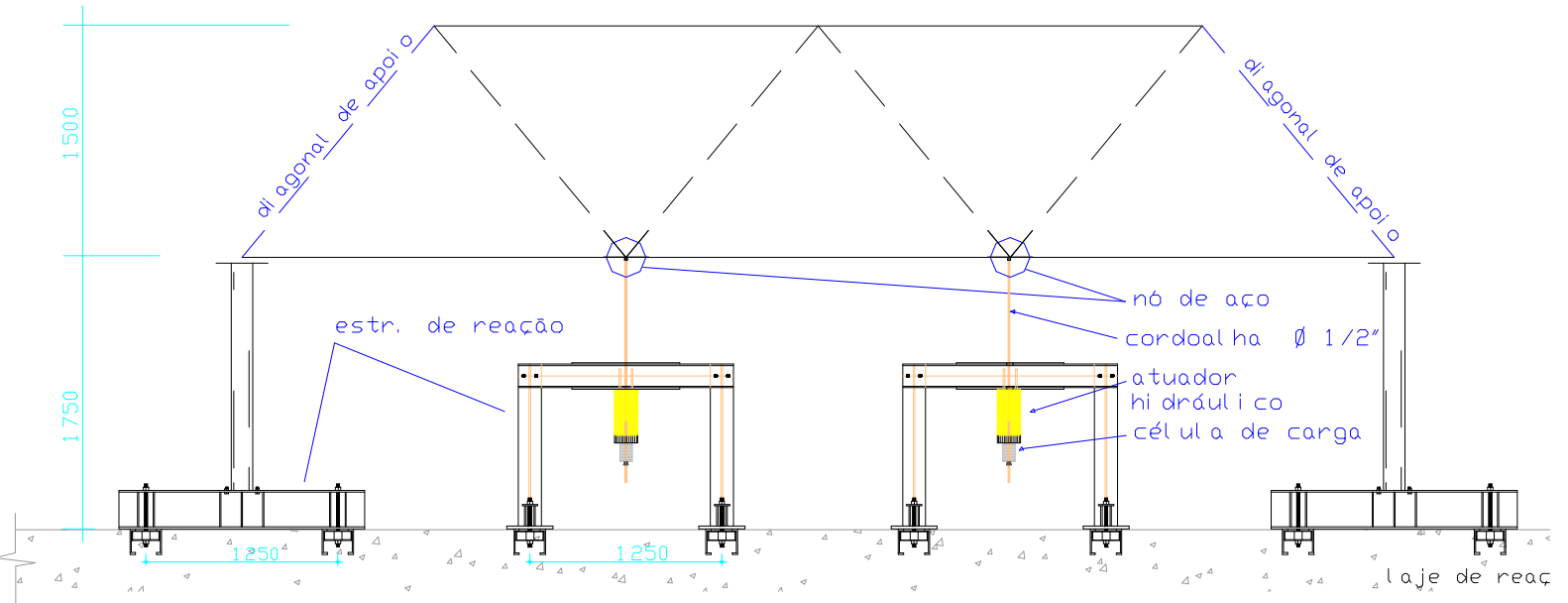

FIGURA 3.9 - Esquema geral do ensaio: aplicação de forças
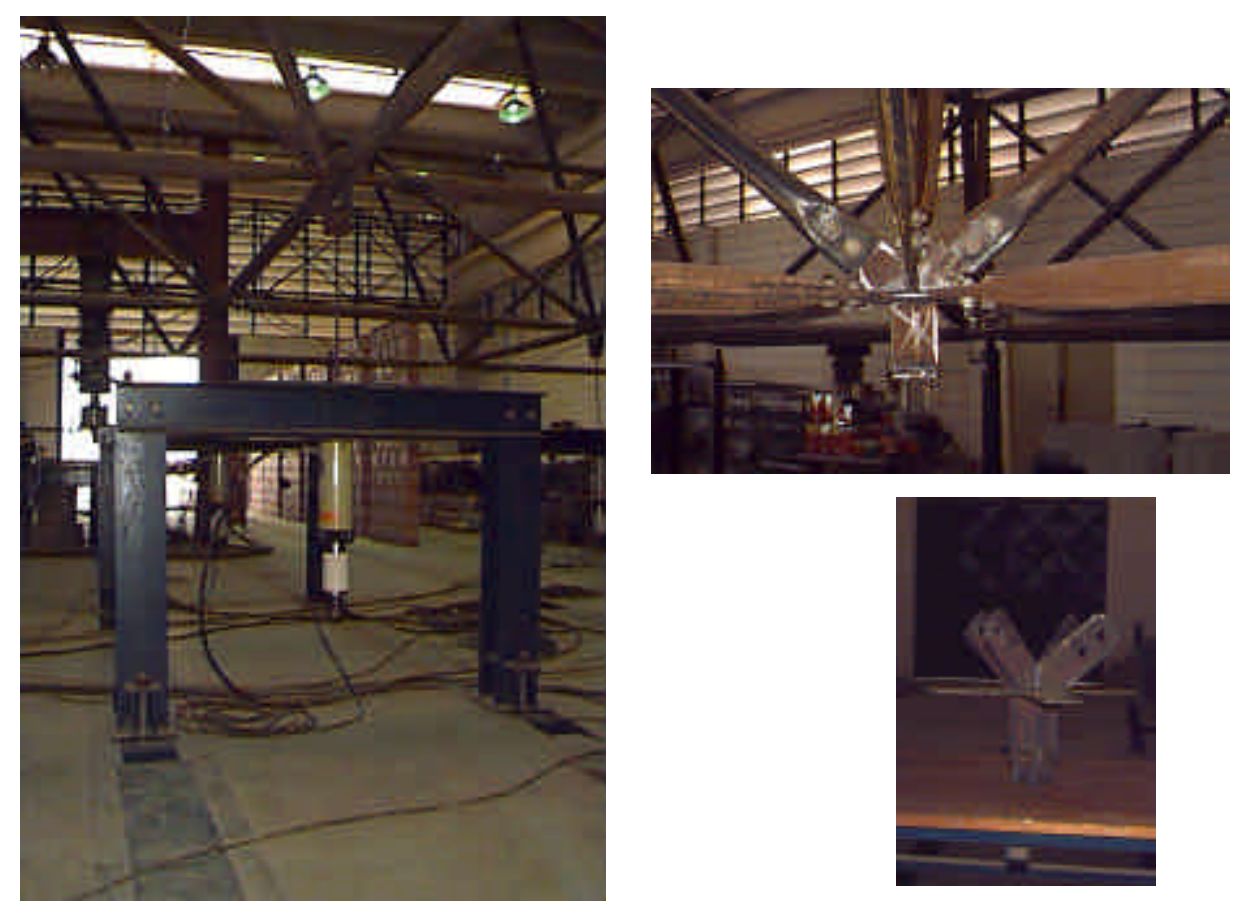

FIGURA 3.10 - Detalhe do sistema de aplicação de forças e do nó de aço fabricado para ancoragem da cordoalha 
Para a medição de deslocamentos nos apoios e em vários pontos dos protótipos foram posicionados transdutores de deslocamentos, marca KYOWA, modelos DT 100A e DT 50A, com curso de $100 \mathrm{~mm}$ e $50 \mathrm{~mm}$ respectivamente, e sensibilidade de $0,05 \mathrm{~mm}$.

Para a medição das deformações foram instalados extensômetros elétricos de resistência uniaxiais, marca KYOWA, modelo KGF-5-120-C1-11, com base de medida de $5 \mathrm{~mm}$, posicionados em diversas seções das barras.

Para registros de força, deslocamentos e deformações foi empregado o sistema de aquisição de dados SYSTEM 4000 - MEASUREMENTS GROUP, com capacidade para a leitura de até 200 canais.

\subsection{1 - Posicionamento da instrumentação}

A instrumentação nos quatro protótipos não foi a mesma, uma vez que à medida que os ensaios eram realizados, novos pontos de interesse eram detectados e então instrumentados nos outros protótipos a ensaiar.

O critério básico de instrumentação foi a seguinte:

Deslocamentos:

- quatro apoios: direções horizontais X e Y e direção vertical Z

Objetivo: monitorar deslocamentos horizontais e verticais dos apoios e verificar simetria no comportamento estrutural.

- nó central (banzo superior): direção vertical Z Objetivo: medir a flecha máxima da estrutura.

- nós periféricos próximos aos apoios (banzo superior): direção vertical Z Objetivo: medir a flecha em quatro pontos simétricos para verificar simetria no comportamento estrutural.

A figura 3.11 mostra alguns detalhes da instrumentação com transdutores de deslocamento 


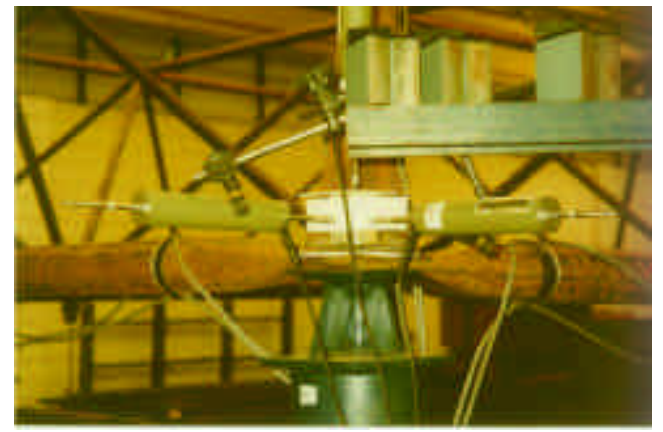

posicionados no apoio

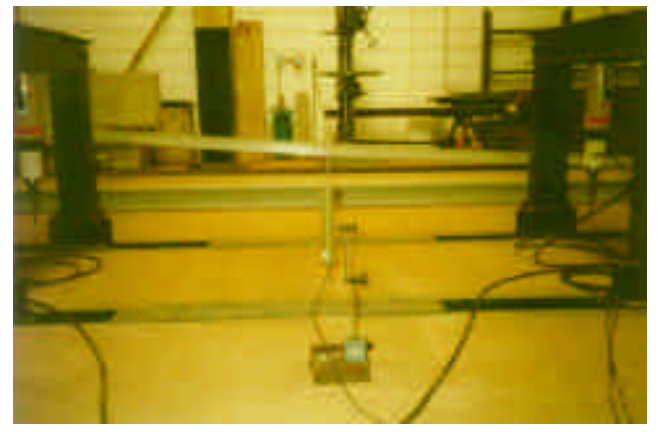

posicionado para medição de flecha

FIGURA 3.11 - Detalhe dos transdutores de deslocamento

Deformações:

Devido a dupla simetria dos protótipos, foi escolhido um dos vértices para ser implementada uma instrumentação mais detalhada (vértice A), enquanto que para os outros três vértices foi instalada apenas uma instrumentação de controle.

Posição dos extensômetros:

- em todas as barras instrumentadas: na seção central.

Objetivo: avaliar a compressão e a evolução da flexão na seção central das barras.

- $\quad$ na diagonal de apoio do vértice $A$ e nos banzos superiores deste: na extremidade superior (região da estampagem), para os PROT 2 a 4.

Objetivo: avaliar deformações junto ao nó (concentração de tensão).

A figura 3.12 representa os detalhes de algumas destas instrumentações com extensômetros elétricos

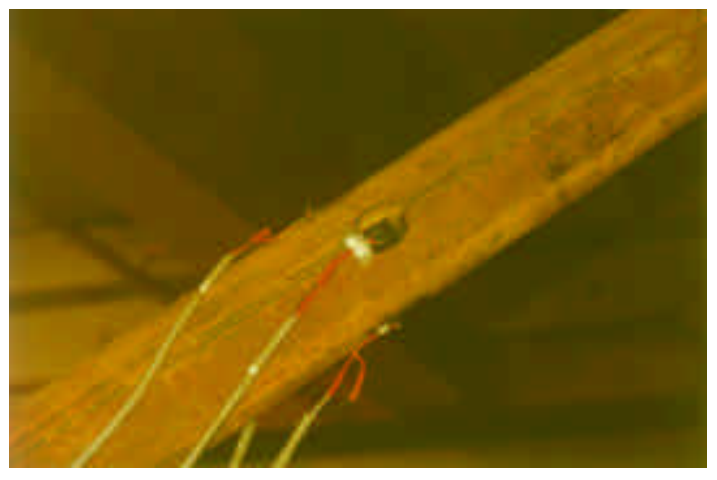

instrumentação da seção central

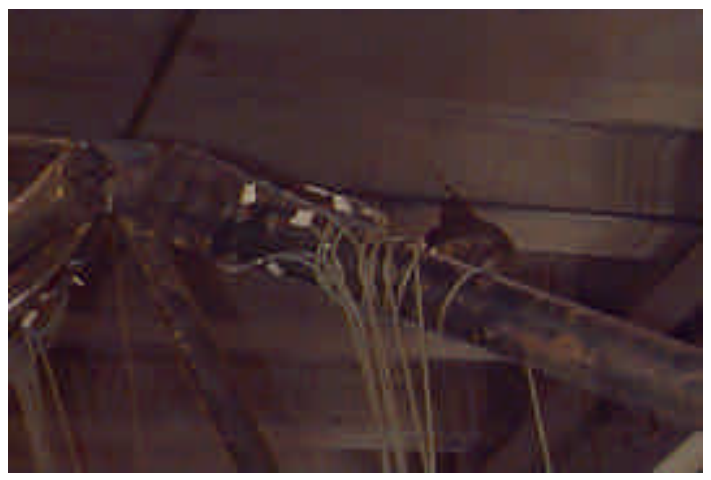

instrumentação da extremidade

FIGURA 3.12 - Detalhe da instrumentação com extensômetros elétricos 


\section{Forças:}

- posicionamento das células de carga: junto a cada atuador hidráulico Objetivo: acompanhamento das forças aplicadas no protótipo.

A figura 3.13 mostra o posicionamento da célula de carga junto ao atuador hidrálico.

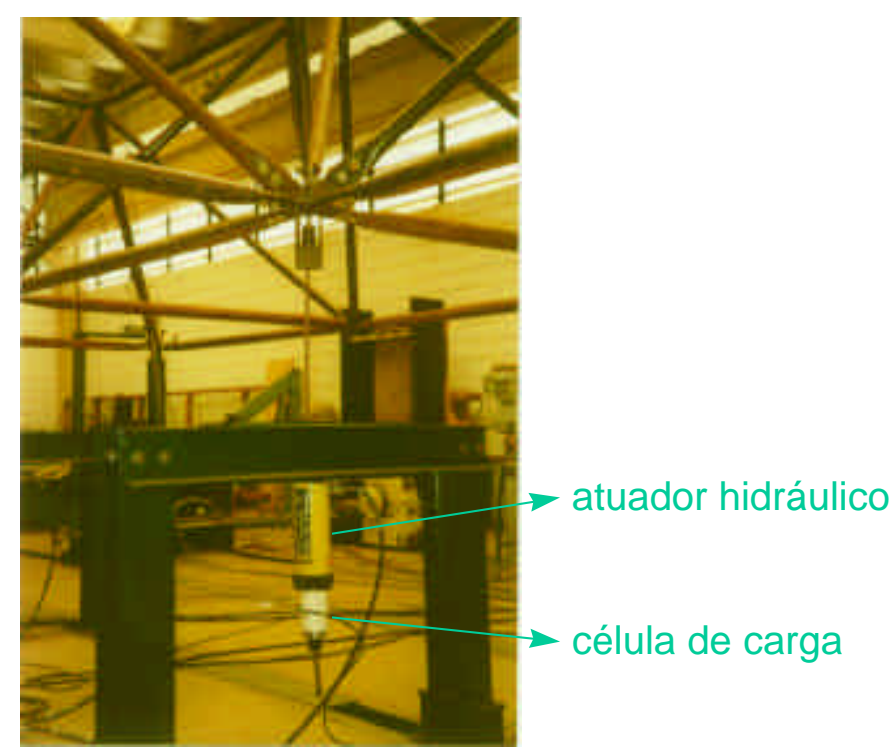

FIGURA 3.13 - Posicionamento da célula de carga

As figuras 3.14 a 3.17 mostram o posicionamento e numeração da instrumentação utilizada nos quatro protótipos ensaiados, a simbologia utilizada nestas figuras é apresentada na tabela 3.3. 
TABELA 3.3 - Legenda da instrumentação

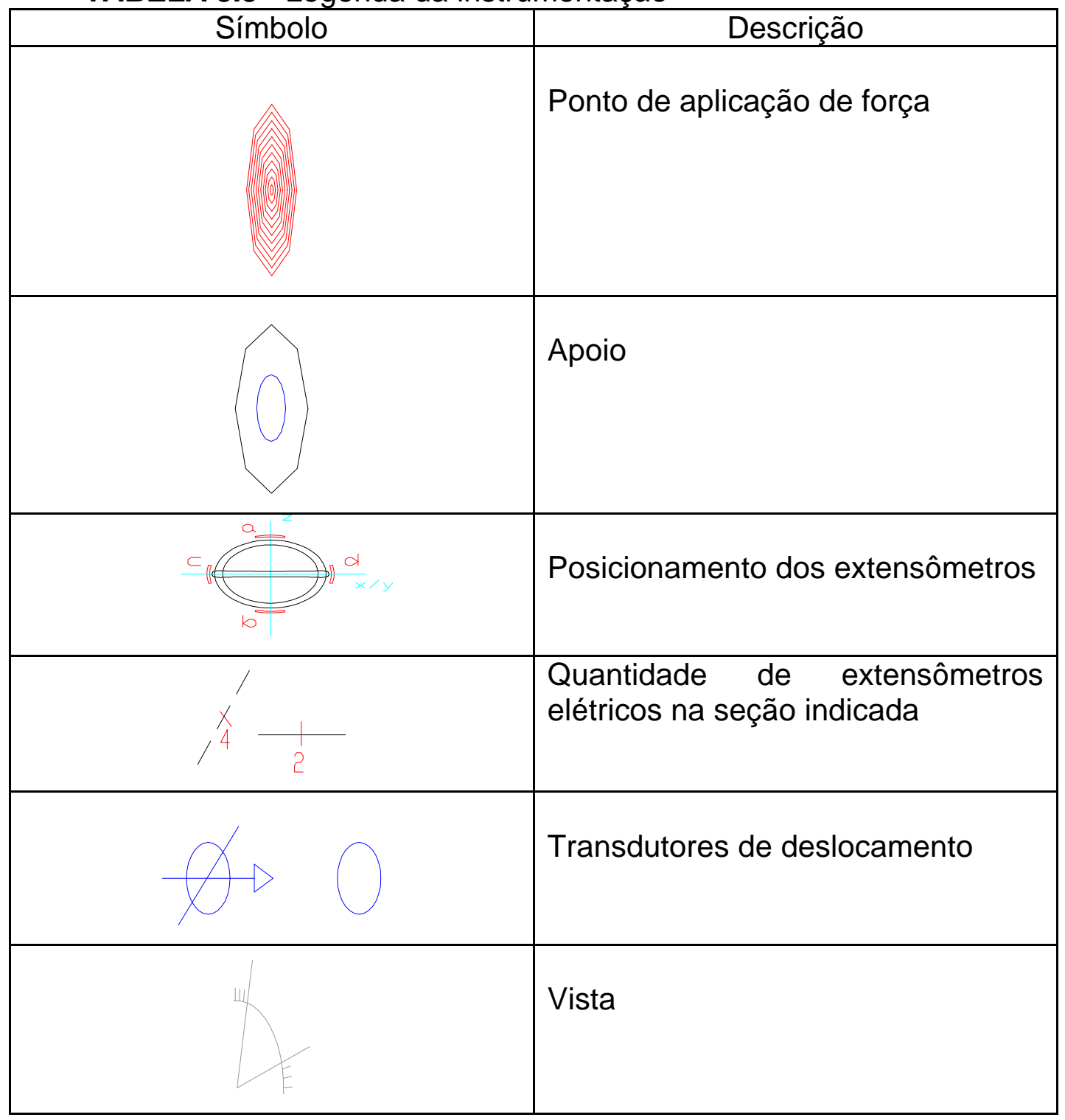




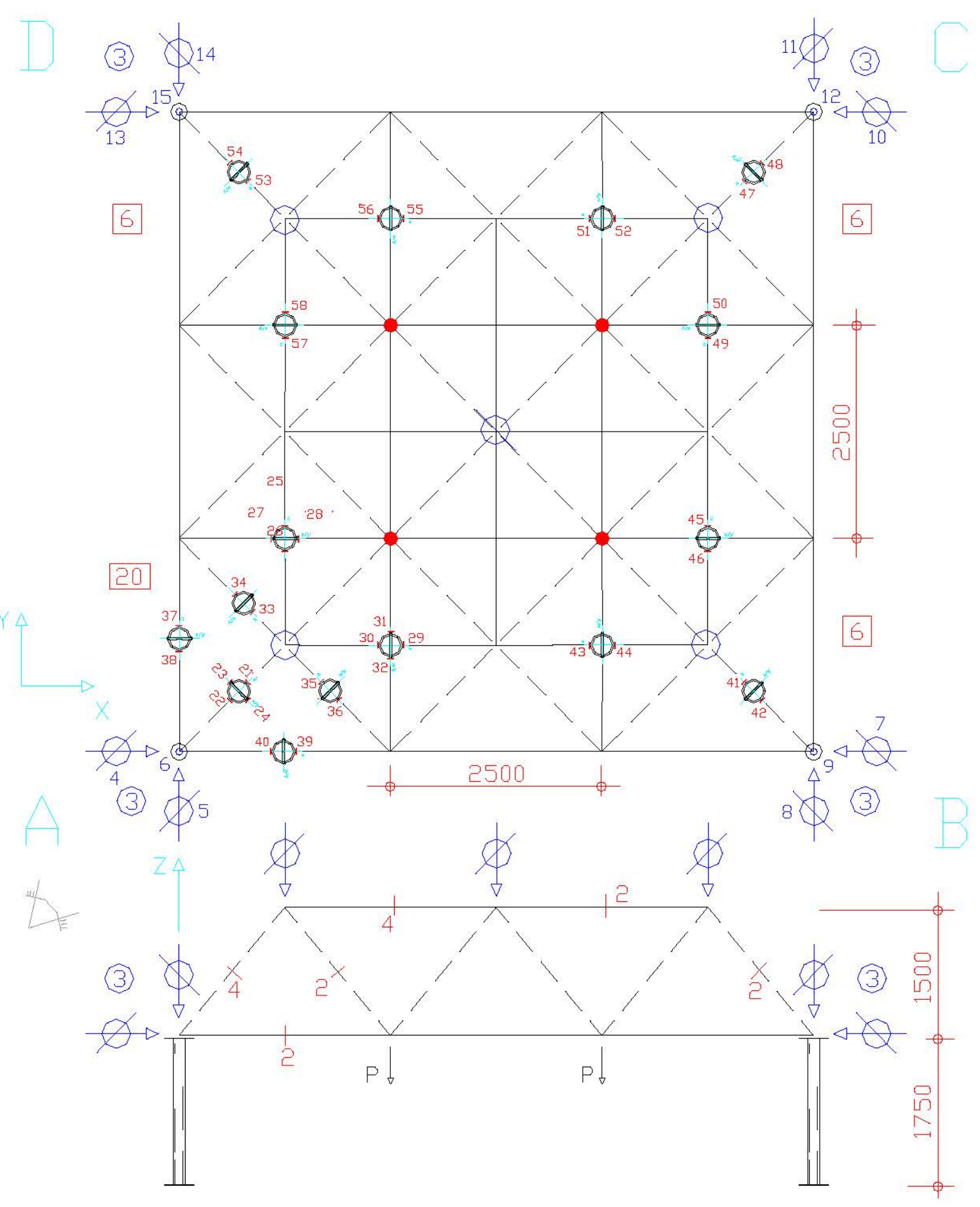

FIGURA 3.14 - Posicionamento da instrumentação do PROT 1 


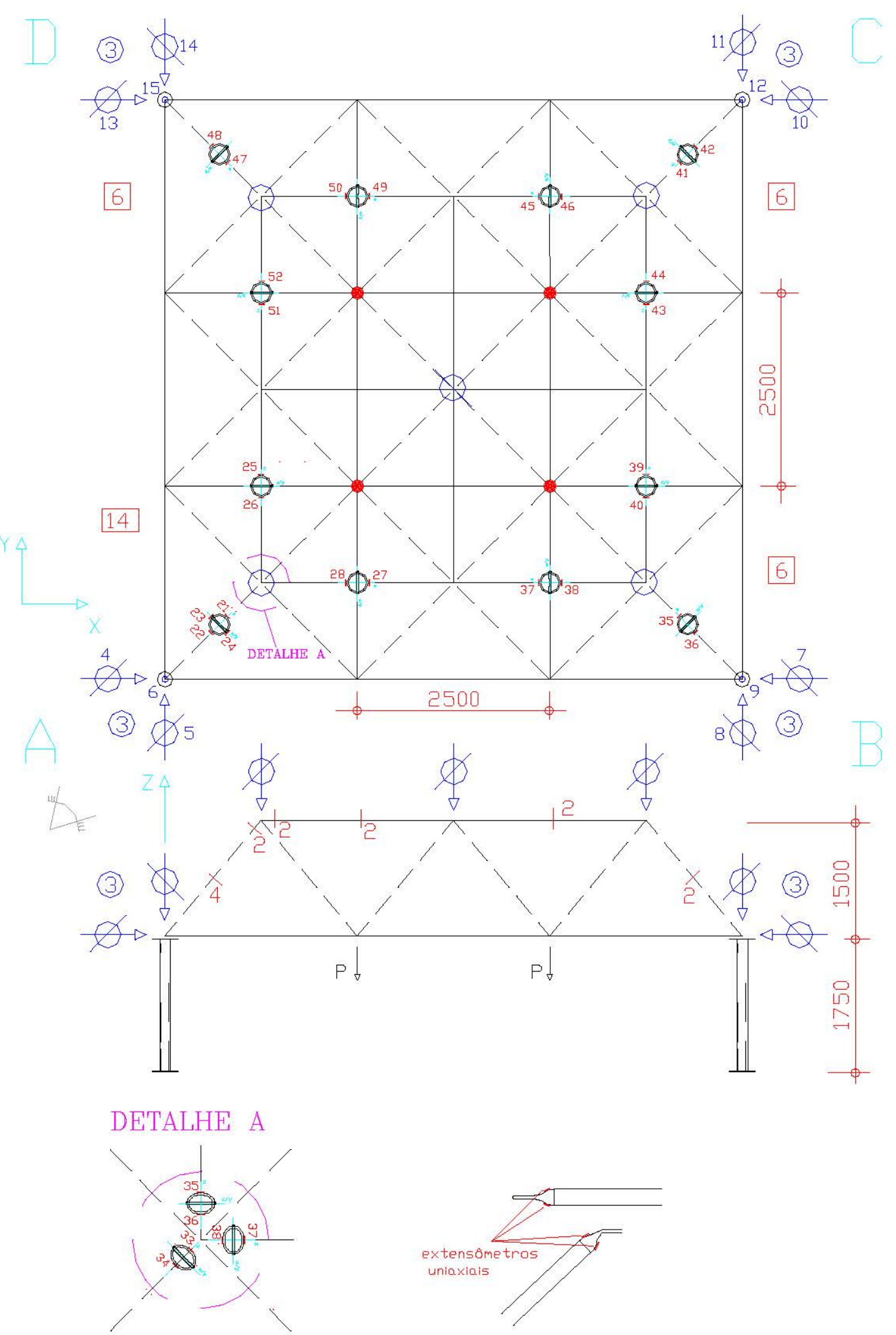

FIGURA 3.15 - Posicionamento da instrumentação do PROT 2 


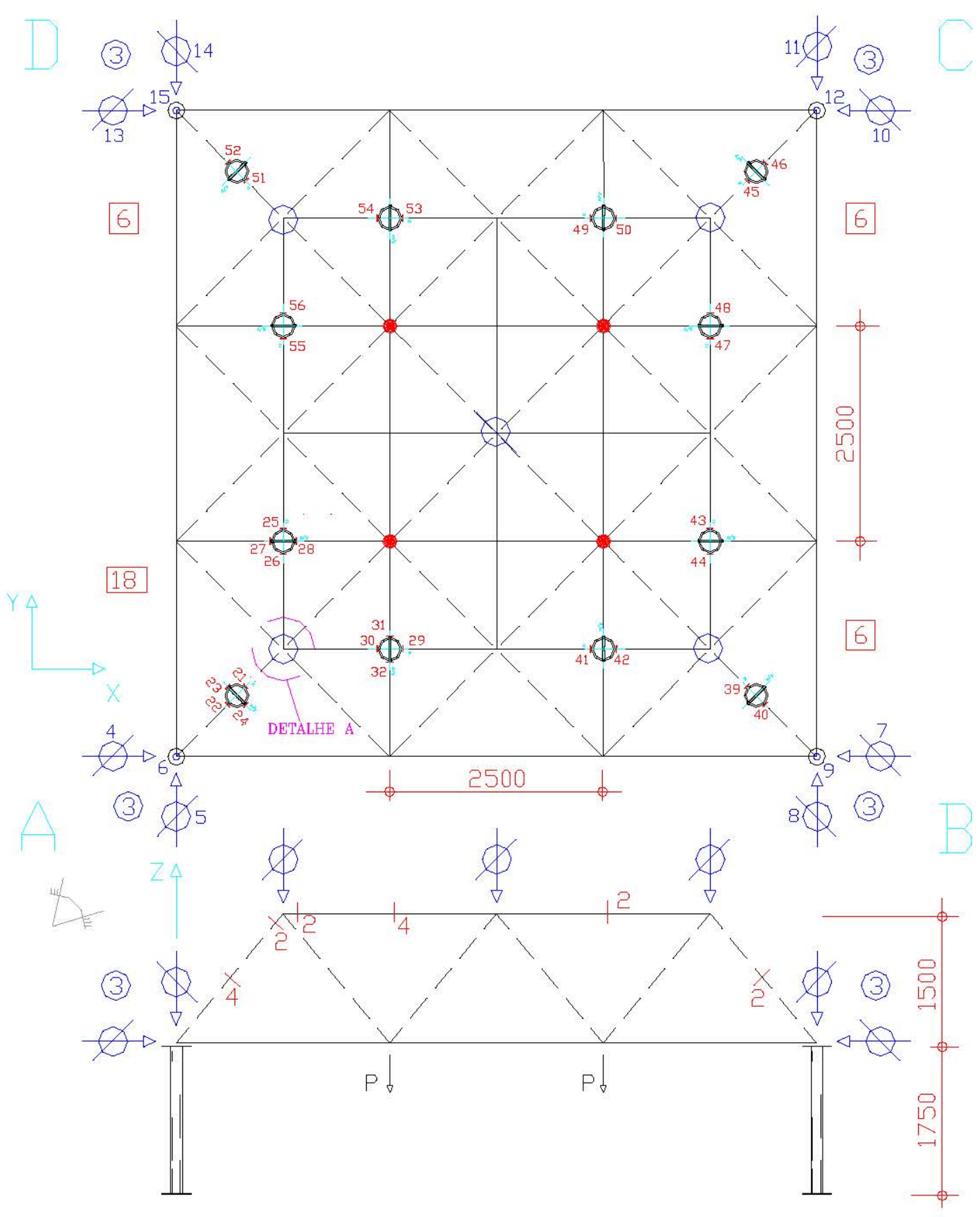

DETALHE A

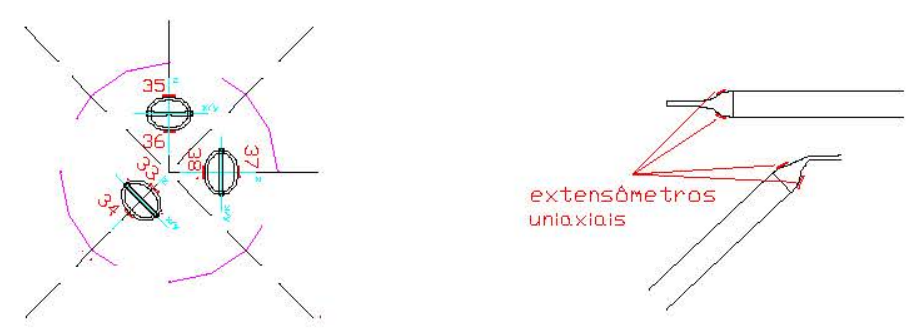

FIGURA 3.16 - Posicionamento da instrumentação PROT 3 


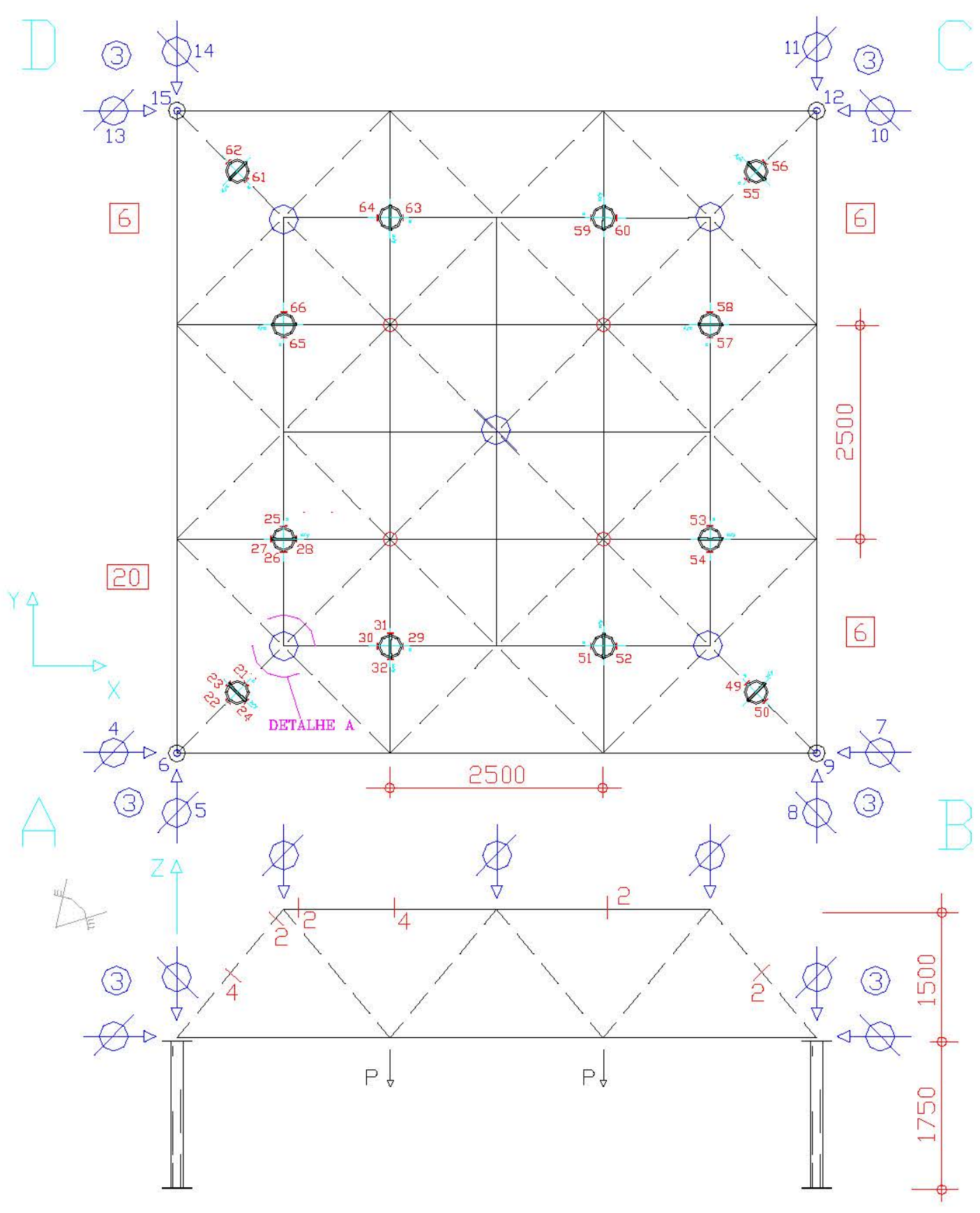

DETALHE A

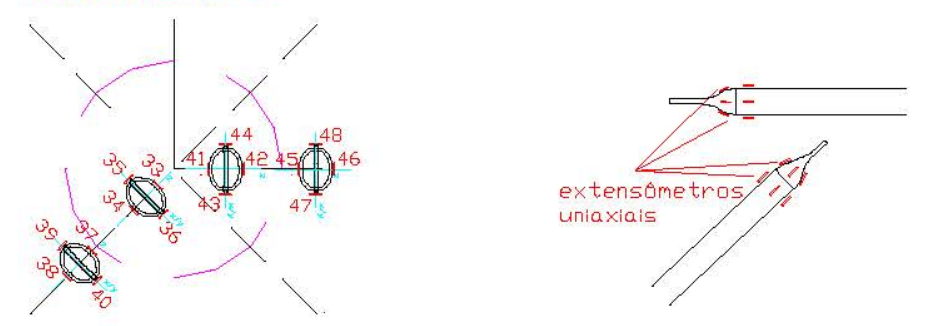

FIGURA 3.17 - Posicionamento da instrumentação PROT 4 


\subsection{Procedimento de ensaio dos protótipos}

Os ensaios foram realizados em duas etapas: a primeira referente ao escorvamento (acomodação da estrutura) seguindo de descarregamento total, e a segunda ao ensaio propriamente dito. $\mathrm{Na}$ fase de escorvamento foram aplicadas três etapas de carregamento, cada uma com intensidade $5 \mathrm{kN}$ por ponto. No ensaio do protótipo PROT 1, o escorvamento foi interrompido para uma força de $12,7 \mathrm{kN}$, uma vez que o mesmo já apresentava deslocamentos excessivos.

Os ensaios foram conduzidos até a ruína, onde foram aplicadas etapas de carregamento de $2,5 \mathrm{kN}$ por ponto para os protótipos PROT $1 \mathrm{e}$ PROT 2 e $5 \mathrm{kN}$ por ponto para os protótipos PROT 3 e PROT 4.

Foram realizados registros de força aplicada, deformações e deslocamentos em todas as etapas de carregamento e também nas etapas onde foram observadas queda brusca na força aplicada, proveniente do deslizamento e giro excessivo das barras junto aos nós. 


\section{ANÁLISE NUMÉRICA}

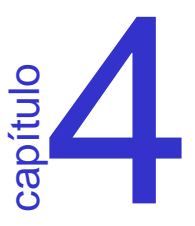

As estruturas em geral são projetadas sem a consideração do comportamento não linear (físico e geométrico), ou seja, é levado em consideração que a relação tensão $x$ deformação se mantenha no regime elástico linear e a posição deformada da estrutura é confundida com a posição original. Para as treliças espaciais isto não é diferente, e percebe-se que na prática o modelo teórico utilizado para estas estruturas é o de treliça ideal, não se levando em consideração as características da conexão e a variação de inércia das barras junto aos nós (no caso: nó típico e de aço).

Neste trabalho foi proposta a execução de uma análise numérica linear e não linear física e geométrica dos protótipos ensaiados, e posterior confronto dos resultados numéricos e experimentais.

O presente capítulo será dedicado à discussão detalhada de toda a fase de análise numérica, realizada via método dos elementos finitos, englobando discretização dos protótipos, características dos elementos finitos utilizados e tipo de análise estrutural adotada.

A análise numérica foi realizada utilizando-se 0 programa computacional via método dos elementos finitos ANSYS, em sua versão 5.4.

Para a consideração da não linearidade geométrica, a formulação adotada foi a disponível no programa em questão, e para solução dos sistemas de equações de equilíbrio foi utilizado o método incremental interativo de Newton-Raphason. 
Para a não linearidade física, foi apresentado no capítulo 2 o modelo constitutivo referenciado por Madi e El-Tayem, mas devido a sua complexidade, este não foi utilizado. Adotou-se portanto para esta análise um modelo bilinear para representar o material tanto na tração (hipótese razoável) como na compressão (hipótese pobre). O modelo adotado é denominado pelo ANSYS de BKIN (Classical Bilinear Kinematic Hardening) este é representado na figura 4.1.

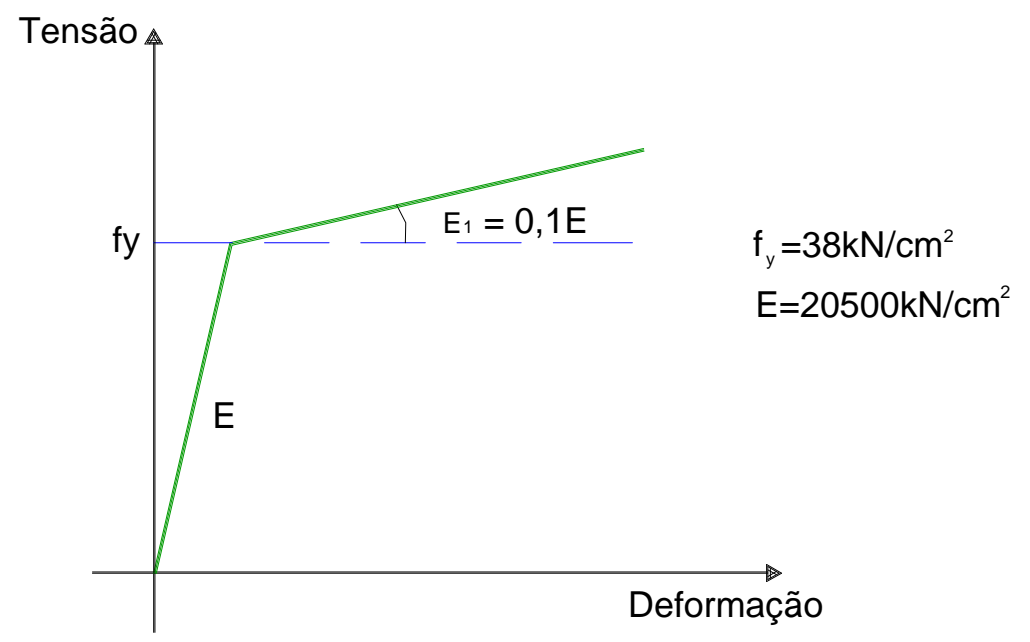

FIGURA 4.1 - Modelo constitutivo do material adotado para a análise numérica.

Onde:

$f_{y}=$ Resistência ao escoamento, adotado o valor representativo encontrado nos ensaios de caracterização do aço a tração

\section{1 - Elementos finitos utilizados}

Optou-se, dentre os disponíveis na biblioteca de elementos finitos do programa ANSYS, pela utilização dos seguintes elementos finitos: o de viga BEAM24 para modelação das barras componentes do protótipo e o elemento de casca SHELL43 para a modelação dos dois tipos de nós, sendo que o nó típico foi simulado também através da sobreposição dos elementos de barra na região do nó. A seguir são descritos com maiores detalhes os dois elementos utilizados. 


\section{BEAM24 (3D - Thin Walled Plastic Beam)}

É um elemento uniaxial de seção transversal arbitrária (aberta ou fechada) com capacidade de avaliar esforços de tração, compressão, flexão e torção de St. Venant, empregados para a modelação de seções transversais abertas ou fechadas com uma única célula.

O elemento tem seis graus de liberdade para cada nó, os quais são:

- translações nodais nas direções $x, y$ e $z$

- rotações em torno dos eixos $x, y$ e $z$.

Este elemento permite a consideração da plasticidade e de grandes deslocamentos. A seção transversal é definida por uma série de segmentos retangulares, na qual a entrada de dados consiste em se fornecer as coordenadas (y e z) da seção transversal, num máximo de 20 segmentos.

$O$ eixo $x$ é longitudinal ao elemento, e a orientação da barra ao longo deste eixo longitudinal é especificada por três nós I, J e K, como pode ser observado na figura 4.2 .
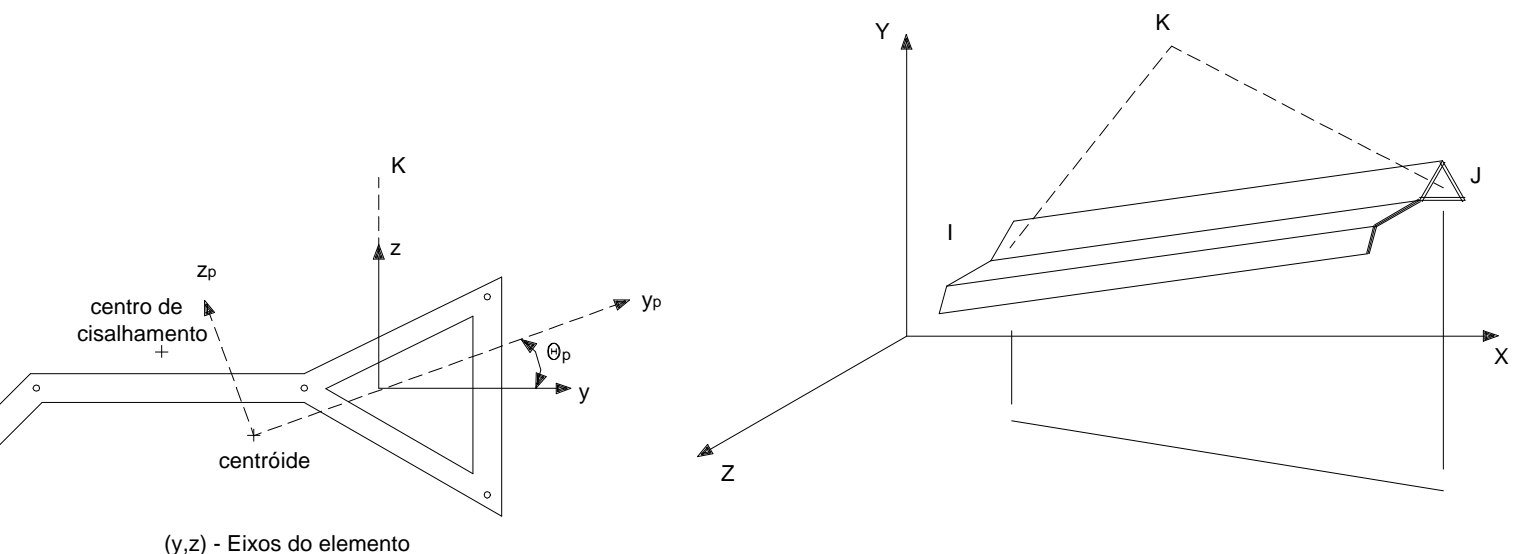

$(y, z)$ - Eixos do elemento

$(y p, Z p)$ - Eixos principais

FIGURA 4.2 - Elemento finito BEAM 24: representação esquemática. 
SHELL 43 (Plastic Large Strain Shell)

Este é um elemento adequado para a modelagem não linear de estruturas de casca. $O$ elemento apresenta seis graus de liberdade para cada um dos seus quatro nós (ou três para uma configuração triangular), os quais são:

- translações nodais nas direções $x, y$ e $z$

- rotações em torno dos eixos $x, y$ e $z$.

As deformações da casca são lineares em ambas as direções dos planos. O elemento admite plasticidade, grandes deslocamentos e deformações, e espessura variável.

A figura 4.3 representa um esquema deste elemento.

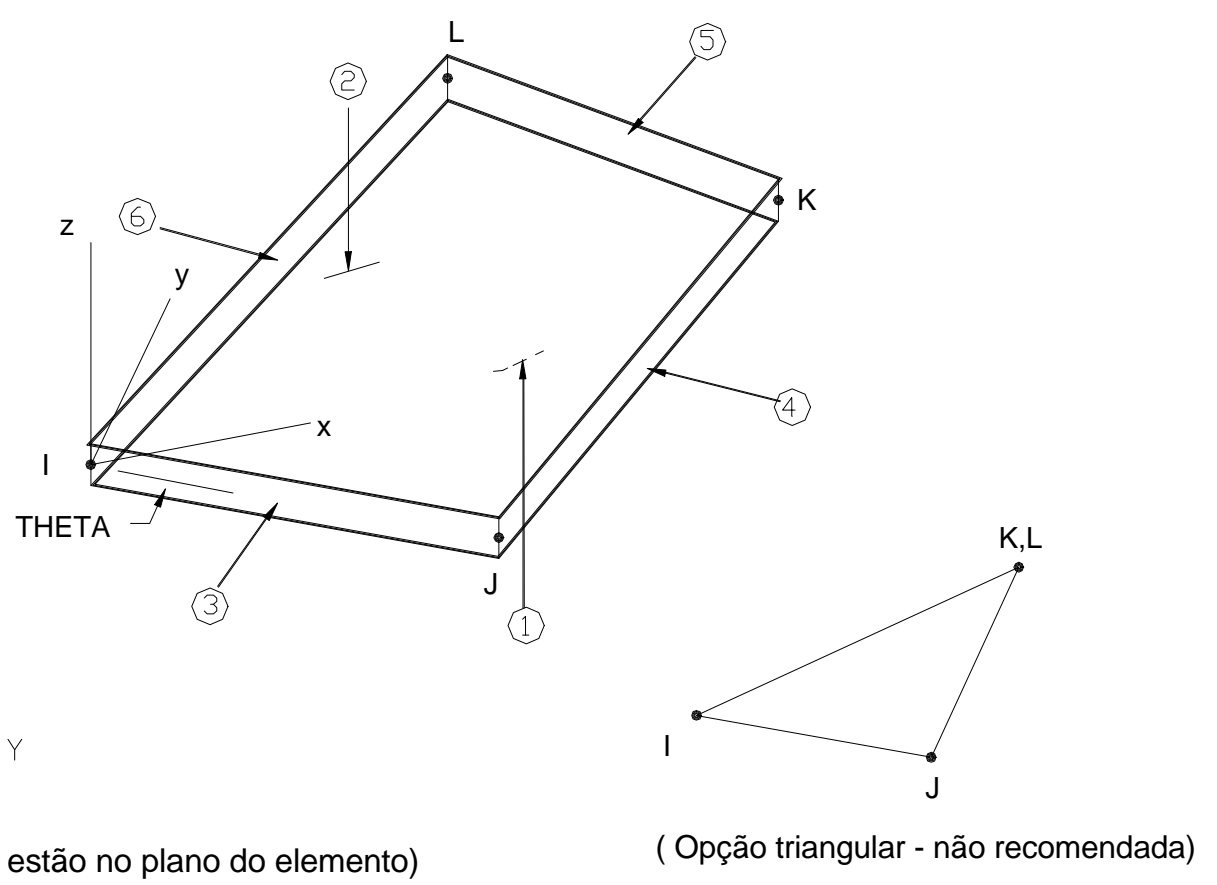

FIGURA 4.3 - Elemento finito SHELL 43: representação esquemática.

Obs: No decorrer do trabalho entenda-se por 'elemento de barra' como elemento gerado com BEAM 24, e 'elemento de casca' como aquele gerado com elemento SHELL 43. 


\section{2 - Descrição da modelação}

Foram consideradas duas hipóteses de análise teórica dos protótipos pelo método dos elementos finitos: uma elástica linear considerando a estrutura como treliça ideal e a outra simulando a influência da região nodal (tanto para o nó típico como para o nó de aço) aplicando as não linearidades física e geométrica.

Na modelação dos protótipos para esta última hipótese de análise, foram consideradas as variações de inércia das extremidades das barras junto aos nós. Para tanto, tomou-se partido das características do elemento de viga utilizado (BEAM 24), o qual permite a discretização da seção transversal do elemento em segmentos retos. Deste modo modelou-se trechos de barras com as dimensões reais, pois estas foram avaliadas em mesa tridimensional de alinhamento, pertencente ao Departamento de Engenharia Elétrica da EESC-USP.

A figura 4.4 ilustra a região da extremidade onde ocorre esta variação de inércia.

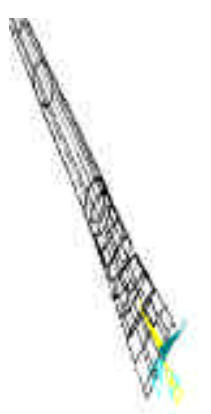

perspectiva: gráfico de arame

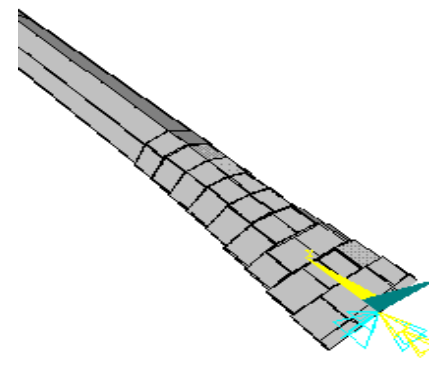

perspectiva: seção cheia

perspectiva: seção cheia

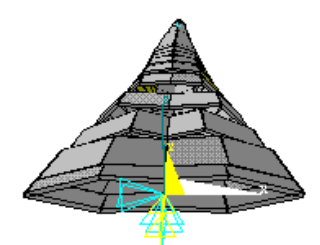

vista frontal

FIGURA 4.4 - Modelação da região amassada da barra utilizando o elemento BEAM24

\subsection{1 - Modelação como treliça ideal.}

Como já mencionado, na prática os projetos das treliças espaciais são desenvolvidos simplesmente com uma análise linear elástica 
considerando-as como treliças ideais; por este motivo tal análise foi adotada como referência.

Para tanto modelou-se as barras componentes do protótipo com 0 elemento BEAM 24 com seção constante, sem considerar o amassamento, e na região dos nós estas foram consideradas apenas concorrentes em um único ponto, simulando a condição de treliça ideal.

\subsection{2 - Modelação dos protótipos com nó típico.}

Nesta modelação cada elemento de barra da treliça espacial, adotado na análise teórica, foi composto de um trecho com seção constante e vários trechos com seções variáveis (representando a extremidade estampada), e para região do nó foram admitidas duas hipóteses de modelação:

- primeira $\Rightarrow$ pelo motivo de não se poder determinar, com precisão, a rigidez do trecho correspondente ao nó, foi considerado o trecho nodal, ou seja, $6 \mathrm{~cm}$ a partir dos extremos da barra, com inércia correspondente somente a extremidade amassada das barras que concorrem nesta região (figuras 4.5 e 4.6 );

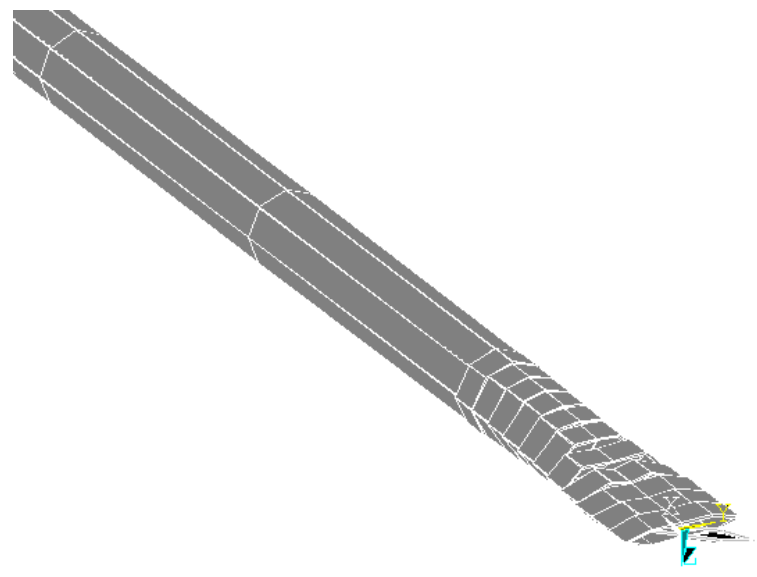

FIGURA 4.5 - Barra modelada com o elemento BEAM 24 (com variação de inércia)

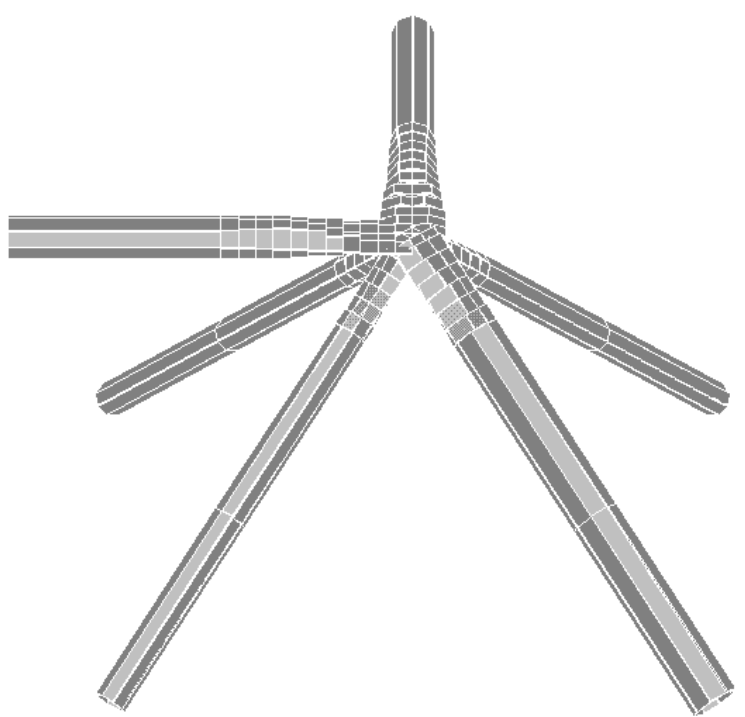

FIGURA 4.6 - Detalhe do nó da estrutura modelada ( $1^{\circ}$ hipótese) 
-segunda $\Rightarrow$ a região nodal foi composta por elementos de casca com inércia equivalente a soma das inércias das extremidades das barras que se encontram sobrepostas no referido nó (figura 4.7).

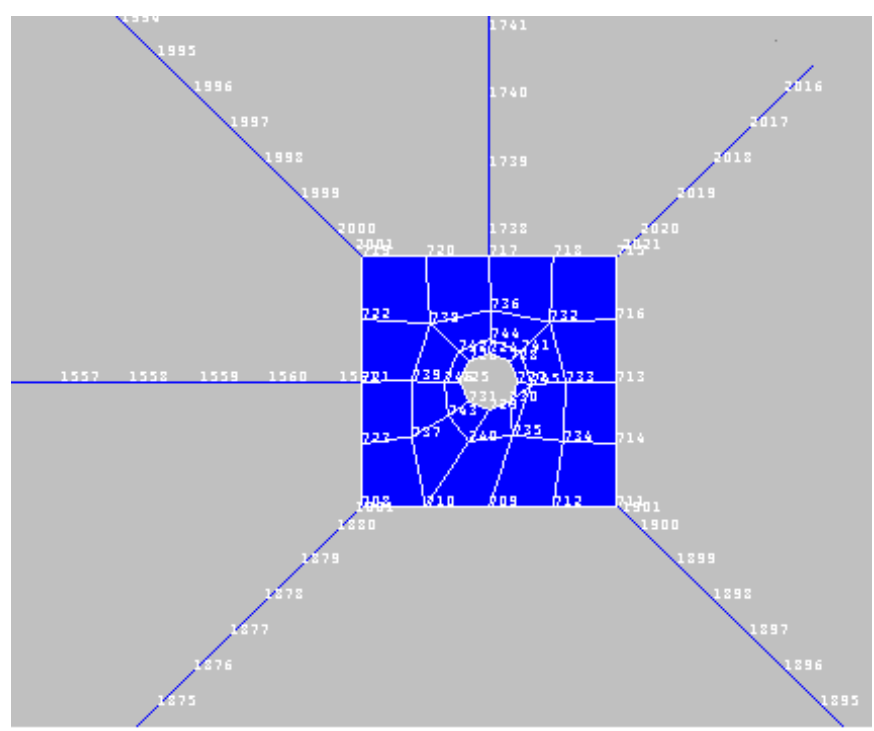

FIGURA 4.7 - Modelação do nó típico com elemento de casca SHELL 43

SOUZA (1998) apresenta uma modelação da mesma estrutura empregando o programa computacional LUSAS*, atribuindo vários valores de momento de inércia para a região nodal. $\mathrm{O}$ valor máximo adotado ( $I=100 \%$ ) corresponde à inércia do monobloco, ou seja, admitindo o nó como uma peça maciça de espessura igual à própria espessura do nó observada na estrutura. A melhor correlação entre resultados teóricos e experimentais foi obtida para uma inércia compreendida entre a inércia de uma extremidade amassada e $5 \%$ da inércia total, o que pode ser visualizado na figura 4.8 .

\footnotetext{
${ }^{*}$ LUSAS $\Rightarrow$ Finite Element Analysis (FEA), Revision 11, Surrey - U.K. 1996.
} 


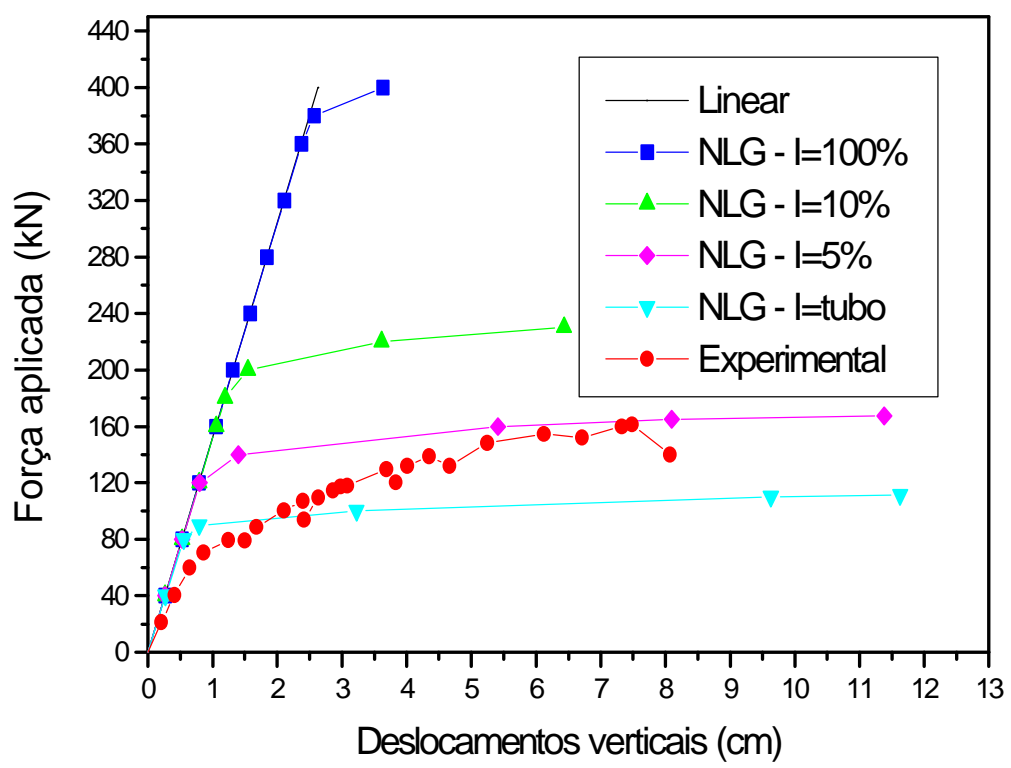

FIGURA 4.8 - Deslocamentos verticais teóricos e experimentais. SOUZA (1998)

Pretendeu-se abordar de maneira um pouco diferente a questão da inércia do nó, não reproduzindo a inércia do monobloco gerado pela sobreposição das extremidades das barras junto ao nó, como apresentado por SOUZA (1998), nem uma porcentagem desta, mas sim, como na primeira hipótese anteriormente citada apenas reproduzindo a inércia de uma extremidade amassada, ou utilizando um elemento de casca representando este nó com uma espessura que produza inércia equivalente a soma das inércias das extremidades das barras que concorrem neste nó, o que foi a segunda hipótese.

A somatória das inércias das extremidades das barras que se sobrepõem no nó típico, equivale apenas a 1,0\% da inércia do monobloco, estando portanto de acordo com a constatação de SOUZA (1998).

\subsection{3 - Modelação do protótipo com nó de aço}

Analogamente à modelação dos nós típicos, os elementos de barra do protótipo foram compostos de um trecho com seção constante, e vários trechos de seções variáveis, correspondente à extremidade estampada, 
com exceção da região da extremidade que sobrepõe a aleta do nó de aço. Esta última, juntamente com o restante do corpo do nó de aço, foi modelada com elementos de casca.

$\mathrm{Na}$ região do nó de aço a espessura do elemento de casca foi a mesma da peça original, sendo que para a região das aletas deste nó, onde ocorre a sobreposição desta com a extremidade do tubo de aço, a espessura do elemento de casca foi estimada de modo que se produza uma inércia igual à gerada pela soma das inércias dos componentes sobrepostos. Na figura 4.9 pode ser visualizado um detalhe desta modelação.

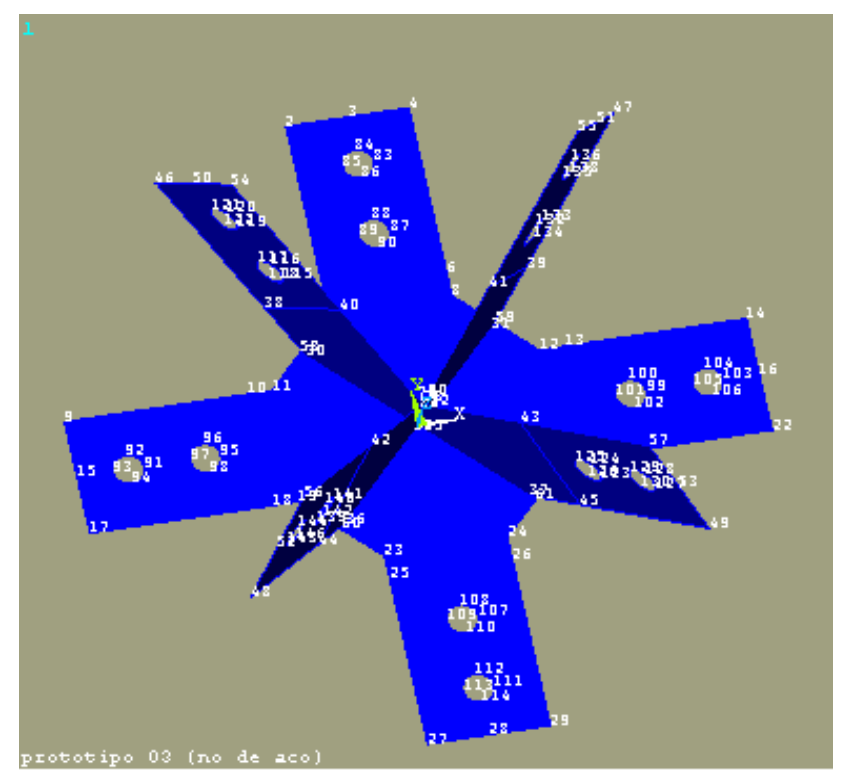

FIGURA 4.9 - Modelação do nó de aço com elemento de casca SHELL 43.

\subsection{4 - Modelação do protótipo com sistema misto de conexão.}

Como já comentado o sistema de conexão mista consiste na utilização, no mesmo protótipo, tanto do nó de aço como do nó típico, sendo o primeiro posicionado nas conexões mais solicitadas e o segundo nas demais.

Para esta modelação a consideração da variação de inércia das barras foi análoga as anteriores. Na região nodal, para os nós de aço a 
modelação foi a apresentada no item 4.2.3, e para o nó típico utilizou-se a modelação apresentada na $1^{\circ}$ hipótese do item 4.2.2.

\subsubsection{Compatibilizações de deslocamentos e rotações}

Detalhe importante a destacar foi o da necessidade de se fazer a compatibilização dos deslocamentos e rotações na região correspondente a interface elemento de barra e elemento de casca. Estas foram as seguintes:

-para o caso do nó típico modelado com elemento de casca:

$\square$ compatibilizou-se os deslocamentos e rotações provenientes dos elementos de barra das diagonais, com os nós internos próximos ao vértice do elemento de casca, impedindo deste modo que estes deslocamentos e rotações fossem transmitidos apenas ao nó do vértice (figura 4.10).

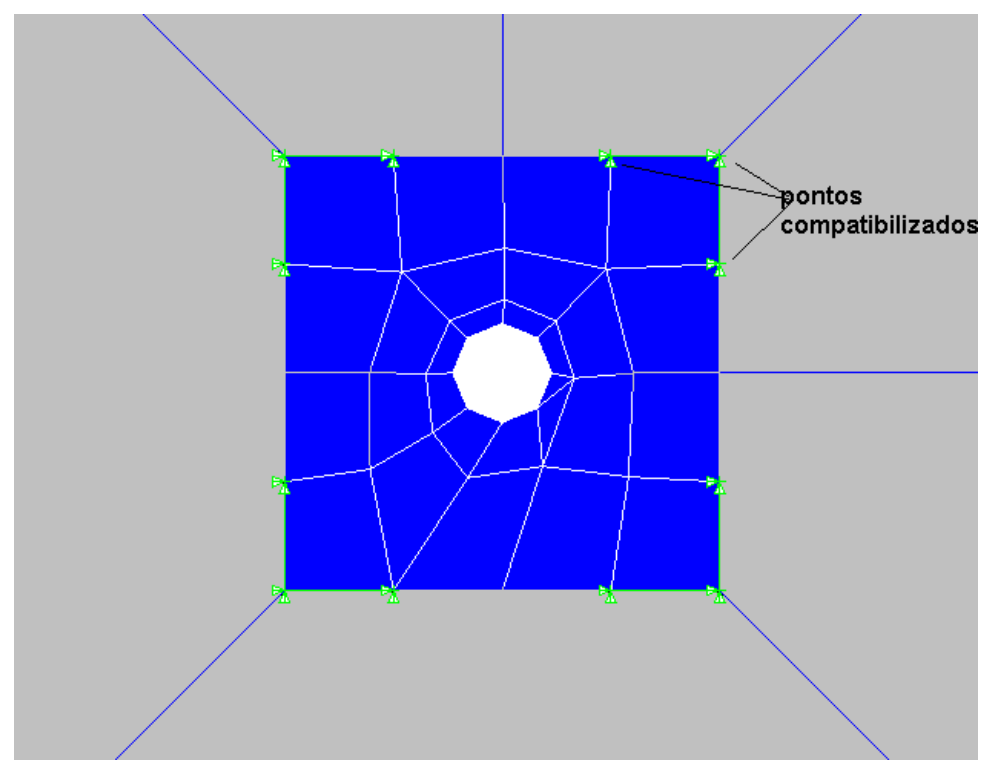

FIGURA 4.10 - Compatibilização dos deslocamentos e rotações entre os elementos barra-chapa (nó típico)

-para o caso do nó de aço:

चfoi feita a compatibilização da transferência dos deslocamentos longitudinais provenientes do elemento de barra, não somente para a extremidade do elemento de casca no ponto comum a estes dois, 
mas também para a região dos furos onde na realidade ocorre a transferência de esforços barra-chapa por intermédio dos parafusos; ■ e também a compatibilização dos deslocamentos e rotações na interface do elemento de barra com o elemento de casca, pois podese notar a desigualdade de nós que compõem cada elemento ali concorrente, ou seja, apenas um nó para a extremidade do elemento de barra para cinco nós do elemento de casca (figura 4.11).

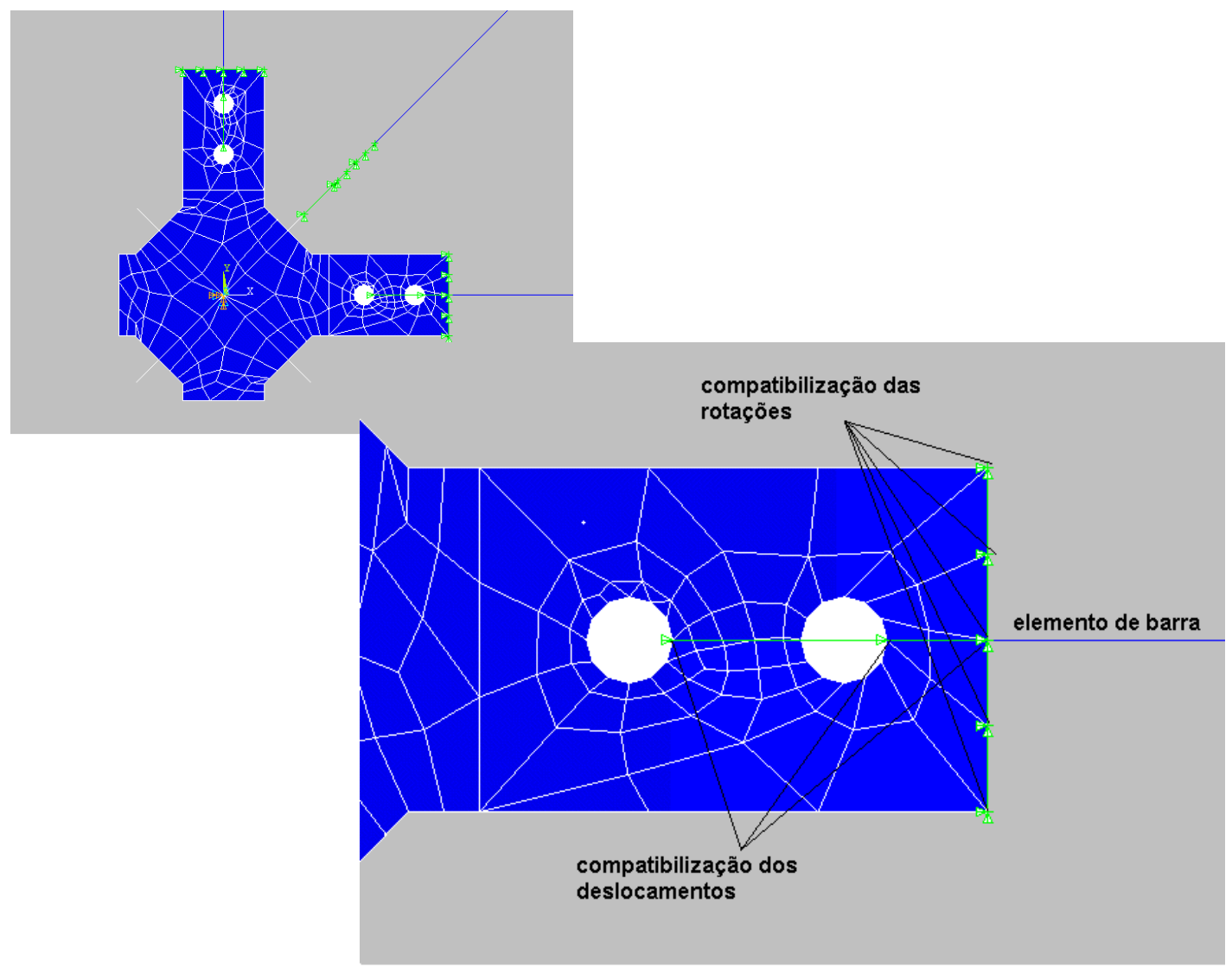

FIGURA 4.11 - Compatibilização dos deslocamentos e rotações entre os elementos barra-chapa (nó de aço) 
5.1 - Resultados da análise numérica.

Primeiramente serão mostrados os resultados da análise numérica linear dos protótipos, os quais apresentam a distribuição de esforços e deslocamentos.

Os resultados foram obtidos para uma força de $1 \mathrm{kN}$ aplicada nos quatro pontos internos do banzo inferior. Os esforços são mostrados na figura 5.1 e os deslocamentos dos pontos principais na tabela 5.1.

TABELA 5.1 - Deslocamentos verticais teóricos para análise linear.

\begin{tabular}{|c|c|c|c|c|c|}
\cline { 2 - 6 } \multicolumn{1}{c|}{} & \multicolumn{5}{|c|}{ Deslocamentos verticais em "mm" (para força de $1 \mathrm{kN}$ por ponto) } \\
\cline { 2 - 6 } \multicolumn{1}{c|}{$\begin{array}{c}\text { diagonal de } \\
\text { apoio (mm) }\end{array}$} & centro & $\begin{array}{c}\text { junto ao } \\
\text { apoio A }\end{array}$ & $\begin{array}{c}\text { junto ao } \\
\text { apoio B }\end{array}$ & $\begin{array}{c}\text { junto ao } \\
\text { apoio C }\end{array}$ & $\begin{array}{c}\text { junto ao } \\
\text { apoio D }\end{array}$ \\
\hline$\phi 76 \times 2,00$ & $-0,28$ & $-0,16$ & $-0,16$ & $-0,16$ & $-0,16$ \\
\hline$\phi 88 \times 2,65$ & $-0,26$ & $-0,15$ & $-0,15$ & $-0,15$ & $-0,15$ \\
\hline
\end{tabular}




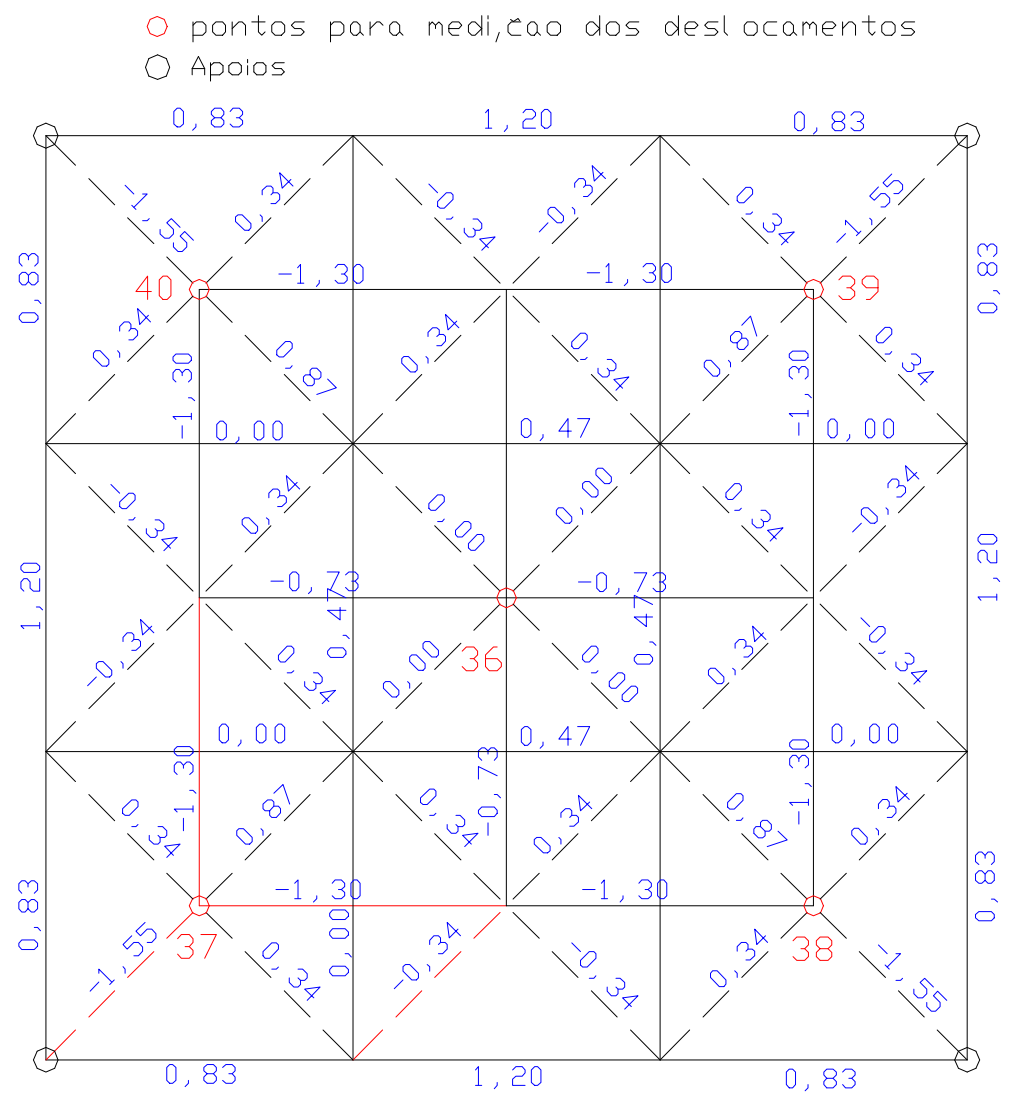

FIGURA 5.1 - Esforços no Protótipo para uma força de $1 \mathrm{kN}$ por ponto (análise linear elástica)

Onde: (+) tração

(-) compressão

Para distribuição de esforços mostrada anteriormente escolheu-se três barras mais solicitadas a compressão (solicitação mais desfavorável), diferenciadas pelas suas dimensões, para que através de cálculos analíticos fossem estimadas as resistências à compressão destas. As barras escolhidas foram as seguintes:

- diagonais de apoio;

- barras do banzo superior unidas às diagonais de apoio; 
- diagonais externas solicitadas à compressão.

A resistência à compressão destas barras foi determinada com base nas normas NBR 8800 (1986) "curva a" , AISI / LRFD (1991) e EUROCODE (1992) "curva c". Os valores destas resistências são apresentadas na tabela 5.3, as propriedades geométricas, esbeltez e resistência ao escoamento, utilizados nestes cálculos estão apresentados na tabela 5.2.

O EUROCODE recomenda a "curva c", quando da utilização nos cálculos do valor da resistência ao escoamento do aço trabalhado a frio.

Para a vinculação das barras, foram supostos apoios simples em ambas as extremidades $(K=1,0)$.

$\mathrm{Na}$ determinação da resistência à compressão foram adotados os valores de resistência ao escoamento do aço obtidos nos ensaios de tração. Para o módulo de elasticidade longitudinal adotou-se E $=205.000 \mathrm{MPa}$.

TABELA 5.2 - Propriedades geométricas, esbeltez e resistência ao escoamento das barras analisadas.

\begin{tabular}{|c|c|c|c|c|c|c|}
\hline $\begin{array}{c}\text { Barra } \\
(\mathrm{mm})\end{array}$ & $\begin{array}{c}\mathrm{A}_{\mathrm{g}} \\
(\mathrm{cm})\end{array}$ & $\begin{array}{c}\mathrm{r} \\
(\mathrm{cm})\end{array}$ & $\begin{array}{c}\mathrm{L} \\
(\mathrm{cm})\end{array}$ & $\lambda$ & \multicolumn{2}{|c|}{$\mathrm{f}_{\mathrm{y}}\left(\mathrm{kN} / \mathrm{cm}^{2}\right)$} \\
\cline { 6 - 8 } & & PROT 1/2 & PROT 3/4 \\
\hline$\phi 60 \times 2,0$ & 3,6 & 2,06 & 231,8 & 112,5 & 42,1 & 39,9 \\
\hline$\phi 76 \times 2,0$ & 4,7 & 2,62 & 250,0 & 95,4 & 37,4 & 39,4 \\
\hline$\phi 76 \times 2,0$ & 4,7 & 2,62 & 231,8 & 88,5 & 37,4 & 39,4 \\
\hline$\phi 88 \times 2,65$ & 7,1 & 3,02 & 231,8 & 76,8 & 35,9 & 37,5 \\
\hline
\end{tabular}


TABELA 5.3 - Resistência a compressão das barras mais solicitadas

\begin{tabular}{|c|c|c|c|c|c|c|c|}
\hline & \multicolumn{6}{|c|}{ Resistência nominal á compressão } \\
\hline & & \multicolumn{2}{|c|}{ NBR $8800 / 86$} & \multicolumn{2}{|c|}{ AISI-LRFD/91 } & \multicolumn{2}{|c|}{ EUROCODE/92 } \\
\hline protótipo & barra & $\begin{array}{c}N_{c r} \\
(\mathrm{kN})\end{array}$ & $\begin{array}{l}N_{c r}{ }^{*} \\
(\mathrm{kN})\end{array}$ & $\begin{array}{c}N_{c r} \\
(\mathrm{kN})\end{array}$ & $\begin{array}{l}N_{c r}{ }^{*} \\
(\mathrm{kN})\end{array}$ & $\begin{array}{c}N_{c r} \\
(\mathrm{kN})\end{array}$ & $\begin{array}{l}N_{c r}{ }^{*} \\
(\mathrm{kN})\end{array}$ \\
\hline \multirow{4}{*}{$\begin{array}{c}\text { PROT } \\
1 / 2\end{array}$} & $\phi 60 \times 2,0$ & 50,4 & 49,4 & 57,4 & 56,4 & 43,1 & 42,2 \\
\hline & $\phi 76 \times 2,0$ & 84,4 & 82,7 & 101,0 & 99,0 & 68,3 & 66,9 \\
\hline & $\begin{array}{c}\phi 76 \times 2,0 \\
(\mathrm{~L}=231,8 \mathrm{~cm})\end{array}$ & 95,3 & 85,8 & 112,2 & 101,0 & 76,3 & 68,7 \\
\hline & $\phi 88 \times 2,65$ & 168,5 & 118,0 & 188,2 & 131,7 & 137,6 & 96,3 \\
\hline \multirow{4}{*}{$\begin{array}{c}\text { PROT } \\
3 / 4\end{array}$} & 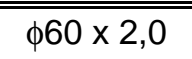 & 499,0 & 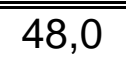 & 57,6 & 56,4 & $4 \quad 40,8$ & 40 \\
\hline & $\phi 76 \times 2,0$ & 85,7 & 84,0 & 103,1 & 101,0 & 72,0 & 70,6 \\
\hline & $\begin{array}{c}\phi 76 \times 2,0 \\
(\mathrm{~L}=231,8 \mathrm{~cm})\end{array}$ & 96,5 & 86,9 & 114,5 & 103,1 & 80,3 & 72,3 \\
\hline & $\phi 88 \times 2,65$ & 172,3 & 120,6 & 193,5 & 135,5 & 143,7 & 100,6 \\
\hline
\end{tabular}

Na tabela 5.4 é feita a relação da força total aplicada na estrutura para a qual é atingida a resistência à compressão das barras anteriormente citadas. O valor da resistência a compressão tomado como referência foi o do EUROCODE para os protótipos PROT 1/2, sem admitir a variação de inércia.

TABELA 5.4 - Estimativa de força última total

\begin{tabular}{|c|c|c|}
\hline Posicionamento da barra & Relação N/F & $\begin{array}{ll}\mathbf{F}_{\mathbf{c r}} & (\mathrm{kN})\end{array}$ \\
\hline Diagonal de apoio $(\phi 88 \times 2,65)$ & 1,55 & 355,1 \\
\hline Diagonal de apoio $(\phi 76 \times 2,0)$ & 1,55 & 196,9 \\
\hline Banzo superior $(\phi 76 \times 2,0)$ & 1,30 & 210,2 \\
\hline Diagonal externa $(\phi 60 \times 2,0)$ & 0,34 & 507,1 \\
\hline \multicolumn{3}{|c|}{$\begin{array}{l}N=\text { força normal na barra correspondente à força } F \text { no protótipo } \\
F=\text { força por nó aplicada no protótipo } \\
F_{c r}=\text { força total aplicada a estrutura, para a qual é atingida a resistência à compressão da } \\
\text { barra. }\end{array}$} \\
\hline
\end{tabular}

Deste modo pode-se estimar que para os protótipos PROT 1, PROT 3 e PROT 4 a falha ocorrerá nas barras do banzo superior próximas aos vértices $(\phi 76 \times 2,0 \mathrm{~mm})$ para uma força total no protótipo $4 \mathrm{~F}=210,2 \mathrm{kN}$, e 
para o protótipo PROT 2 esta acorrerá na diagonal de apoio $(\phi 76 \times 2,0 \mathrm{~mm})$ para a força 4Fde 196,9 kN, admitindo-se análise linear.

A seguir serão mostrados os resultados da análise numérica para cada protótipo comparando-os com os resultados experimentais, estes serão na forma de gráficos representando o deslocamento do nó central e as deformações das barras mais solicitadas à compressão (diagonal de apoio e banzo superior). Para os protótipos PROT1 e PROT2 serão comparadas também as duas hipóteses de modelação não linear adotadas.

Vale salientar que para o protótipo em estudo a consideração das não linearidades física e geométrica não influenciou significativamente na análise, devido principalmente às dimensões destes. Entretanto para outras estruturas é aconselhável o cálculo considerando as não linearidades. Os elevados deslocamentos observados no ensaio são provenientes exclusivamente dos sistemas de conexão.

Para as figuras 5.2 a 5.7 referentes aos protótipos PROT 1 e PROT2 a denominação 'teórico $\mathrm{H} 1$ ', refere-se à análise teórica não linear cuja modelação da região do nó típico foi composta pela sobreposição dos elementos de barra ( $1^{\text {a }}$ hipótese de modelação do nó típico), e 'teórico H2' refere-se à modelação da região do nó típico composta por elementos de casca com inércia equivalente à soma das inércias das extremidades das barras que concorrem no referido nó ( $2^{\mathrm{a}}$ hipóteses de modelação).

As duas hipóteses de análise teórica não linear citadas anteriormente, apresentaram para o protótipo PROT 1 resultados de deslocamentos próximos aos da análise teórica linear, figura 5.2, sendo que para a $1^{\text {a }}$ modelação (teórico $\mathrm{H} 1$ ), a força teórica limite, representada pelo início do patamar $(223 \mathrm{kN})$, foi $6,1 \%$ superior à estimada analiticamente e $38,3 \%$ da força última obtida experimentalmente. Para a $2^{\mathrm{a}}$ modelação estas porcentagens foram de $65,6 \%$ e $115,6 \%$, respectivamente.

Estes resultados são confirmados nas figuras 5.3 e 5.4, referentes as deformações nas barras mais solicitadas à compressão, onde observa-se que após atingir a carga teórica limite, para a $1^{\text {a }}$ hipótese de modelação, houve um alívio de deformações (e portanto tensões) na barra em questão. 


\section{Protótipo PROT1:}

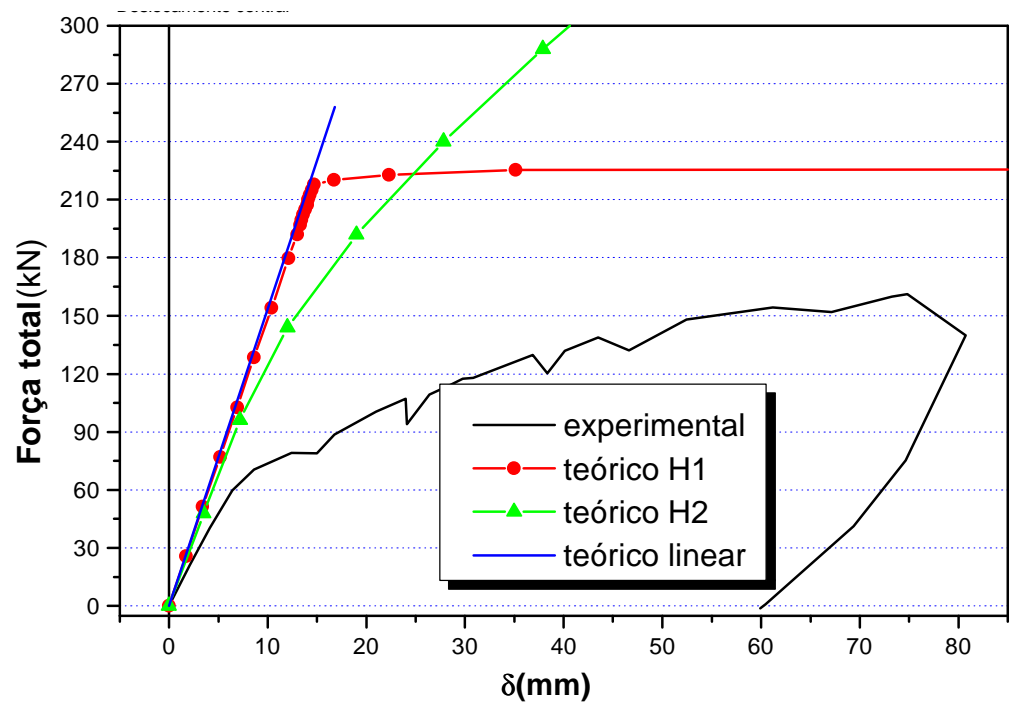

FIGURA 5.2 - Deslocamento vertical do nó central (PROT 1 - análise numérica)

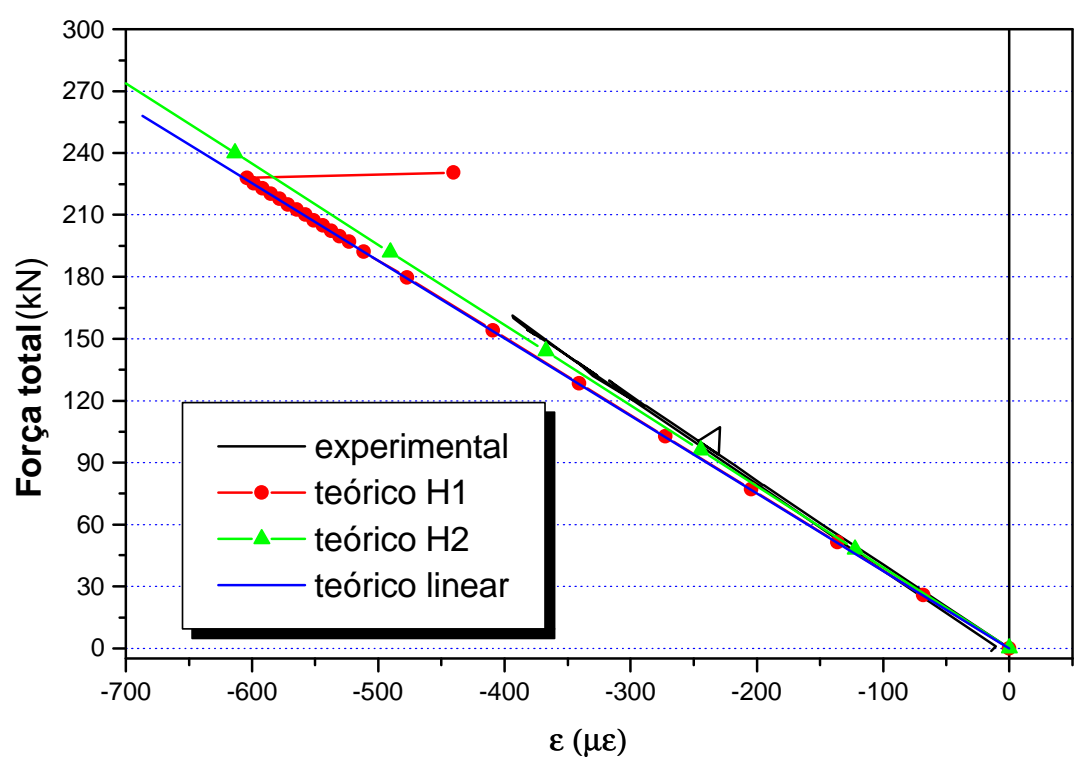

FIGURA 5.3 - Deformação da diagonal de apoio (PROT 1 - análise numérica) 


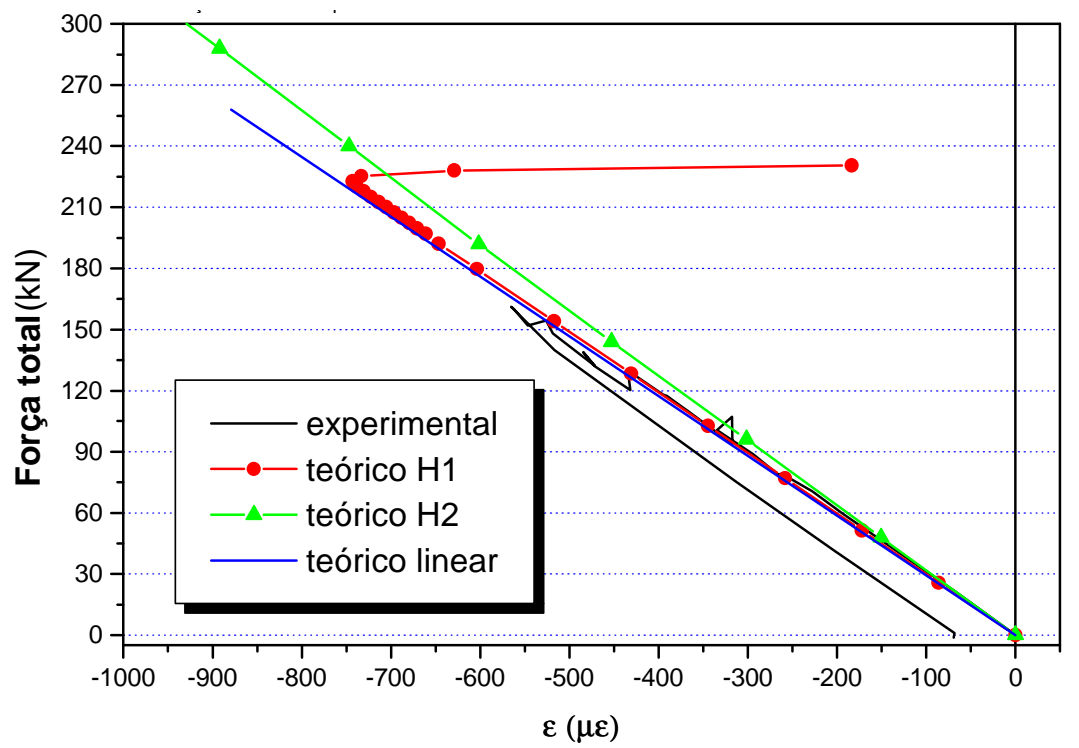

FIGURA 5.4 - Deformação da barra do banzo superior (PROT 1 - análise numérica)

\section{Protótipo PROT 2}

Para o protótipo PROT 2, resultados de deslocamentos (figura 5.5), bem como das deformações (figuras 5.6 e 5.7), foram similares ao do $1^{\circ}$ protótipo, sendo que para a $1^{a}$ modelação (teórico $\mathrm{H} 1$ ), a força teórica limite resultou $6,6 \%$ superior à estimada analiticamente e $31,1 \%$ da força última obtida em ensaio. Para a $2^{\mathrm{a}}$ modelação (teórico H2) estas porcentagens foram de $47,3 \%$ e $81,1 \%$, respectivamente.

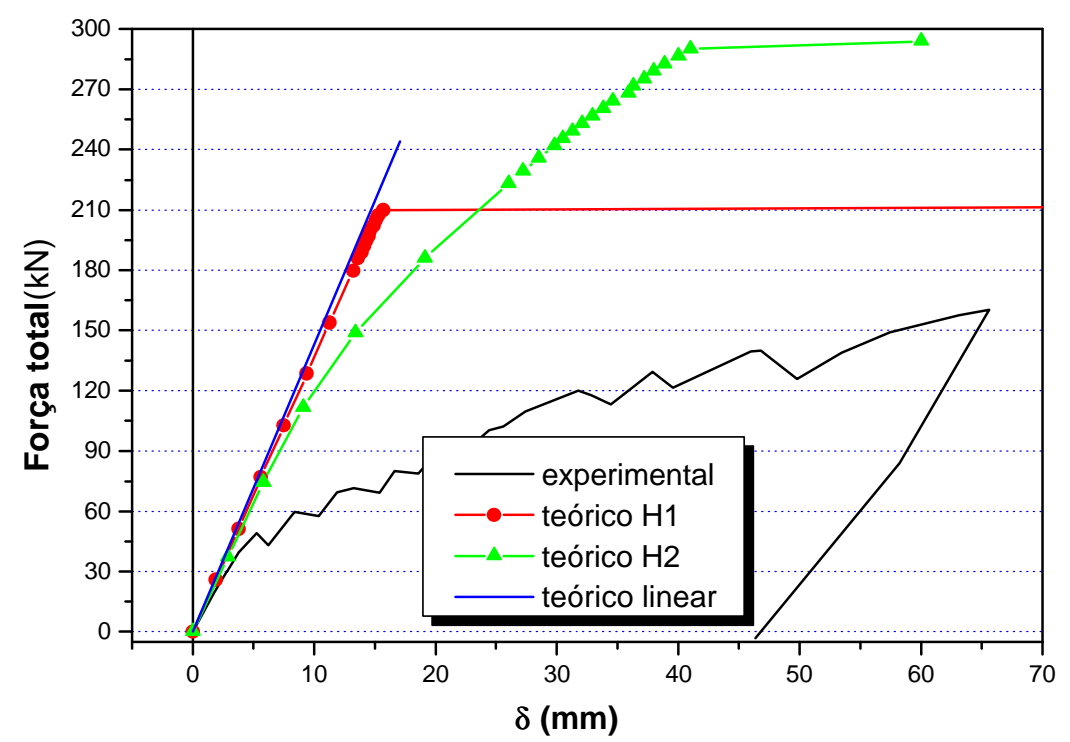

FIGURA 5.5 - Deslocamento vertical do nó central (PROT 2 - análise numérica) 


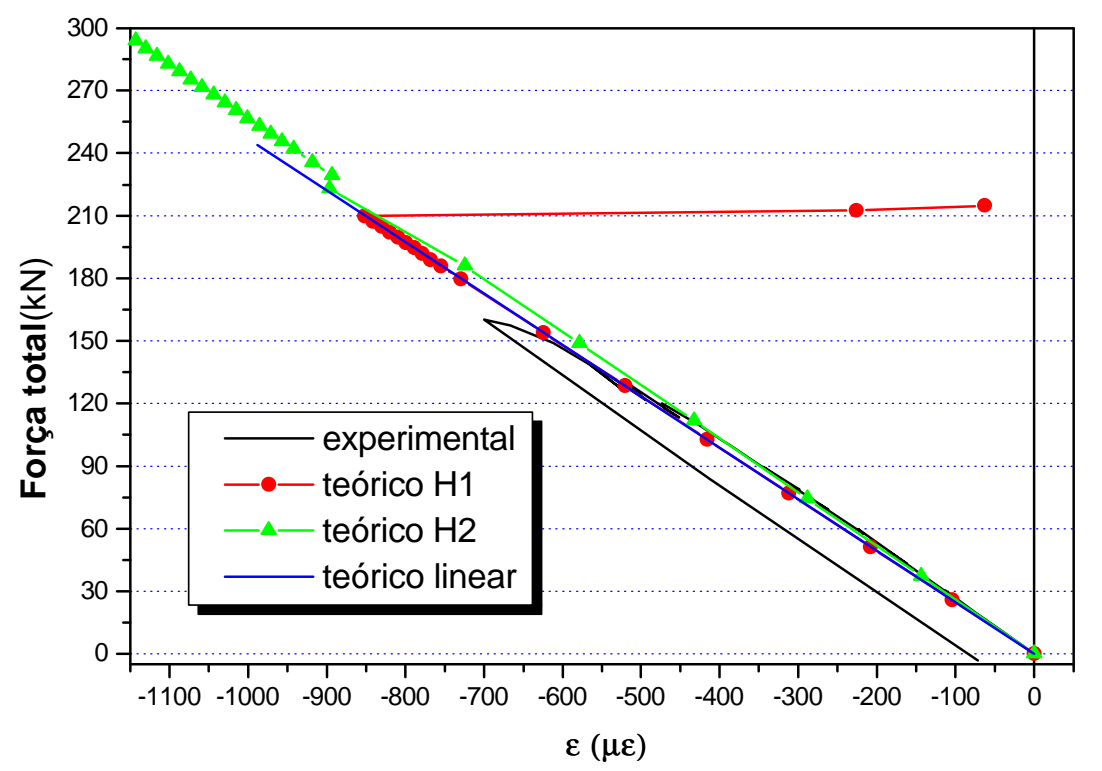

FIGURA 5.6 - Deformação da diagonal de apoio (PROT 2 - análise numérica)

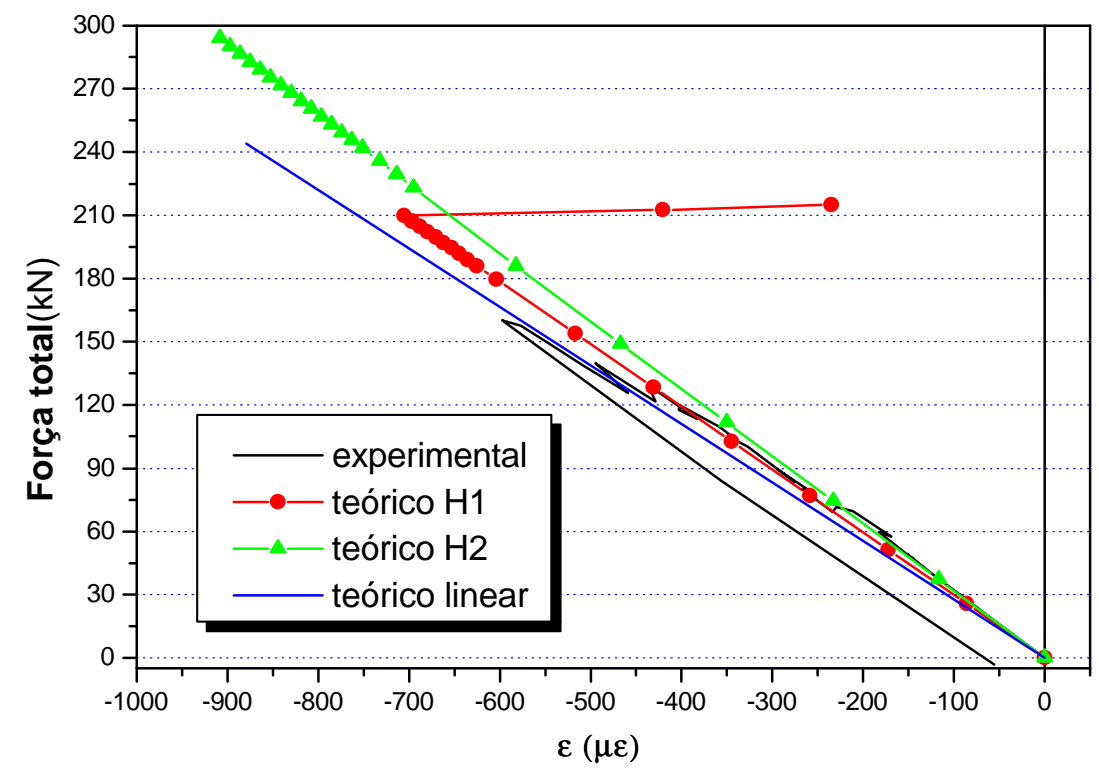

FIGURA 5.7 - Deformação da barra do banzo superior (PROT 2 - análise numérica) 


\section{Protótipo PROT 3}

Para o protótipo PROT 3 a modelação dos nós de aço para a análise teórica não linear foi feita com elementos de casca, a qual é explicada com maiores detalhes no item 4.2.3.

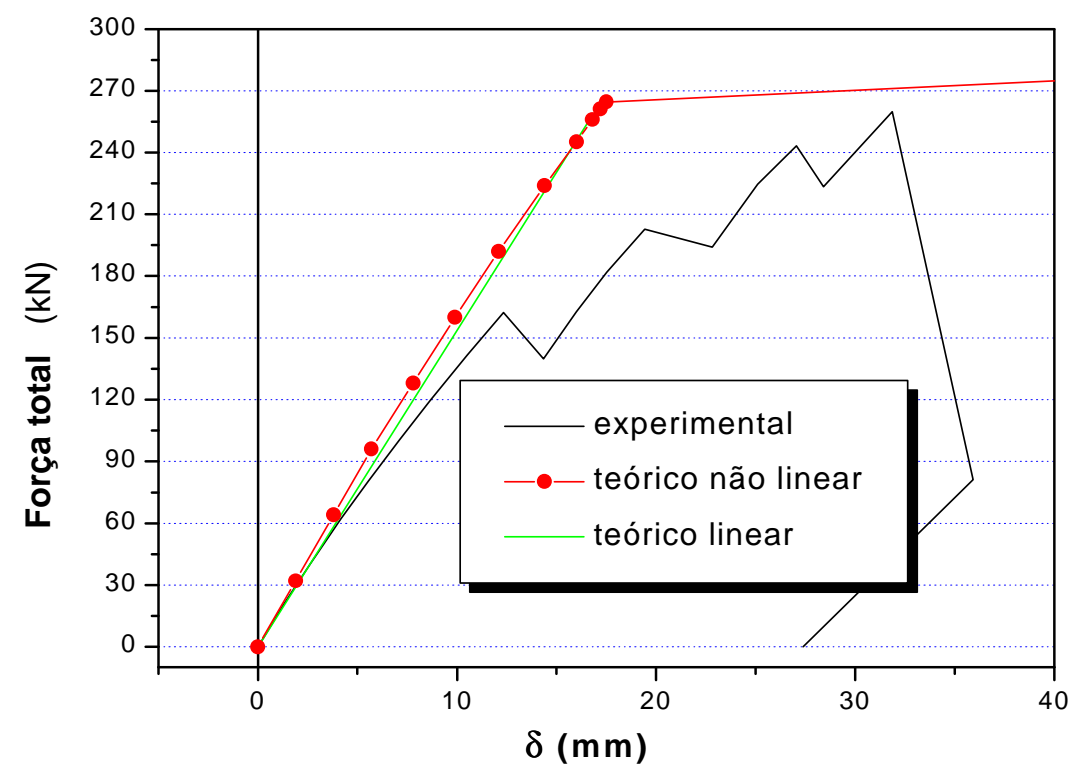

FIGURA 5.8 - Deslocamento vertical do nó central (PROT3 - análise numérica)

$\mathrm{Na}$ figura 5.8, pode-se observar que os resultados da modelação teórica não linear foram praticamente análogos aos da teórica linear (sem consideração da variação de inércia nas extremidades das barras). A força teórica limite foi $4 \%$ superior à força última experimental.

Quanto às deformações, na figura 5.10, para análise teórica não linear foi observada a falha prematura da barra do banzo superior junto a diagonal de apoio, representada pelo alívio de deformações, para um carregamento de $214 \mathrm{kN}$, contra $210 \mathrm{kN}$ estimado analiticamente. Tal valor é $22 \%$ inferior ao encontrado para força teórica limite da estrutura pela mesma análise, evidenciando uma reserva de resistência na estrutura modelada. 


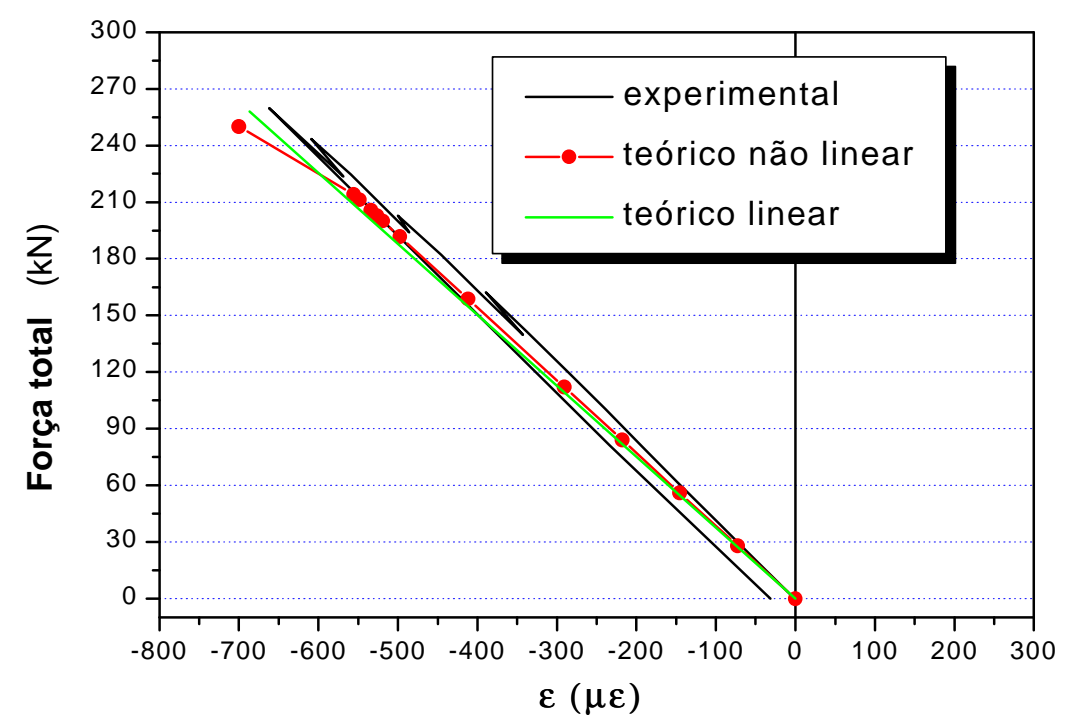

FIGURA 5.9 - Deformação da diagonal de apoio (PROT 3 - análise numérica)

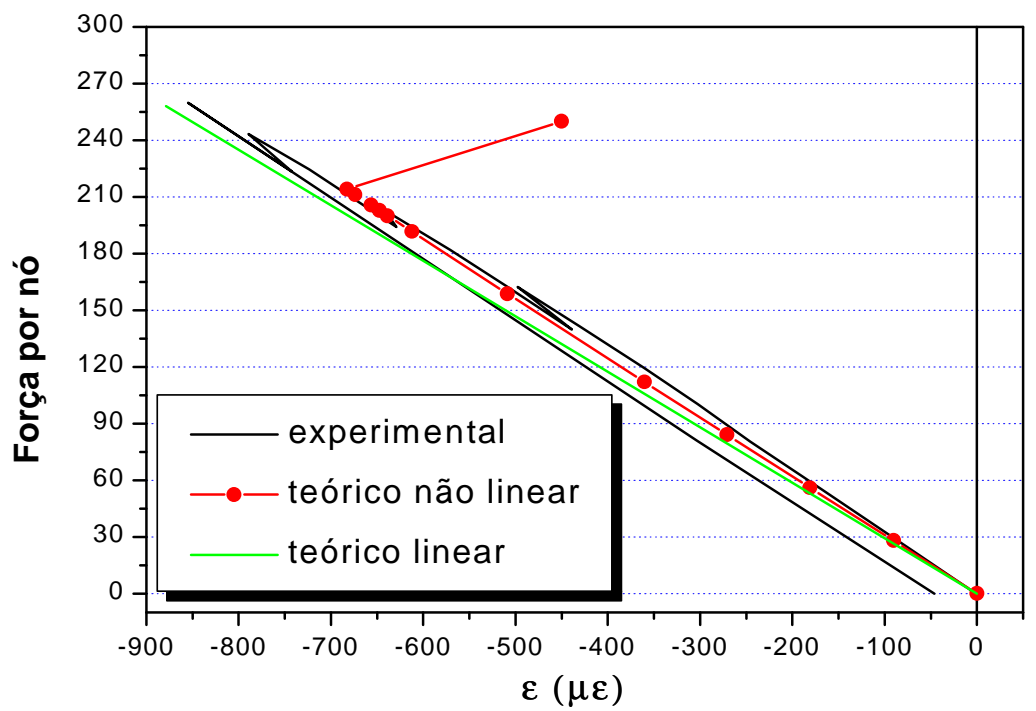

FIGURA 5.10 - Deformação da barra do banzo superior (PROT 3 - análise numérica)

\section{Protótipo PROT 4}

Para este $4^{\circ}$ protótipo, formado por sistema misto de conexão, na modelação da região dos nós típicos, utilizou-se da $1^{\text {a }}$ hipótese de modelação do nó típico, e para o região dos nós de aço este foram modelados com elementos de casca. 
Os resultados da análise teórica não linear deste foram intermediários aos apresentados pelos protótipos PROT 1 e PROT 3, tanto para os deslocamentos (figura 5.11), quanto para as deformações (figuras $5.12 \mathrm{e}$ 5.13), apresentando força teórica limite da estrutura $26,7 \%$ superior á força última encontrada experimentalmente. Para deformação da barra do banzo superior junto a diagonal de apoio, figura 5.13, a análise não linear detectou a instabilidade desta barra para uma força de $227 \mathrm{kN}$ o que corresponde a $8 \%$ da estimado analiticamente.

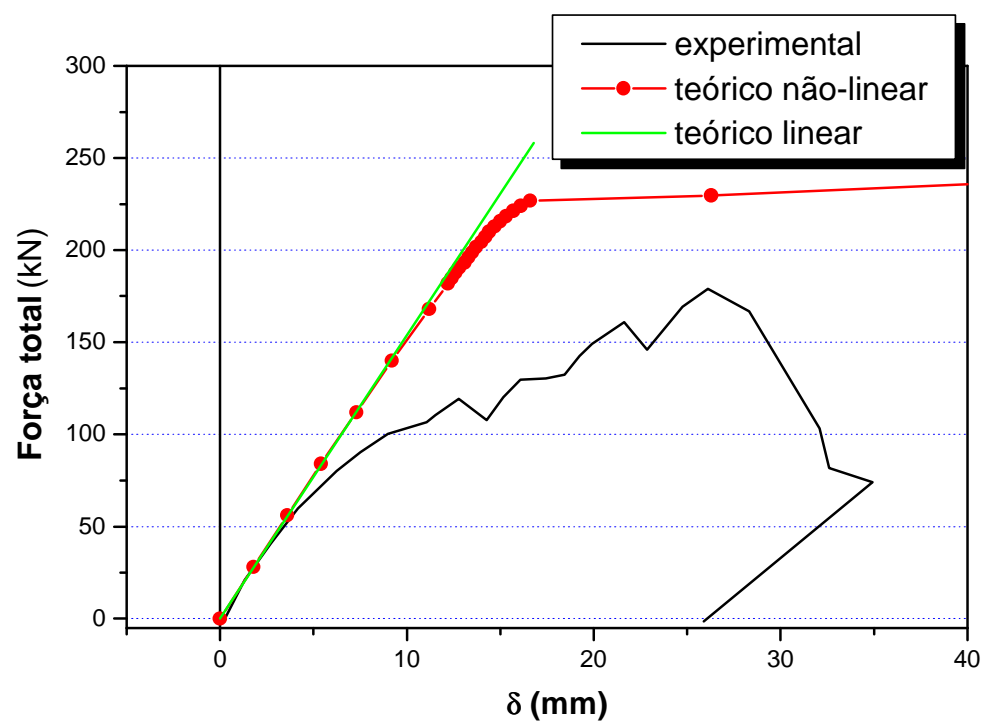

FIGURA 5.11 - Deslocamento vertical do nó central (PROT4 - análise numérica)

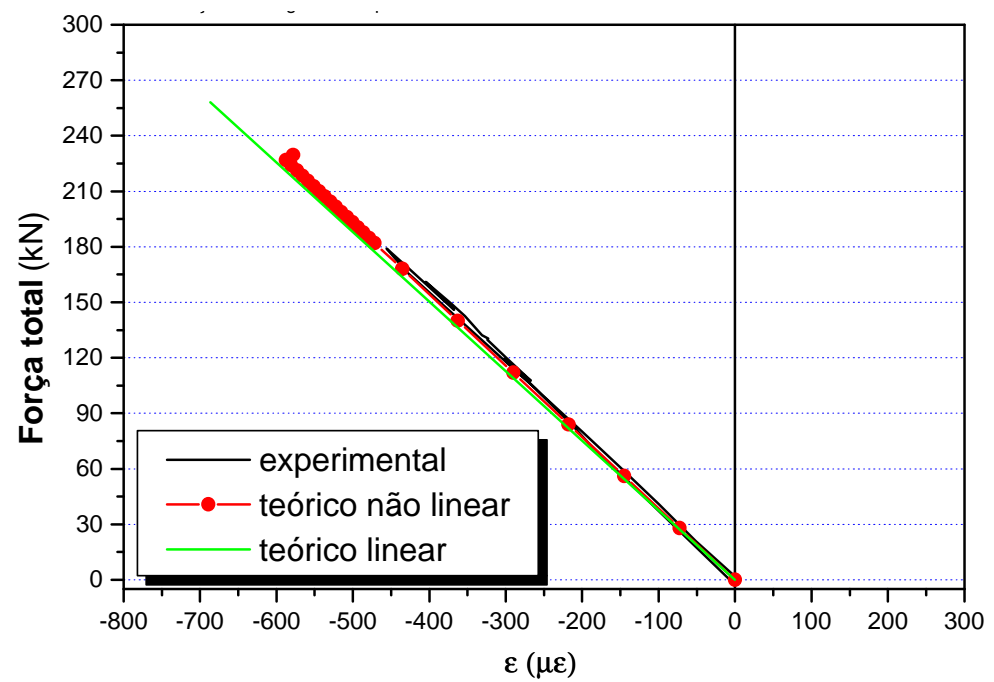

FIGURA 5.12 - Deformação da diagonal de apoio (PROT 4 - análise numérica) 


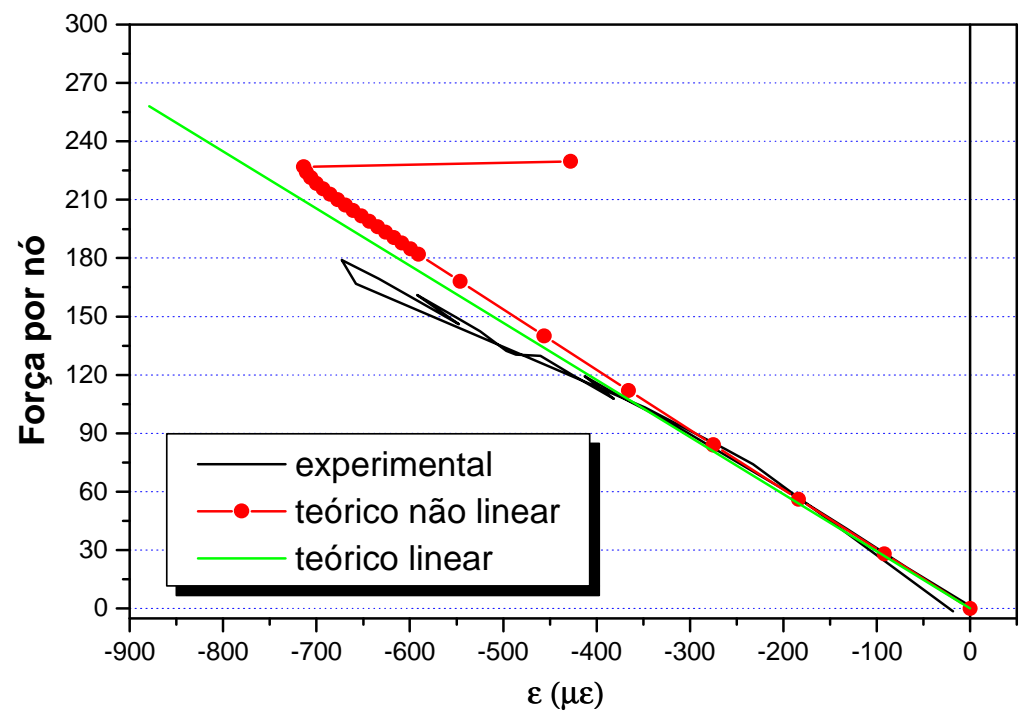

FIGURA 5.13 - Deformação da barra do banzo superior (PROT 4 - análise numérica)

Os resultados teóricos apresentados confirmam que a consideração das não linearidades não tiveram influência significativa nestes, pois as deformações e, principalmente os deslocamentos teóricos, foram relativamente pequenos quando comparados com os obtidos nos ensaios, aproximando-se dos resultados teóricos lineares, onde considerou-se barras sem variação de inércia nas extremidades, nós perfeitamente articulados e sem excentricidades.

Isto se deve ao fato de terem sido analisados pequenos protótipos, com elevada relação altura/vão (1:5), portanto trata-se de casos com grande influência da força cortante. $E$ também pelo fato da análise teórica não linear desenvolvida ter procurado representar de maneira simples e viável de ser empregada na prática de projetos, o detalhe das extremidades das barras e suas conexões, a qual tornou deste modo extremamente difícil a consideração nesta análise de fatores relevantes como os deslizamentos e abertura dos nós típicos e as imperfeições geométricas iniciais, que alteram a resposta estrutural. 


\section{2 - Resultados da análise experimental}

Primeiramente serão apresentados aqui alguns resultados da caracterização de amostras retiradas dos tubos de aço, referentes aos protótipos ensaiados, tubos esses de aço USI-SAC-41, apresentando as seguintes dimensões: $\phi 60 \times 2,0(\mathrm{~mm}), \phi 76 \times 2,0(\mathrm{~mm})$ e $\phi 88 \times 2,65(\mathrm{~mm})$.

\subsection{1 - Ensaio de tração}

A caracterização mecânica do aço foi feita mediante ensaios de tração, conforme a especificação norte-americana: AMERICAN SOCIETY FOR TESTING AND MATERIALS A-370 'Standard test methods and definitions for mechanical testing of steel products' (ASTM A370-96).

As amostras constituíram-se de segmentos de tubo, sendo duas amostras para cada diâmetro ensaiado, para cada um destes foram extraídos quatro corpos-de-prova, em posições diametralmente opostas (figura 5.14), sendo que um dos quatro corpos-de-prova de cada segmento tinha seu eixo posicionado na região da costura.
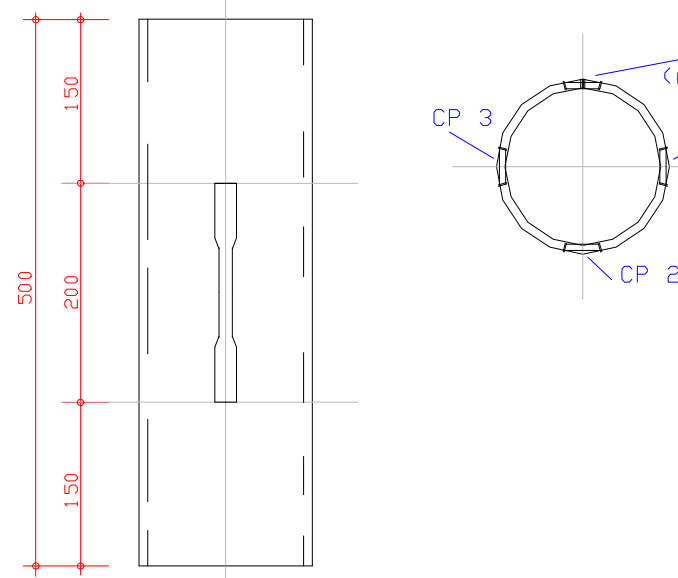

EXTRACÂA DUS CIRPGS-DE-PRQVA

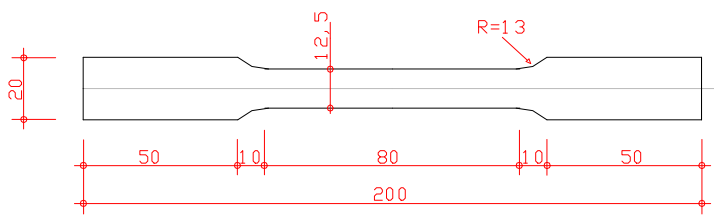

FIGURA 5.14 - Extração e dimensões dos corpos-de-prova (ensaio de tração). 
$\mathrm{Na}$ figura 5.15 pode-se visualizar um destes corpos-de-prova retirado da região da costura, deve-se observar que nas extremidades deste houve a remoção da solda, para melhor fixação da garra da máquina de ensaio.

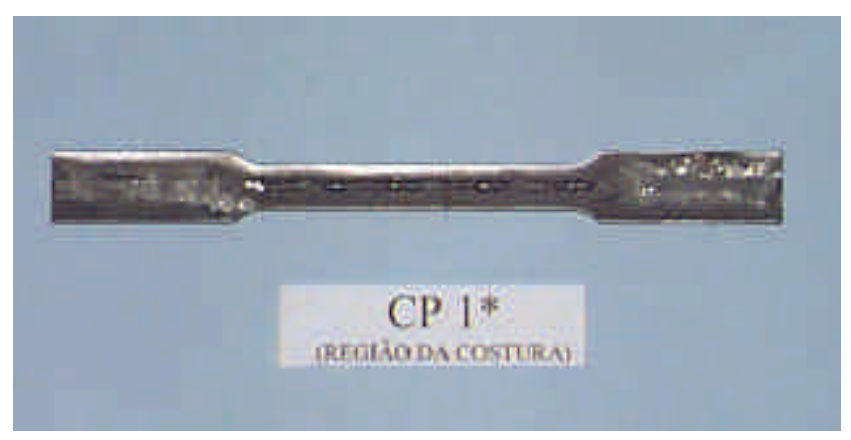

FIGURA 5.15 - Corpo-de-prova retirado da região da costura.

Foram ensaiados apenas um conjunto de corpos-de-prova de um segmento de cada diâmetro, tendo o segundo sido guardado para uma eventual contra prova. A figura 5.14 mostra as dimensões destes corpos de prova segundo a ASTM A370-96.

Total de 12 corpos-de-prova foram ensaiados à tração em máquina de ensaio mecânica INSTRON (figura 5.16) com taxa de deslocamento relativo entre garras de $2 \mathrm{~mm} / \mathrm{min}$ no trecho inicial (que corresponde aproximadamente ao início da fase de escoamento, ultrapassando a deformação $0,2 \%$ ) e de $5 \mathrm{~mm} / \mathrm{min}$ no trecho final (início de escoamento até a ruptura), sendo que nesse último trecho foi retirado o extensômetro removível.

As deformações nos corpos-de-prova foram obtidas a partir de extensômetro removível (clip-gage), com base de medida de $25 \mathrm{~mm}$, posicionado no trecho central desses. 


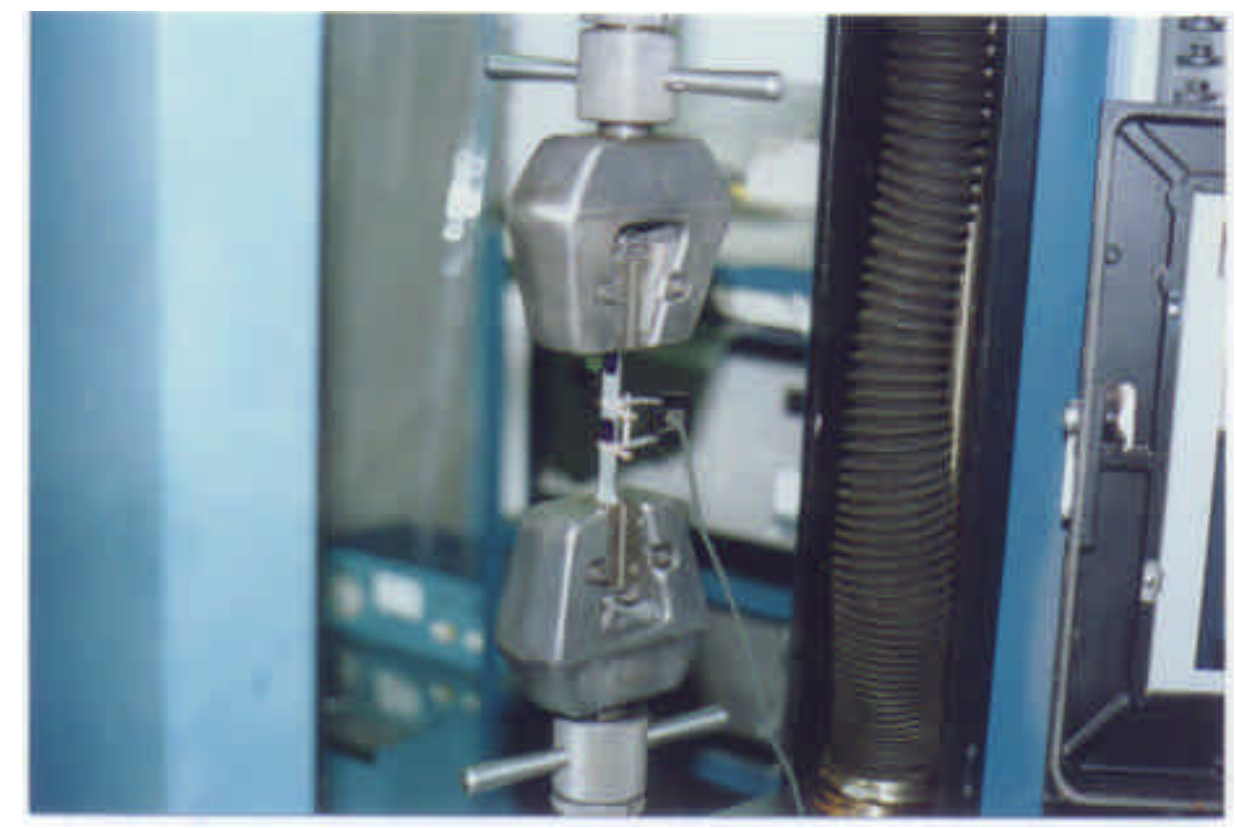

FIGURA 5.16- Vista geral do ensaio de tração do aço.

Os resultados dos ensaios estão apresentados nas tabelas 5.5 e 5.6 seguintes: 


\section{Protótipos PROT 1 e PROT 2}

Tabela 5.5 - Resultados do ensaio de tração do aço (PROT 1 e PROT 2).

\begin{tabular}{|c|c|c|c|c|c|c|c|c|}
\hline & C.P. & $\begin{array}{c}\mathrm{A} \\
(\%)\end{array}$ & $\begin{array}{c}F_{y} \\
(k N)\end{array}$ & $\begin{array}{l}F_{\text {máx }} \\
(\mathrm{kN})\end{array}$ & $\begin{array}{c}f_{y} \\
(\mathrm{MPa})\end{array}$ & $\begin{array}{c}f_{y} \\
\text { méd.(MPa) }\end{array}$ & $\begin{array}{c}\mathrm{f}_{\mathrm{u}} \\
(\mathrm{MPa})\end{array}$ & $\begin{array}{c}\mathrm{f}_{\mathrm{u}} \\
\text { méd. (MPa) }\end{array}$ \\
\hline \multirow{2}{*}{ Tubo } & $1^{*}$ & 17,6 & 13,35 & 14,15 & 542,7 & 542,7 & 575,2 & 575,2 \\
\hline & 2 & \multirow{3}{*}{24,9} & 11,05 & 11,75 & 447,4 & \multirow{3}{*}{420,5} & 475,7 & \multirow{3}{*}{477,9} \\
\hline \multirow{2}{*}{ A4 } & 3 & & 10,20 & 12,15 & 404,8 & & 482,1 & \\
\hline & 4 & & 10,15 & 11,80 & 409,3 & & 475,8 & \\
\hline & $1^{*}$ & 15,6 & 12,60 & 13,60 & 504,0 & 504,0 & 544,0 & 544,0 \\
\hline & 2 & \multirow{3}{*}{26,7} & 9,80 & 11,30 & 392,0 & \multirow{3}{*}{374,0} & 452,0 & \multirow{3}{*}{457,1} \\
\hline \multirow{2}{*}{ A2 } & 3 & & 8,80 & 11,40 & 353,4 & & 457,8 & \\
\hline & 4 & & 9,30 & 11,40 & 376,5 & & 461,5 & \\
\hline & $1^{*}$ & 19,4 & 16,30 & 17,90 & 473,8 & 473,8 & 520,3 & 520,3 \\
\hline & 2 & \multirow{3}{*}{32,0} & 12,60 & 14,80 & 384,1 & \multirow{3}{*}{358,8} & 451,2 & \multirow{3}{*}{448,1} \\
\hline \multirow{2}{*}{ A1 } & 3 & & 11,45 & 14,90 & 343,8 & & 447,4 & \\
\hline & 4 & & 11,40 & 14,90 & 348,6 & & 445,7 & \\
\hline $\begin{array}{l}F_{y} \\
F_{m}\end{array}$ & & & insaio & $\begin{array}{l}e \text { mec } \\
\text { ments }\end{array}$ & $\begin{array}{l}0 \mathrm{~mm}) \\
f_{y}=r( \\
f_{u}=r\end{array}$ & ência à & $\begin{array}{l}\text { coamer } \\
\text { tura }\end{array}$ & \\
\hline
\end{tabular}




\section{Protótipos PROT 3 e PROT 4}

Tabela 5.6 - Resultados do ensaio de tração do aço (PROT 3 e PROT 4).

\begin{tabular}{|c|c|c|c|c|c|c|c|c|}
\hline & C.P. & $\begin{array}{c}A \\
(\%)\end{array}$ & $\begin{array}{c}\mathrm{F}_{\mathrm{y}} \\
(\mathrm{kN})\end{array}$ & $\begin{array}{l}\begin{array}{l}\text { Fáx } \\
(\mathrm{kN})\end{array} \\
\end{array}$ & $\begin{array}{c}f_{y} \\
(\mathrm{MPa}) \\
\end{array}$ & $\begin{array}{c}\mathrm{f}_{\mathrm{y}} \\
\text { méd.(MPa) }\end{array}$ & $\begin{array}{c}\mathrm{f}_{\mathrm{u}} \\
(\mathrm{MPa}) \\
\end{array}$ & $\begin{array}{c}\mathrm{f}_{\mathrm{u}} \\
\text { méd. (MPa) }\end{array}$ \\
\hline \multirow{2}{*}{ Tubo } & $1^{*}$ & 10,6 & 13,05 & 14,10 & 529,2 & 529,2 & 571,8 & 571,8 \\
\hline & 2 & \multirow{3}{*}{33,7} & 10,25 & 11,45 & 405,8 & \multirow{3}{*}{398,8} & 453,3 & \multirow{3}{*}{453,8} \\
\hline \multirow{2}{*}{ B3 } & 3 & & 9,80 & 11,30 & 398,4 & & 459,3 & \\
\hline & 4 & & 9,70 & 11,10 & 392,1 & & 448,7 & \\
\hline \multirow{2}{*}{ Tubo } & $1^{*}$ & 8,4 & 13,70 & 14,60 & 546,7 & 546,7 & 582,6 & 582,6 \\
\hline & 2 & \multirow{3}{*}{33,2} & 9,75 & 12,05 & 386,0 & \multirow{3}{*}{393,5} & 477,0 & \multirow{3}{*}{476,8} \\
\hline \multirow{2}{*}{ B2 } & 3 & & 10,00 & 12,00 & 397,8 & & 477,3 & \\
\hline & 4 & & 10,00 & 12,00 & 396,8 & & 476,2 & \\
\hline \multirow{2}{*}{ Tubo } & $1^{*}$ & 16,3 & 17,75 & 19,15 & 528,9 & 528,9 & 570,6 & 570,6 \\
\hline & 2 & \multirow{3}{*}{32,6} & 12,70 & 16,15 & 377,2 & \multirow{3}{*}{374,7} & 479,7 & \multirow{3}{*}{479,2} \\
\hline \multirow{2}{*}{ B1 } & 3 & & 12,35 & 16,05 & 366,8 & & 476,7 & \\
\hline & 4 & & 12,80 & 16,20 & 380,2 & & 481,1 & \\
\hline
\end{tabular}

*região da costura

Onde:

$A=$ Alongamento na ruptura (base de medida $50 \mathrm{~mm}$ )

$F_{y}=$ Força correspondente ao escoamento $\quad f_{y}=$ resistência ao escoamento

$F_{\text {máx }}=$ Força máxima de ensaio

$f_{y}=$ resistência ao escoa
$f_{u}=$ resistência à ruptura 


\subsection{2 - Ensaio de compressão:}

Para o ensaio de compressão os corpos-de-prova eram constituídos por segmentos dos tubos, dois para cada diâmetro ensaiado de cada lote, sendo que $01^{\circ}$ lote era formado por tubos dos protótipos PROT 1 e PROT 2 e $02^{\circ}$ lote por tubos dos protótipos PROT 3 e PROT 4, totalizando 12 corpos de prova (figura 5.17).

O comprimento de cada corpo de prova foi estabelecido de modo a se manter a mesma esbeltez para os três diferentes diâmetros ensaiados, conforme descrito na tabela 5.7:

TABELA 5.7 - Dimensões das amostras para o ensaio de compressão.

\begin{tabular}{|c|c|c|}
\hline Tubo & $\begin{array}{c}\text { Comprimento do } \\
\text { corpo de prova }(\mathrm{mm})\end{array}$ & $\begin{array}{c}\text { Esbeltez } \\
(\lambda)\end{array}$ \\
\hline$\phi 60 \times 2,00(\mathrm{~mm})$ & 236 & 11,45 \\
\hline$\phi 76 \times 2,00(\mathrm{~mm})$ & 300 & 11,45 \\
\hline$\phi 88 \times 2,65(\mathrm{~mm})$ & 346 & 11,45 \\
\hline
\end{tabular}

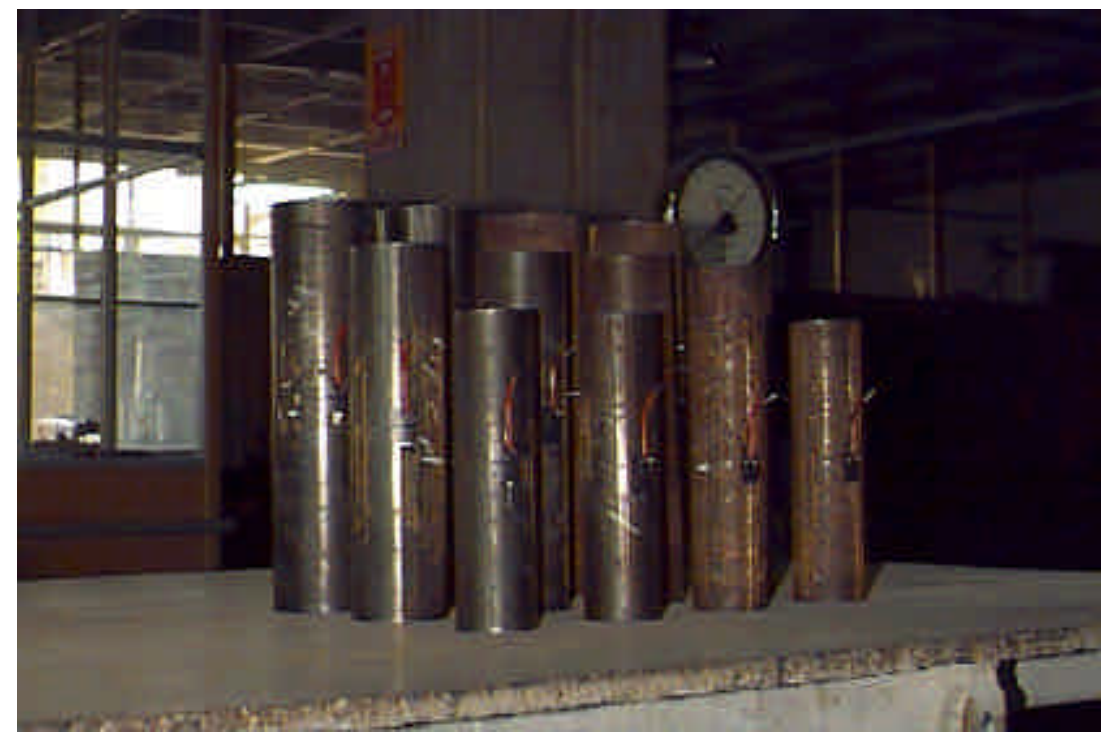

FIGURA 5.17 - Corpos-de-prova dos ensaios de compressão

Para avaliação do módulo de elasticidade foram posicionados dois extensômetros elétricos uniaxiais na seção central, em posição diametralmente opostas e associados em série. 
O ensaio foi realizado na máquina Servo Hidráulica INSTRON (figura 5.18), onde foi aplicada a taxa de deslocamento entre apoios de $0,01 \mathrm{~mm} / \mathrm{min}$, até a ruína do corpo de prova.

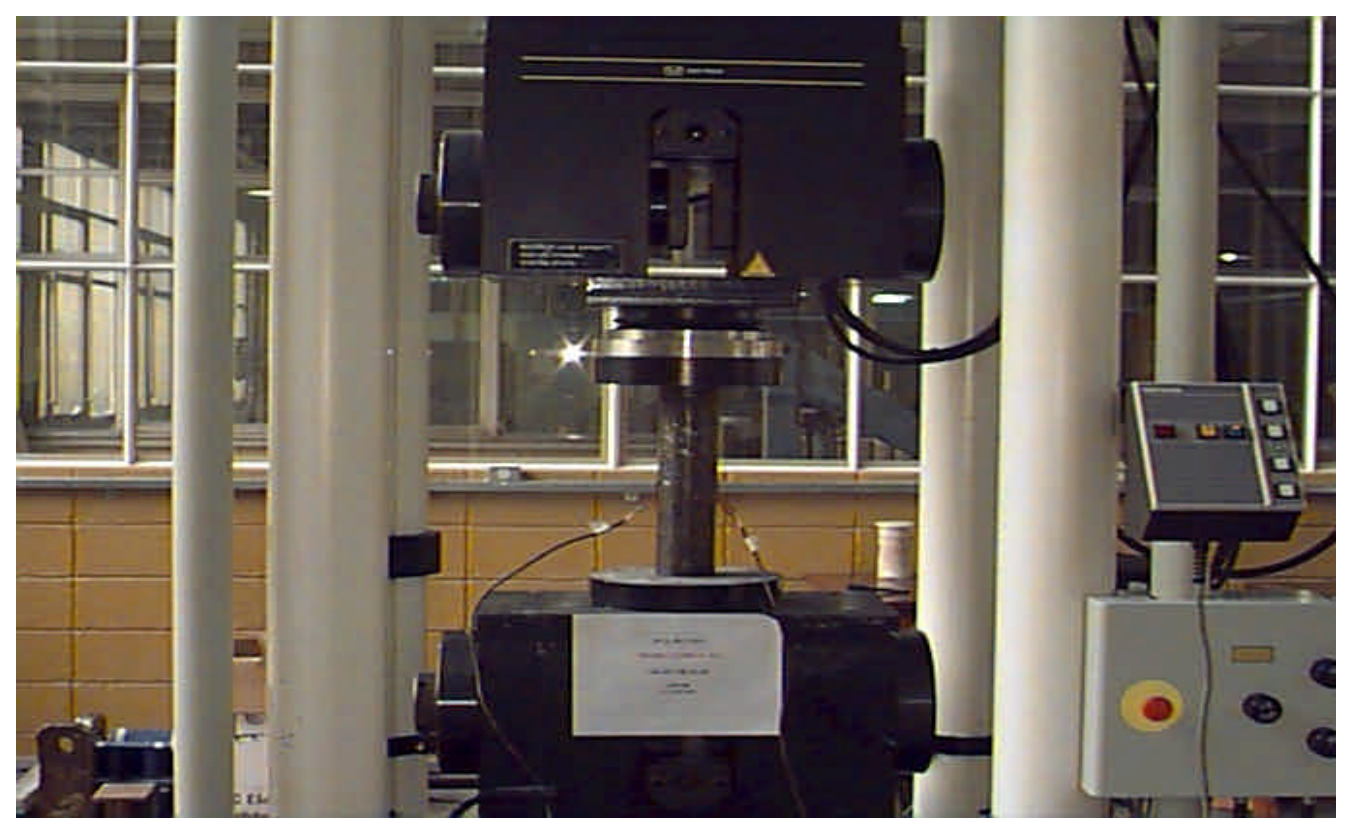

FIGURA 5.18 - Vista geral do ensaio de compressão

As tensões últimas alcançadas no ensaio, bem como a resistência ao escoamento são apresentadas na tabela 5.8 e os respectivos gráficos tensão x deformação são mostrados nas figuras 5.19 e 5.20 .

TABELA 5.8 - Resultados dos ensaios de compressão

\begin{tabular}{|c|c|c|c|c|}
\hline & \multicolumn{3}{|c|}{ Barras } \\
\hline & & $\phi 60 \times 2,0$ & $\phi 76 \times 2,0$ & $\phi 88 \times 2,65$ \\
\hline \multirow{2}{*}{$\begin{array}{c}\text { Resistência ao Escoamento } \\
\mathrm{f}_{\mathrm{y}}\left(\mathrm{kN} / \mathrm{cm}^{2}\right)\end{array}$} & PROT 1/2 & 39,5 & 33,9 & 34,7 \\
\hline & PROT 3/4 & 37,3 & 37,4 & 37,5 \\
\hline Resistência à ruptura & PROT 1/2 & 44,4 & 38,7 & 40,3 \\
\hline $\mathrm{f}_{\mathrm{u}}\left(\mathrm{kN} / \mathrm{cm}^{2}\right)$ & PROT 3/4 & 41,7 & 40,9 & 42,25 \\
\hline
\end{tabular}




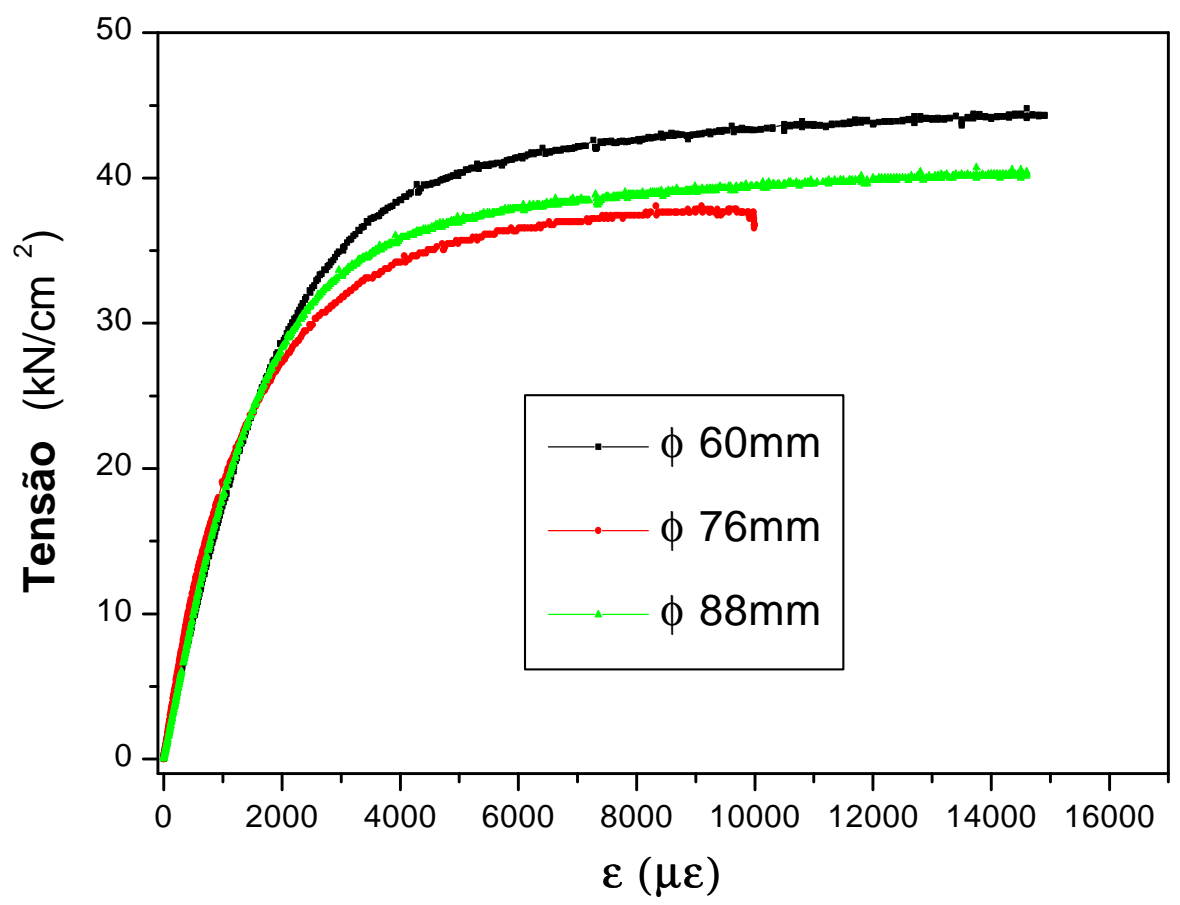

Figura 5.19 - Tensão x deformação, ensaio de compressão (PROT1/2)

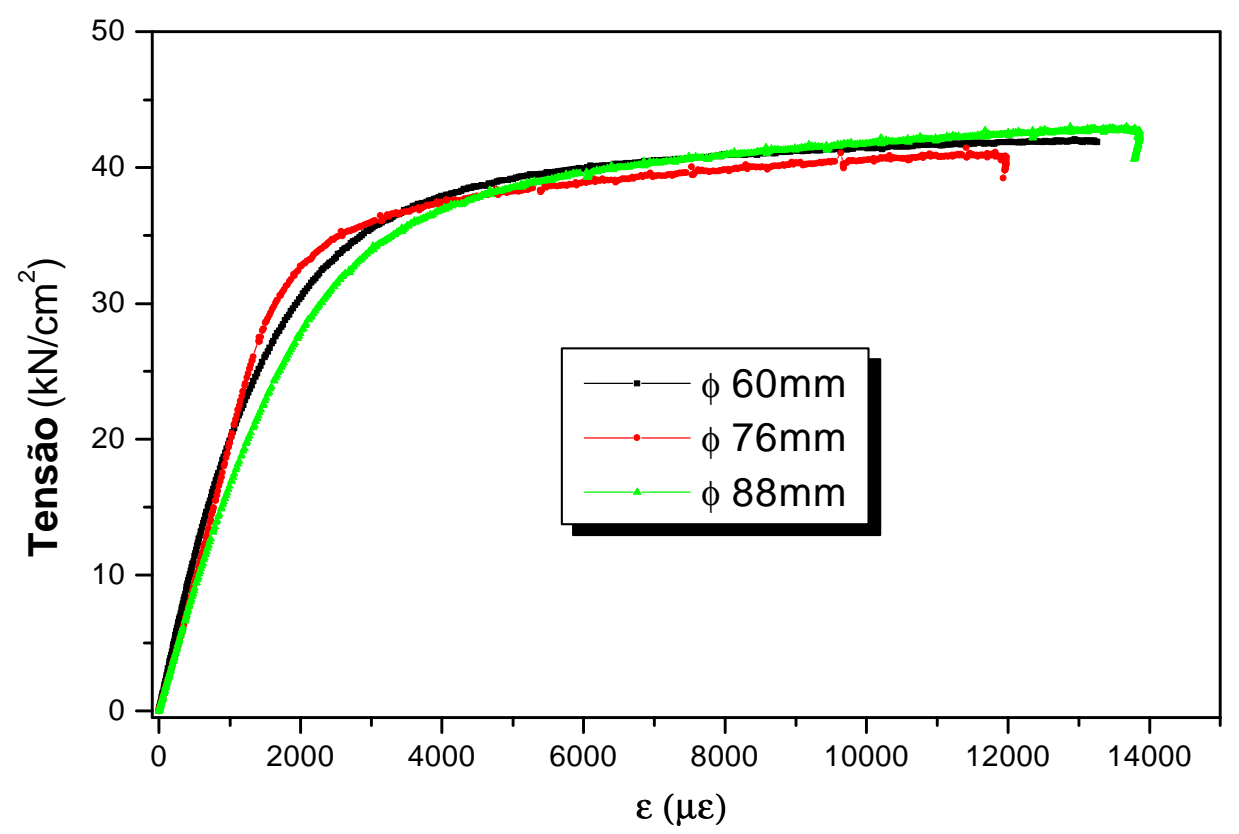

Figura 5.20 - Tensão x deformação, ensaio de compressão (PROT3/4) 


\subsection{3 - Ensaio dos protótipos}

Neste item são apresentados os resultados (deslocamentos e deformações) mais significativos obtidos nos ensaios dos quatro protótipos (PROT 1 a PROT 4), confrontando os resultados experimentais com os provenientes da análise teórica linear. No apêndice A são apresentadas todas as planilhas de resultados referentes aos ensaios.

Para os protótipos constituídos por nós típicos (PROT 1 e PROT 2), a falha foi caracterizada pela rotação e abertura excessiva de alguns nós, ocasionando a plastificação das barras na região da estampagem. Os protótipos PROT 3 (nós de aço) e PROT 4 (sistema misto) apresentaram flambagem de algumas barras do banzo superior (comprimido).

Da simples observação dos modos de falha, pôde-se concluir que o nó típico não permitiu que as barras comprimidas mais solicitadas atingissem sua capacidade, enquanto o nó de aço conduziu à flambagem das barras comprimidas, evidenciando sua eficiência estrutural.

\subsubsection{Modos de falha}

\section{Protótipo PROT1:}

- rotação excessiva da conexão da diagonal de apoio com as barras do banzo superior, junto aos vértices $C$ e D (figuras 5.20 e 5.21).

- deformação excessiva por flexão na extremidade da barra do banzo superior, posicionada entre os vértices $\mathrm{B}$ e $\mathrm{C}$ (figura 5.22). 


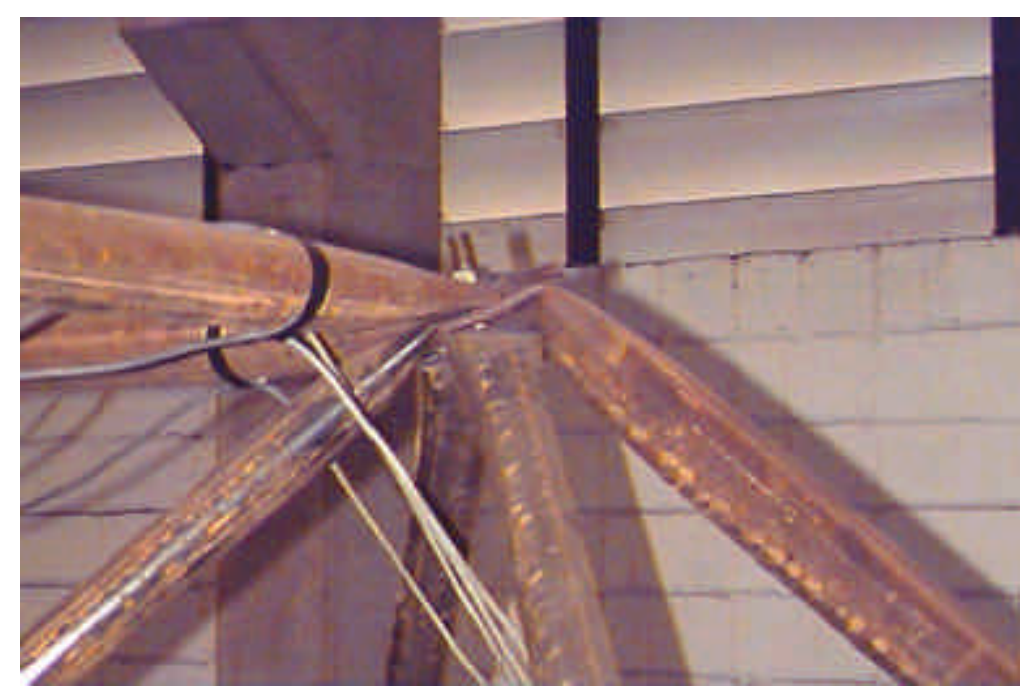

FIGURA 5.21 - Rotação do nó junto ao vértice C (PROT 1).

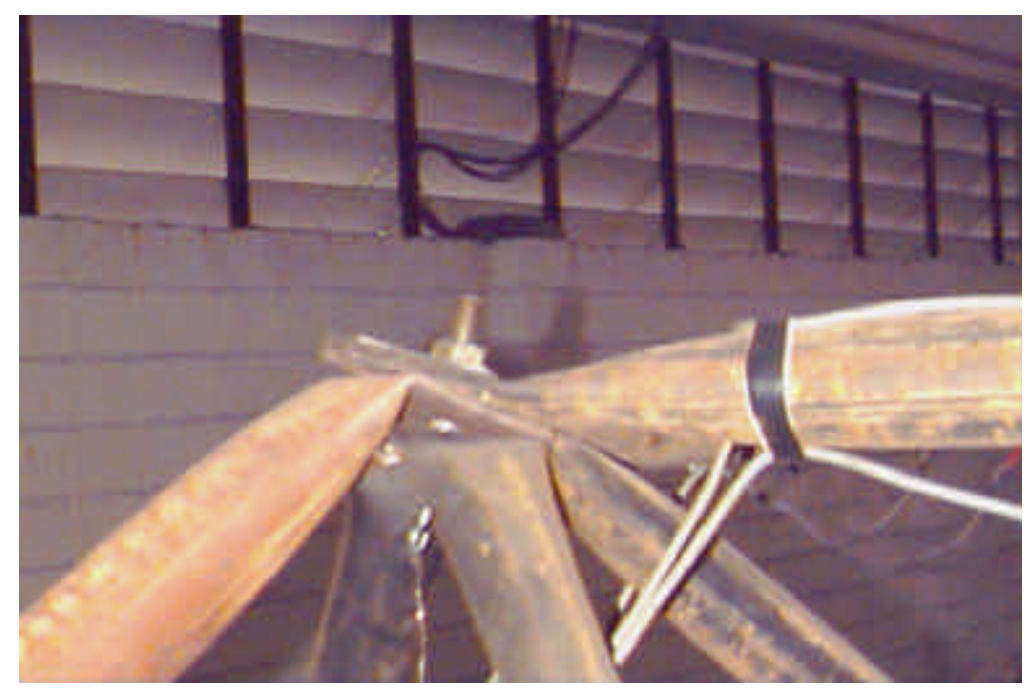

FIGURA 5.22 - Rotação do nó junto ao vértice D (PROT 1).

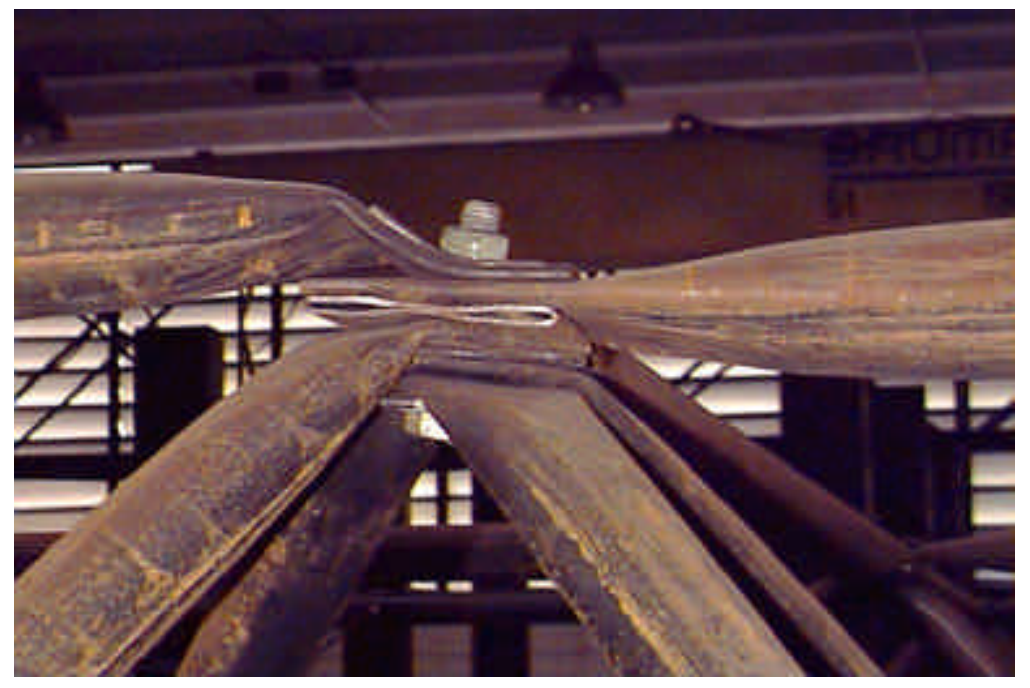

FIGURA 5.23 -Flexão de extremidade da barra do banzo superior (PROT 1). 
Protótipo PROT 2:

- rotação excessiva da conexão da diagonal de apoio com as barras do banzo superior, junto aos vértices $\mathrm{B}$ e $\mathrm{C}$.

\section{Protótipo PROT 3:}

- flambagem de uma barra externa do banzo superior (mais solicitada) seguida pela flambagem de uma barra interna (menos solicitada), caracterizando assim um "repasse" de esforço para esta barra (figura 5.24).

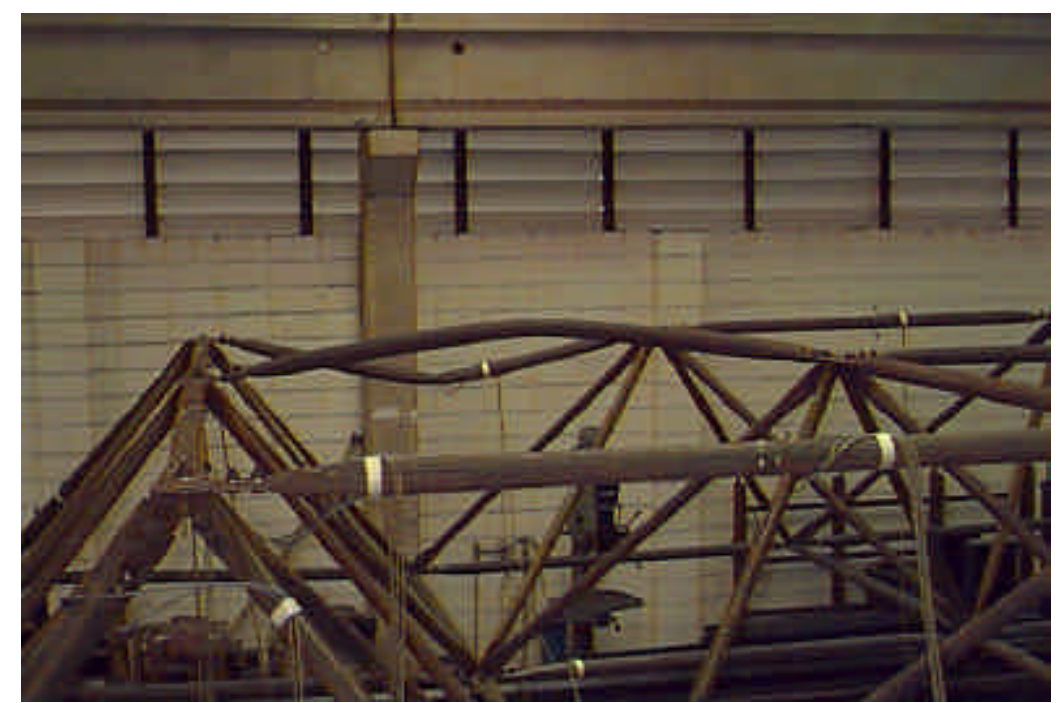

FIGURA 5.24 - Flambagem de duas barras do banzo superior do PROT3

\section{Protótipo PROT 4}

- flambagem de uma barra externa do banzo superior (figura 5.25) 


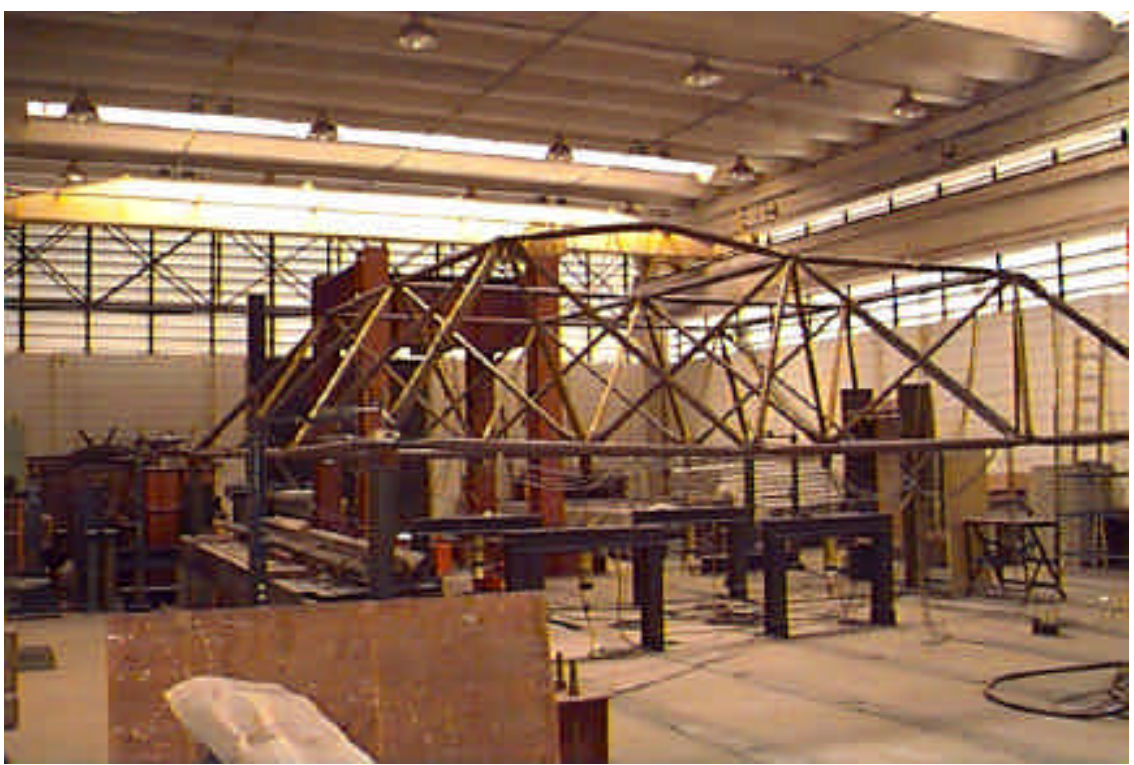

FIGURA 5.25 - Flambagem de uma barra do banzo superior do PROT4

\subsubsection{Deslocamentos}

Os deslocamentos nos protótipos foram medidos pela instrumentação feita com transdutores de deslocamento, os quais foram posicionados igualmente para os quatro protótipos, de modo a avaliar os deslocamentos dos apoios segundo três direções e também os deslocamentos verticais no centro dos protótipos e nos quatro nós externos do banzo superior próximo aos vértices.

Os deslocamentos de apoio apresentaram significativa divergência entre os quatro apoios, e entre os quatro protótipos, entretanto com a ordem de grandeza esperada. A divergência é proveniente das imperfeições construtivas dos protótipos, da montagem do ensaio, e da aplicação do carregamento. Como ilustração, a figura 5.26 apresenta os deslocamentos dos quatro apoios do protótipo PROT 2. 


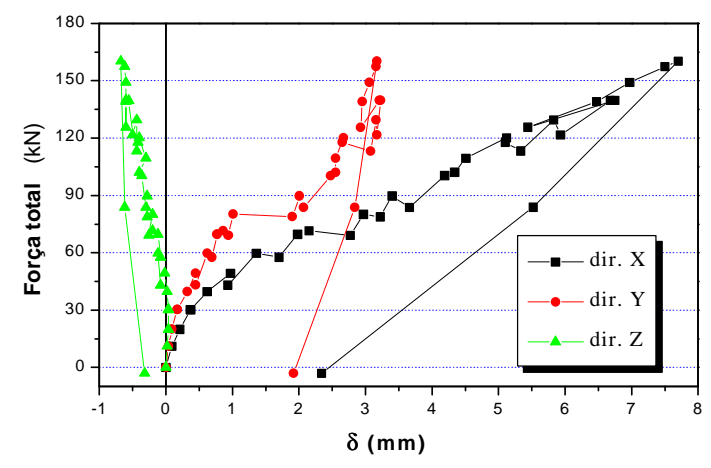

a) vértice $A$

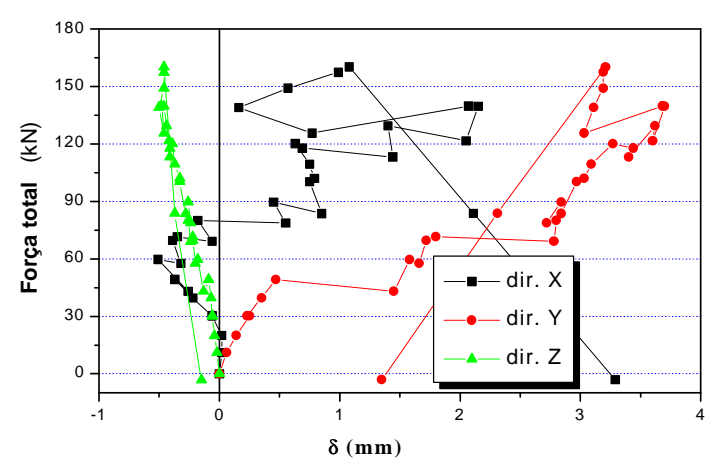

c) vértice $\mathrm{C}$

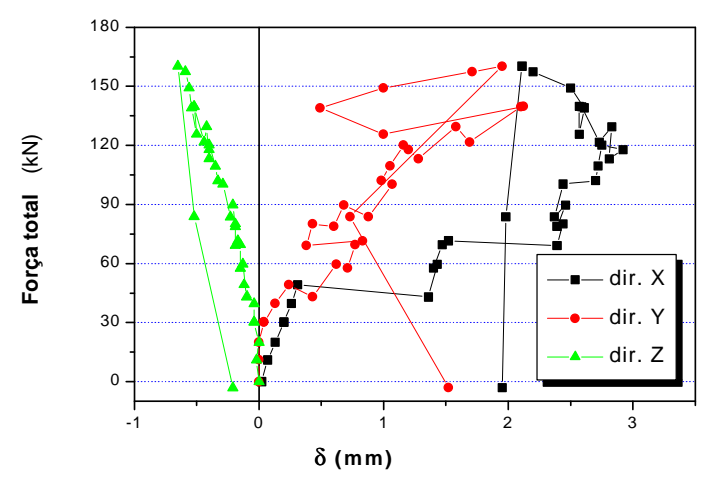

b) vértice $B$

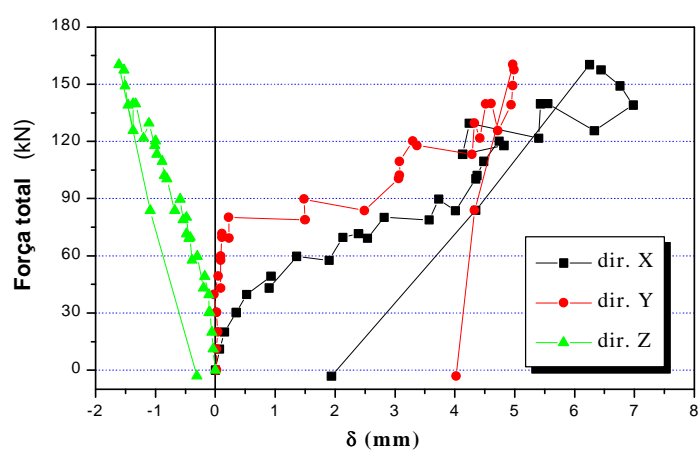

d) vértice $D$

FIGURA 5.26 - Deslocamento de apoio do PROT 2

A figura 5.27 apresenta o deslocamento vertical central ocorrido no protótipo PROT 1, onde foi conveniente sobrepor as etapas de carregamento devido ao elevado deslocamento apresentado ainda na fase de escorvamento (realizada em duas etapas). $O$ deslocamento residual foi de $77,6 \mathrm{~mm}$. O início e fim de cada etapa podem ser identificados pelos pontos de descarregamento (força nula). 


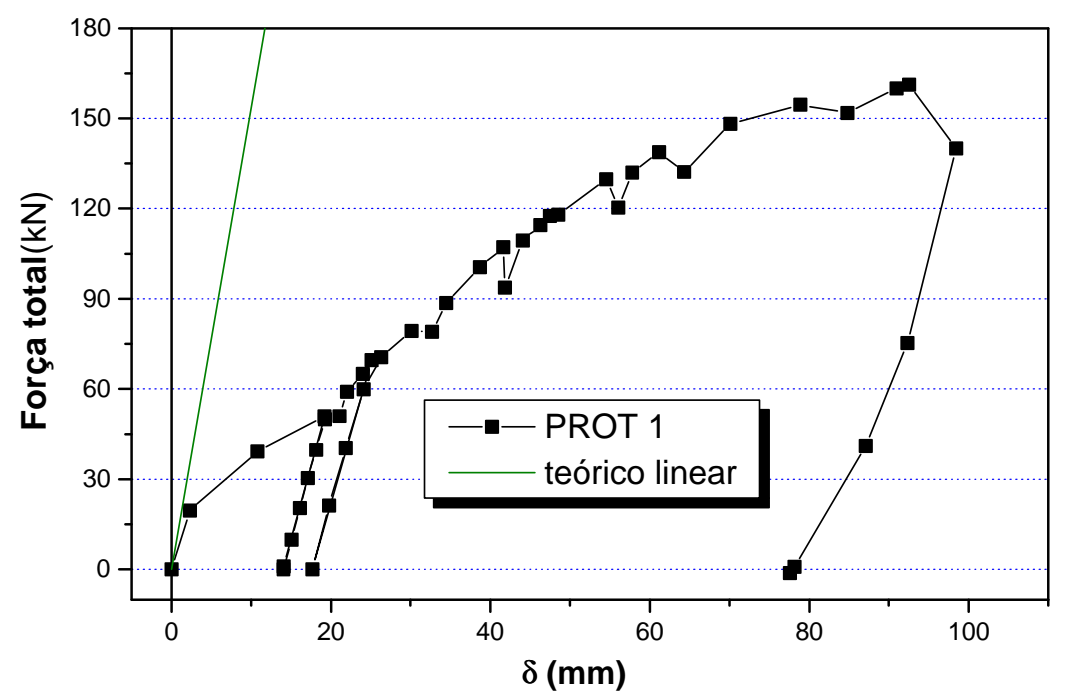

FIGURA 5.27 - Deslocamento vertical do nó central PROT1 (experimental)

Para os deslocamentos dos nós do banzo superior próximos aos vértices, estes apresentaram uma pequena divergência em seus valores, sendo esta aumentada nas últimas etapas de carregamento devido a ocorrência das falhas localizadas. Este comportamento é representado pela figura 5.28 referente ao protótipo PROT 3, onde pode ser observado o maior deslocamento no final do ensaio do vértice $D$ onde ocorreu a flambagem das barras do banzo superior. Para os outros protótipos este comportamento foi análogo.

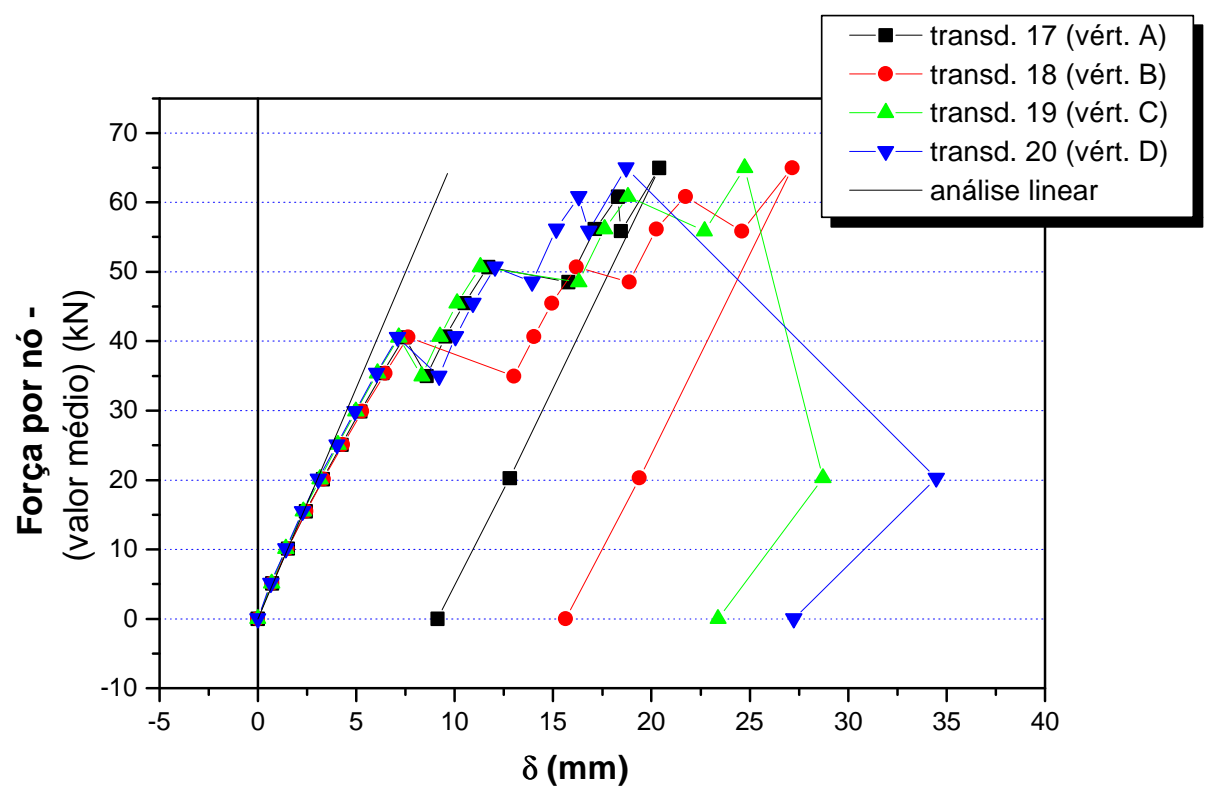

FIGURA 5.28 - Deslocamentos dos nós do banzo superior junto aos vértices (PROT3) 
Para os gráficos anteriores as perturbações percebidas são conseqüência de acomodações na estrutura devido principalmente ao escorregamento relativo entre barras, proveniente dos sistemas de conexão utilizados.

Na figura 5.29 apresenta-se a comparação dos deslocamentos dos nós centrais entre os protótipos PROT 1 e PROT 2, os quais apresentavam o mesmo sistema de conexão (nó típico) mas se diferenciavam pela dimensão das diagonais de apoio. Em seguida, a figura 5.30 apresenta a mesma comparação para os protótipos PROT 1, PROT 3 e PROT 4 os quais apresentavam as mesmas dimensões da seção transversal de suas barras, diferenciando-se apenas pelo sistema de conexão: nós típicos, nós de aço e configuração mista, respectivamente.

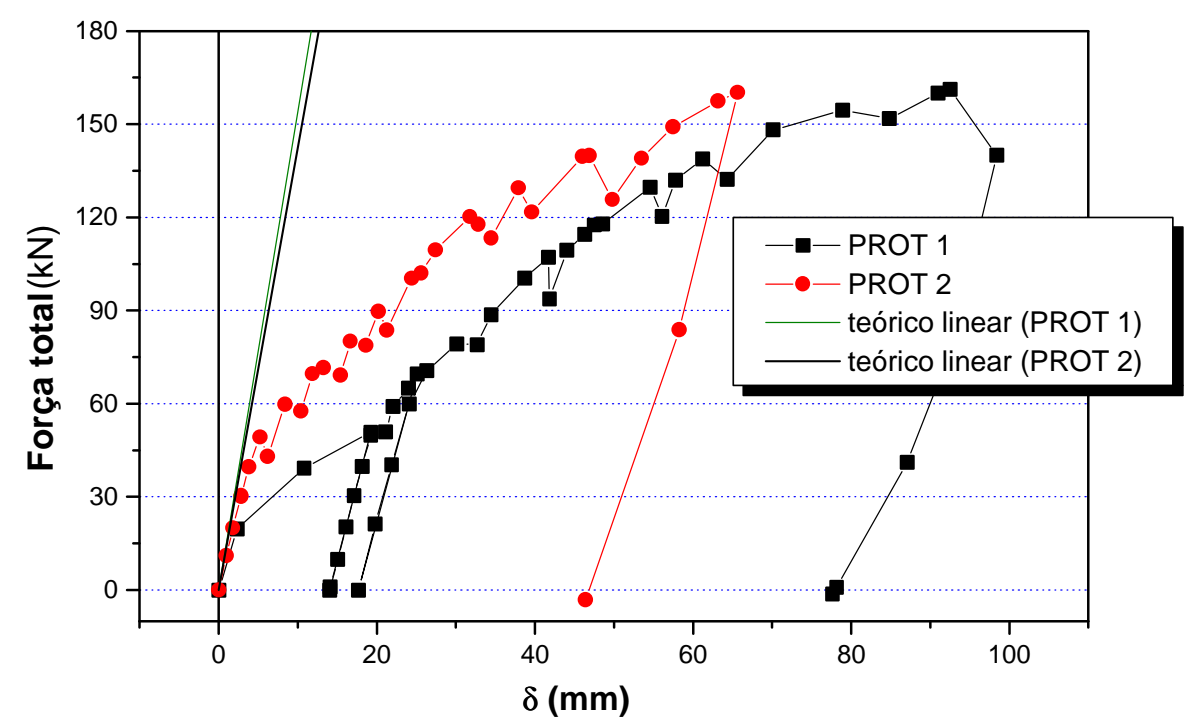

FIGURA 5.29 - Deslocamento vertical do nó central (PROT 1 x PROT 2)

Não houve controle de torque no aperto dos parafusos do PROT 1, o que pode explicar o maior deslocamento vertical deste em relação ao PROT 2, para o qual este controle foi executado adequadamente conforme especificações da ALUSUD. 


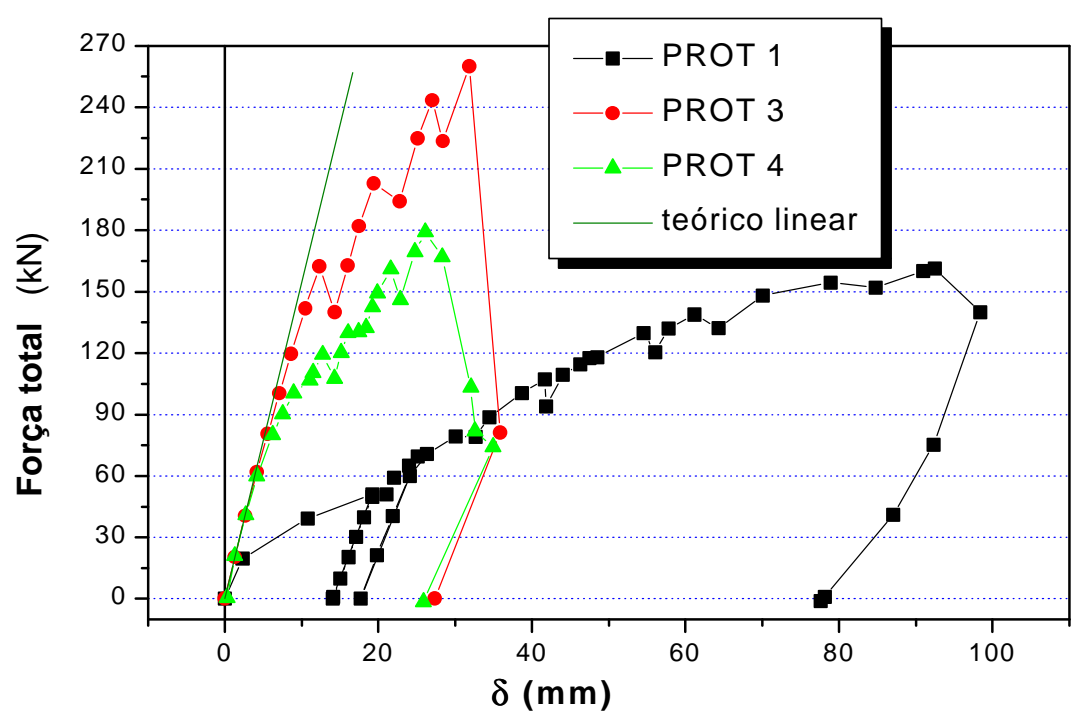

FIGURA 5.30 - Deslocamento vertical do nó central (PROT 1 x PROT 3 x PROT 4)

$\mathrm{Na}$ a figura 5.30 pode-se notar a maior rigidez do PROT 3 (constituído por nós de aço), mantendo um comportamento linear até metade do carregamento máximo, rigidez pouco menor pode ser vista no PROT 4 com configuração mista de conexão. Já para o PROT 1 observa-se um comportamento fortemente não linear, mesmo para níveis de carregamento inferiores ao carregamento de serviço.

A tabela 5.9 apresenta os valores teóricos e experimentais dos deslocamento relativos ao carregamento de serviço, comparados com os obtidos na análise teórica linear, aqui adotada como referência por ser usual em projetos, onde pode-se notar a significativa perda de rigidez apresentada pelos protótipos constituídos por nós típicos (PROT 1 e PROT 2) em relação aos protótipos constituídos por nós de aço e sistema misto (PROT 3 e PROT 4). A relação entre o deslocamento experimental e teórico, considerando o carregamento de serviço, foi da ordem de 1,4 para os primeiros e 3,5 para os últimos. 
TABELA 5.9- Deslocamentos de serviço dos protótipos

\begin{tabular}{|c|c|c|c|c|}
\cline { 2 - 5 } \multicolumn{1}{c|}{} & Força total $(\mathrm{kN})$ & \multicolumn{3}{c|}{ Deslocamento (mm) } \\
\hline Protótipo & $\begin{array}{c}\text { estimativa do valor } \\
\text { de serviço* }\end{array}$ & teórico & experimental & exp./teórico \\
\hline PROT 1 & 105 & 6,8 & 24,0 & 3,5 \\
\hline PROT 2 & 98,5 & 6,9 & 24,4 & 3,5 \\
\hline PROT 3 & 105 & 6,8 & 7,9 & 1,2 \\
\hline PROT 4 & 105 & 6,8 & 11,1 & 1,6 \\
\hline
\end{tabular}

* Admitindo com carregamento de serviço na estrutura aquele correspondente a metade da capacidade nominal da barra mais solicitada.

\subsubsection{3 - Deformações}

Para monitorar as deformações ocorridas na estrutura, foram posicionados extensômetros elétricos de resistência nas seções transversais centrais das barras mais solicitadas à compressão e também nas extremidades de algumas barras( ver item 3.4.1).

A distribuição destes extensômetros nas barras, posicionados em faces opostas para cada seção, teve como intuito acompanhar a evolução das flexões nestas seções, quando ocorressem.

As figuras 5.31 e 5.32 demonstram este comportamento com relação as deformações da seção transversal central da diagonal de apoio e banzo superior do vértice $A$ do protótipo PROT 1, respectivamente.

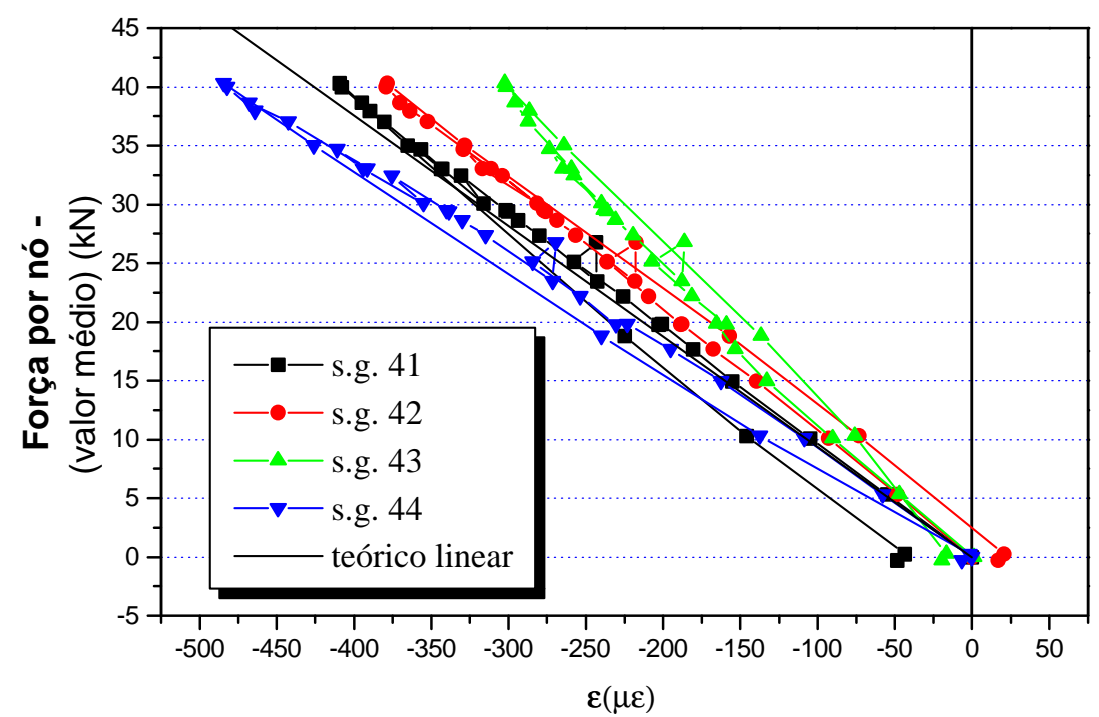

FIGURA 5.31 - Deformações da diagonal de apoio do vértice A (PROT 1). 


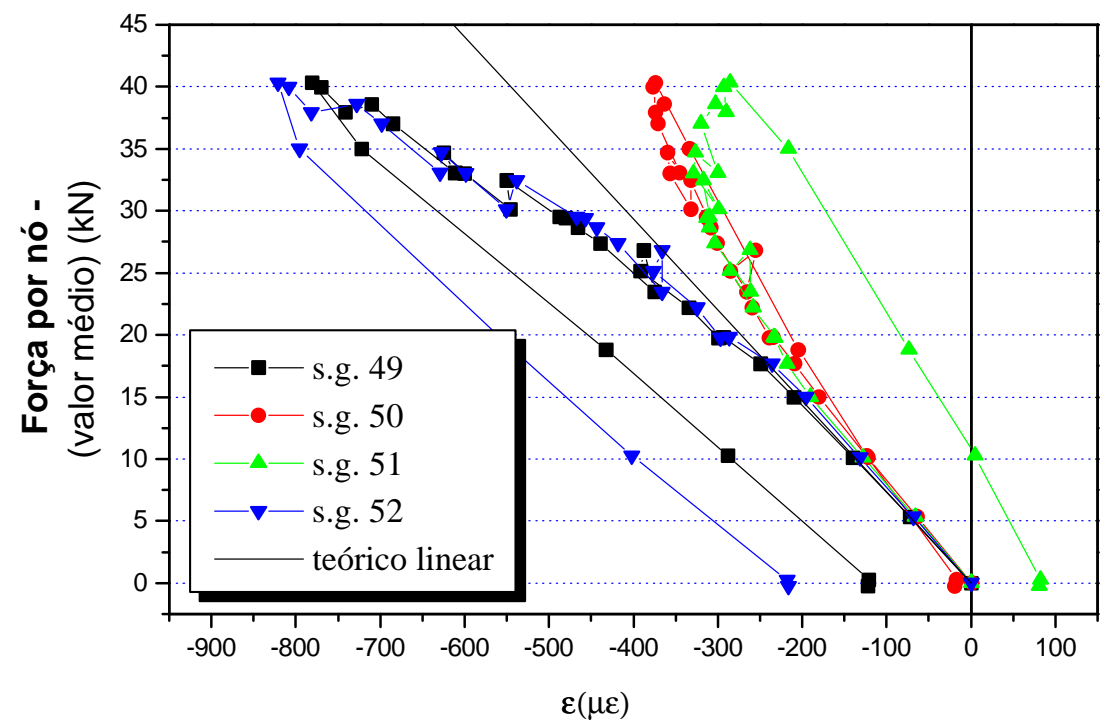

FIGURA 5.32 - Deformações de uma barra do banzo superior junto ao vértice A (PROT 1).

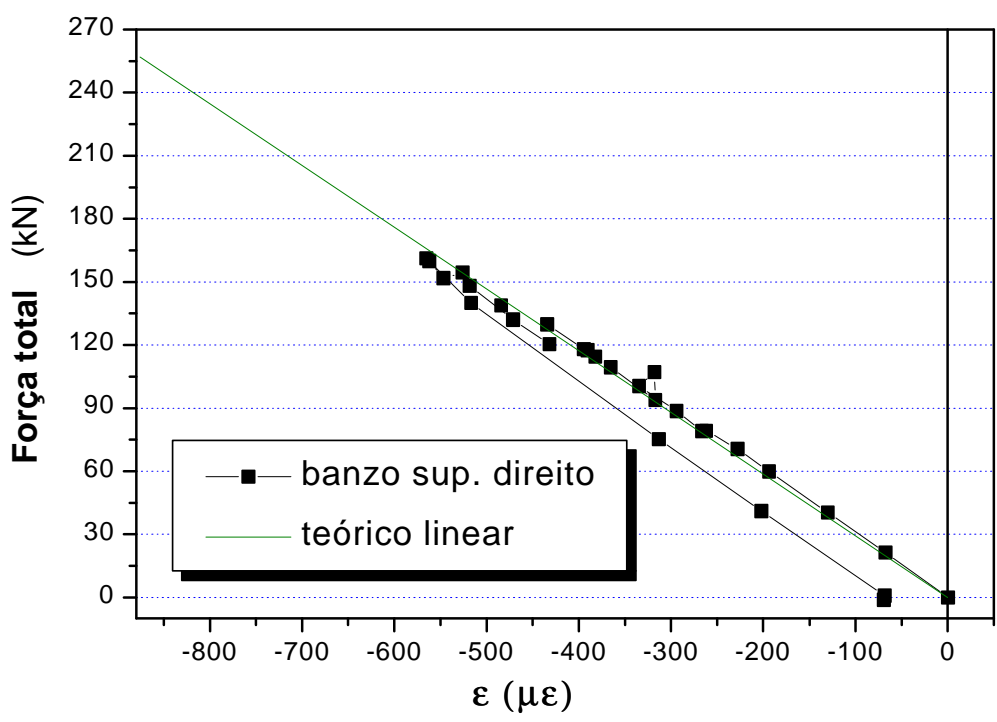

FIGURA 5.33- Deformação média de uma barra do banzo superior junto ao vértice $A$ (PROT 1)

Para as outras barras instrumentadas em sua seção transversal central o comportamento foi análogo ao apresentado anteriormente, com exceção das barras que sofreram flambagem. Como pode-se observar na figura 5.33, onde é apresentada a deformação média do banzo superior direito do vértice $A$, o comportamento desta barra no decorrer das etapas de carregamento foi linear, apresentando após o descarregamento uma 
deformação residual relativamente baixa, caracterizando um comportamento elástico.

Para as figuras 5.34 a 5.37 são apresentados os valores médios de deformação para a seção central das barras instrumentadas posicionadas nas regiões onde foram observadas as falhas localizadas, ou seja, vértice $D$ para os protótipos PROT 1, 3 e 4, e vértice B para o protótipo PROT 2, comparadas com o respectivo valor teórico linear.

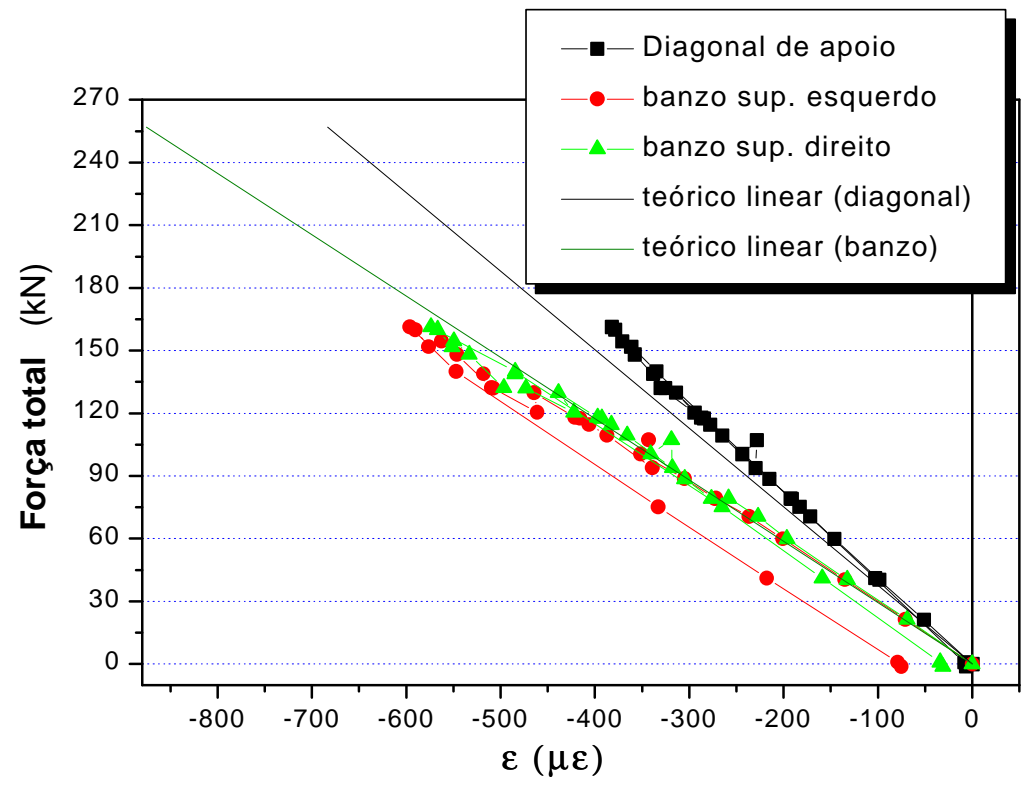

FIGURA 5.34 - Deformações médias das barras comprimidas junto ao vértice $D(P R O T 1)$ 


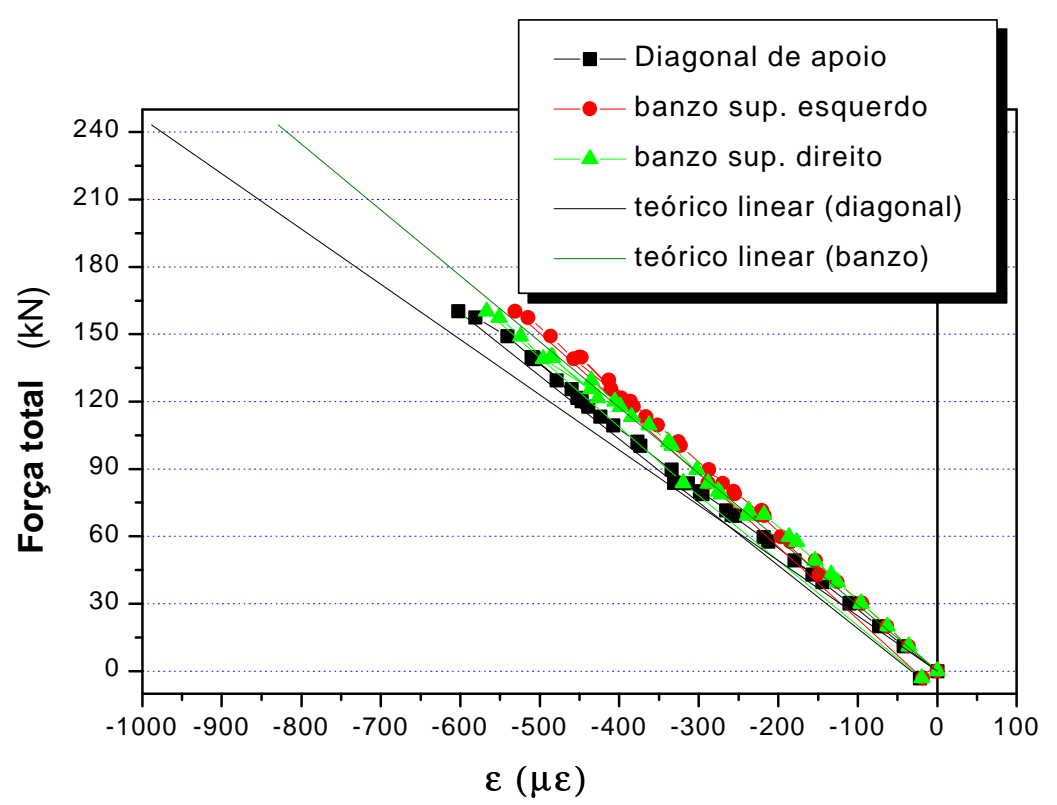

FIGURA 5.35 - Deformações médias das barras comprimidas junto ao vértice $B$ (PROT 2)

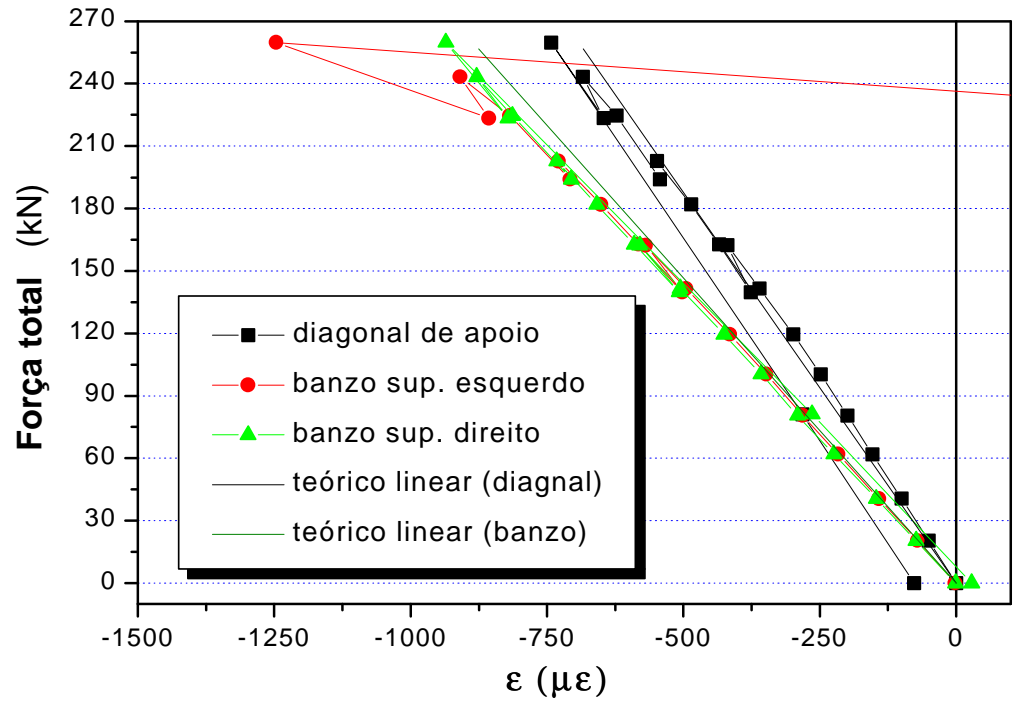

FIGURA 5.36 - Deformações médias das barras comprimidas junto ao vértice $D$ (PROT 3) 


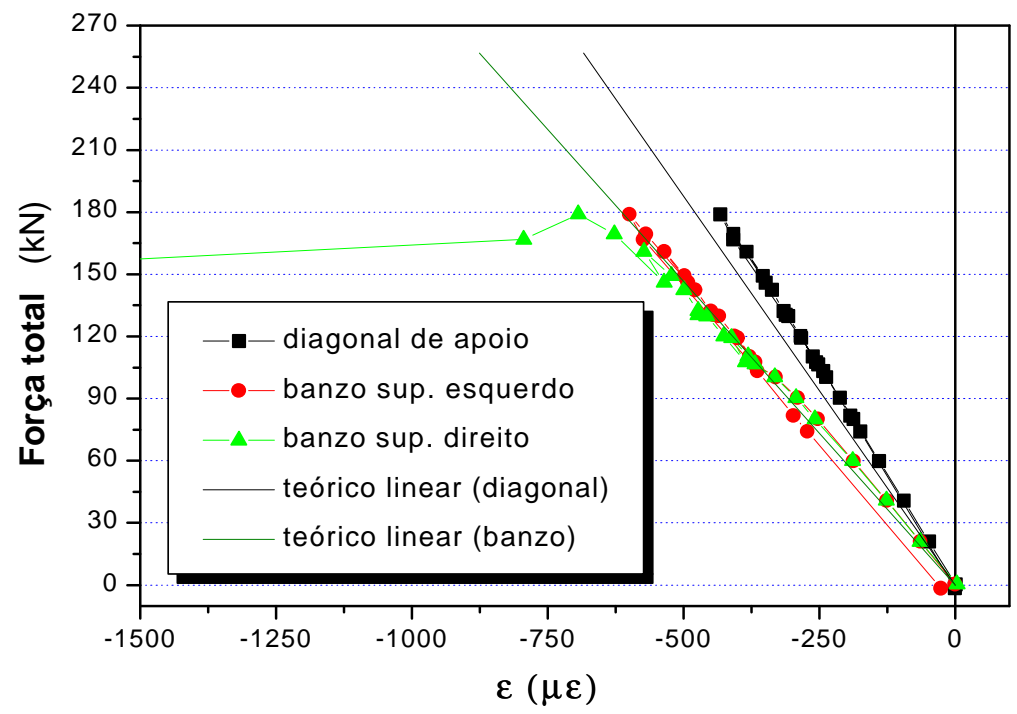

FIGURA 5.37 - Deformações médias das barras comprimidas junto ao vértice $D$ (PROT 4)

No caso das deformações ocorridas nas barras comprimidas posicionadas nos vértices onde foram observadas as falhas localizadas, o comportamento destas pode ser admitido linear conforme pode ser observado nas figuras 5.34 e 5.35. Esta afirmação é válida também para as figuras 5.36 e 5.37 até etapas que antecedem a flambagem das barras.

Quanto às extremidades estampadas das barras, estas apresentam uma forte não uniformidade de tensões, o que tem sido analisado por VENDRAME (1999), o qual apresenta a figura 5.38 com as curvas de isotensões para as extremidades da diagonal de apoio e banzo superior componentes do nó típico, onde pode-se observar regiões tracionadas em barras solicitadas à compressão, o que é proveniente do efeito de restauração da seção transversal original do tubo. 


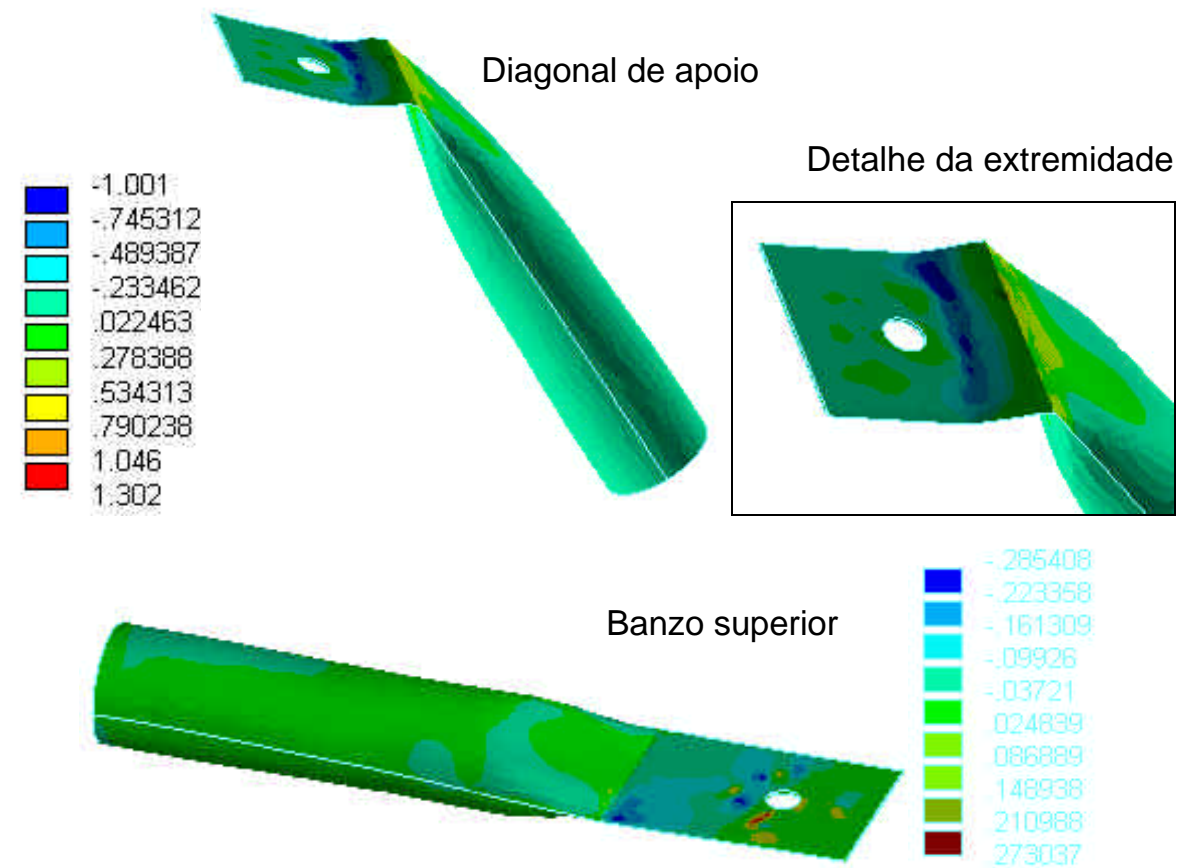

FIGURA 5.38 - Distribuição de tensões nas extremidades estampadas das barras componentes do nó típico. VENDRAME (1999)

Este efeito de restauração da seção transversal original é comprovada pela instrumentação posicionada na região das extremidades amassadas do vértice A para os protótipos PROT 2, 3 e 4, a qual indica tração em barras comprimidas. Este comportamento é mostrado nas figuras 5.38 a 5.41 onde estão representadas as médias das deformações da seção central das barras e as das suas extremidades.

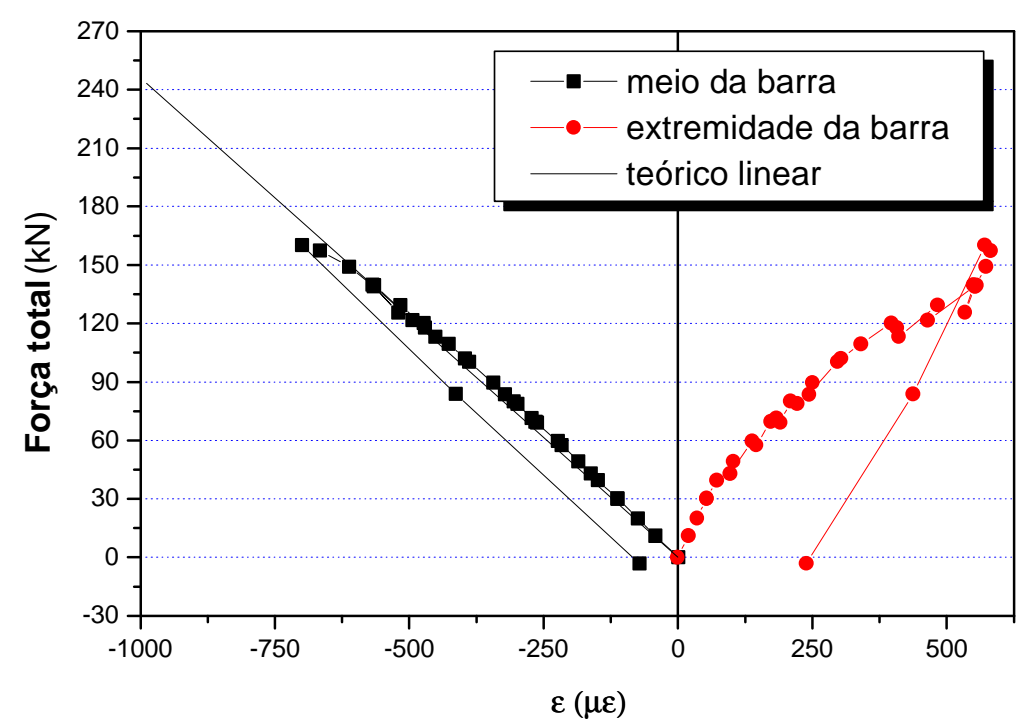

FIGURA 5.39 - Deformações médias da diagonal de apoio do vértice A (PROT 2) 


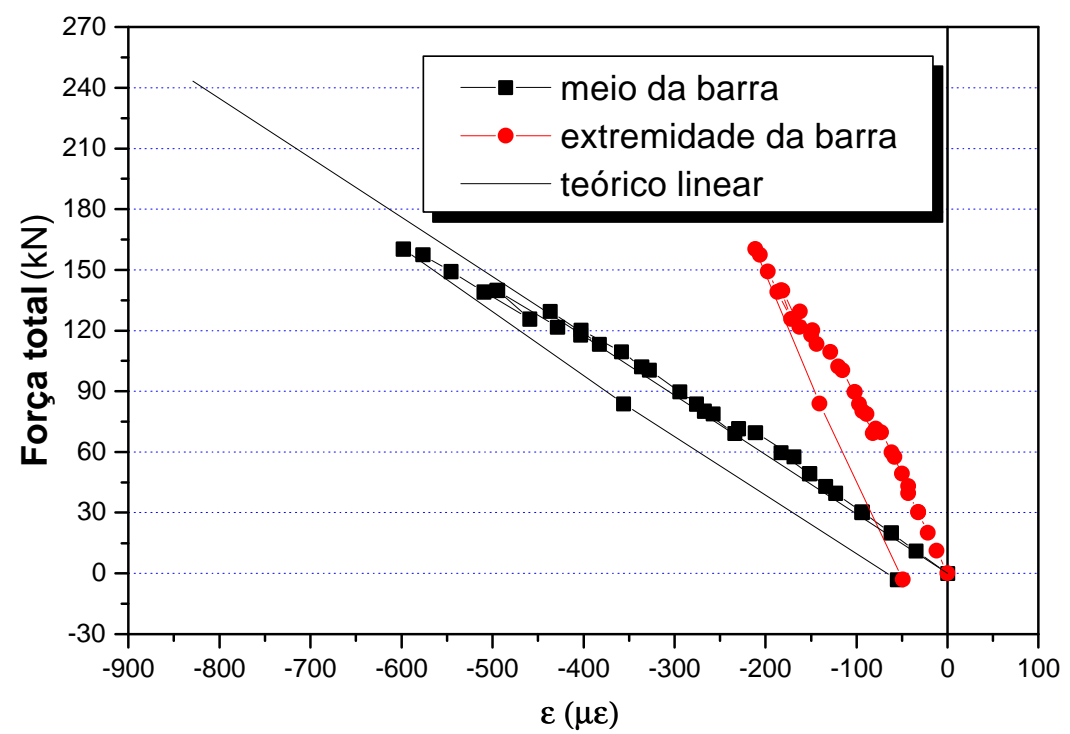

FIGURA 5.40 - Deformações médias da barra do banzo superior junto ao vértice $A$ (PROT 2)

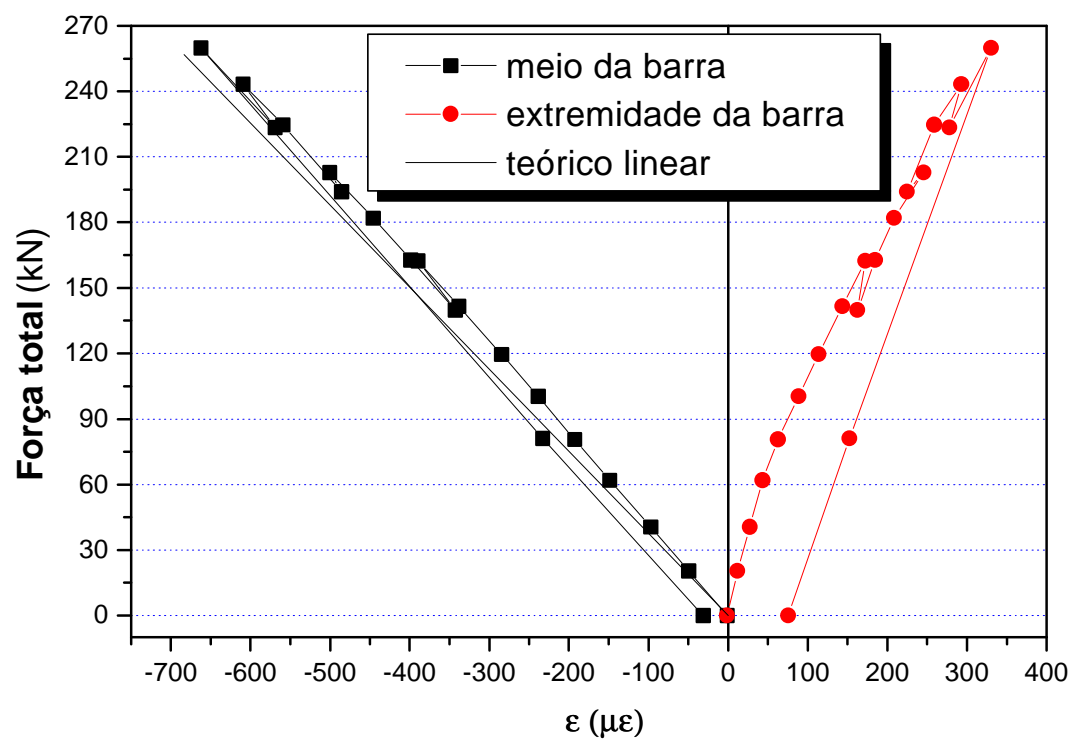

FIGURA 5.41 - Deformações médias da diagonal de apoio do vértice A (PROT 3) 


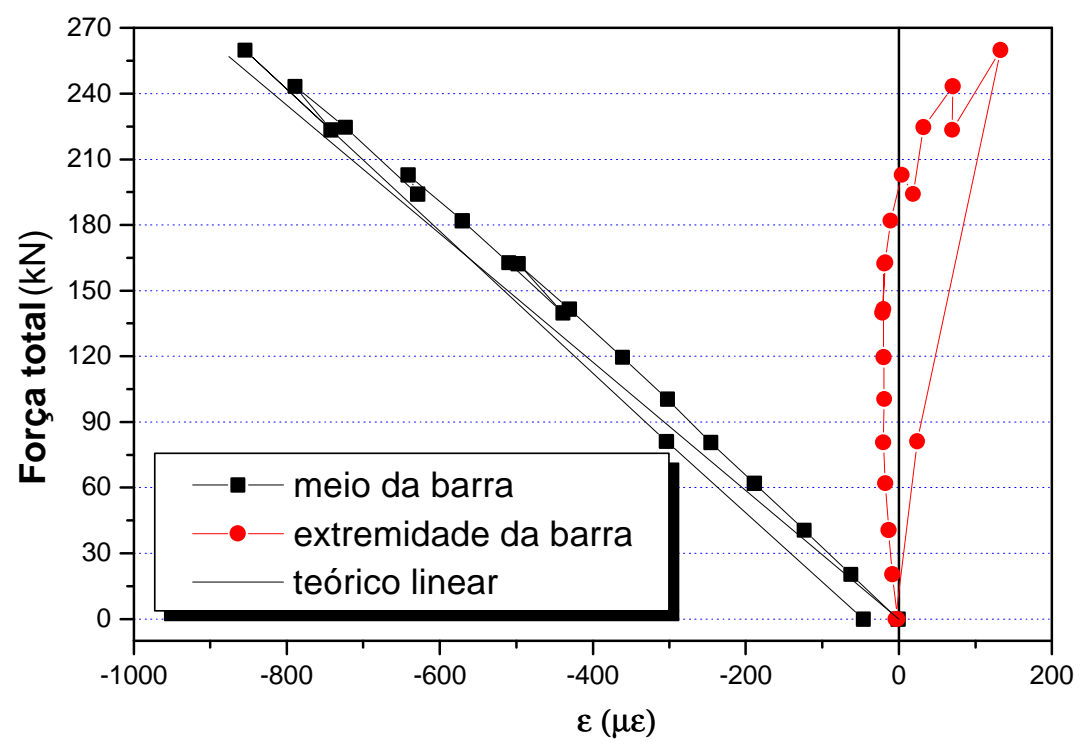

FIGURA 5.42 - Deformações médias da barra do banzo superior junto ao vértice $A$ (PROT 3)

Para visualizar melhor este comportamento, as extremidades da diagonal de apoio e banzo superior direito do vértice A do protótipo PROT 4 foram instrumentadas com quatro extensômetros elétricos de resistência, dispostos em faces opostas e em duas seções, com a primeira distante $150 \mathrm{~mm}$ da extremidade, como aplicado para os protótipos PROT 2 e PROT 3, e a segunda seção com 50mm além desta (figura 5.42). As figuras 5.43 e 5.44 apresentam as deformações para estas seções relativas a diagonal de apoio.

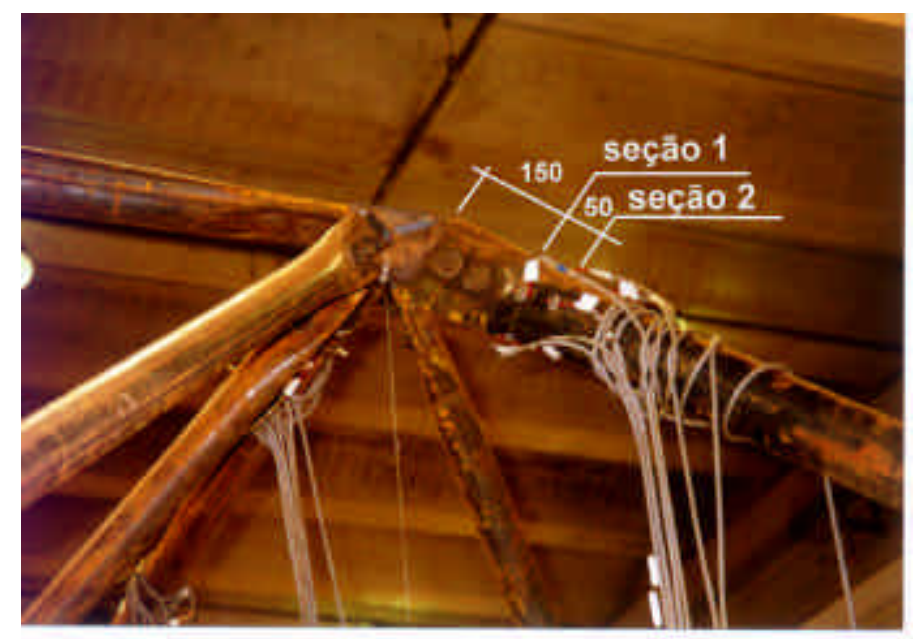

FIGURA 5.43 - Posicionamento da instrumentação nas extremidades das barras do vértice $A$ do PROT 4 

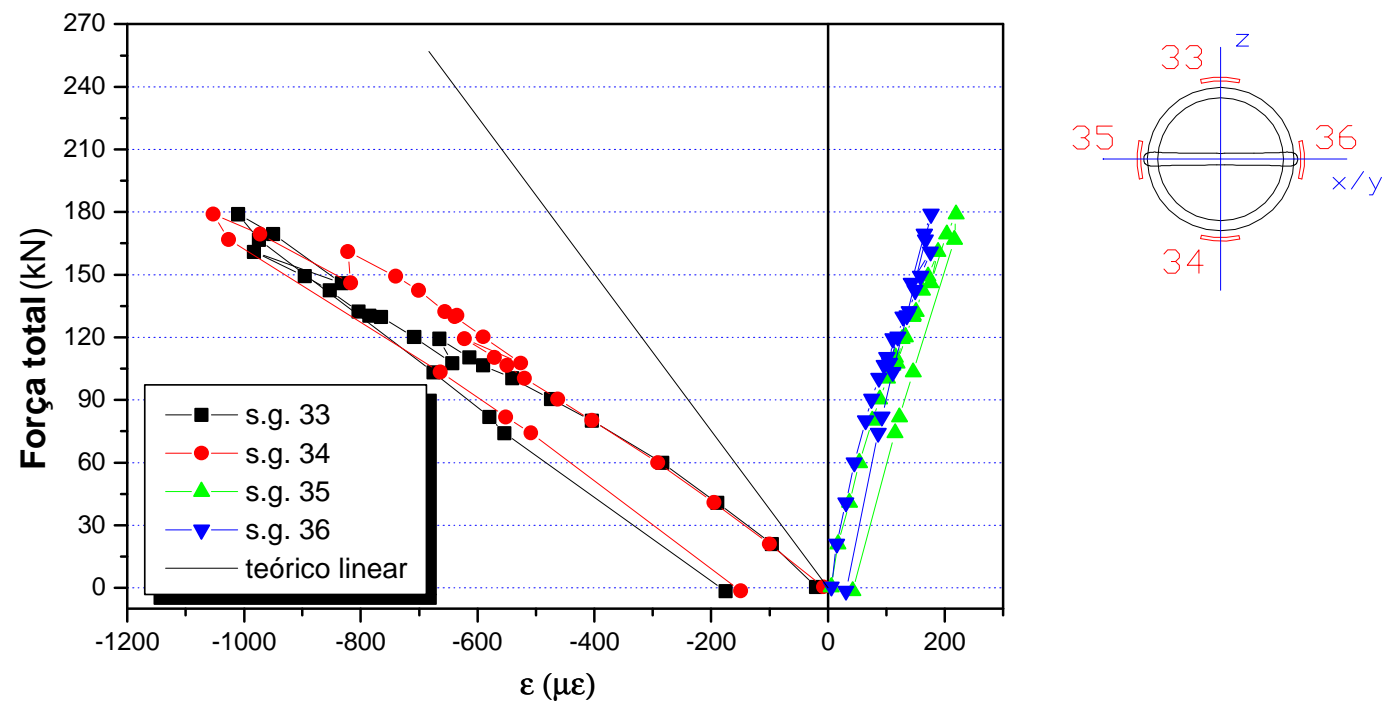

FIGURA 5.44- Deformações da extremidade da diagonal de apoio do vértice A (seção 1 - PROT 4)

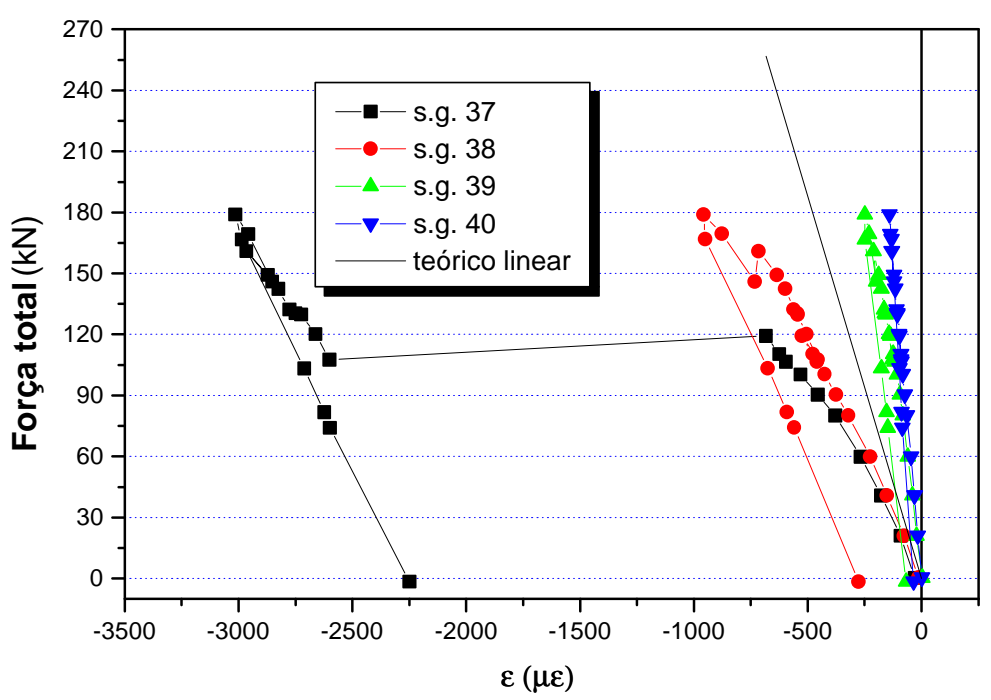

FIGURA 5.45 - Deformações da extremidade da diagonal de apoio do vértice $A$ (seção 2 - PROT 4)

Conforme já esperado, a figura 5.44 indica uma maior uniformidade de tensões da seção 2 em relação a seção 1. As figuras 5.45 e 5.46 apresentam a comparação das médias das deformações desta segunda seção com as da seção transversal central para as barras da diagonal de apoio e do banzo superior direito junto ao vértice A do PROT 4. 


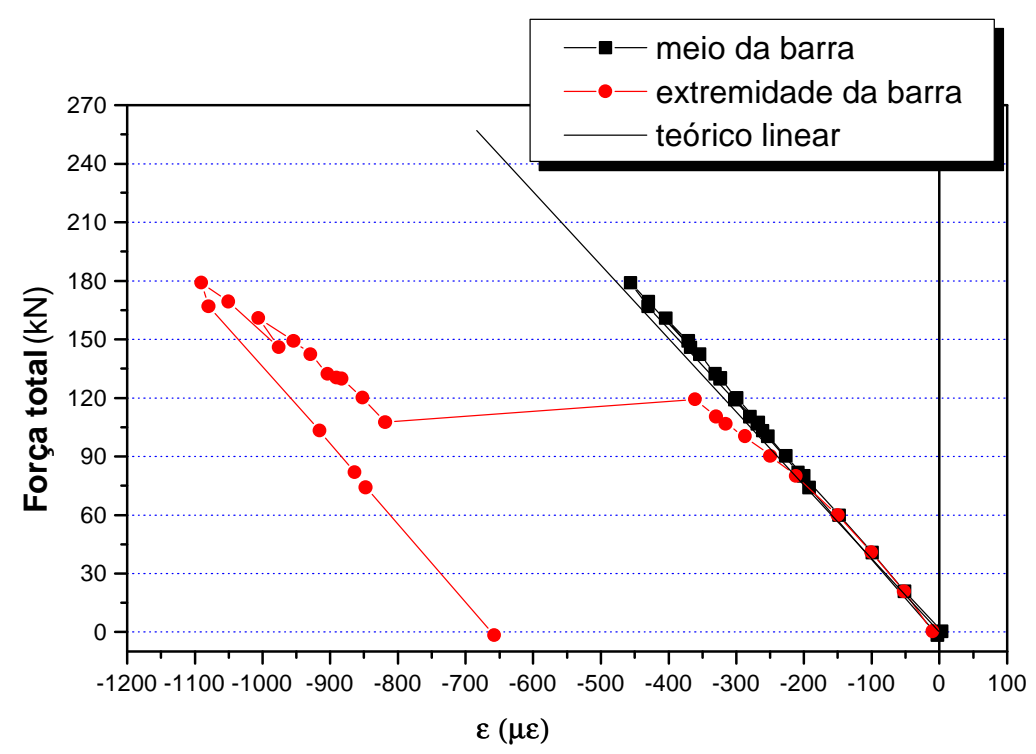

FIGURA 5.46 - Deformações médias da diagonal de apoio do vértice A

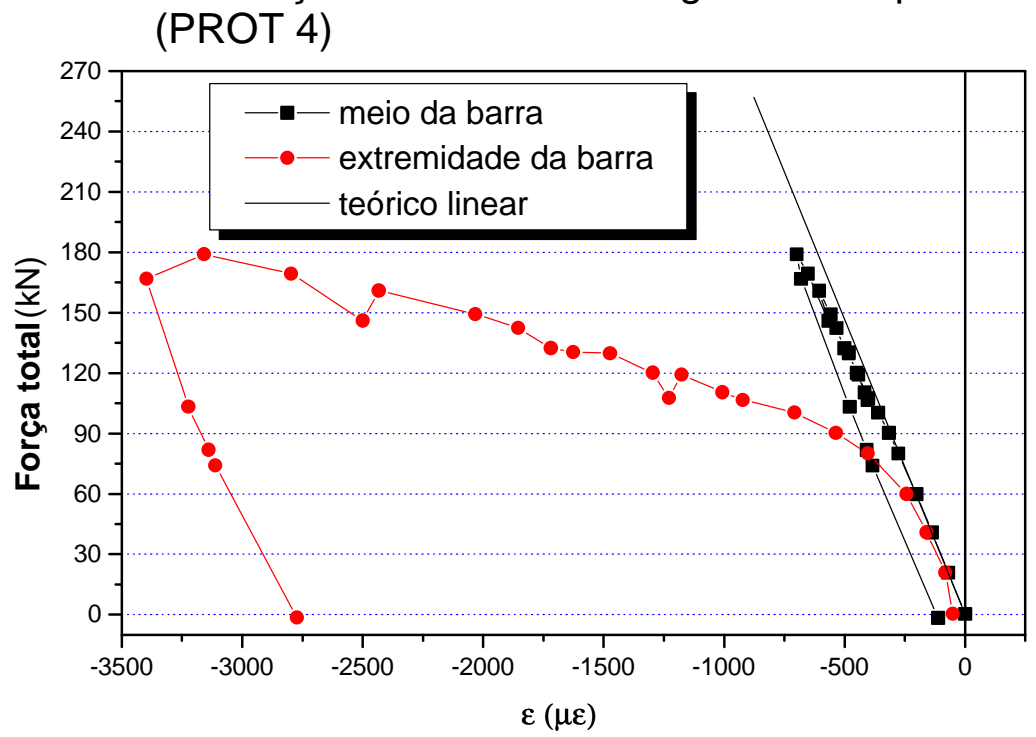

FIGURA 5.47 - Deformações médias do banzo superior direito do vértice $A$ (PROT 4)

Paras figuras 5.45 e 5.46 verifica-se que as extremidades das barras comprimidas junto ao vértice A (nós de aço) apresentam plastificação, enquanto as suas seções centrais permanecem em regime elástico linear. Os protótipos constituídos por nós típicos (PROT 1 e PROT 2) receberam uma instrumentação insuficiente nas extremidades das barras, não permitindo extrair conclusões consistentes. Entretanto, tendo em vista que a falha destes protótipos ocorreu exatamente nesta região, é provável que a plastificação seja ainda mais significativa e prematura nestes casos. 


\section{CONCLUSÕES}

As treliças metálicas espaciais têm sido cada vez mais empregadas nas coberturas de grandes áreas, apresentando características que fazem desta opção uma solução viável economicamente e esteticamente satisfatória. São leves, geometricamente harmônicas, apresentam grande uniformidade de barras e nós, e necessitam de um número reduzido de apoios nas duas direções (comportamento global de placa).

Construtivamente existem no mercado vários sistemas, em aço e alumínio. Em geral empregam-se barras de seção tubular circular, conectadas entre si a dispositivos denominados "nós". Do ponto de vista econômico, os nós representam uma parcela significativa do custo destas estruturas, podendo inviabilizar o emprego de um determinado sistema. Várias empresas e pesquisadores de vários países vêm procurando desenvolver novos sistemas que sejam bem sucedidos em relação a custo e eficiência estrutural.

No Brasil são adotados sistemas simples, abordados neste trabalho, onde empregam-se barras de seção tubular circular com extremidades estampadas e conectadas entre si por um único parafuso (denominado usualmente por "nó típico"), ou conectadas a dispositivos constituídos por aletas de aço soldadas, onde cada aleta conecta uma barra (denominado "nó de aço"). O primeiro sistema apresenta excentricidades significativas, enquanto o segundo, teoricamente, não apresenta excentricidades. 
$\mathrm{Na}$ prática de projetos, têm-se observado que o modelo teórico empregado é o de treliça ideal, ou seja, barras sem variação de inércia e nós perfeitamente articulados sem excentricidades, procedendo-se à análise linear. Em seguida, o dimensionamento é feito admitindo-se também as barras sem variação de inércia e perfeitamente articuladas nas extremidades. Entretanto, vários pesquisadores chamam a atenção para a necessidade de se analisar tais estruturas considerando seu comportamento não linear, principalmente a não linearidade geométrica.

Ensaios em barras isoladas, realizados no Laboratório de Estruturas da EESC-USP, mostraram que a variação de inércia nas extremidades pode conduzir à uma redução significativa da resistência à compressão da barra, dependendo da sua esbeltez e do tipo de estampagem.

Além da variação de inércia, outros fatores podem influenciar de maneira significativa a resistência das treliças espaciais, como por exemplo: imperfeições geométricas iniciais, excentricidades nos nós, flexibilidade dos sistemas de conexão, e para o caso dos nós típicos, o deslizamento das barras proveniente da perda do atrito nas conexões.

A análise teórica não linear desenvolvida neste trabalho procurou representar de maneira simples e viável de ser empregada na prática de projetos, o detalhe das extremidades das barras e suas conexões. Como foram analisados pequenos protótipos, a não linearidade não foi significativa, pois as deformações e os deslocamentos teóricos foram relativamente pequenos. Entretanto, é extremamente difícil considerar numa análise teórica fatores relevantes como os deslizamentos e a abertura dos nós típicos e as imperfeições geométricas iniciais, que alteram de maneira significativa a resposta estrutural. Análises preliminares desenvolvidas para estruturas maiores refletem a necessidade de uma análise não linear para melhor avaliar a resposta estrutural.

A análise experimental foi realizada em quatro protótipos com elevada relação altura/vão (1:5), cujo objetivo principal foi comparar o desempenho estrutural de dois sistemas usualmente empregados no Brasil: nó típico e nó de aço. 
Como já esperado, os protótipos constituídos por nós típicos apresentaram rigidez e resistência muito inferiores aos constituídos somente por nós de aço ou pelo sistema misto (nós de aço associados a nós típicos em regiões de pequenos esforços). No decorrer dos ensaios dos protótipos com nós típicos foram notórias as diversas fases de acomodação da estrutura, indicando perda de atrito, e induzindo a deslocamentos excessivos e à falha do próprio nó por rotação e abertura. Por outro lado, os protótipos com nós de aço apresentaram como modo de falha a flambagem de barras comprimidas, evidenciando a eficiência da nó.

Comparando os deslocamentos teóricos provenientes da análise linear com os experimentais, tabela 6.1, pode-se concluir que, em serviço, o modelo teórico de treliça ideal foi satisfatório para os protótipos com nós de aço, mesmo havendo variação de inércia nas extremidades das barras. Para os protótipos com nós típicos, tal modelo se mostrou inadequado desde as primeiras etapas de carregamento.

TABELA 6.1- Deslocamentos de serviço dos protótipos

\begin{tabular}{|c|c|c|c|c|}
\hline 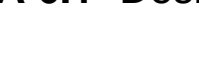 & Força total $(\mathrm{kN})$ & \multicolumn{3}{|c|}{ Deslocamento (mm) } \\
\hline Protótipo & $\begin{array}{l}\text { estimativa do valor } \\
\text { de serviço* }\end{array}$ & teórico & experimental & exp./teórico \\
\hline PROT 1 & 105 & 6,8 & 24,0 & 3,5 \\
\hline PROT 2 & 98,5 & 6,9 & 24,4 & 3,5 \\
\hline PROT 3 & 105 & 6,8 & 7,9 & 1,2 \\
\hline PROT 4 & 105 & 6,8 & 11,1 & 1,6 \\
\hline
\end{tabular}

Da tabela 6.2 pode-se observar que o protótipo PROT 3 (nós de aço) foi o único que apresentou valores de força última experimental superior à teórica. 
TABELA 6.2 - Forças últimas teóricas e experimentais

\begin{tabular}{|c|c|c|c|c|c|c|c|}
\hline \multirow{2}{*}{ (1) } & \multicolumn{7}{|c|}{ Forças totais últimas } \\
\hline & $\begin{array}{c}(2) \\
\text { EUROCODE } \\
(1992) \\
\text { "curva c" }\end{array}$ & $\begin{array}{c}(3) \\
\text { AISI/LRFD } \\
(1991)\end{array}$ & $\begin{array}{c}(4) \\
\text { NBR 8800 } \\
(1986) \\
\text { "curva a" }\end{array}$ & (5) & (6) & (7) & (8) \\
\hline Protótipo & $\begin{array}{c}\mathrm{F}_{\mathrm{u}}(\mathrm{kN}) \\
\text { teórico }\end{array}$ & $\begin{array}{c}\mathrm{F}_{\mathrm{u}}(\mathrm{kN}) \\
\text { teórico }\end{array}$ & $\begin{array}{c}\mathrm{F}_{\mathrm{u}}(\mathrm{kN}) \\
\text { teórico }\end{array}$ & $\begin{array}{l}\mathrm{F}_{\mathrm{u}}(\mathrm{kN}) \\
\text { experim. }\end{array}$ & $(5) /(2)$ & $(5) /(3)$ & $(5) /(4)$ \\
\hline PROT 1 & 210,2 & 310,8 & 259,7 & 161,3 & 0,77 & 0,52 & 0,62 \\
\hline PROT 2 & 197,0 & 289,5 & 245,9 & 160,2 & 0,81 & 0,55 & 0,65 \\
\hline PROT 3 & 210,2 & 310,8 & 259,7 & 259,9 & 1,24 & 0,84 & 1,0 \\
\hline PROT4 & 210,2 & 310,8 & 259,7 & 179,0 & 0,85 & 0,58 & 0,69 \\
\hline
\end{tabular}

Quanto a análise experimental desenvolvida neste trabalho, é importante registrar que foram ensaiados apenas quatro protótipos com elevada relação altura/vão (1:5), tratando-se de casos com grande influência da força cortante, cujo objetivo principal foi comparar o desempenho estrutural de sistemas usualmente empregados no país. Para obter conclusões mais relevantes a respeito do comportamento estrutural é necessário analisar estruturas com menores relações altura/vão, onde a influência do momento fletor é preponderante sobre a influência da força cortante.

O nó típico, embora com custo de fabricação e montagem relativamente baixo, constitui-se num detalhe limitado do ponto de vista estrutural, não explorando a capacidade das barras e induzindo à uma baixa rigidez da estrutura, tomando-se como parâmetro de comparação a treliça ideal. A falha deste nó é caracterizada por rotação excessiva, abertura e a conseqüente plastificação da extremidade de barras. Desta forma, tais estruturas devem ser empregadas com restrições. O nó de aço apresentou maior eficiência estrutural, conduzindo à uma maior rigidez e resistência da estrutura. 
Conforme esperado, o protótipo PROT 4 constituído pelo sistema misto apresentou valores de rigidez e resistência intermediários aos outros dois sistemas analisados. Este pode representar uma solução interessante em alguns casos, embora necessite de mais estudos tendo em vista a limitação estrutural observada pelo nó típico. 


\section{BIBLIOGRAFIA}

AGERSKOV, H. (1986). Optimum geometry design of double-layer space structures. Journal of the Structural Engineering, v.112, n. 6, p.14541463, June.

ANSYS (1995). Structural nonlinearities: user's guide for revision 5.1. Houston. V.1.

AMERICAN IRON AND STEEL INSTITUTE (1986). Cold-formed steel design manual. Washington, DC.

AMERICAN IRON AND STEEL INSTITUTE (1991). LRFD - Load and resistance factor design specification for cold-formed steel manual. Washington, DC.

AMERICAN SOCIETY FOR TESTING AND MATERIALS (1992). A-370 - Standard test methods and definitions for mechanical testing of steel products. Philadelphia.

AMERICAN SOCIETY FOR TESTING AND MATERIALS (1994). E 8M -

Standard test methods for tension testing of metallic materials [metric].

Philadelphia.

ASSOCIAÇÃO BRASILEIRA DE NORMAS TÉCNICAS (1986). NBR-8800 Projeto e execução de estruturas de aço de edifícios: método dos estados limites. Rio de Janeiro.

ASSOCIAÇÃO BRASILEIRA DE NORMAS TÉCNICAS (1967). NB-143 Cálculo de estruturas de aço, constituídas por perfis leves. Rio de Janeiro.

BATISTA, E. M.; BATISTA, C. R. (1997). Determinação experimental dos mecanismos de colapso de uma junta típica de estruturas metálicas reticuladas espaciais. In: JORNADAS SUL-AMERICANAS DE ENGENHARIA ESTRUTURAL, 28., São Carlos, 1-5 set. 1997. Estruturas e fundações. São Carlos, EESC-USP / ASEE, v. 2, p. 665674.

BUTTERWORTH, J.W. (1981). Analysis of double-layer grids. In: MAKOWSKI, Z.S., ed. Analysis, design and construction of double-layer grids. London, Applied Science Publishers. p.57-91. 
CARAMELLI, S. (1993). Attualitá e prospettive della costruzione in acciaio italiana in europa e nel mondo. Costruzione Metalliche, v.45, n. 6, p. 327-376, nov.-dez.

CARVALHO, E. M. L.; PFEIL, M. S.; BATISTA, R. C. (1997). Habilitação via reforços da estrutura metálica de uma grande calota esférica de cobertura. In: JORNADAS SUL-AMERICANAS DE ENGENHARIA ESTRUTURAL, 28., São Carlos, 1-5 set. 1997. Estruturas e fundações. São Carlos, EESC-USP / ASEE, v. 3, p. 1127-1136.

CHAPMAN, J.C.; BUHAGIER, D.; DOWLING, P.J. (1993). Developments in cold-formed space structures. In: INTERNATIONAL CONFERENCE ON SPACE STRUCTURES, 4., Guildford, U.K., 1993. Proceedings. London, Thomas Telford. v.2, p.1604-1612.

CODD, E.T.; ARCH, B.; FRAIA; AIDA. (1984). Low technology space frames. In: INTERNATIONAL CONFERENCE ON SPACE STRUCTURES, 3., Guildford, U.K., 1984. Proceedings. London/New York, Elsevier Applied Science. p.955-960.

DADDI, I. (1969). Strutture reticolare spaziali per coperture piane. Costruzioni metalliche, n.6, p.502-509.

DE MARTINO, A. (1992). Relazione generale: progettazione, lavorazione e montaggio. Costruzione Metalliche, v.44, n. 1, p. 14-54, gen.-feb.

EBERLEIN, H. (1981). The use of the MERO industrialised system of construction in double-layer grids. In: MAKOWSKI, Z.S., ed. Analysis, design and construction of double-layer grids. London, Applied Science Publishers, p.355-380.

EL-SHEIKH, A.I.; McCONNEL, R.E. (1993). Experimental study of behavior of composite space trusses. Journal of the Structural Engineering, v.119, n. 3, p.747-766, March. 
EL-SHEIKH, A.I.; EL-BAKRY, H. (1996). Experimental study of behavior of new space truss system. Journal of the Structural Engineering, v.122, n. 8, p.845-853, August.

EUROPEAN COMMITTEE FOR STANDARDIZATION (CEN) (1992). Eurocode 3: Design of steel structures. Part 1.1: General rules and rules for buildings. Brussels.

FATHELBAB, F. (1993). Tangent stiffness matrix for space frame members with both member and joint imperfections. In: INTERNATIONAL CONFERENCE ON SPACE STRUCTURES, 4. Guildford, U.K., 1993. Proceedings. London, Thomas Telford. v.2, p.1323-1333.

GONÇALVES, R.M.; FAKURY, R.H.; MAGALHÃES, J.R.M. (1996). Performance of tubular steel sections subjected to compression: theoretical-experimental analysis. In: INTERNATIONAL COLLOQUIUM STRUCTURAL STABILITY, 5., Rio de Janeiro, 1996. Stability problems in designing, construction and rehabilitation of metal structures: Proceedings. Rio de Janeiro, COPPE/UFRJ. p.439-449

HANAOR, A.; SCHMIDT, L.C. (1980). Space truss studies with force limiting devices. Journal of the Structural Division, v.106, n. ST11, p.2313-2329, November.

HANAOR, A.; MARSH, C.; PARKE, G.A.R. (1989). Modification of behavior of double-layer grids: overview. Journal of the Structural Engineering, v.115, n. 5, p.1021-1037, May.

HILL, C.; BLANDFORD, G.; WANG S. (1989). Postbuckling analysis of steel space trusses. Journal of the Structural Engineering, v.115, n. 4, p.900919

HOLLAWAY, L.; KOLOSOWSKI, J. (1981) Experimental investigation of double-layer grids. In: MAKOWSKI, Z.S., ed. Analysis, design and construction of double-layer grids. London, Applied Science Publishers. p.269-287.

MADI, U.R.; EL-TAYEM, A. (1994). Collapse patterns for double-layer grids. In: INTERNATIONAL CONFERENCE ON SPACE STRUCTURES, 4. Guildford, U.K., 1993. Proceedings. London, Thomas Telford. v.1, p.631639 
MAGALHÃES, J.R.M.; MALITE,M; SALLES, E.R.P. (1997). Estruturas metálicas espaciais no Brasil. In: JORNADAS SUL-AMERICANAS DE ENGENHARIA ESTRUTURAL, 28., São Carlos, 1-5 set. 1997. Estruturas e fundações. São Carlos, EESC-USP / ASEE, v. 2, p. 885894.

MAGALHÃES, J.R.M.; MALITE, M. (1996). Alguns aspectos relativos ao projeto e à construção de estruturas metálicas espaciais. In: CONGRESSO DE ENGENHARIA CIVIL DA UFJF, 2.,Juiz de Fora, 1996. Anais. Juiz de Fora, UFJF. p.282-291.

MAGALHÃES, J.R.M. (1996). Sobre o projeto e a construção de estruturas metálicas espaciais. São Carlos. Dissertação (Mestrado) - Escola de Engenharia de São Carlos, Universidade de São Paulo.

MAGALHÃES, J.R.M.; MALITE, M; SÁLES, J.J.; GONÇALVES, R.M. (1996). Barras comprimidas com variações de inércia ao longo do comprimento. Ciência e Tecnologia, Revista Construção Metálica, ABCEM, n.27, p.1417

MAIOLA, C.H.; SÁLES, J.J.; MALITE, M.(1998). Treliças metálicas espaciais: análise teórica e experimental de protótipos constituídos por barras tubulares com extremidades estampadas. In: CONGRESSO DE ENGENHARIA CIVIL DA UFJF, 3., Juiz de Fora, agosto 1998. p.11-20

MAKOWSKI, Z.S. (1981a). Review of development of various types of double-layer grids. In: MAKOWSKI, Z.S., ed. Analysis, design and construction of double-layer grids. London, Applied Science Publishers. p.1-55.

MAKOWSKI, Z.S. (1981b). Aproximate stress analysis of grid frameworks obteined by slab analogies. In: MAKOWSKI, Z.S., ed. Analysis, design and construction of double-layer grids. London, Applied Science Publishers. p.185-244.

MAKOWSKI, Z. S. (1968). Estructuras espaciales de acero. Barcelona, Gustavo Gili.

MALITE, M.; GONÇALVES, R. M.; TAKEYA, T.; MAGALHÃES, J. R. M.; MAIOLA, C. H. (1997). Barras de aço comprimidas de seção tubular com extremidades estampadas: análise teórica e experimental. In: 
JORNADAS SUL-AMERICANAS DE ENGENHARIA ESTRUTURAL, 28., São Carlos, 1-5 set. 1997. Estruturas e fundações. São Carlos, EESC-USP / ASEE, v. 1, p. 417-426.

MALITE, M.; GONÇALVES, R. M.; TAKEYA, T.; MAGALHÃES, J. R. M.; MAIOLA, C. H. (1997). Barras de aço comprimidas de seção tubular com extremidades estampadas: análise teórica e experimental. Engenharia \& Estrutura, v. 1, p. 24, jan./mar.

MALITE, M.; GONÇALVES, R.M.; SÁLES, J.J. (1997). Tubular section bars with flatened (stamped) ends subjected to compression - a theoretical and experimental analysis. In: SSRC ANNUAL TECHNICAL SESSION AND MEETING, Toronto - Canada, june 1997.

MALITE, M.; GONÇALVES, R. M; SÁLES. J.J.; MAGALHÃES, J.R.M.; SALLES, E.R.P. (1998). Space structures in brazil. In: WORLD CONFERENCE ON STEEL IN CONSTRUCTION, 2., San Sebastian, Spain, 11-13 May, 1998. Proceedings. Oxford, Elsevier Science, 1998. $14 p$.

MALLA, R.B.; SERRETTE, R.L. (1996). Double-layer grids: review of static and thermal analysis methods and special topics. Journal of the Structural Engineering, v.122, n.8, p.882-892, August.

MARSH, C.; FARD, M.R. (1984). Optimisation of space trusses using nonlinear behaviour of eccentric diagonals. In: INTERNATIONAL CONFERENCE ON SPACE STRUCTURES, 3., Guildford, U.K., 1984. Proceedings. London/New York, Elsevier Applied Science. p.669-671.

MARSH, C. (1986). Improving space truss performance by member removal. In: IASS SYMPOSIUM ON SHELLS, MEMBRANES AND SPACE FRAMES, Osaka. Proceedings, v.3, p.215-220.

MEZZINA, M.; PRETE, G. (1974). Indagne teorico-sperimentale sul comportamento statico di grigliati spaziali metallici. Costruzioni metalliche, n.3, p.168-180.

MURTHA-SMITH, E. (1988). Alternate path analysis of space trusses for progressive collapse. Journal of the Structural Engeneering, v.114, n. 9, p.1978-1999, September. 
MURTHA-SMITH, E.; LEARY, S.F. (1993). Space truss structural integrity, In: INTERNATIONAL CONFERENCE ON SPACE STRUCTURES, 4. Guildford, U.K., 1993. Proceedings. London, Thomas Telford. v.1, p.640648

MURTHA-SMITH, E.; HWANG, S.H.; CHOU, Y.H. (1993). Space truss testing. In: INTERNATIONAL CONFERENCE ON SPACE STRUCTURES, 4. Guildford, U.K., 1993. Proceedings. London, Thomas Telford. v.2, p.1831-1840.

MURTHA-SMITH, E. (1994). Compression-member models for space trusses: review. Journal of the Structural Engeneering, v.120, n. 8, p.2399-2407, August.

PARKE, G.A.R.; WALKER, H.B. (1984). A limit state design of double-layer grids. In: INTERNATIONAL CONFERENCE ON SPACE STRUCTURES, 3., Guildford, U.K., 1984. Proceedings. London/New York, Elsevier Applied Science. p.528-532.

PARKE, G.A.R. (1993). A novel soft member for space trusses. In: INTERNATIONAL CONFERENCE ON SPACE STRUCTURES, 4., Guildford, U.K., 1993. Proceedings. London, Thomas Telford. v 1, p.116126.

PISCOPO, G.; PRETE, G. (1982). Su di una speciale soluzione costrutiva con grigliato piano incrociato per grandi coperture spaziali. Costruzione metalliche, n.3, p.137-150.

SADIQ, O. M; ABATAN, A. O. (1993). Stability analysis of space truss systems under random element imperfections. In: INTERNATIONAL CONFERENCE ON SPACE STRUCTURES, 4., Guildford, U.K., 1993. Proceedings. London, Thomas Telford. v.1, p.108-115.

SÁLES, J.J. et al. (1996a). Ensaios de compressão em corpos-de-prova e barras de alumínio com extremidades estampadas. São Carlos, EESCUSP. (Relatório Técnico).

SÁLES, J.J. et al. (1996b). Ensaios de compressão em barras de aço com extremidades estampadas. São Carlos, EESC-USP. (Relatório Técnico) SAKA, T.; HEKI, K. (1984). The effect of joints on the strength of space trusses. In: INTERNATIONAL CONFERENCE ON SPACE 
STRUCTURES, 3., Guildford, U.K., 1984. Proccedings. London/New York, Elsevier applied Science. p.417-422.

SCHIMIDT, L.C.; MORGAN, P.R.; CLARKSON, J.A. (1976). Space trusses with brittle-type strut buckling. Journal of the Structural Division, v.102, n. ST7, p.1479-1492, July.

SCHIMIDT, L.C.; HANAOR, A. (1979). Force limiting devices in space trusses. Journal of the Structural Division, v.105, n. ST5, p.939-951, May. SCHIMIDT, L.C.; MORGAN, P.R.; HANAOR, A. (1982). Ultimate load testing of space trusses. Journal of the Structural Division, v.108, n. ST6, p.13241335, June.

SOUZA, A.S.C. (1998). Contribuição ao estudo das estruturas metálicas espaciais. São Carlos. Dissertação (Mestrado) - Escola de Engenharia de São Carlos, Universidade de São Paulo.

SUPPLE, W.J.; COLLINS, I. (1981). Limit state analysis of double-layer grids In: MAKOWSKI, Z.S., ed. Analysis, design and construction of doublelayer grids. London, Applied Science Publishers. p.93-117.

TARZI, A.I. (1981). A general theory for the analysis of regular structures by the calculus of finite diferences. In: MAKOWSKI, Z.S., ed. Analysis, design and construction of double-layer grids. London, Applied Science Publishers. p.245-268.

VENDRAME. M.A. (1999). Contribuição ao estudo das cúpulas treliçadas utilizando elementos tubulares em aço. São Carlos. Dissertação (Mestrado) - Escola de Engenharia de São Carlos, Universidade de São Paulo.

WALKER, H.B. (1981). The NODUS system for the design and construction of space frames. In: MAKOWSKI, Z.S., ed. Analysis, design and construction of double-layer grids. London, Applied Science Publishers. p.331-354. 


\section{APÊNDICE 1}

Planilha dos resultados dos ensaios dos protótipos PROT 1 a PROT 4

Obs.: Locação dos canais, ver figuras 3.14 a 3.17. 
Resultados do ensaio do protótipo PROT 1 
Chan 20 Chan 21 Chan 22 Chan 23 Chan 24 Chan 25 Chan 26

$\begin{array}{lllllll}\mathrm{kN} & \mathrm{kN} & \mathrm{kN} & \mathrm{kN} & \mathrm{mm} & \mathrm{mm} & \mathrm{mm}\end{array}$

primeiro escorvamento

$\begin{array}{rrrrrrr}0,00 & 0,15 & 0,00 & 0,00 & 0,00 & 0,00 & 0,00 \\ -4,72 & -4,85 & -5,15 & -4,94 & 0,30 & 0,15 & 0,00 \\ -9,59 & -9,84 & -10,16 & -9,73 & 1,40 & 1,56 & 0,08 \\ -12,25 & -12,57 & -13,10 & -12,92 & 2,24 & 3,16 & 0,04 \\ -0,30 & -0,15 & -0,15 & -0,44 & 1,57 & 2,91 & 0,06\end{array}$

segundo escorvamento

$\begin{array}{rr}0,00 & 0,15 \\ -2,36 & -2,57 \\ -5,02 & -5,15 \\ -7,38 & -7,72 \\ -9,74 & -10,15 \\ -12,25 & -12,57 \\ -12,25 & -12,57 \\ -14,61 & -14,99 \\ -16,09 & -16,51 \\ -17,12 & -17,72 \\ 0,00 & 0,00\end{array}$

$\begin{array}{rr}0,00 & 0,00 \\ -2,65 & -2,32 \\ -5,30 & -4,94 \\ -7,80 & -7,40 \\ -10,16 & -9,73 \\ -12,81 & -12,20 \\ -13,40 & -12,78 \\ -15,16 & -14,37 \\ -16,64 & -15,83 \\ -17,81 & -16,99 \\ 0,00 & 0,00\end{array}$

0,00

0,00

0,00

0,09

0,02

0,21

0,06

0,08

0,50

0,11

0,69

0,92

0,15

0,62

0,58

0,97

1,10

0,60

1,14

0,62

0,32

0,00

0,00

0,00

0,00

$-0,02$

$-0,02$

$-0,04$

$-0,06$

0,24

$-0,06$

$-0,06$

ensaio

$$
\begin{array}{r}
0,00 \\
-5,46 \\
-10,18 \\
-15,05 \\
-17,71 \\
-19,92 \\
-20,07 \\
-22,14 \\
-25,09 \\
-26,71 \\
-23,02 \\
-27,30 \\
-28,63 \\
-29,22 \\
-29,52 \\
-32,32 \\
-29,52 \\
-32,61 \\
-34,53 \\
-32,47 \\
-36,89 \\
-38,07 \\
-37,78 \\
-39,55 \\
-39,99 \\
-35,71 \\
-18,89 \\
-10,33 \\
-0,30 \\
0,30
\end{array}
$$

0,00

0,30

$$
\begin{array}{r}
-5,45 \\
-10,30 \\
-15,14 \\
-17,57 \\
-19,84 \\
-19,99 \\
-22,11 \\
-24,99 \\
-26,65 \\
-23,17 \\
-27,26 \\
-28,62 \\
-29,38 \\
-29,38 \\
-32,41 \\
-30,59 \\
-33,01 \\
-34,53 \\
-32,56 \\
-37,25 \\
-38,77 \\
-38,16 \\
-39,98 \\
-40,13 \\
-33,16 \\
-18,32 \\
-10,15 \\
0,00 \\
0,15
\end{array}
$$

$$
\begin{array}{r}
0,00 \\
-5,15 \\
-10,01 \\
-14,87 \\
-17,81 \\
-19,88 \\
-19,58 \\
-22,38 \\
-25,47 \\
-27,09 \\
-23,41 \\
-27,53 \\
-28,86 \\
-29,59 \\
-29,74 \\
-32,83 \\
-30,18 \\
-33,42 \\
-35,19 \\
-34,16 \\
-37,40 \\
-39,31 \\
-38,43 \\
-40,64 \\
-41,37 \\
-37,69 \\
-18,85 \\
-10,16 \\
-0,29 \\
0,29
\end{array}
$$

0,00
$-5,23$
$-9,87$
$-14,81$
$-17,57$
$-19,60$
$-19,46$
$-22,07$
$-24,97$
$-26,71$
$-24,25$
$-27,30$
$-28,46$
$-29,33$
$-29,33$
$-32,23$
$-30,05$
$-32,96$
$-34,56$
$-32,96$
$-36,59$
$-38,33$
$-37,46$
$-39,78$
$-39,78$
$-33,39$
$-19,17$
$-10,45$
$-0,29$
0,44

0,00
0,22
0,50
0,84
1,12
1,40
1,38
1,48
1,63
1,72
2,77
2,88
2,88
2,88
2,86
2,95
2,84
2,97
3,07
4,71
4,88
5,52
5,42
5,39
5,39
4,77
3,70
3,27
2,52
1,74

$-0,02$
0,08
0,13
0,23
0,32
0,39
0,36
0,41
0,36
0,38
0,47
0,51
0,47
0,43
0,38
0,21
0,96
0,92
0,88
0,69
0,71
0,60
0,38
0,28
0,26
0,32
0,13
0,00
00,04
0,02

$-0,02$
0,02
0,00
0,02
$-0,14$
$-0,18$
$-0,20$
$-0,22$
$-0,30$
$-0,34$
$-0,24$
$-0,30$
$-0,30$
$-0,34$
$-0,38$
$-0,40$
$-0,56$
$-0,56$
$-0,56$
$-0,42$
$-0,40$
$-0,40$
$-0,12$
$-0,14$
$-0,14$
$-0,14$
$-0,12$
$-0,10$
$-0,14$
2,90


PROT1

Chan 27 Chan 28 Chan 29 Chan $30 \quad$ Chan 31 Chan 32 Chan 33

$\begin{array}{lllllll}\mathrm{mm} & \mathrm{mm} & \mathrm{mm} & \mathrm{mm} & \mathrm{mm}\end{array}$

\begin{tabular}{|c|c|c|c|c|c|c|}
\hline 0,02 & 0,00 & 0,00 & 0,00 & 0,00 & 0,00 & 0,00 \\
\hline$-0,11$ & 0,21 & $-0,04$ & $-0,04$ & 0,16 & 0,00 & 0,30 \\
\hline 0,32 & 2,00 & 0,26 & 0,10 & 1,49 & $-0,09$ & 1,66 \\
\hline 0,15 & 2,63 & 0,24 & 1,12 & 2,31 & $-0,07$ & 2,15 \\
\hline 0,30 & 2,44 & 0,33 & 1,14 & 2,03 & $-0,04$ & 1,72 \\
\hline
\end{tabular}

segundo escorvamento

$\begin{array}{rr}0,00 & 0,00 \\ 0,02 & 0,04 \\ 0,00 & 0,06 \\ 0,00 & 0,10 \\ -0,04 & 0,13 \\ -0,08 & 0,21 \\ -0,36 & 0,21 \\ -0,45 & 0,27 \\ -0,43 & 0,35 \\ -0,43 & 0,42 \\ -0,30 & 0,12\end{array}$

$\begin{array}{rr}0,00 & 0,00 \\ 0,00 & 0,00 \\ -0,04 & -0,02 \\ -0,06 & 0,00 \\ -0,07 & 0,02 \\ -0,11 & 0,00 \\ -0,09 & 0,16 \\ -0,11 & 0,12 \\ -0,13 & 0,10 \\ -0,15 & 0,10 \\ 0,00 & 0,10\end{array}$

0,02

0,02

0,02

0,00

0,06

0,00

0,09

0,12

0,18

0,22

0,02

0,17

0,26

0,29

0,02

0,37

0,35

0,02

0,50

0,39

$-0,04$

0,43

0,43

0,47

0,51

$-0,02$

0,60

$-0,02$

0,56

0,12

0,02

$-0,04$

ensaio

$\begin{array}{rrrr}0,00 & 0,00 & 0,00 & 0,00 \\ -0,08 & 0,04 & -0,07 & -0,02 \\ -0,17 & 0,12 & -0,11 & -0,04 \\ -0,23 & 0,21 & -0,17 & -0,08 \\ -0,34 & 0,31 & -0,20 & -0,12 \\ -0,17 & 0,79 & -0,24 & 0,00 \\ -0,02 & 0,79 & -0,26 & 1,89 \\ -0,04 & 0,83 & -0,28 & 1,75 \\ 0,02 & 1,09 & -0,37 & 1,34 \\ 0,02 & 1,06 & -0,40 & 1,18 \\ 1,56 & 1,13 & -4,44 & 1,20 \\ 1,50 & 1,07 & -4,46 & 1,12 \\ 1,47 & 1,06 & -4,46 & 0,95 \\ 1,41 & 1,04 & -4,46 & 0,89 \\ 1,35 & 0,98 & -4,48 & 0,79 \\ 1,05 & 0,79 & -27,75 & 0,45 \\ 1,01 & 0,67 & -27,75 & 0,83 \\ 0,90 & 0,69 & -27,75 & 0,57 \\ 0,75 & 0,58 & -27,75 & 0,47 \\ 2,27 & 0,33 & -27,79 & 0,55 \\ 2,05 & 0,15 & -27,75 & 0,32 \\ 1,33 & -0,15 & -27,75 & 0,26 \\ 1,48 & -0,33 & -27,75 & -0,39 \\ 1,52 & -0,52 & -27,75 & -0,77 \\ 1,45 & -0,58 & -27,75 & -0,89 \\ 1,78 & -1,42 & -27,77 & -0,32 \\ 2,10 & -1,67 & -27,75 & -0,12 \\ 2,08 & -1,57 & -27,77 & -0,14 \\ 2,29 & -1,29 & -27,75 & -0,12 \\ 2,46 & -1,17 & -27,72 & -0,02 \\ & & & \end{array}$

0,00
0,14
0,23
0,33
0,47
0,84
0,55
0,61
0,59
0,51
0,39
0,47
0,39
0,33
0,25
0,04
$-0,22$
$-0,06$
$-0,14$
$-0,31$
$-0,23$
$-0,12$
$-0,25$
$-0,33$
$-0,45$
$-1,45$
$-2,09$
$-2,29$
$-2,33$
$-2,23$

0,00

0,00

0,02

0,19

0,02

0,34

0,02

0,47

0,00

0,73

$-0,06$

0,80

2,15

$-0,28$

2,24

2,22

$-0,24$

2,50

2,05

$-0,18$

$-0,18$

2,18

2,18

$-0,20$

$-0,20$

2,17

2,18

$-0,18$
$-0,13$

2,11

$-0,31$

2,88

$-0,31$

3,01

$-0,30$

2,91

2,48

$-0,26 \quad 2,46$

$-0,26 \quad 1,59$

$-0,13 \quad 1,16$

$-0,13 \quad 1,01$

$-0,11 \quad 0,91$

$-0,04 \quad-0,09$

$-0,07-0,73$

$-0,07 \quad-0,93$

$0,07-1,10$

$0,18-1,08$ 


Chan 34 Chan 35 Chan 36 Chan 37 Chan 38 Chan $39 \quad$ Chan 40

$\begin{array}{llllll}\mathrm{mm} & \mathrm{mm} & \mathrm{mm} & \mathrm{mm} & \mathrm{mm}\end{array}$

primeiro escorvamento

$\begin{array}{rrrrrrr}0,02 & 0,00 & 0,00 & 0,00 & 0,00 & 0,00 & 0,00 \\ 0,04 & -0,04 & -2,31 & -1,22 & -1,35 & -1,25 & -1,50 \\ 0,97 & -0,06 & -10,79 & -6,73 & -9,20 & -6,48 & -7,97 \\ 2,69 & -0,11 & -19,20 & -12,70 & -14,04 & -12,84 & -13,34 \\ 2,70 & -0,04 & -14,10 & -9,68 & -10,87 & -9,68 & -10,05\end{array}$

segundo escorvamento

$\begin{array}{rr}0,00 & 0,00 \\ 0,00 & 0,00 \\ 0,00 & -0,02 \\ 0,00 & -0,02 \\ 0,02 & -0,06 \\ 0,04 & -0,06 \\ -0,02 & -0,09 \\ -0,04 & -0,11 \\ -0,14 & -0,17 \\ -0,23 & -0,20 \\ -0,18 & 0,02\end{array}$

$$
\begin{array}{r}
0,04 \\
-0,95 \\
-2,02 \\
-3,01 \\
-4,04 \\
-5,14 \\
-6,98 \\
-7,93 \\
-9,91 \\
-11,01 \\
-3,60
\end{array}
$$

$$
\begin{array}{r}
0,00 \\
-0,43 \\
-1,12 \\
-1,69 \\
-2,30 \\
-2,99 \\
-4,14 \\
-4,71 \\
-6,26 \\
-6,83 \\
-2,45
\end{array}
$$

$$
\begin{array}{r}
0,04 \\
-0,36 \\
-1,05 \\
-1,71 \\
-2,40 \\
-3,16 \\
-5,75 \\
-6,29 \\
-7,42 \\
-8,04 \\
-3,49
\end{array}
$$

$$
\begin{array}{r}
0,00 \\
-0,44 \\
-1,14 \\
-1,73 \\
-2,35 \\
-3,09 \\
-3,97 \\
-4,49 \\
-5,67 \\
-6,55 \\
-1,91
\end{array}
$$

0,00 $-0,58$ $-1,28$ $-1,94$ $-2,56$ $-3,29$ $-3,95$ $-4,53$ $-6,07$ $-7,02$ $-2,01$

ensaio

$\begin{array}{rrrr}-0,02 & 0,00 & 0,00 & 0,00 \\ 0,04 & -0,06 & -2,09 & -1,19 \\ 0,05 & -0,09 & -4,15 & -2,41 \\ 0,04 & -0,22 & -6,42 & -3,81 \\ -0,05 & -0,46 & -8,63 & -5,14 \\ -0,20 & -0,59 & -12,41 & -7,30 \\ -0,36 & -0,85 & -14,98 & -8,60 \\ -0,40 & -0,92 & -16,78 & -9,57 \\ -0,52 & -1,14 & -21,00 & -12,34 \\ -0,70 & -1,03 & -23,97 & -14,71 \\ -0,47 & -1,16 & -24,12 & -14,89 \\ -0,40 & -1,20 & -26,36 & -16,22 \\ -0,47 & -1,29 & -28,60 & -17,66 \\ -0,52 & -1,33 & -29,77 & -18,42 \\ -0,56 & -1,37 & -30,84 & -19,10 \\ -0,72 & -1,49 & -36,86 & -22,70 \\ 1,33 & -1,62 & -38,36 & -24,03 \\ 1,41 & -1,66 & -40,09 & -24,96 \\ 1,30 & -1,75 & -43,47 & -27,09 \\ 0,99 & -1,72 & -46,62 & -29,75 \\ 0,92 & -1,77 & -52,42 & -32,91 \\ 0,49 & -1,79 & -61,20 & -37,05 \\ 0,36 & -1,62 & -67,11 & -38,99 \\ 0,40 & -1,64 & -73,27 & -41,47 \\ 0,36 & -1,68 & -74,82 & -42,48 \\ 0,16 & -1,68 & -80,73 & -43,38 \\ -0,23 & -1,49 & -74,63 & -38,92 \\ -0,43 & -1,38 & -69,38 & -35,94 \\ -0,61 & -1,18 & -60,43 & -30,72 \\ -0,58 & -1,05 & -59,91 & -30,40\end{array}$

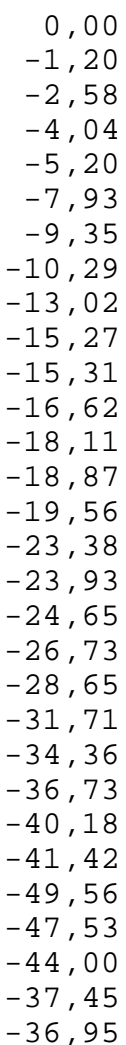

$$
\begin{aligned}
& 0,00 \\
& -1,18 \\
& -2,50 \\
& -4,01 \\
& -5,22 \\
& -7,73 \\
& -10,78 \\
& -12,18 \\
& -15,71 \\
& -17,70 \\
& -17,77 \\
& -19,17 \\
& -21,19 \\
& -22,11 \\
& -22,96 \\
& -28,04 \\
& -28,92 \\
& -29,87 \\
& -32,71 \\
& -34,58 \\
& -39,22 \\
& -45,29 \\
& -50,88 \\
& -57,14 \\
& -58,28 \\
& -62,44 \\
& -58,83 \\
& -55,15 \\
& -48,57
\end{aligned}
$$

0,00

$-1,28$

$-2,63$

$-4,24$

$-6,18$

$-8,41$

$-10,71$

$-12,06$

$-15,28$

$-17,65$

$-17,73$

$-19,23$

$-21,13$

$-22,04$

$-22,95$

$-27,78$

$-30,45$

$-31,62$

$-34,65$

$-36,66$

$-41,81$

$-51,61$

$-55,74$

$-60,12$

$-61,07$

$-61,26$

$-56,25$

$-52,92$

$-46,71$

$-48,16-46,35$ 
PROT1

Chan 41 Chan 42 Chan 43 Chan 44

ue

Chan 45

Chan 46

Chan 47

ue

ue

ue

ue

ue

ue

$\begin{array}{rr}\text { primeiro escorvamento } \\ 0,00 & 0,00 \\ -52,01 & -44,58 \\ -117,03 & -74,31 \\ -145,83 & -99,38 \\ -18,58 & 14,86\end{array}$

0,00

$-41,80$

$-80,81$

$-104,96$

2,79

0,93

$-55,78$

$-108,78$

$-138,53$

$-4,65$

0,00
$-58,71$
$-104,16$
$-140,14$
$-1,89$

0,93

$-74,34$

$-135,68$

$-183,07$

3,72

0,00

$-64,12$

$-98,50$

$-141,25$

22,30

segundo escorvamento

0,00
$-25,08$
$-52,01$
$-76,16$
$-101,24$
$-127,25$
$-130,04$
$-150,47$
$-164,40$
$-176,48$
$-3,72$

$$
\begin{array}{r}
0,00 \\
-22,29 \\
-46,44 \\
-68,73 \\
-90,10 \\
-114,25 \\
-117,03 \\
-136,54 \\
-152,33 \\
-162,54 \\
-0,93
\end{array}
$$

0,93
$-21,36$
$-44,58$
$-66,88$
$-88,24$
$-111,46$
$-108,67$
$-128,18$
$-119,82$
$-130,04$
17,65

0,93
$-25,10$
$-52,07$
$-78,10$
$-103,20$
$-131,09$
$-137,60$
$-159,91$
$-196,17$
$-207,33$
$-18,59$

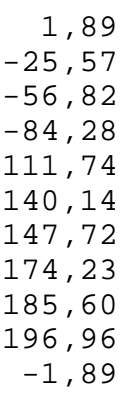

$$
\begin{array}{r}
0,93 \\
-36,24 \\
-74,34 \\
-110,58 \\
-146,83 \\
-185,86 \\
-198,87 \\
-230,46 \\
-245,33 \\
-261,13 \\
-0,93
\end{array}
$$

0,93

$-31,60$

$-65,05$

$-96,65$

$-129,17$

$-163,55$

$-174,70$

$-201,65$

$-210,02$

$-222,10$

3,72

ensaio

$\begin{array}{rrrr}0,00 & 0,00 & 0,93 & 0,00 \\ -54,85 & -48,35 & -47,44 & -57,64 \\ -105,06 & -92,97 & -90,23 & -108,78 \\ -155,27 & -139,46 & -133,02 & -162,70 \\ -180,37 & -167,35 & -153,48 & -195,24 \\ -200,82 & -187,81 & -165,57 & -223,14 \\ -202,68 & -188,74 & -159,06 & -230,57 \\ -225,93 & -209,19 & -181,39 & -253,82 \\ -257,54 & -236,15 & -207,43 & -284,50 \\ -243,59 & -217,56 & -186,04 & -269,62 \\ -242,66 & -218,49 & -187,90 & -271,48 \\ -279,85 & -256,61 & -219,53 & -315,18 \\ -293,80 & -268,69 & -230,69 & -330,06 \\ -300,31 & -276,13 & -236,27 & -338,42 \\ -302,16 & -277,06 & -238,13 & -340,28 \\ -330,99 & -304,02 & -257,66 & -375,61 \\ -316,11 & -281,71 & -239,99 & -355,16 \\ -343,07 & -317,04 & -265,11 & -394,21 \\ -357,02 & -329,13 & -273,48 & -410,94 \\ -344,00 & -311,46 & -259,52 & -391,42 \\ -380,26 & -352,37 & -287,43 & -442,55 \\ -395,14 & -370,04 & -295,80 & -467,66 \\ -389,56 & -363,53 & -286,50 & -463,94 \\ -408,15 & -379,33 & -301,38 & -482,53 \\ -409,08 & -378,40 & -302,31 & -484,39 \\ -365,39 & -328,20 & -264,17 & -425,82 \\ -225,00 & -157,13 & -136,74 & -239,87 \\ -145,97 & -73,45 & -76,28 & -137,60 \\ -43,70 & 20,45 & -16,74 & -1,86 \\ -48,35 & 16,74 & -19,53 & -6,51\end{array}$

0,94

$-61,21$

$-115,83$

$-171,40$

$-202,48$

$-223,19$

$-229,79$

$-254,27$

$-291,94$

$-299,48$

$-287,23$

$-328,67$

$-343,74$

$-355,04$

$-359,75$

$-399,30$

$-388,00$

$-420,02$

$-436,03$

$-437,91$

$-472,76$

$-494,42$

$-496,30$

$-515,13$

$-521,73$

$-439,80$

$-241,09$

$-145,97$

$-39,55$

$-40,50$
0,93

$-68,83$

$-133,95$

$-199,06$

$-234,41$

$-245,57$

$-248,36$

$-277,20$

$-318,13$

$-316,27$

$-319,99$

$-368,36$

$-383,24$

$-395,33$

$-398,12$

$-439,98$

$-425,10$

$-470,68$

$-485,56$

$-507,89$

$-556,26$

$-596,25$

$-595,32$

$-621,37$

$-627,88$

$-494,86$

$-250,22$

$-145,11$

$-34,42$

$-36,28$ 
PROT1

Chan 48 Chan 49 Chan 50 Chan 51

ue

Chan 52

Chan 53

Chan 54

ue

ue

ue

ue

ue

ue

primeiro escorvamento

$\begin{array}{rrrrrrr}0,00 & 0,00 & 0,00 & -0,95 & -0,95 & 0,00 & -0,95 \\ -69,70 & -67,80 & -59,60 & -59,60 & -70,00 & 21,77 & 17,03 \\ -142,18 & -131,89 & -121,08 & -104,06 & -150,41 & 40,70 & 40,68 \\ -181,21 & -148,61 & -142,84 & -147,57 & -146,63 & 70,98 & 71,89 \\ -17,66 & 21,36 & 3,78 & 6,62 & 12,30 & 19,88 & 28,38\end{array}$

segundo escorvamento

0,93
$-30,67$
$-65,05$
$-96,65$
$-129,17$
$-162,62$
$-174,70$
$-200,72$
$-220,24$
$-234,18$
$-7,43$

$$
\begin{array}{r}
0,93 \\
-32,51 \\
-67,80 \\
-101,24 \\
-134,68 \\
-170,90 \\
-164,40 \\
-196,91 \\
-212,70 \\
-230,35 \\
10,22
\end{array}
$$

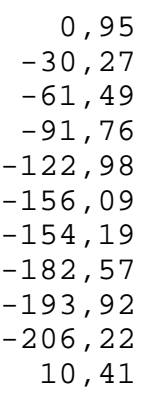

0,95
$-31,22$
$-63,38$
$-96,49$
$-126,76$
$-160,82$
$-150,41$
$-176,90$
$-197,71$
$-212,84$
10,41
0,95

11,36

23,66

33,13

42,59

52,05

64,36

70,98

82,34

87,07

17,04
0,00

9,46

\begin{tabular}{|c|c|c|}
\hline 0,93 & 0,00 & 0,95 \\
\hline$-68,87$ & $-71,66$ & $-63,38$ \\
\hline$-133,08$ & $-139,60$ & $-122,03$ \\
\hline$-197,30$ & $-209,40$ & $-179,74$ \\
\hline$-233,59$ & $-249,41$ & $-209,06$ \\
\hline$-263,37$ & $-293,15$ & $-234,60$ \\
\hline$-280,13$ & $-298,74$ & $-238,39$ \\
\hline$-308,98$ & $-334,10$ & $-259,20$ \\
\hline$-353,65$ & $-391,80$ & $-284,74$ \\
\hline$-332,24$ & $-388,08$ & $-255,41$ \\
\hline$-335,03$ & $-375,05$ & $-265,82$ \\
\hline$-388,08$ & $-439,27$ & $-300,82$ \\
\hline$-404,83$ & $-466,26$ & $-308,39$ \\
\hline$-417,86$ & $-480,22$ & $-312,17$ \\
\hline$-422,52$ & $-487,66$ & $-313,12$ \\
\hline$-469,98$ & $-550,01$ & $-332,04$ \\
\hline$-445,78$ & $-545,36$ & $-332,04$ \\
\hline$-490,45$ & $-600,27$ & $-356,63$ \\
\hline$-505,34$ & $-624,47$ & $-359,47$ \\
\hline$-501,62$ & $-611,44$ & $-345,28$ \\
\hline$-538,85$ & $-684,96$ & $-370,82$ \\
\hline$-529,54$ & $-710,09$ & $-363,25$ \\
\hline$-518,37$ & $-741,73$ & $-373,66$ \\
\hline$-531,40$ & $-769,65$ & $-376,50$ \\
\hline$-533,26$ & $-780,82$ & $-373,66$ \\
\hline$-418,79$ & $-722,18$ & $-332,98$ \\
\hline$-196,37$ & $-432,75$ & $-204,33$ \\
\hline$-96,79$ & $-287,57$ & $-122,98$ \\
\hline 20,47 & $-120,98$ & $-17,03$ \\
\hline 17,68 & $-121,92$ & $-18,92$ \\
\hline
\end{tabular}

19,87

27,43

35,95

44,46

56,76

63,38

72,84

77,57

15,14

ensaio

0,00

$-68,11$

$-131,49$

$-195,82$

$-235,55$

$-286,63$

$-297,04$

$-324,47$

$-376,50$

$-366,09$

$-366,09$

$-418,12$

$-443,66$

$-456,91$

$-467,31$

$-538,26$

$-550,56$

$-598,80$

$-627,18$

$-629,07$

$-698,13$

$-728,40$

$-781,38$

$-808,81$

$-821,11$

$-795,57$

$-542,04$

$-402,04$

$-217,57$

$-216,63$

$\begin{array}{rr}0,00 & -0,95 \\ 19,86 & 16,07 \\ 36,87 & 31,20 \\ 55,78 & 48,22 \\ 67,13 & 58,62 \\ 67,13 & 55,78 \\ 65,24 & 50,11 \\ 74,69 & 60,51 \\ 82,26 & 67,13 \\ 61,46 & 69,97 \\ 69,02 & 57,68 \\ 84,15 & 73,75 \\ 90,77 & 81,31 \\ 94,55 & 84,15 \\ 95,50 & 85,10 \\ 106,84 & 96,44 \\ 71,86 & 58,62 \\ 87,93 & 77,53 \\ 100,22 & 86,99 \\ 88,88 & 79,42 \\ 113,46 & 97,39 \\ 143,72 & 121,97 \\ 112,51 & 89,82 \\ 133,32 & 106,84 \\ 140,88 & 113,46 \\ 108,73 & 84,15 \\ 45,38 & 30,26 \\ 14,18 & 4,73 \\ -23,64 & -24,58 \\ -27,42 & -30,26\end{array}$




Chan 55 Chan 56 Chan 57 Chan 58 Chan 59 Chan 60 Chan 61

ue ne ne ue ue ue ue

\begin{tabular}{rrrrrrr} 
primeiro escorvamento & \multicolumn{7}{c}{} \\
0,00 & 0,00 & 0,00 & 0,00 & 0,00 & $-0,88$ & 0,00 \\
18,92 & 19,88 & 33,11 & 37,86 & 42,57 & 34,15 & $-50,79$ \\
51,08 & 53,00 & 54,87 & 79,50 & 80,41 & 77,06 & $-111,20$ \\
52,97 & 58,68 & 62,43 & 84,23 & 99,33 & 102,45 & $-139,22$ \\
9,46 & 7,57 & $-23,65$ & $-10,41$ & $-9,46$ & 19,26 & $-18,39$
\end{tabular}

segundo escorvamento

$\begin{array}{rr}0,00 & 1,89 \\ 10,41 & 13,25 \\ 20,81 & 25,55 \\ 29,33 & 35,02 \\ 38,78 & 46,38 \\ 46,35 & 56,79 \\ 38,78 & 45,43 \\ 46,35 & 56,79 \\ 57,70 & 69,09 \\ 62,43 & 75,72 \\ 0,00 & 1,89\end{array}$

0,95
18,92
38,78
54,87
70,95
87,98
89,87
105,00
114,46
122,03
$-0,95$

0,95

0,95

0,88

0,00

20,82

23,65

41,64

60,57

78,56

48,24

70,00

90,81

98,43

112,57

98,43

112,57

114,52

127,77

132,44

147,57

137,23

157,03

1,89

18,39

36,78

52,54

69,17

85,81

86,69

100,70

111,20

119,96

0,88

$-23,64$

$-49,91$

$-72,68$

$-96,32$

$-122,59$

$-122,59$

$-144,48$

$-160,24$

0,95

$-173,37$

$-4,38$

ensaio

\begin{tabular}{|c|c|c|c|c|}
\hline 0,00 & 0,00 & 0,00 & 0,95 & 0,95 \\
\hline 17,02 & 21,76 & 35,95 & 37,82 & 46,35 \\
\hline 32,15 & 41,62 & 68,11 & 73,75 & 87,03 \\
\hline 48,22 & 62,43 & 101,22 & 110,62 & 129,60 \\
\hline 55,78 & 71,89 & 121,08 & 130,48 & 153,2 \\
\hline 69,02 & 90,81 & 134,33 & 147,50 & 172 \\
\hline 57,68 & 81,35 & 131,49 & 149,39 & 170, \\
\hline 66,19 & 93,65 & 146,63 & 168,30 & 190,1 \\
\hline 69,02 & 104,06 & 160,82 & 194,77 & 211, \\
\hline 39,71 & 81,35 & 143,79 & 173,03 & 192 \\
\hline 46,33 & 80,41 & 144,73 & 179,65 & 190 \\
\hline 61,46 & 98,38 & 171,22 & 209,90 & 225, \\
\hline 68,08 & 107,84 & 178,79 & 223,14 & 235, \\
\hline 68,08 & 106,90 & 182,57 & 229,76 & 240 \\
\hline 69,02 & 108,79 & 182,57 & 232,59 & 242, \\
\hline 73,75 & 117,30 & 199,60 & 260,01 & 263 \\
\hline 55,78 & 102,17 & 169,33 & 228,81 & 244, \\
\hline 69,02 & 113,52 & 195,82 & 256,23 & 273 \\
\hline 75,64 & 122,98 & 200,55 & 267,58 & 280 \\
\hline 38,77 & 83,25 & 189,20 & 253,39 & 262 \\
\hline 66,19 & 117,30 & 214,74 & 288,38 & 295, \\
\hline 83,20 & 136,22 & 231,76 & 300,67 & 310, \\
\hline 78,48 & 138,11 & 226,09 & 298,78 & 305 , \\
\hline 91,71 & 151,36 & 240,28 & 314,85 & 321,6 \\
\hline 00,22 & 159,87 & 247,85 & 324,31 & 329, \\
\hline 150,34 & 218,52 & 208,11 & 284,60 & 293 \\
\hline 109,68 & 181,63 & 89,87 & 158,84 & 153 \\
\hline 65,24 & 137,17 & 30,27 & 89,82 & 77, \\
\hline 5,67 & 73,79 & $-35,00$ & 1,89 & -10 \\
\hline & & & & \\
\hline
\end{tabular}

$\begin{array}{rr}0,00 & 0,00 \\ 34,37 & -56,05 \\ 66,93 & -105,77 \\ 99,49 & -157,30 \\ 118,48 & -185,32 \\ 132,05 & -207,02 \\ 134,76 & -210,64 \\ 151,04 & -234,14 \\ 173,66 & -266,69 \\ 160,09 & -260,36 \\ 159,18 & -259,45 \\ 185,41 & -292,00 \\ 197,17 & -305,56 \\ 203,50 & -312,79 \\ 205,31 & -315,50 \\ 227,92 & -343,53 \\ 210,74 & -328,16 \\ 233,35 & -357,99 \\ 240,58 & -367,94 \\ 227,92 & -356,18 \\ 254,15 & -391,44 \\ 265,91 & -405,91 \\ 261,39 & -398,67 \\ 273,14 & -414,04 \\ 280,38 & -411,33 \\ 244,20 & -354,38 \\ 130,24 & -227,81 \\ 69,64 & -151,88 \\ -6,33 & -51,53 \\ -11,76 & -53,34\end{array}$


PROT1

Chan 62 Chan 63 Chan 64 Chan 65

ue

ue

ue

primeiro escorvamento

$\begin{array}{rr}0,00 & 0,00 \\ -42,01 & -65,67 \\ -68,27 & -140,98 \\ -91,90 & -176,88 \\ 14,88 & -14,89\end{array}$

0,00
$-60,83$
$-126,20$
$-141,64$
2,72

0,92
$-61,39$
$-109,03$
$-142,02$
2,75

$-0,88$
$-69,21$
$-115,64$
$-162,07$
4,38

0,00

$-89,36$

$-125,27$

$-12,26$ ue

ue

(1)

segundo escorvamento

0,00
$-21,88$
$-45,51$
$-66,52$
$-86,65$
$-108,53$
$-109,40$
$-126,03$
$-135,66$
$-144,41$
$-0,88$

$$
\begin{array}{r}
0,88 \\
-31,52 \\
-64,80 \\
-97,19 \\
-129,59 \\
-163,74 \\
-158,49 \\
-188,26 \\
-206,65 \\
-223,29 \\
2,63
\end{array}
$$

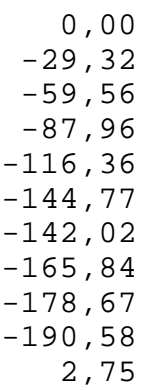

0,88
$-31,54$
$-65,70$
$-98,12$
$-130,53$
$-165,57$
$-183,97$
$-210,25$
$-226,02$
$-239,16$
$-9,64$
0,00

$-21,02$

$-45,55$

$-67,45$

$-89,36$

$-112,13$

$-116,51$

$-132,28$

$-144,55$

$-156,81$

$-7,88$
Chan 68

0,88

$-45,55$

$-88,48$

$-109,50$

6,13

ensaio

$\begin{array}{rrrr}0,00 & 0,00 & 0,00 & 0,00 \\ -46,11 & -72,32 & -64,29 & -64,25 \\ -89,50 & -138,32 & -121,24 & -121,04 \\ -130,18 & -206,12 & -179,10 & -176,91 \\ -153,68 & -244,99 & -214,00 & -206,71 \\ -171,76 & -275,73 & -250,74 & -228,12 \\ -170,86 & -285,67 & -253,50 & -234,64 \\ -190,75 & -317,31 & -278,30 & -259,78 \\ -213,35 & -369,75 & -309,53 & -297,02 \\ -194,36 & -356,18 & -295,75 & -297,02 \\ -192,56 & -360,70 & -292,08 & -294,23 \\ -228,72 & -417,66 & -329,73 & -331,47 \\ -239,57 & -444,78 & -340,75 & -344,51 \\ -245,89 & -456,53 & -346,27 & -353,82 \\ -246,80 & -464,67 & -348,10 & -356,61 \\ -270,30 & -522,52 & -374,74 & -392,00 \\ -252,22 & -513,48 & -368,31 & -381,75 \\ -284,77 & -564,11 & -398,62 & -415,27 \\ -292,90 & -583,09 & -400,46 & -423,65 \\ -275,73 & -584,00 & -400,46 & -424,58 \\ -315,50 & -653,61 & -428,01 & -460,90 \\ -331,78 & -674,40 & -440,87 & -470,21 \\ -324,54 & -670,78 & -439,95 & -465,55 \\ -340,82 & -684,34 & -452,81 & -493,49 \\ -339,01 & -684,34 & -453,73 & -500,94 \\ -277,53 & -602,98 & -429,85 & -402,24 \\ -124,76 & -356,18 & -272,79 & -236,50 \\ -46,11 & -225,10 & -180,02 & -156,43 \\ 38,87 & -65,99 & -62,46 & -56,80 \\ 35,26 & -67,80 & -65,21 & -58,66\end{array}$

$-0,90$

$-71,45$

$-137,48$

$-205,31$

$-246,01$

$-265,00$

$-275,86$

$-306,61$

$-347,31$

$-345,50$

$-344,60$

$-391,63$

$-407,00$

$-419,67$

$-421,48$

$-461,27$

$-442,28$

$-486,60$

$-494,74$

$-501,07$

$-544,48$

$-564,38$

$-549,00$

$-549,91$

$-534,53$

$-300,28$

$-77,78$

22,61

123,01

117,58
0,88

$-21,90$

$-46,43$

$-69,21$

$-91,98$

$-115,64$

$-119,14$

$-137,54$

$-149,80$

$-160,31$

3,50

$\begin{array}{rr}0,00 & 0,00 \\ -47,94 & -50,65 \\ -93,16 & -97,68 \\ -136,57 & -146,52 \\ -160,09 & -173,66 \\ -179,99 & -193,55 \\ -184,51 & -188,13 \\ -207,12 & -210,74 \\ -236,06 & -236,97 \\ -226,11 & -221,59 \\ -226,11 & -223,40 \\ -255,96 & -256,86 \\ -269,53 & -269,53 \\ -275,86 & -275,86 \\ -277,67 & -277,67 \\ -303,90 & -303,90 \\ -286,71 & -285,81 \\ -317,46 & -318,37 \\ -325,60 & -327,41 \\ -310,23 & -315,65 \\ -345,50 & -347,31 \\ -361,78 & -363,59 \\ -352,74 & -350,93 \\ -363,59 & -371,73 \\ -359,97 & -377,16 \\ -316,56 & -309,32 \\ -207,12 & -143,81 \\ -135,67 & -60,60 \\ -36,18 & 24,42 \\ -34,37 & 21,71\end{array}$


PROT1

Chan 69 Chan $70 \quad$ Chan $71 \quad$ Chan 72

ue

ue

$\begin{array}{rr}\text { primeiro escorvamento } \\ 1,75 & 0,00 \\ -67,42 & -64,45 \\ -154,99 & -146,39 \\ -194,39 & -172,17 \\ -28,90 & -25,78\end{array}$

segundo escorvamento

$\begin{array}{rr}0,00 & 0,92 \\ -7,88 & -27,62 \\ -65,67 & -58,93 \\ -97,19 & -87,47 \\ -129,59 & -115,09 \\ -164,62 & -144,55 \\ -175,13 & -151,00 \\ -203,15 & -169,41 \\ -224,16 & -183,22 \\ -241,67 & -193,35 \\ -8,76 & -0,92\end{array}$

$-0,92$

$-69,02$

$-159,20$

$-195,09$

$-14,72$ ue

0,00

$-60,74$

$-118,71$

$-148,16$

1,84
Chan 73

ue

0,00

$-49,69$

$-106,75$

$-131,60$

$-16,56$
Chan 74

ue

0,00

$-46,65$

$-82,10$

$-114,75$

11,20
Chan 75

ue

0,93

$-81,21$

$-159,61$

$-188,55$

13,07

ensaio

0,90
$-70,58$
$-136,64$
$-207,22$
$-245,22$
$-285,94$
$-310,38$
$-346,57$
$-399,05$
$-385,48$
$-393,63$
$-447,92$
$-477,78$
$-495,88$
$-507,64$
$-588,18$
$-575,51$
$-639,75$
$-675,95$
$-704,00$
$-802,63$
$-856,93$
$-844,26$
$-868,69$
$-884,98$
$-746,53$
$-413,53$
$-260,61$
$-107,68$
$-104,97$
-39

0,00
$-62,45$
$-118,37$
$-171,49$
$-196,66$
$-215,30$
$-224,62$
$-244,19$
$-260,03$
$-245,12$
$-239,53$
$-265,63$
$-269,35$
$-272,15$
$-269,35$
$-273,08$
$-263,76$
$-284,27$
$-274,01$
$-272,15$
$-254,44$
$-233,01$
$-249,78$
$-256,31$
$-246,99$
$-152,85$
$-116,50$
$-68,04$
11,18
13,05

0,93

$-76,43$

$-147,26$

$-220,89$

$-264,69$

$-307,57$

$-315,96$

$-357,90$

$-419,41$

$-422,21$

$-414,75$

$-470,67$

$-499,56$

$-512,61$

$-521,93$

$-588,11$

$-572,26$

$-632,84$

$-642,16$

$-646,82$

$-699,95$

$-723,25$

$-729,77$

$-745,62$

$-750,28$

$-678,51$

$-414,75$

$-263,76$

$-86,68$

$-82,02$

0,00

$-62,48$

$-120,29$

$-177,17$

$-210,74$

$-238,72$

$-234,99$

$-259,23$

$-286,27$

$-271,35$

$-276,01$

$-307,72$

$-317,04$

$-322,64$

$-323,57$

$-348,75$

$-339,42$

$-371,13$

$-379,52$

$-384,18$

$-409,36$

$-414,95$

$-409,36$

$-446,66$

$-456,92$

$-427,08$

$-279,74$

$-193,96$

$-80,19$

$-75,53$
0,92

$-22,09$

$-46,93$

$-69,94$

$-92,03$

$-115,95$

$-119,63$

$-138,04$

$-150,92$

$-162,89$

$-4,60$

0,00
$-25,19$
$-51,31$
$-75,57$
$-100,76$
$-126,88$
$-128,75$
$-148,34$
$-162,33$
$-172,59$
0,00

0,93

$-38,27$

$-80,27$

$-121,34$

$-161,48$

$-202,55$

$-202,55$

$-234,28$

$-255,75$

$-279,09$

7,47

$\begin{array}{rrr}0,00 & 0,94 & 0,00 \\ -49,40 & -53,39 & -84,76 \\ -94,13 & -103,03 & -163,86 \\ -141,67 & -150,80 & -248,62 \\ -166,83 & -177,02 & -292,88 \\ -186,40 & -198,57 & -345,62 \\ -182,68 & -200,44 & -356,92 \\ -207,84 & -221,98 & -406,83 \\ -234,87 & -252,89 & -486,88 \\ -219,03 & -237,90 & -477,47 \\ -219,96 & -238,84 & -479,35 \\ -255,37 & -274,43 & -553,75 \\ -268,42 & -287,54 & -589,53 \\ -274,95 & -294,10 & -608,37 \\ -277,74 & -296,91 & -621,55 \\ -302,91 & -325,01 & -706,31 \\ -282,40 & -306,28 & -703,48 \\ -315,96 & -344,68 & -784,47 \\ -323,41 & -353,11 & -803,31 \\ -313,16 & -338,12 & -787,30 \\ -341,12 & -374,65 & -843,80 \\ -355,10 & -386,83 & -870,17 \\ -347,64 & -375,59 & -887,12 \\ -362,56 & -394,32 & -910,67 \\ -354,17 & -410,24 & -922,91 \\ -329,94 & -340,00 & -831,56 \\ -219,03 & -147,05 & -475,58 \\ -147,26 & -58,07 & -307,95 \\ -46,60 & 29,97 & -117,72 \\ -43,81 & 30,91 & -112,07\end{array}$


PROT1

Chan $76 \quad$ Chan $77 \quad$ Chan 78

ue ue ue

$\begin{array}{rrr}\text { primeiro escorvamento } & \\ 0,92 & 0,92 & 0,00 \\ -51,56 & -71,78 & -68,10 \\ -99,44 & -161,97 & -155,52 \\ -116,93 & -197,86 & -182,21 \\ 11,97 & -31,29 & -25,77\end{array}$

segundo escorvamento

$\begin{array}{rrr}0,92 & -0,92 & 0,92 \\ -25,78 & -33,13 & -31,29 \\ -53,40 & -68,10 & -64,42 \\ -78,26 & -100,31 & -94,79 \\ -103,12 & -134,36 & -125,16 \\ -127,06 & -169,33 & -156,44 \\ -125,22 & -179,45 & -164,73 \\ -141,79 & -204,30 & -187,73 \\ -149,15 & -225,46 & -203,38 \\ -159,28 & -240,19 & -215,34 \\ 9,21 & -6,44 & -3,68\end{array}$

ensaio

$0,93 \quad 0,00 \quad 0,00$

$-56,85$

$-106,25$

$-71,80$

$-66,21$

$-152,85$

$-179,88$

$-197,59$

$-188,27$

$-203,18$

$-216,23$

$-208,77$

$-198,52$

$-220,89$

$-222,75$

$-223,69$

$-220,89$

$-222,75$

$-219,03$

$-231,14$

$-233,01$

$-232,07$

$-248,85$

$-255,37$

$-265,63$

$-270,29$

$-269,35$

$-262,83$

$-190,13$

$-127,69$

$-40,08$

$-138,01$

$-126,82$

$-207,01$

$-240,58$

$-185,56$

$-297,46--255,50$

$-330,10 \quad-279,74$

$-378,59 \quad-303,06$

$-374,86 \quad-262,96$

$-367,40-268,55$

$-426,14-305,85$

$-451,32-314,25$

$-466,24 \quad-318,91$

$-475,57 \quad-318,91$

$-545,50 \quad-331,96$

$-534,31 \quad-310,52$

$-600,52-345,95$

$-629,42-340,36$

$-652,74 \quad-340,36$

$-719,88-346,88$

$-703,09-396,30$

$-700,29-402,83$

$-715,21 \quad-418,68$

$-726,40 \quad-421,48$

$-608,91-359,94$

$-331,96-198,62$

$-207,94-110,03$

$-38,21$

$-71,80$

3,73 
Resultados do ensaio do protótipo PROT 2 
PROT2

\begin{tabular}{|c|c|c|c|c|c|c|}
\hline Chan 0 & Chan 1 & Chan 2 & Chan 3 & Chan 4 & Chan 5 & Chan \\
\hline $\mathrm{kN}$ & $\mathrm{kN}$ & $\mathrm{kN}$ & $\mathrm{kN}$ & $\mathrm{mm}$ & $\mathrm{mm}$ & $\mathrm{mm}$ \\
\hline \multicolumn{7}{|c|}{ escorvamento } \\
\hline 0,00 & 0,00 & 0,00 & 0,00 & 0,00 & 0,00 & 0,00 \\
\hline$-3,39$ & $-2,42$ & $-2,65$ & $-2,61$ & 0,13 & 0,09 & 0,00 \\
\hline$-5,46$ & $-4,69$ & $-5,01$ & $-5,23$ & 0,26 & 0,15 & 0,00 \\
\hline$-7,67$ & $-7,27$ & $-7,51$ & $-7,70$ & 0,47 & 0,24 & $-0,02$ \\
\hline$-10,48$ & $-9,84$ & $-10,01$ & $-10,02$ & 0,84 & 0,39 & $-0,08$ \\
\hline$-1,33$ & $-0,30$ & $-0,59$ & $-0,87$ & 0,22 & 0,08 & $-0,10$ \\
\hline \multicolumn{7}{|l|}{ ensaio } \\
\hline 0,00 & 0,15 & 0,00 & 0,00 & 0,00 & 0,00 & 0,00 \\
\hline$-2,66$ & $-2,88$ & $-2,80$ & $-2,76$ & 0,09 & 0,04 & 0,02 \\
\hline$-4,87$ & $-5,00$ & $-5,01$ & $-5,08$ & 0,21 & 0,09 & 0,04 \\
\hline$-7,38$ & $-7,72$ & $-7,66$ & $-7,55$ & 0,37 & 0,17 & 0,04 \\
\hline$-7,38$ & $-7,72$ & $-7,51$ & $-7,55$ & 0,37 & 0,17 & 0,04 \\
\hline$-9,74$ & $-10,15$ & $-10,01$ & $-9,73$ & 0,62 & 0,32 & 0,02 \\
\hline$-12,25$ & $-12,57$ & $-12,37$ & $-12,05$ & 0,97 & 0,45 & $-0,02$ \\
\hline$-10,63$ & $-10,75$ & $-11,19$ & $-10,45$ & 0,93 & 0,45 & $-0,08$ \\
\hline$-14,91$ & $-15,30$ & $-15,02$ & $-14,52$ & 1,36 & 0,62 & $-0,12$ \\
\hline$-14,17$ & $-13,78$ & $-14,72$ & $-14,95$ & 1,70 & 0,69 & $-0,08$ \\
\hline$-17,56$ & $-17,11$ & $-17,67$ & $-17,28$ & 1,98 & 0,77 & $-0,12$ \\
\hline$-18,00$ & $-17,57$ & $-18,26$ & $-17,71$ & 2,15 & 0,86 & $-0,20$ \\
\hline$-17,12$ & $-16,51$ & $-18,26$ & $-17,28$ & 2,77 & 0,94 & $-0,26$ \\
\hline$-20,07$ & $-19,84$ & $-20,32$ & $-19,89$ & 2,97 & 1,01 & $-0,20$ \\
\hline$-19,33$ & $-19,84$ & $-19,58$ & $-20,04$ & 3,22 & 1,90 & $-0,28$ \\
\hline$-22,43$ & $-22,26$ & $-22,82$ & $-22,21$ & 3,40 & 2,01 & $-0,28$ \\
\hline$-20,81$ & $-20,90$ & $-20,76$ & $-21,20$ & 3,66 & 2,07 & $-0,30$ \\
\hline$-24,94$ & $-24,99$ & $-25,62$ & $-24,83$ & 4,19 & 2,48 & $-0,36$ \\
\hline$-25,38$ & $-24,84$ & $-26,50$ & $-25,41$ & 4,34 & 2,55 & $-0,40$ \\
\hline$-27,30$ & $-27,26$ & $-27,97$ & $-27,01$ & 4,51 & 2,55 & $-0,30$ \\
\hline$-29,81$ & $-29,98$ & $-30,77$ & $-29,62$ & 5,12 & 2,67 & $-0,40$ \\
\hline$-29,96$ & $-29,08$ & $-30,18$ & $-28,60$ & 5,10 & 2,65 & $-0,42$ \\
\hline$-28,19$ & $-28,47$ & $-28,71$ & $-27,88$ & 5,33 & 3,08 & $-0,44$ \\
\hline$-32,17$ & $-32,26$ & $-33,13$ & $-31,94$ & 5,83 & 3,16 & $-0,44$ \\
\hline$-30,70$ & $-30,89$ & $-30,62$ & $-29,47$ & 5,93 & 3,17 & $-0,50$ \\
\hline$-34,83$ & $-34,68$ & $-35,78$ & $-34,41$ & 6,68 & 3,23 & $-0,56$ \\
\hline$-34,53$ & $-34,83$ & $-35,78$ & $-34,70$ & 6,75 & 3,21 & $-0,60$ \\
\hline$-32,17$ & $-31,35$ & $-32,39$ & $-29,76$ & 5,44 & 2,93 & $-0,60$ \\
\hline$-34,09$ & $-34,22$ & $-35,78$ & $-34,99$ & 6,47 & 2,95 & $-0,60$ \\
\hline$-37,04$ & $-36,95$ & $-38,28$ & $-36,88$ & 6,97 & 3,06 & $-0,60$ \\
\hline$-39,11$ & $-39,22$ & $-40,19$ & $-38,91$ & 7,50 & 3,16 & $-0,62$ \\
\hline$-39,85$ & $-39,98$ & $-40,93$ & $-39,49$ & 7,70 & 3,17 & $-0,68$ \\
\hline$-21,25$ & $-20,14$ & $-21,50$ & $-20,91$ & 5,52 & 2,84 & $-0,62$ \\
\hline 0,74 & 1,06 & 0,59 & 0,73 & 2,34 & 1,92 & $-0,32$ \\
\hline
\end{tabular}


PROT2

\begin{tabular}{|c|c|c|c|c|c|c|}
\hline Chan 7 & Chan 8 & Chan 9 & Chan 10 & Chan 11 & Chan 12 & Chan 13 \\
\hline $\mathrm{mm}$ & $\mathrm{mm}$ & $\mathrm{mm}$ & $\mathrm{mm}$ & $\mathrm{mm}$ & $\mathrm{mm}$ & $\mathrm{mm}$ \\
\hline \multicolumn{7}{|c|}{ escorvamento } \\
\hline 0,00 & 0,00 & 0,00 & 0,00 & 0,00 & 0,00 & 0,00 \\
\hline 0,00 & 0,00 & 0,09 & 0,06 & 0,06 & $-0,02$ & 0,09 \\
\hline 0,00 & 0,00 & 0,15 & 0,06 & 0,14 & $-0,02$ & 0,19 \\
\hline$-0,06$ & 0,00 & 0,22 & $-0,08$ & 0,22 & $-0,04$ & 0,34 \\
\hline$-0,21$ & $-0,12$ & 0,28 & $-0,28$ & 0,33 & $-0,09$ & 0,77 \\
\hline$-0,11$ & $-0,06$ & 0,04 & $-0,08$ & 0,02 & $-0,04$ & 0,26 \\
\hline \multicolumn{7}{|l|}{ ensaio } \\
\hline 0,00 & 0,00 & 0,02 & 0,00 & 0,00 & 0,00 & 0,00 \\
\hline 0,00 & $-0,02$ & 0,07 & 0,02 & 0,06 & $-0,02$ & 0,07 \\
\hline 0,00 & 0,00 & 0,13 & 0,02 & 0,14 & $-0,04$ & 0,15 \\
\hline$-0,04$ & $-0,04$ & 0,20 & $-0,06$ & 0,25 & $-0,06$ & 0,35 \\
\hline$-0,04$ & $-0,04$ & 0,20 & $-0,06$ & 0,23 & $-0,06$ & 0,35 \\
\hline$-0,13$ & $-0,04$ & 0,26 & $-0,22$ & 0,35 & $-0,07$ & 0,52 \\
\hline$-0,24$ & $-0,12$ & 0,31 & $-0,37$ & 0,47 & $-0,09$ & 0,93 \\
\hline$-0,43$ & $-0,10$ & 1,36 & $-0,26$ & 1,45 & $-0,13$ & 0,90 \\
\hline$-0,62$ & $-0,13$ & 1,43 & $-0,51$ & 1,58 & $-0,18$ & 1,36 \\
\hline$-0,71$ & $-0,15$ & 1,40 & $-0,32$ & 1,66 & $-0,20$ & 1,90 \\
\hline$-0,77$ & $-0,15$ & 1,47 & $-0,39$ & 1,72 & $-0,22$ & 2,13 \\
\hline$-0,83$ & $-0,17$ & 1,52 & $-0,35$ & 1,80 & $-0,22$ & 2,39 \\
\hline$-0,38$ & $-0,19$ & 2,39 & $-0,06$ & 2,78 & $-0,24$ & 2,54 \\
\hline$-0,43$ & $-0,19$ & 2,44 & $-0,18$ & 2,80 & $-0,26$ & 2,82 \\
\hline$-0,60$ & $-0,19$ & 2,39 & 0,55 & 2,72 & $-0,24$ & 3,57 \\
\hline$-0,68$ & $-0,21$ & 2,46 & 0,45 & 2,84 & $-0,26$ & 3,73 \\
\hline$-0,88$ & $-0,23$ & 2,37 & 0,85 & 2,84 & $-0,28$ & 4,01 \\
\hline$-1,07$ & $-0,29$ & 2,44 & 0,75 & 2,97 & $-0,33$ & 4,35 \\
\hline$-0,98$ & $-0,33$ & 2,70 & 0,79 & 3,03 & $-0,33$ & 4,37 \\
\hline$-1,05$ & $-0,35$ & 2,72 & 0,75 & 3,09 & $-0,37$ & 4,48 \\
\hline$-1,16$ & $-0,40$ & 2,75 & 0,63 & 3,27 & $-0,39$ & 4,74 \\
\hline$-1,20$ & $-0,40$ & 2,92 & 0,69 & 3,44 & $-0,41$ & 4,82 \\
\hline$-1,28$ & $-0,40$ & 2,81 & 1,44 & 3,40 & $-0,41$ & 4,13 \\
\hline$-1,58$ & $-0,42$ & 2,83 & 1,40 & 3,62 & $-0,44$ & 4,24 \\
\hline$-1,69$ & $-0,44$ & 2,73 & 2,05 & 3,60 & $-0,42$ & 5,40 \\
\hline$-2,10$ & $-0,52$ & 2,59 & 2,15 & 3,70 & $-0,46$ & 5,43 \\
\hline$-2,12$ & $-0,52$ & 2,57 & 2,07 & 3,68 & $-0,48$ & 5,55 \\
\hline$-1,00$ & $-0,50$ & 2,57 & 0,77 & 3,03 & $-0,46$ & 6,33 \\
\hline$-0,49$ & $-0,54$ & 2,61 & 0,16 & 3,11 & $-0,50$ & 6,98 \\
\hline$-1,00$ & $-0,56$ & 2,50 & 0,57 & 3,19 & $-0,46$ & 6,76 \\
\hline$-1,71$ & $-0,59$ & 2,20 & 0,99 & 3,19 & $-0,46$ & 6,44 \\
\hline$-1,95$ & $-0,65$ & 2,11 & 1,08 & 3,21 & $-0,46$ & 6,25 \\
\hline$-0,73$ & $-0,52$ & 1,98 & 2,11 & 2,31 & $-0,37$ & 4,35 \\
\hline 1,52 & $-0,21$ & 1,95 & 3,29 & 1,35 & $-0,15$ & 1,94 \\
\hline
\end{tabular}




Chan 14 Chan 15 Chan $16 \quad$ Chan 17 Chan 18 Chan $19 \quad$ Chan 20

\begin{tabular}{|c|c|c|c|c|c|c|}
\hline $\mathrm{mm}$ & $\mathrm{mm}$ & $\mathrm{mm}$ & $\mathrm{mm}$ & $\mathrm{mm}$ & $\mathrm{mm}$ & $\mathrm{mm}$ \\
\hline \multicolumn{7}{|c|}{ escorvamento } \\
\hline 0,00 & 0,00 & 0,00 & 0,00 & 0,00 & 0,00 & 0,04 \\
\hline 0,04 & $-0,02$ & $-0,99$ & $-0,58$ & $-0,65$ & $-0,59$ & $-0,58$ \\
\hline 0,05 & $-0,02$ & $-2,06$ & $-1,26$ & $-1,31$ & $-1,25$ & $-1,28$ \\
\hline 0,07 & $-0,06$ & $-3,19$ & $-1,98$ & $-2,04$ & $-1,91$ & $-1,97$ \\
\hline 0,18 & $-0,15$ & $-4,44$ & $-2,84$ & $-2,87$ & $-2,72$ & $-2,81$ \\
\hline 0,20 & $-0,02$ & $-1,03$ & $-0,72$ & $-0,76$ & $-0,66$ & $-0,80$ \\
\hline \multicolumn{7}{|l|}{ ensaio } \\
\hline 0,02 & 0,00 & 0,00 & 0,04 & 0,00 & 0,00 & 0,00 \\
\hline 0,02 & $-0,04$ & $-0,99$ & $-0,61$ & $-0,62$ & $-0,59$ & $-0,48$ \\
\hline 0,04 & $-0,06$ & $-1,80$ & $-1,12$ & $-1,13$ & $-1,07$ & $-1,02$ \\
\hline 0,02 & $-0,09$ & $-2,83$ & $-1,73$ & $-1,75$ & $-1,69$ & $-1,64$ \\
\hline 0,02 & $-0,11$ & $-2,83$ & $-1,73$ & $-1,75$ & $-1,69$ & $-1,64$ \\
\hline$-0,02$ & $-0,11$ & $-3,78$ & $-2,30$ & $-2,36$ & $-2,32$ & $-2,27$ \\
\hline 0,05 & $-0,18$ & $-5,25$ & $-3,45$ & $-3,31$ & $-3,09$ & $-3,18$ \\
\hline 0,09 & $-0,20$ & $-6,20$ & $-3,88$ & $-4,18$ & $-3,83$ & $-3,44$ \\
\hline 0,09 & $-0,30$ & $-8,41$ & $-5,58$ & $-5,60$ & $-5,04$ & $-4,68$ \\
\hline 0,09 & $-0,39$ & $-10,39$ & $-7,30$ & $-6,18$ & $-5,56$ & $-5,85$ \\
\hline 0,11 & $-0,42$ & $-11,86$ & $-8,31$ & $-7,16$ & $-6,40$ & $-6,73$ \\
\hline 0,11 & $-0,48$ & $-13,25$ & $-9,60$ & $-8,15$ & $-6,88$ & $-7,38$ \\
\hline 0,23 & $-0,44$ & $-15,38$ & $-11,65$ & $-10,15$ & $-7,98$ & $-8,41$ \\
\hline 0,22 & $-0,48$ & $-16,63$ & $-12,48$ & $-10,95$ & $-8,72$ & $-9,06$ \\
\hline 1,50 & $-0,54$ & $-18,58$ & $-14,14$ & $-11,93$ & $-9,90$ & $-11,07$ \\
\hline 1,48 & $-0,59$ & $-20,19$ & $-15,18$ & $-12,95$ & $-10,85$ & $-12,17$ \\
\hline 2,49 & $-0,68$ & $-21,22$ & $-15,79$ & $-13,24$ & $-11,33$ & $-14,51$ \\
\hline 3,06 & $-0,81$ & $-24,41$ & $-18,20$ & $-15,53$ & $-13,28$ & $-16,63$ \\
\hline 3,08 & $-0,85$ & $-25,59$ & $-19,06$ & $-16,87$ & $-14,05$ & $-17,36$ \\
\hline 3,08 & $-0,89$ & $-27,42$ & $-20,50$ & $-18,44$ & $-15,31$ & $-18,49$ \\
\hline 3,30 & $-1,00$ & $-31,79$ & $-23,96$ & $-21,96$ & $-18,14$ & $-21,35$ \\
\hline 3,37 & $-1,01$ & $-32,82$ & $-24,53$ & $-22,73$ & $-19,06$ & $-22,00$ \\
\hline 4,29 & $-0,98$ & $-34,47$ & $-25,40$ & $-23,67$ & $-19,39$ & $-22,95$ \\
\hline 4,33 & $-1,11$ & $-37,89$ & $-27,81$ & $-26,58$ & $-21,82$ & $-25,18$ \\
\hline 4,42 & $-1,20$ & $-39,57$ & $-28,74$ & $-27,27$ & $-22,70$ & $-26,21$ \\
\hline 4,52 & $-1,33$ & $-46,00$ & $-32,70$ & $-33,49$ & $-28,37$ & $-29,93$ \\
\hline 4,61 & $-1,37$ & $-46,84$ & $-33,42$ & $-34,22$ & $-29,18$ & $-30,48$ \\
\hline 4,72 & $-1,37$ & $-49,78$ & $-33,67$ & $-36,04$ & $-38,70$ & $-32,05$ \\
\hline 4,94 & $-1,46$ & $-53,45$ & $-35,76$ & $-38,87$ & $-41,83$ & $-34,28$ \\
\hline 4,97 & $-1,51$ & $-57,45$ & $-38,31$ & $-43,67$ & $-44,59$ & $-36,55$ \\
\hline 4,99 & $-1,53$ & $-63,14$ & $-42,16$ & $-50,04$ & $-48,64$ & $-40,31$ \\
\hline 4,97 & $-1,61$ & $-65,64$ & $-44,06$ & $-52,29$ & $-50,29$ & $-42,07$ \\
\hline 4,33 & $-1,09$ & $-58,26$ & $-39,60$ & $-47,53$ & $-45,84$ & $-37,54$ \\
\hline 4,02 & $-0,31$ & $-46,37$ & $-31,94$ & $-38,80$ & $-38,15$ & $-29,42$ \\
\hline
\end{tabular}


Chan 21 Chan 22 Chan 23 Chan $24 \quad$ Chan $25 \quad$ Chan $26 \quad$ Chan 27

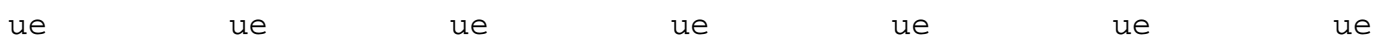

escorvamento

0,92

$-35,88$

$-69,92$

$-103,95$

$-143,51$

$-8,28$
0,92

$-32,21$

$-63,51$

$-95,72$

$-129,77$

$-8,28$
0,92

$-41,40$

$-79,11$

$-116,83$

$-160,07$

$-1,84$

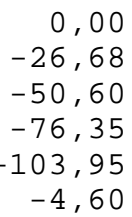

$-4,60$

$$
\begin{array}{r}
0,93 \\
-35,23 \\
-67,68 \\
-101,06 \\
-139,08 \\
-5,56
\end{array}
$$

$-32,71$

$-65,42$

$-96,26$

$-131,77$

1,87 ensaio

$\begin{array}{rrr}0,00 & 0,92 & 0,00 \\ -40,48 & -44,16 & -36,82 \\ -71,76 & -78,19 & -65,35 \\ -108,55 & -118,67 & -98,48 \\ -108,55 & -117,75 & -98,48 \\ -144,43 & -155,47 & -129,77 \\ -180,31 & -191,35 & -163,83 \\ -158,23 & -167,43 & -145,42 \\ -218,95 & -230,90 & -199,72 \\ -211,59 & -223,54 & -195,12 \\ -258,50 & -274,14 & -237,46 \\ -266,78 & -280,58 & -249,42 \\ -256,66 & -270,46 & -242,06 \\ -297,14 & -316,46 & -277,04 \\ -289,78 & -310,02 & -268,75 \\ -333,02 & -358,78 & -305,57 \\ -310,94 & -336,70 & -286,24 \\ -371,65 & -409,37 & -337,78 \\ -376,25 & -419,49 & -349,75 \\ -405,69 & -452,61 & -373,68 \\ -441,57 & -510,57 & -422,46 \\ -430,53 & -515,17 & -425,22 \\ -409,37 & -498,61 & -417,86 \\ -456,29 & -581,40 & -492,41 \\ -411,21 & -582,32 & -467,56 \\ -457,21 & -678,91 & -589,05 \\ -447,09 & -695,47 & -597,33 \\ -414,89 & -632,92 & -578,92 \\ -436,05 & -700,99 & -624,02 \\ -434,21 & -793,91 & -690,29 \\ -375,33 & -961,33 & -800,74 \\ -328,42 & -1072,65 & -890,93 \\ -217,11 & -614,52 & -629,54 \\ 21,16 & -171,11 & -265,99\end{array}$

0,00

$-46,92$

$-83,71$

$-126,95$

$-126,03$

$-167,43$

$-205,15$

$-177,55$

$-245,62$

$-236,42$

$-289,78$

$-291,62$

$-280,58$

$-331,18$

$-325,66$

$-378,09$

$-354,18$

$-434,21$

$-438,81$

$-475,61$

$-517,92$

$-511,49$

$-481,13$

$-536,32$

$-515,17$

$-536,32$

$-534,48$

$-457,21$

$-504,13$

$-528,96$

$-528,96$

$-505,97$

$-192,27$

128,79
0,00

$-30,36$

$-53,36$

$-80,95$

$-80,95$

$-104,87$

$-127,87$

$-114,99$

$-154,55$

$-147,19$

$-181,23$

$-194,11$

$-196,87$

$-220,79$

$-211,59$

$-236,42$

$-219,87$

$-254,82$

$-258,50$

$-271,38$

$-291,62$

$-285,18$

$-265,86$

$-289,78$

$-277,82$

$-289,78$

$-281,50$

$-262,18$

$-277,82$

$-279,66$

$-267,70$

$-256,66$

$-163,75$

33,12
0,00

$-38,94$

$-70,46$

$-106,62$

$-106,62$

$-140,93$

$-175,24$

$-152,98$

$-211,39$

$-190,07$

$-241,06$

$-265,17$

$-270,73$

$-313,38$

$-303,18$

$-352,32$

$-331,93$

$-400,54$

$-413,52$

$-445,04$

$-513,65$

$-521,07$

$-498,82$

$-583,19$

$-579,48$

$-699,09$

$-708,36$

$-655,51$

$-740,81$

$-811,27$

$-885,45$

$-939,22$

$-547,96$

$-143,71$
0,00

$-40,18$

$-71,02$

$-107,47$

$-107,47$

$-142,05$

$-171,02$

$-153,26$

$-207,46$

$-199,99$

$-247,65$

$-240,17$

$-221,48$

$-265,40$

$-275,68$

$-316,80$

$-300,91$

$-376,61$

$-384,09$

$-418,66$

$-480,34$

$-481,28$

$-489,69$

$-565,38$

$-544,82$

$-622,39$

$-628,93$

$-578,47$

$-639,21$

$-689,67$

$-752,29$

$-795,28$

$-450,44$

$-90,65$ 


\begin{tabular}{|c|c|c|c|c|c|c|}
\hline Chan 28 & Chan 29 & Chan 30 & Chan 31 & Chan 32 & Chan 33 & Chan 34 \\
\hline ue & ue & ue & ue & ue & ue & ue \\
\hline \multicolumn{7}{|c|}{ orvamento } \\
\hline 0,92 & 2,76 & 0,93 & 0,93 & 0,93 & 0,93 & 1,86 \\
\hline$-27,61$ & 22,08 & 26,04 & $-9,30$ & $-9,30$ & $-23,25$ & $-11,16$ \\
\hline$-52,46$ & 42,32 & 53,93 & $-19,54$ & $-20,47$ & $-46,50$ & $-24,19$ \\
\hline$-78,23$ & 63,48 & 83,69 & $-29,77$ & $-31,63$ & $-70,67$ & $-38,15$ \\
\hline$-106,76$ & 85,55 & 117,17 & $-40,94$ & $-45,59$ & $-98,57$ & $-53,96$ \\
\hline 5,52 & 34,96 & 39,06 & 1,86 & $-7,44$ & $-9,30$ & $-1,8$ \\
\hline
\end{tabular}

$\begin{array}{rrr}\text { ensaio } & \\ 0,00 & -1,84 & 0,00 \\ -30,37 & 15,64 & 23,25 \\ -54,30 & 28,52 & 41,85 \\ -81,91 & 43,24 & 63,23 \\ -81,91 & 43,24 & 63,23 \\ -107,69 & 58,88 & 85,55 \\ -131,62 & 80,95 & 124,61 \\ -120,57 & 72,68 & 121,82 \\ -160,15 & 104,87 & 171,10 \\ -157,39 & 111,31 & 179,47 \\ -189,60 & 137,07 & 208,30 \\ -192,36 & 146,27 & 219,46 \\ -186,84 & 151,79 & 228,76 \\ -216,29 & 170,19 & 249,22 \\ -226,42 & 183,07 & 260,38 \\ -252,19 & 216,19 & 283,62 \\ -238,38 & 212,51 & 275,25 \\ -282,56 & 277,82 & 315,24 \\ -280,72 & 298,98 & 306,87 \\ -295,44 & 363,38 & 317,10 \\ -313,85 & 515,17 & 278,97 \\ -311,09 & 552,88 & 261,31 \\ -304,65 & 574,04 & 247,36 \\ -324,90 & 706,51 & 259,45 \\ -307,41 & 785,63 & 143,21 \\ -325,82 & 976,05 & 134,84 \\ -318,45 & 1031,25 & 68,81 \\ -295,44 & 1028,49 & 39,06 \\ -316,61 & 1052,41 & 53,93 \\ -326,74 & 1064,37 & 81,83 \\ -325,82 & 1050,57 & 112,52 \\ -318,45 & 1025,73 & 116,24 \\ -185,00 & 903,38 & -28,83 \\ 33,13 & 770,91 & -293,85\end{array}$

0,00
$-13,03$
$-23,26$
$-34,42$
$-34,42$
$-45,59$
$-50,24$
$-40,94$
$-58,61$
$-53,03$
$-67,92$
$-72,57$
$-78,15$
$-89,32$
$-85,59$
$-97,69$
$-93,04$
$-107,92$
$-107,92$
$-111,64$
$-118,16$
$-119,09$
$-115,37$
$-128,39$
$-131,18$
$-142,35$
$-145,14$
$-132,11$
$-147,00$
$-156,30$
$-161,88$
$-162,81$
$-85,59$
$-23,26$

0,00
$-11,16$
$-19,54$
$-29,77$
$-29,77$
$-40,01$
$-49,31$
$-44,66$
$-64,20$
$-63,27$
$-77,22$
$-84,66$
$-85,59$
$-97,69$
$-92,11$
$-106,06$
$-101,41$
$-122,81$
$-132,11$
$-146,07$
$-178,63$
$-180,49$
$-172,12$
$-195,38$
$-193,52$
$-220,50$
$-220,50$
$-211,19$
$-226,08$
$-238,17$
$-250,27$
$-259,57$
$-195,38$
$-75,36$

0,00
$-26,97$
$-48,36$
$-73,46$
$-73,46$
$-95,78$
$-113,45$
$-97,64$
$-139,49$
$-139,49$
$-171,10$
$-158,09$
$-142,28$
$-173,89$
$-180,40$
$-210,16$
$-201,79$
$-248,29$
$-252,01$
$-268,74$
$-291,06$
$-291,99$
$-320,82$
$-349,65$
$-349,65$
$-372,89$
$-384,98$
$-359,88$
$-379,40$
$-397,07$
$-409,16$
$-412,88$
$-277,11$
$-150,65$

$-0,93$

$-15,82$

$-27,91$

$-42,80$

$-41,87$

$-54,89$

$-67,92$

$-64,20$

$-86,52$

$-83,73$

$-101,41$

$-96,76$

$-87,45$

$-103,27$

$-110,71$

$-125,60$

$-122,81$

$-150,72$

$-154,44$

$-166,54$

$-191,66$

$-192,59$

$-197,24$

$-221,43$

$-213,05$

$-241,90$

$-243,76$

$-230,73$

$-248,41$

$-263,29$

$-282,83$

$-297,72$

$-194,45$

$-78,15$ 


\begin{tabular}{|c|c|c|c|c|c|c|}
\hline Chan 35 & Chan 36 & Chan 37 & Chan 38 & Chan 39 & Chan 40 & Chan 4. \\
\hline ue & ue & ue & ue & ue & ue & ue \\
\hline \multicolumn{7}{|c|}{ orvamento } \\
\hline 0,94 & 0,93 & 1,86 & 0,93 & 1,86 & 0,93 & 0,93 \\
\hline$-33,89$ & $-38,13$ & $-33,48$ & $-28,83$ & $-26,04$ & $-34,42$ & $-38,13$ \\
\hline$-68,73$ & $-74,39$ & $-64,16$ & $-56,72$ & $-53,01$ & $-68,85$ & $-74,39$ \\
\hline$-102,62$ & $-109,73$ & $-94,85$ & $-83,69$ & $-79,04$ & $-103,27$ & $-110,66$ \\
\hline$-138,40$ & $-147,86$ & $-128,33$ & $-112,52$ & $-106,01$ & $-141,42$ & $-148,79$ \\
\hline$-8,47$ & $-5,58$ & $-2,79$ & $-1,86$ & $-2,79$ & $-7,44$ & $-7,44$ \\
\hline
\end{tabular}

ensaio

$\begin{array}{rr}0,00 & 0,00 \\ -40,49 & -43,71 \\ -69,67 & -76,25 \\ -105,45 & -115,31 \\ -104,51 & -115,31 \\ -138,40 & -150,65 \\ -172,30 & -186,91 \\ -149,70 & -164,59 \\ -209,02 & -227,83 \\ -203,37 & -222,25 \\ -248,56 & -268,74 \\ -256,09 & -275,25 \\ -246,68 & -262,24 \\ -287,16 & -309,66 \\ -288,10 & -302,22 \\ -324,82 & -343,14 \\ -308,82 & -318,96 \\ -367,19 & -379,40 \\ -373,78 & -380,33 \\ -404,85 & -410,09 \\ -449,10 & -445,43 \\ -439,69 & -438,92 \\ -428,39 & -419,39 \\ -483,00 & -475,19 \\ -453,81 & -451,94 \\ -472,64 & -544,00 \\ -466,99 & -553,30 \\ -429,33 & -490,99 \\ -444,39 & -570,97 \\ -397,32 & -684,42 \\ -274,92 & -887,14 \\ -215,61 & -989,43 \\ -214,67 & -447,29 \\ -6,59 & -37,20 \\ & \end{array}$

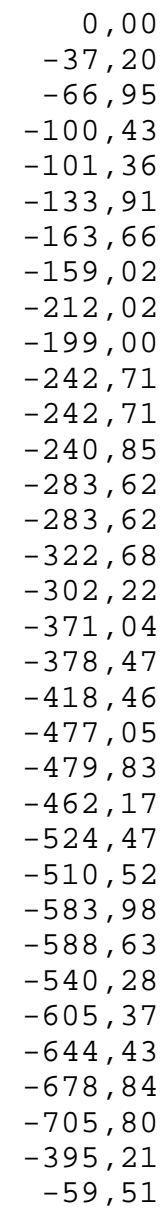

0,00

$-34,41$

$-59,51$

$-89,27$

$-89,27$

$-117,17$

$-142,28$

$-137,63$

$-181,33$

$-170,17$

$-204,58$

$-199,00$

$-194,35$

$-228,76$

$-225,97$

$-252,01$

$-237,13$

$-275,25$

$-272,46$

$-284,55$

$-294,78$

$-284,55$

$-270,60$

$-302,22$

$-284,55$

$-311,52$

$-310,59$

$-280,83$

$-308,73$

$-328,26$

$-350,58$

$-356,16$

$-181,33$

23,25
0,00

$-31,62$

$-54,86$

$-83,69$

$-83,69$

$-109,73$

$-132,98$

$-118,10$

$-161,80$

$-152,51$

$-189,70$

$-205,51$

$-210,16$

$-238,99$

$-237,13$

$-264,10$

$-254,80$

$-300,36$

$-306,87$

$-332,91$

$-384,05$

$-379,40$

$-369,18$

$-418,46$

$-411,95$

$-453,80$

$-455,66$

$-414,74$

$-455,66$

$-470,54$

$-477,97$

$-476,12$

$-286,41$

$-26,97$
0,00 $-41,85$ $-74,39$ $-113,45$ $-112,52$ $-147,86$ $-184,12$ $-159,94$ $-223,18$ $-221,32$ $-265,03$ $-273,39$

$-264,10$

$-305,94$

$-304,08$

$-345,93$

$-327,33$

$-393,35$

$-401,72$

$-430,55$

$-470,54$

$-459,38$

$-448,22$

$-506,80$

$-477,05$

$-552,37$

$-560,74$

$-522,61$

$-569,11$

$-579,34$

$-557,95$

$-533,77$

$-358,95$

$-58,58$ 


\begin{tabular}{|c|c|c|c|c|c|c|}
\hline Chan 42 & Chan 43 & Chan 44 & Chan 45 & Chan 46 & Chan 47 & Chan $4 \varepsilon$ \\
\hline ue & ue & ue & ue & ue & ue & ue \\
\hline \multicolumn{7}{|c|}{ orvamento } \\
\hline 0,00 & 0,93 & 0,93 & 0,00 & 0,93 & 0,93 & 0,93 \\
\hline$-40,94$ & $-34,42$ & $-31,63$ & $-33,91$ & $-34,44$ & $-36,28$ & $-41,89$ \\
\hline$-78,15$ & $-65,13$ & $-60,47$ & $-66,88$ & $-66,09$ & $-68,85$ & $-80,05$ \\
\hline$-117,23$ & $-95,83$ & $-90,25$ & $-98,91$ & $-98,67$ & $-103,27$ & $-119,15$ \\
\hline$-156,30$ & $-129,32$ & $-120,95$ & $-130,94$ & $-130,32$ & $-137,69$ & $-160,10$ \\
\hline$-13,03$ & $-8,37$ & $-6,51$ & $-6,59$ & $-5,58$ & $-12,09$ & $-5,58$ \\
\hline
\end{tabular}

ensaio

$\begin{array}{rrr}0,00 & 0,00 & 0,00 \\ -43,73 & -37,21 & -35,35 \\ -76,29 & -65,13 & -61,40 \\ -116,30 & -98,62 & -93,04 \\ -116,30 & -98,62 & -93,04 \\ -152,58 & -128,39 & -121,88 \\ -189,80 & -160,02 & -148,86 \\ -168,40 & -121,88 & -114,44 \\ -230,73 & -177,70 & -164,68 \\ -229,80 & -162,81 & -149,79 \\ -272,60 & -200,96 & -186,07 \\ -280,04 & -217,71 & -199,10 \\ -274,46 & -219,57 & -200,03 \\ -315,40 & -253,99 & -233,52 \\ -313,54 & -262,36 & -246,55 \\ -351,68 & -292,14 & -277,25 \\ -332,14 & -271,67 & -259,57 \\ -393,55 & -319,12 & -310,74 \\ -401,92 & -324,70 & -318,19 \\ -432,62 & -348,89 & -341,45 \\ -483,79 & -387,96 & -381,45 \\ -476,35 & -386,10 & -373,08 \\ -458,67 & -367,50 & -347,03 \\ -530,31 & -420,53 & -395,41 \\ -503,33 & -391,69 & -362,84 \\ -581,48 & -466,12 & -423,32 \\ -582,41 & -467,98 & -424,25 \\ -512,63 & -412,15 & -366,57 \\ -588,92 & -476,35 & -427,04 \\ -654,05 & -504,26 & -457,74 \\ -768,49 & -534,96 & -488,44 \\ -847,57 & -549,85 & -505,19 \\ -452,16 & -286,55 & -275,39 \\ -70,71 & 13,03 & 20,47\end{array}$

0,00

$-37,68$

$-66,88$

$-100,79$

$-100,79$

$-130,94$

$-162,02$

$-162,02$

$-211,95$

$-209,12$

$-244,92$

$-244,92$

$-249,63$

$-286,36$

$-289,19$

$-324,98$

$-308,97$

$-370,20$

$-382,45$

$-408,82$

$-457,80$

$-450,27$

$-435,20$

$-496,43$

$-472,88$

$-556,71$

$-564,25$

$-501,14$

$-581,20$

$-619,82$

$-668,81$

$-697,07$

$-416,36$

$-94,20$
0,00

$-37,23$

$-66,09$

$-100,53$

$-100,53$

$-132,18$

$-161,03$

$-157,31$

$-205,71$

$-198,27$

$-232,71$

$-230,85$

$-233,64$

$-265,29$

$-262,49$

$-296,00$

$-276,46$

$-329,51$

$-336,03$

$-352,78$

$-380,71$

$-375,12$

$-355,58$

$-402,12$

$-375,12$

$-420,74$

$-420,74$

$-376,06$

$-427,25$

$-445,87$

$-466,35$

$-475,65$

$-243,88$

24,20
0,00

$-38,15$

$-66,99$

$-102,34$

$-101,41$

$-133,97$

$-167,47$

$-149,79$

$-204,68$

$-205,61$

$-244,69$

$-252,13$

$-247,48$

$-282,83$

$-277,25$

$-319,12$

$-299,58$

$-358,19$

$-367,50$

$-392,62$

$-433,55$

$-429,83$

$-411,22$

$-467,05$

$-442,86$

$-504,26$

$-507,05$

$-471,70$

$-506,12$

$-537,75$

$-559,15$

$-565,67$

$-376,80$

$-66,99$
0,00 $-45,61$ $-81,91$

$-124,73$

$-124,73$

$-162,90$

$-201,99$

$-176,86$

$-242,02$

$-233,64$

$-283,90$

$-291,35$

$-283,90$

$-324,86$

$-316,48$

$-361,16$

$-334,17$

$-405,84$

$-417,01$

$-444,94$

$-492,41$

$-485,89$

$-466,35$

$-538,02$

$-504,51$

$-591,08$

$-594,80$

$-532,43$

$-602,25$

$-649,72$

$-713,02$

$-753,97$

$-386,29$

$-29,79$ 
PROT2

\begin{tabular}{crrr} 
Chan 49 & Chan 50 & Chan 51 & Chan 52 \\
ue & ue & ue & \multicolumn{1}{c}{ ue } \\
& & & \\
& & & \\
corvamento & & & 0,94 \\
0,00 & 0,94 & 0,00 & $-31,09$ \\
$-40,94$ & $-27,32$ & $-34,85$ & $-58,40$ \\
$-79,08$ & $-53,69$ & $-66,88$ & $-88,55$ \\
$-119,09$ & $-79,13$ & $-98,91$ & $-120,57$ \\
$-159,09$ & $-103,62$ & $-133,76$ & $-3,77$ \\
$-9,30$ & $-1,88$ & $-8,48$ &
\end{tabular}

$\begin{array}{rrrr}\text { ensaio } & & & \\ 0,93 & 0,00 & 0,00 & 0,00 \\ -43,73 & -31,09 & -38,62 & -34,85 \\ -78,15 & -54,64 & -67,82 & -61,23 \\ -120,02 & -81,95 & -101,73 & -93,26 \\ -119,09 & -81,95 & -101,73 & -93,26 \\ -158,16 & -106,44 & -133,76 & -121,52 \\ -195,38 & -128,11 & -165,79 & -151,66 \\ -178,63 & -118,69 & -133,76 & -116,81 \\ -239,11 & -153,54 & -186,51 & -166,73 \\ -238,17 & -153,54 & -167,67 & -144,12 \\ -287,48 & -179,92 & -213,83 & -183,69 \\ -288,42 & -177,09 & -232,67 & -195,93 \\ -281,90 & -170,50 & -242,09 & -196,87 \\ -324,70 & -190,28 & -276,94 & -225,13 \\ -345,17 & -190,28 & -286,36 & -222,31 \\ -398,20 & -207,24 & -328,75 & -257,16 \\ -373,08 & -195,93 & -301,43 & -233,61 \\ -467,98 & -226,08 & -365,49 & -284,48 \\ -483,79 & -227,02 & -377,74 & -292,96 \\ -519,15 & -230,79 & -403,17 & -312,74 \\ -598,23 & -230,79 & -459,69 & -344,77 \\ -595,44 & -222,31 & -465,34 & -344,77 \\ -601,95 & -220,42 & -442,73 & -310,85 \\ -700,57 & -222,31 & -507,73 & -358,90 \\ -658,70 & -204,41 & -483,24 & -325,93 \\ -778,72 & -200,64 & -571,78 & -388,10 \\ -787,09 & -195,93 & -577,44 & -386,21 \\ -707,08 & -179,92 & -524,68 & -355,13 \\ -811,28 & -186,51 & -593,45 & -388,10 \\ -878,27 & -172,38 & -644,32 & -413,53 \\ -961,07 & -150,72 & -709,31 & -420,12 \\ -1009,45 & -134,70 & -758,30 & -414,47 \\ -555,43 & -85,72 & -425,78 & -239,26 \\ -100,48 & 74,42 & -78,18 & 41,45\end{array}$


Resultados do ensaio do protótipo PROT 3 
PROT3

\begin{tabular}{|c|c|c|c|c|c|c|}
\hline Chan 0 & Chan 1 & Chan 2 & Chan 3 & Chan 4 & Chan 5 & Chan 6 \\
\hline $\mathrm{kN}$ & $\mathrm{kN}$ & $\mathrm{kN}$ & $\mathrm{kN}$ & $\mathrm{mm}$ & $\mathrm{mm}$ & $\mathrm{mm}$ \\
\hline \multicolumn{7}{|c|}{ escorvamento } \\
\hline$-0,30$ & $-0,29$ & $-0,29$ & $-0,15$ & $-0,02$ & $-0,04$ & $-0,03$ \\
\hline$-5,17$ & $-5,59$ & $-5,23$ & $-5,45$ & 0,55 & 0,08 & $-0,08$ \\
\hline$-10,04$ & $-10,45$ & $-10,74$ & $-10,90$ & 0,88 & 0,21 & $-0,15$ \\
\hline$-14,76$ & $-15,16$ & $-15,97$ & $-15,90$ & 0,96 & 0,45 & $-0,20$ \\
\hline$-0,44$ & $-0,29$ & $-0,44$ & $-0,30$ & $-0,13$ & 0,06 & $-0,02$ \\
\hline \multicolumn{7}{|l|}{ ensaio } \\
\hline 0,00 & 0,00 & 0,00 & 0,00 & $-0,02$ & 0,00 & 0,00 \\
\hline$-4,87$ & $-5,15$ & $-5,08$ & $-5,30$ & 0,51 & 0,08 & $-0,05$ \\
\hline$-9,59$ & $-10,01$ & $-10,31$ & $-10,60$ & 0,98 & 0,23 & $-0,12$ \\
\hline$-14,76$ & $-15,02$ & $-15,97$ & $-16,20$ & 1,07 & 0,41 & $-0,18$ \\
\hline$-19,33$ & $-19,58$ & $-20,91$ & $-20,75$ & 1,18 & 0,68 & $-0,25$ \\
\hline$-24,05$ & $-24,59$ & $-26,13$ & $-25,59$ & 1,26 & 0,92 & $-0,30$ \\
\hline$-28,78$ & $-29,30$ & $-31,07$ & $-30,44$ & 1,39 & 1,18 & $-0,37$ \\
\hline$-34,09$ & $-34,89$ & $-36,73$ & $-35,89$ & 1,56 & 1,54 & $-0,45$ \\
\hline$-39,11$ & $-40,05$ & $-41,96$ & $-41,19$ & 1,71 & 2,01 & $-0,52$ \\
\hline$-34,24$ & $-32,68$ & $-36,88$ & $-36,04$ & 2,69 & 1,99 & $-0,45$ \\
\hline$-39,70$ & $-39,02$ & $-42,40$ & $-41,65$ & 2,80 & 2,40 & $-0,54$ \\
\hline$-44,42$ & $-43,87$ & $-47,19$ & $-46,49$ & 2,78 & 2,87 & $-0,64$ \\
\hline$-49,59$ & $-49,03$ & $-52,41$ & $-51,79$ & 2,71 & 3,51 & $-0,74$ \\
\hline$-47,22$ & $-47,26$ & $-50,96$ & $-48,61$ & 1,58 & 3,36 & $-0,69$ \\
\hline$-54,90$ & $-54,77$ & $-58,08$ & $-56,94$ & 1,58 & 4,08 & $-0,84$ \\
\hline$-59,47$ & $-59,48$ & $-62,72$ & $-61,63$ & 1,58 & 4,58 & $-0,92$ \\
\hline$-55,34$ & $-53,30$ & $-59,09$ & $-55,73$ & 1,09 & 4,28 & $-0,82$ \\
\hline$-63,90$ & $-63,90$ & $-66,35$ & $-65,72$ & 1,77 & 4,96 & $-1,00$ \\
\hline$-20,51$ & $-19,73$ & $-20,91$ & $-19,99$ & 1,20 & 1,93 & $-0,27$ \\
\hline 0,00 & 0,00 & 0,15 & 0,15 & 0,00 & 1,05 & 0,02 \\
\hline
\end{tabular}


PROT3

\begin{tabular}{|c|c|c|c|c|c|c|}
\hline Chan 7 & Chan 8 & Chan 9 & Chan 10 & Chan 11 & Chan 12 & Chan 13 \\
\hline $\mathrm{mm}$ & $\mathrm{mm}$ & $\mathrm{mm}$ & $\mathrm{mm}$ & $\mathrm{mm}$ & $\mathrm{mm}$ & $\mathrm{mm}$ \\
\hline \multicolumn{7}{|c|}{ escorvamento } \\
\hline$-0,03$ & $-0,02$ & $-0,03$ & $-0,02$ & $-0,02$ & $-0,02$ & $-0,04$ \\
\hline 0,00 & 0,22 & $-0,03$ & 0,13 & 0,02 & $-0,04$ & $-0,04$ \\
\hline 0,00 & 0,50 & $-0,03$ & 0,39 & 0,08 & $-0,04$ & $-0,04$ \\
\hline 0,17 & 0,83 & $-0,03$ & 0,72 & 0,12 & $-0,04$ & $-0,02$ \\
\hline 0,16 & 0,07 & $-0,03$ & 0,17 & 0,02 & $-0,04$ & 0,02 \\
\hline \multicolumn{7}{|l|}{ ensaio } \\
\hline 0,00 & 0,00 & 0,00 & $-0,02$ & 0,00 & 0,02 & $-0,02$ \\
\hline 0,02 & 0,22 & 0,00 & 0,04 & 0,02 & 0,02 & $-0,02$ \\
\hline 0,02 & 0,50 & 0,00 & 0,24 & 0,06 & 0,02 & 0,00 \\
\hline 0,10 & 0,78 & 0,02 & 0,57 & 0,12 & 0,02 & 0,00 \\
\hline 0,45 & 1,12 & 0,00 & 0,90 & 0,14 & $-0,02$ & 0,04 \\
\hline 0,69 & 1,43 & 0,00 & 1,22 & 0,20 & $-0,04$ & 0,04 \\
\hline 1,01 & 1,76 & 0,00 & 1,55 & 0,26 & $-0,08$ & 0,07 \\
\hline 1,23 & 2,13 & 0,00 & 1,90 & 0,32 & $-0,12$ & 0,13 \\
\hline 1,58 & 2,52 & $-0,02$ & 2,21 & 0,38 & $-0,16$ & 0,23 \\
\hline$-0,36$ & 1,94 & $-1,23$ & 1,51 & 0,68 & $-0,26$ & $-0,79$ \\
\hline$-0,24$ & 2,26 & $-1,23$ & 1,70 & 0,70 & $-0,26$ & $-0,72$ \\
\hline$-0,05$ & 2,57 & $-1,23$ & 1,86 & 0,70 & $-0,28$ & $-0,65$ \\
\hline 0,54 & 2,94 & $-1,19$ & 2,16 & 0,76 & $-0,28$ & $-0,52$ \\
\hline 1,82 & 3,13 & $-1,60$ & 1,00 & 0,50 & $-0,37$ & $-0,50$ \\
\hline 2,10 & 3,49 & $-1,59$ & 1,18 & 0,58 & $-0,39$ & $-0,32$ \\
\hline 2,39 & 3,70 & $-1,57$ & 1,33 & 0,68 & $-0,39$ & $-0,20$ \\
\hline 2,95 & 3,39 & $-2,08$ & 1,31 & 0,56 & $-0,45$ & $-0,63$ \\
\hline 3,14 & 3,77 & $-2,03$ & 1,44 & 0,80 & $-0,43$ & $-0,27$ \\
\hline 0,94 & 1,49 & $-2,17$ & $-0,94$ & 0,26 & $-0,16$ & $-2,29$ \\
\hline 0,00 & 0,26 & $-2,11$ & $-1,97$ & 0,00 & $-0,06$ & $-2,20$ \\
\hline
\end{tabular}


PROT3

\begin{tabular}{|c|c|c|c|c|c|c|}
\hline Chan 14 & Chan 15 & Chan 16 & Chan 17 & Chan 18 & Chan 19 & Chan \\
\hline $\mathrm{mm}$ & $\mathrm{mm}$ & $\mathrm{mm}$ & $\mathrm{mm}$ & $\mathrm{mm}$ & $\mathrm{mm}$ & $\mathrm{mm}$ \\
\hline \multicolumn{7}{|c|}{ scorvamento } \\
\hline$-0,02$ & $-0,04$ & $-0,04$ & 0,04 & $-0,04$ & $-0,04$ & $-0,04$ \\
\hline 0,11 & $-0,04$ & $-1,36$ & $-0,73$ & $-0,76$ & $-0,77$ & $-0,73$ \\
\hline 0,24 & $-0,04$ & $-2,76$ & $-1,56$ & $-1,62$ & $-1,58$ & $-1,57$ \\
\hline 0,36 & $-0,04$ & $-4,12$ & $-2,36$ & $-2,48$ & $-2,39$ & $-2,34$ \\
\hline 0,02 & $-0,04$ & $-0,18$ & $-0,04$ & $-0,14$ & $-0,15$ & $-0,15$ \\
\hline \multicolumn{7}{|l|}{ ensaio } \\
\hline 0,00 & 0,00 & 0,00 & 0,00 & 0,00 & 0,00 & 0,00 \\
\hline 0,13 & 0,00 & $-1,29$ & $-0,73$ & $-0,72$ & $-0,70$ & $-0,66$ \\
\hline 0,26 & 0,00 & $-2,65$ & $-1,53$ & $-1,51$ & $-1,43$ & $-1,43$ \\
\hline 0,36 & 0,00 & $-4,16$ & $-2,44$ & $-2,45$ & $-2,31$ & $-2,27$ \\
\hline 0,50 & $-0,04$ & $-5,56$ & $-3,31$ & $-3,35$ & $-3,16$ & $-3,07$ \\
\hline 0,62 & $-0,04$ & $-7,10$ & $-4,25$ & $-4,32$ & $-4,07$ & $-4,02$ \\
\hline 0,75 & $-0,06$ & $-8,65$ & $-5,20$ & $-5,29$ & $-4,99$ & $-4,93$ \\
\hline 0,86 & $-0,09$ & $-10,52$ & $-6,33$ & $-6,47$ & $-6,09$ & $-6,03$ \\
\hline 0,86 & $-0,11$ & $-12,33$ & $-7,45$ & $-7,63$ & $-7,16$ & $-7,09$ \\
\hline 0,67 & $-0,30$ & $-14,35$ & $-8,58$ & $-13,02$ & $-8,33$ & $-9,21$ \\
\hline 0,64 & $-0,32$ & $-16,00$ & $-9,53$ & $-14,03$ & $-9,25$ & $-10,05$ \\
\hline 0,56 & $-0,34$ & $-17,51$ & $-10,51$ & $-14,93$ & $-10,13$ & $-10,93$ \\
\hline 0,41 & $-0,35$ & $-19,43$ & $-11,71$ & $-16,19$ & $-11,31$ & $-12,06$ \\
\hline 0,50 & $-0,54$ & $-22,81$ & $-15,78$ & $-18,88$ & $-16,30$ & $-13,93$ \\
\hline 0,34 & $-0,58$ & $-25,09$ & $-17,13$ & $-20,25$ & $-17,62$ & $-15,17$ \\
\hline 0,24 & $-0,60$ & $-27,04$ & $-18,29$ & $-21,73$ & $-18,80$ & $-16,30$ \\
\hline 0,30 & $-0,63$ & $-28,40$ & $-18,44$ & $-24,60$ & $-22,69$ & $-16,81$ \\
\hline 0,19 & $-0,67$ & $-31,86$ & $-20,40$ & $-27,16$ & $-24,74$ & $-18,71$ \\
\hline 0,39 & $-0,39$ & $-35,91$ & $-12,80$ & $-19,39$ & $-28,71$ & $-34,47$ \\
\hline$-0,30$ & $-0,32$ & $-27,37$ & $-9,13$ & $-15,65$ & $-23,38$ & $-27,23$ \\
\hline
\end{tabular}


PROT3

\begin{tabular}{|c|c|c|c|c|c|c|}
\hline Chan 21 & Chan 22 & Chan 23 & Chan 24 & Chan 25 & Chan 26 & Chan 2 \\
\hline ue & ue & ue & ue & ue & ue & ue \\
\hline \multicolumn{7}{|c|}{ escorvamento } \\
\hline$-1,87$ & 0,00 & $-0,94$ & $-0,94$ & $-0,94$ & $-0,94$ & 0,00 \\
\hline$-34,60$ & $-60,79$ & $-43,96$ & $-50,50$ & $-58,92$ & $-60,18$ & $-56,48$ \\
\hline$-66,40$ & $-124,39$ & $-88,85$ & $-101,94$ & $-118,78$ & $-122,24$ & $-114,84$ \\
\hline$-101,94$ & $-180,50$ & $-130,00$ & $-151,51$ & $-176,76$ & $-181,49$ & $-171,31$ \\
\hline$-1,87$ & 4,68 & 0,94 & 2,81 & 3,74 & 3,76 & 2,82 \\
\hline
\end{tabular}

$-1,87$
$-36,47$
$-69,21$
$-106,62$
$-142,16$
$-178,63$
$-216,98$
$-260,93$
$-302,08$
$-241,29$
$-278,70$
$-318,92$
$-363,81$
$-478,84$
$-522,80$
$-544,31$
$-510,64$
$-556,47$
$-235,68$
$-95,39$

$$
\begin{array}{r}
0,00 \\
-44,89 \\
-88,85 \\
-135,61 \\
-174,89 \\
-216,04 \\
-256,26 \\
-302,08 \\
-344,17 \\
-303,95 \\
-352,59 \\
-389,06 \\
-424,60 \\
-380,64 \\
-436,76 \\
-464,82 \\
-428,34 \\
-480,71 \\
-147,77 \\
26,19
\end{array}
$$

ensaio

$-1,87$
$-54,24$
$-106,62$
$-162,73$
$-211,36$
$-261,87$
$-314,24$
$-375,03$
$-434,89$
$-380,64$
$-444,24$
$-502,22$
$-573,30$
$-579,85$
$-670,57$
$-743,52$
$-699,56$
$-834,24$
$-309,56$
$-79,50$

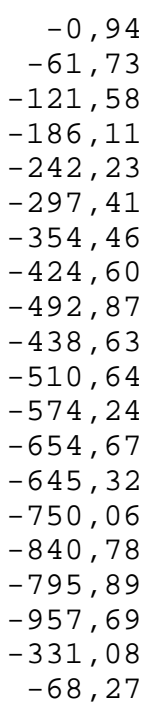

$-0,94$

$-63,94$

$-125,07$

$-191,83$

$-250,13$

$-307,49$

$-367,67$

$-436,32$

$-502,14$

$-440,08$

$-509,67$

$-567,97$

$-629,09$

$-614,04$

$-697,74$

$-737,23$

$-690,21$

$-753,22$

$-276,46$

$-24,45$
$-0,94$

$-59,30$

$-117,66$

$-179,78$

$-233,44$

$-287,09$

$-340,74$

$-401,93$

$-457,46$

$-395,34$

$-460,29$

$-511,11$

$-559,12$

$-522,41$

$-601,48$

$-633,48$

$-579,83$

$-656,07$

$-96,95$

110,13 
PROT3

Chan 28 Chan 29 Chan 30 Chan 31 Chan 32 Chan 33 Chan 34

ue ue ue ue ue ue ue

\begin{tabular}{rrrrrrr} 
escorvamento & \multicolumn{7}{c}{0} \\
0,00 & 1,87 & 0,00 & 0,00 & $-0,94$ & $-0,94$ & $-0,94$ \\
$-61,73$ & $-54,27$ & $-67,84$ & $-64,04$ & $-59,33$ & 15,07 & 14,13 \\
$-125,32$ & $-110,41$ & $-137,56$ & $-129,96$ & $-119,60$ & 34,84 & 31,09 \\
$-185,18$ & $-164,68$ & $-203,52$ & $-192,12$ & $-177,05$ & 52,74 & 47,11 \\
5,61 & 4,68 & 1,88 & 1,88 & 1,88 & 7,53 & 6,60
\end{tabular}

ensaio

$\begin{array}{rrrrrrr}-0,94 & -4,68 & 0,00 & 0,00 & 0,00 & -1,88 & -0,94 \\ -66,40 & -62,69 & -69,72 & -66,86 & -61,21 & 12,24 & 11,31 \\ -130,93 & -115,09 & -138,51 & -131,84 & -121,49 & 29,19 & 25,44 \\ -198,27 & -174,04 & -212,94 & -201,53 & -184,58 & 46,15 & 40,52 \\ -258,13 & -225,50 & -278,90 & -261,81 & -240,15 & 66,86 & 58,42 \\ -317,98 & -274,16 & -348,62 & -324,90 & -294,77 & 94,17 & 82,91 \\ -381,58 & -321,88 & -419,29 & -388,94 & -349,39 & 119,60 & 107,41 \\ -460,14 & -379,90 & -505,97 & -468,99 & -410,60 & 150,68 & 136,62 \\ -538,70 & -432,29 & -588,88 & -548,10 & -466,16 & 180,82 & 163,95 \\ -482,58 & -387,38 & -513,51 & -486,88 & -405,89 & 170,46 & 154,52 \\ -559,27 & -446,33 & -603,02 & -566,93 & -474,64 & 194,00 & 175,25 \\ -630,35 & -492,18 & -680,28 & -639,45 & -526,44 & 220,37 & 196,92 \\ -723,88 & -543,64 & -769,79 & -731,74 & -574,46 & 259,92 & 230,84 \\ -734,16 & -523,99 & -753,77 & -734,56 & -537,74 & 234,49 & 214,82 \\ -845,46 & -590,43 & -882,85 & -850,40 & -618,73 & 271,22 & 246,86 \\ -945,53 & -630,66 & -969,54 & -952,11 & -646,04 & 307,95 & 277,95 \\ -904,38 & -600,72 & -886,62 & -892,78 & -590,47 & 292,88 & 262,88 \\ -1052,15 & -666,22 & -1043,97 & -1071,71 & -642,27 & 349,39 & 310,93 \\ -510,64 & -209,60 & -279,84 & -412,48 & -80,05 & 161,04 & 144,16 \\ -202,95 & -11,23 & -33,92 & -155,39 & 107,36 & 80,05 & 70,67\end{array}$


PROT3

\begin{tabular}{|c|c|c|c|c|c|c|}
\hline Chan 35 & Chan 36 & Chan 37 & Chan 38 & Chan 39 & Chan 40 & Chan 41 \\
\hline ue & ue & ue & ue & ue & ue & ue \\
\hline \multicolumn{7}{|c|}{ scorvamento } \\
\hline$-0,95$ & 0,00 & $-0,94$ & $-0,94$ & 0,00 & 0,94 & 0,00 \\
\hline$-8,52$ & $-1,88$ & $-6,59$ & 10,36 & $-33,90$ & $-62,97$ & $-55,43$ \\
\hline$-13,25$ & $-0,94$ & $-12,24$ & 23,54 & $-69,69$ & $-129,70$ & $-112,73$ \\
\hline$-19,88$ & 1,88 & $-16,95$ & 39,55 & $-103,59$ & $-191,74$ & $-165,34$ \\
\hline 3,79 & 8,48 & 3,77 & 9,42 & $-1,88$ & 7,52 & 2,82 \\
\hline
\end{tabular}

ensaio

$\begin{array}{rr}-1,89 & -1,88 \\ -11,36 & -5,65 \\ -18,93 & -7,53 \\ -26,50 & -8,48 \\ -34,07 & -6,59 \\ -36,91 & -0,94 \\ -43,54 & 3,77 \\ -50,16 & 10,36 \\ -55,84 & 17,89 \\ -57,73 & 15,07 \\ -57,73 & 22,60 \\ -56,79 & 34,84 \\ -50,16 & 58,39 \\ -33,13 & 70,63 \\ -24,61 & 89,47 \\ 5,68 & 135,61 \\ 7,57 & 131,84 \\ 62,47 & 203,42 \\ -18,93 & 66,86 \\ -37,86 & 29,19\end{array}$

$\begin{array}{rr}0,00 & -1,88 \\ -9,42 & 6,59 \\ -16,95 & 17,89 \\ -24,49 & 29,19 \\ -29,19 & 47,09 \\ -31,08 & 73,46 \\ -34,84 & 99,83 \\ -35,79 & 134,67 \\ -35,79 & 172,34 \\ -36,73 & 170,46 \\ -34,84 & 192,12 \\ -31,08 & 223,19 \\ -24,49 & 280,64 \\ -16,01 & 319,25 \\ -5,65 & 364,46 \\ 6,59 & 437,91 \\ -0,94 & 429,44 \\ 23,54 & 517,96 \\ -48,97 & 282,52 \\ -52,74 & 209,07\end{array}$

0,00
$-36,73$
$-70,63$
$-106,42$
$-141,26$
$-177,05$
$-213,78$
$-257,10$
$-296,65$
$-317,37$
$-353,15$
$-383,29$
$-420,02$
$-420,02$
$-468,99$
$-568,81$
$-602,72$
$-688,42$
$-362,57$
$-182,70$

$-0,94$

$-66,73$

$-132,52$

$-202,07$

$-262,23$

$-321,44$

$-381,59$

$-456,78$

$-531,03$

$-418,25$

$-503,77$

$-574,27$

$-662,61$

$-649,46$

$-764,12$

$-781,98$

$-650,40$

$-779,16$

$-186,10$

63,91

0,00
$-57,30$
$-114,61$
$-173,79$
$-223,58$
$-274,31$
$-322,22$
$-375,76$
$-423,68$
$-363,55$
$-418,98$
$-458,43$
$-492,25$
$-465,01$
$-506,34$
$-487,56$
$-456,55$
$-401,13$
$-159,70$
35,70


Chan 42 Chan 43 Chan $44 \quad$ Chan $45 \quad$ Chan $46 \quad$ Chan $47 \quad$ Chan 48

ue

ue

ue

ue

0,00

$-34,06$

$-70,00$

$-105,95$

$-1,89$ ue

0,94

$-62,03$

$-128,76$

$-189,86$

5,64 ue

1,88

$-62,06$

$-128,83$

$-192,77$

5,64 ue

2,82

$-59,21$

$-123,12$

$-184,22$

6,58

ensaio

0,00
$-71,43$
$-141,92$
$-219,93$
$-287,60$
$-359,03$
$-430,46$
$-517,87$
$-600,58$
$-581,78$
$-680,47$
$-763,18$
$-866,57$
$-854,35$
$-1013,19$
$-1178,61$
$-1089,32$
$-1435,19$
$-506,59$
$-194,55$

$$
\begin{array}{r}
0,94 \\
-66,76 \\
-132,59 \\
-201,23 \\
-263,30 \\
-325,36 \\
-390,24 \\
-470,17 \\
-545,40 \\
-473,93 \\
-554,80 \\
-622,51 \\
-700,56 \\
-678,93 \\
-788,95 \\
-865,12 \\
-791,77 \\
-946,93 \\
-357,33 \\
-88,39
\end{array}
$$

0,00
$-66,42$
$-131,92$
$-201,10$
$-261,07$
$-321,95$
$-382,84$
$-456,64$
$-524,90$
$-484,31$
$-560,88$
$-623,61$
$-700,18$
$-700,18$
$-800,73$
$-905,89$
$-856,08$
$-1050,73$
$-479,70$
$-192,80$

$-0,95$

$-0,94$

$-0,94$
$-64,85$

$-36,89$

$-71,89$

$-129,70$

$-200,19$

$-108,79$
$-145,68$

$-258,47$

$-184,47$

$-224,20$

$-269,60$

$-317,68$

$-375,95$

$-445,50$

$-312,17$

$-253,52$

$-514,11$

$-481,22$

$-294,20$

$-334,88$

$-560,17$

$-624,08$

$-381,23$

$-355,69$

$-703,97$

$-724,65$

$-408,66$

$-444,61$

$-390,69$

$-836,49$

$-915,44$

$-880,67$

$-463,53$

$-20,81$

$-1016,01$

$-524,45$

85,14

$-216,17$

$-0,94$

$-65,79$

$-129,70$

$-197,37$

$-256,59$

$-316,74$

$-379,71$

$-456,78$

$-531,97$

$-474,64$

$-550,77$

$-618,44$

$-708,67$

$-738,74$

$-863,75$

$-1000,97$

$-950,22$

$-1277,29$

$-512,23$

$-212,41$ 
escorvamento

$\begin{array}{rr}2,82 & 1,89 \\ -59,24 & -66,22 \\ -123,19 & -139,06 \\ -184,31 & -208,11 \\ 6,58 & 2,84\end{array}$

$-0,95$

$-34,06$

$-70,00$

$-106,90$

$-1,89$
0,00

$-61,52$

$-125,88$

$-183,61$

6,63
2,84

$-69,06$

$-145,68$

$-219,47$

8,51
0,95

$-58,65$

$-122,98$

$-182,57$

3,78
2,84

$-70,00$

$-146,63$

$-219,47$

7,57

ensaio

0,00

$-65,82$

$-129,77$

$-197,47$

$-254,83$

$-310,31$

$-365,79$

$-429,74$

$-486,16$

$-431,62$

$-494,62$

$-544,46$

$-592,42$

$-543,52$

$-608,40$

$-630,97$

$-582,07$

$-620,63$

$-157,98$

52,66

$$
\begin{array}{r}
0,00 \\
-70,00 \\
-140,95 \\
-217,57 \\
-284,74 \\
-356,63 \\
-428,53 \\
-515,56 \\
-598,80 \\
-519,34 \\
-610,15 \\
-687,72 \\
-780,43 \\
-770,97 \\
-915,70 \\
-1022,60 \\
-939,35 \\
-1148,41 \\
-276,22 \\
-15,14
\end{array}
$$

0,00

$-35,95$

$-71,89$

$-111,63$

$-148,52$

$-188,25$

$-227,03$

$-274,33$

$-319,74$

$-301,77$

$-344,33$

$-381,23$

$-429,47$

$-424,74$

$-481,50$

$-524,07$

$-514,61$

$-563,80$

66,22

99,33
0,00

$-64,36$

$-127,77$

$-194,97$

$-249,86$

$-308,54$

$-370,06$

$-446,72$

$-519,60$

$-451,46$

$-525,28$

$-590,58$

$-667,25$

$-661,57$

$-762,84$

$-845,18$

$-777,03$

$-921,84$

$-629,39$

$-253,65$
$-1,89$

$-78,52$

$-156,09$

$-239,33$

$-312,17$

$-388,80$

$-468,26$

$-570,42$

$-670,70$

$-606,37$

$-705,70$

$-798,40$

$-933,68$

$-953,54$

$-1140,85$

$-1432,21$

$-1366,93$

$-2813,33$

\#\#\#\#\#\#\#\#\# \#\#\#\#\#\#\#\#\#\#

\#\#\# \# \# \#\# \#\#\# \#\# \# \# \# \# \# \# \#\#
$-1,89$

$-77,57$

$-154,19$

$-235,55$

$-306,50$

$-375,55$

$-446,50$

$-530,69$

$-608,26$

$-535,42$

$-621,51$

$-691,51$

$-769,08$

$-742,59$

$-854,22$

$-922,33$

$-864,62$

$-980,98$

$-293,25$

21,76 
PROT3

Chan 56

ue

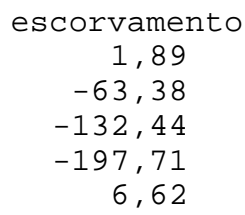


Resultados do ensaio do protótipo PROT 4 
PROT4

\begin{tabular}{|c|c|c|c|c|c|c|}
\hline Chan 0 & Chan 1 & Chan 2 & Chan 3 & Chan 4 & Chan 5 & Chan \\
\hline $\mathrm{kN}$ & $\mathrm{kN}$ & $\mathrm{kN}$ & $\mathrm{kN}$ & $\mathrm{mm}$ & $\mathrm{mm}$ & $\mathrm{mm}$ \\
\hline \multicolumn{7}{|c|}{ escorvamento } \\
\hline 0,00 & 0,00 & $-0,15$ & 0,00 & 0,00 & 0,02 & 0,00 \\
\hline$-4,28$ & $-4,86$ & $-5,15$ & $-5,23$ & 0,75 & 0,08 & 0,00 \\
\hline$-4,72$ & $-5,15$ & $-5,45$ & $-5,52$ & 0,88 & 0,11 & 0,00 \\
\hline$-9,74$ & $-10,31$ & $-10,60$ & $-11,03$ & 1,41 & 0,23 & 0,02 \\
\hline$-13,87$ & $-14,58$ & $-14,99$ & $-15,54$ & 1,52 & 0,36 & 0,00 \\
\hline$-0,15$ & 0,00 & $-0,15$ & $-0,15$ & $-0,32$ & 0,08 & $-0,02$ \\
\hline \multicolumn{7}{|l|}{ ensaio } \\
\hline 0,00 & 0,00 & $-0,15$ & 0,00 & 0,00 & 0,08 & $-0,02$ \\
\hline$-4,87$ & $-5,30$ & $-5,45$ & $-5,37$ & 0,77 & 0,06 & 0,00 \\
\hline$-9,59$ & $-10,16$ & $-10,30$ & $-10,74$ & 1,47 & 0,17 & 0,00 \\
\hline$-14,17$ & $-15,02$ & $-15,14$ & $-15,54$ & 1,97 & 0,24 & 0,00 \\
\hline$-19,18$ & $-20,02$ & $-20,14$ & $-20,76$ & 2,11 & 0,53 & 0,03 \\
\hline$-21,55$ & $-22,53$ & $-22,72$ & $-23,38$ & 2,61 & 0,62 & 0,05 \\
\hline$-24,05$ & $-25,18$ & $-25,29$ & $-25,84$ & 2,73 & 0,96 & 0,03 \\
\hline$-25,68$ & $-26,65$ & $-26,96$ & $-27,30$ & 2,46 & 1,88 & $-0,07$ \\
\hline$-26,56$ & $-27,68$ & $-27,86$ & $-28,31$ & 2,67 & 1,90 & $-0,07$ \\
\hline$-28,78$ & $-29,89$ & $-30,14$ & $-30,49$ & 3,05 & 1,93 & $-0,05$ \\
\hline$-25,24$ & $-26,94$ & $-27,26$ & $-28,17$ & 2,73 & 1,84 & $-1,45$ \\
\hline$-29,07$ & $-30,03$ & $-30,29$ & $-30,78$ & 3,21 & 1,86 & $-1,45$ \\
\hline$-31,29$ & $-32,54$ & $-32,71$ & $-33,25$ & 3,52 & 1,92 & $-1,45$ \\
\hline$-30,84$ & $-31,95$ & $-33,77$ & $-33,83$ & 4,06 & 1,90 & $-1,62$ \\
\hline$-32,47$ & $-32,83$ & $-34,22$ & $-32,81$ & 4,14 & 1,88 & $-2,29$ \\
\hline$-34,53$ & $-35,78$ & $-35,89$ & $-36,30$ & 4,45 & 1,92 & $-2,32$ \\
\hline$-36,16$ & $-37,54$ & $-37,56$ & $-38,04$ & 4,70 & 1,97 & $-2,31$ \\
\hline$-38,96$ & $-40,49$ & $-40,58$ & $-40,94$ & 4,72 & 2,10 & $-2,39$ \\
\hline$-35,12$ & $-37,69$ & $-35,89$ & $-37,31$ & 4,85 & 2,16 & $-3,83$ \\
\hline$-41,03$ & $-42,70$ & $-42,71$ & $-42,98$ & 5,53 & 2,33 & $-3,83$ \\
\hline$-43,39$ & $-45,05$ & $-45,13$ & $-45,44$ & 5,68 & 2,40 & $-3,81$ \\
\hline$-40,44$ & $-41,22$ & $-43,46$ & $-41,67$ & 5,38 & 2,63 & $-38,56$ \\
\hline$-23,91$ & $-27,09$ & $-24,84$ & $-27,44$ & 4,02 & 1,78 & $-38,55$ \\
\hline$-19,04$ & $-21,50$ & $-19,54$ & $-21,78$ & 3,57 & 1,43 & $-38,55$ \\
\hline$-17,71$ & $-19,43$ & $-17,87$ & $-19,17$ & 3,93 & 0,98 & $-38,55$ \\
\hline 0,30 & 0,29 & 0,45 & 0,44 & 1,95 & 0,90 & $-38,53$ \\
\hline
\end{tabular}


PROT4

\begin{tabular}{|c|c|c|c|c|c|c|}
\hline Chan 7 & Chan 8 & Chan 9 & Chan 10 & Chan 11 & Chan 12 & Chan 13 \\
\hline $\mathrm{mm}$ & $\mathrm{mm}$ & $\mathrm{mm}$ & $\mathrm{mm}$ & $\mathrm{mm}$ & $\mathrm{mm}$ & $\mathrm{mm}$ \\
\hline \multicolumn{7}{|c|}{ escorvamento } \\
\hline 0,09 & 0,07 & 0,00 & 0,00 & 0,00 & 0,00 & $-0,02$ \\
\hline 0,02 & 0,10 & 0,00 & 0,02 & 0,14 & 0,00 & 0,14 \\
\hline 0,02 & 0,14 & 0,00 & 0,04 & 0,16 & 0,00 & 0,13 \\
\hline 0,02 & 0,26 & 0,00 & 0,09 & 0,32 & 0,00 & 0,23 \\
\hline 0,05 & 0,54 & $-0,02$ & 0,24 & 0,56 & $-0,08$ & 0,65 \\
\hline 0,03 & 0,19 & 0,00 & 0,13 & 0,12 & $-0,06$ & 0,25 \\
\hline \multicolumn{7}{|l|}{ ensaio } \\
\hline 0,03 & 0,19 & 0,00 & 0,13 & 0,12 & $-0,06$ & 0,25 \\
\hline$-0,02$ & 0,10 & $-0,02$ & 0,00 & 0,14 & 0,02 & 0,16 \\
\hline 0,00 & 0,22 & $-0,02$ & 0,06 & 0,32 & 0,02 & 0,29 \\
\hline 0,02 & 0,36 & $-0,05$ & 0,11 & 0,46 & 0,02 & 0,38 \\
\hline$-0,07$ & 0,67 & $-0,07$ & 1,07 & 0,78 & $-0,10$ & 1,44 \\
\hline$-0,10$ & 1,17 & $-0,07$ & 1,25 & 1,24 & $-0,12$ & 1,68 \\
\hline$-0,10$ & 1,52 & $-0,09$ & 1,53 & 1,52 & $-0,16$ & 1,95 \\
\hline 0,00 & 1,74 & $-0,09$ & 2,60 & 1,62 & $-0,22$ & 2,79 \\
\hline 0,02 & 1,80 & $-0,09$ & 2,62 & 1,64 & $-0,24$ & 2,81 \\
\hline 0,09 & 1,92 & $-0,10$ & 2,77 & 1,76 & $-0,24$ & 2,94 \\
\hline 0,54 & 2,07 & $-0,12$ & 2,93 & 1,68 & $-0,22$ & 3,79 \\
\hline 0,57 & 2,14 & $-0,14$ & 2,95 & 1,76 & $-0,24$ & 3,88 \\
\hline 0,59 & 2,23 & $-0,14$ & 3,01 & 1,84 & $-0,24$ & 3,93 \\
\hline 1,42 & 2,44 & $-0,24$ & 3,17 & 2,12 & $-0,32$ & 4,18 \\
\hline 1,44 & 2,95 & $-0,22$ & 3,47 & 2,96 & $-0,33$ & 4,00 \\
\hline 1,44 & 3,02 & $-0,22$ & 3,49 & 2,98 & $-0,33$ & 4,07 \\
\hline 1,46 & 3,08 & $-0,22$ & 3,54 & 3,02 & $-0,33$ & 4,11 \\
\hline 1,56 & 3,33 & $-0,26$ & 3,78 & 3,24 & $-0,37$ & 4,31 \\
\hline 1,18 & 3,11 & $-0,22$ & 4,02 & 3,62 & $-0,33$ & 4,22 \\
\hline 1,20 & 3,37 & $-0,20$ & 4,11 & 3,68 & $-0,41$ & 4,31 \\
\hline 1,23 & 3,47 & $-0,20$ & 4,21 & 3,76 & $-0,41$ & 4,42 \\
\hline 0,94 & 3,52 & $-0,27$ & 5,00 & 3,88 & $-0,51$ & 4,07 \\
\hline 0,92 & 3,27 & $-0,20$ & 4,82 & 3,60 & $-0,49$ & 3,98 \\
\hline 0,97 & 3,11 & $-0,20$ & 4,80 & 3,44 & $-0,47$ & 3,91 \\
\hline 0,92 & 2,99 & $-0,15$ & 4,72 & 3,30 & $-0,37$ & 3,79 \\
\hline 1,01 & 2,25 & $-0,09$ & 4,63 & 2,64 & $-0,30$ & 2,36 \\
\hline
\end{tabular}


PROT4

Chan 14 Chan 15 Chan 16 Chan 17 Chan 18 Chan 19 Chan 20

$\mathrm{mm}$

$\mathrm{mm}$

$\mathrm{mm}$

$\mathrm{mm}$

$\mathrm{mm}$

$\mathrm{mm}$

escorvamento

$\begin{array}{lrrrrrr}0,00 & 0,00 & 0,00 & 0,00 & 0,00 & 0,00 & 0,00 \\ 0,06 & -0,02 & -1,21 & -0,76 & -0,76 & -2,77 & -0,77 \\ 0,09 & 0,00 & -1,32 & -0,80 & -0,79 & -0,83 & -0,80 \\ 0,17 & -0,02 & -2,80 & -1,67 & -1,62 & -1,70 & -1,68 \\ 0,36 & -0,04 & -4,38 & -2,58 & -2,55 & -2,61 & -2,56 \\ 0,15 & 0,00 & -0,29 & -0,15 & -0,18 & -0,32 & -0,22\end{array}$

ensaio

\begin{tabular}{|c|c|c|c|c|c|c|}
\hline 0,15 & 0,00 & $-0,29$ & $-0,15$ & $-0,18$ & $-0,32$ & $-0,22$ \\
\hline 0,06 & $-0,04$ & $-1,32$ & $-0,80$ & $-0,79$ & $-0,75$ & $-0,77$ \\
\hline 0,15 & $-0,04$ & $-2,72$ & $-1,64$ & $-1,58$ & $-1,54$ & $-1,57$ \\
\hline 0,21 & $-0,04$ & $-4,16$ & $-2,47$ & $-2,41$ & $-2,37$ & $-2,41$ \\
\hline 0,47 & $-0,11$ & $-6,25$ & $-3,56$ & $-3,67$ & $-4,11$ & $-3,62$ \\
\hline 0,52 & $-0,13$ & $-7,51$ & $-4,22$ & $-4,50$ & $-5,06$ & $-4,31$ \\
\hline 0,92 & $-0,15$ & $-8,98$ & $-5,13$ & $-5,36$ & $-6,01$ & $-5,30$ \\
\hline 1,93 & $-0,19$ & $-11,07$ & $-6,51$ & $-6,26$ & $-7,44$ & $-7,24$ \\
\hline 1,96 & $-0,19$ & $-11,52$ & $-6,73$ & $-6,47$ & $-7,71$ & $-7,49$ \\
\hline 2,00 & $-0,21$ & $-12,77$ & $-7,38$ & $-7,09$ & $-8,66$ & $-8,33$ \\
\hline 2,11 & $-0,15$ & $-14,28$ & $-10,76$ & $-7,95$ & $-9,34$ & $-9,36$ \\
\hline 2,13 & $-0,15$ & $-15,16$ & $-11,31$ & $-8,45$ & $-9,81$ & $-9,87$ \\
\hline 2,19 & $-0,15$ & $-16,08$ & $-11,82$ & $-8,96$ & $-10,32$ & $-10,34$ \\
\hline 2,47 & $-0,19$ & $-17,44$ & $-12,87$ & $-10,11$ & $-11,16$ & $-11,11$ \\
\hline 2,56 & $-0,19$ & $-18,43$ & $-13,20$ & $-10,86$ & $-11,75$ & $-11,51$ \\
\hline 2,60 & $-0,19$ & $-19,24$ & $-13,64$ & $-11,33$ & $-12,22$ & $-11,92$ \\
\hline 2,64 & $-0,21$ & $-19,90$ & $-14,00$ & $-11,73$ & $-12,62$ & $-12,32$ \\
\hline 2,73 & $-0,19$ & $-21,63$ & $-14,95$ & $-12,59$ & $-13,69$ & $-13,27$ \\
\hline 2,62 & $-0,26$ & $-22,85$ & $-16,04$ & $-12,77$ & $-14,56$ & $-16,41$ \\
\hline 2,80 & $-0,26$ & $-24,76$ & $-17,24$ & $-13,81$ & $-15,62$ & $-17,65$ \\
\hline 2,84 & $-0,26$ & $-26,12$ & $-18,07$ & $-14,64$ & $-16,42$ & $-18,42$ \\
\hline 2,75 & $-0,28$ & $-28,33$ & $-19,49$ & $-18,78$ & $-17,92$ & $-19,33$ \\
\hline 1,53 & $-0,17$ & $-32,08$ & $-22,87$ & $-16,12$ & $-15,55$ & $-28,98$ \\
\hline 1,22 & $-0,17$ & $-32,60$ & $-23,49$ & $-15,11$ & $-14,52$ & $-31,25$ \\
\hline 0,71 & $-0,11$ & $-34,92$ & $-25,16$ & $-14,78$ & $-14,16$ & $-34,90$ \\
\hline 0,64 & $-0,04$ & $-25,90$ & $-19,31$ & $-11,37$ & $-10,88$ & $-26,54$ \\
\hline
\end{tabular}


Chan 21 Chan 22 Chan 23 Chan $24 \quad$ Chan $25 \quad$ Chan 26 Chan 27

ne ne ne ne ue ue ue

\begin{tabular}{crrrrrr} 
escorvamento & \multicolumn{7}{c}{0} & \\
0,93 & 0,00 & 0,93 & 0,00 & 1,86 & 0,93 & 0,00 \\
$-35,25$ & $-59,37$ & $-44,53$ & $-48,21$ & $-65,86$ & $-57,88$ & $-53,35$ \\
$-38,03$ & $-64,01$ & $-48,24$ & $-51,92$ & $-70,50$ & $-63,48$ & $-58,03$ \\
$-76,07$ & $-127,08$ & $-95,55$ & $-102,92$ & $-141,93$ & $-126,97$ & $-115,12$ \\
$-110,39$ & $-178,10$ & $-135,43$ & $-144,64$ & $-203,15$ & $-182,98$ & $-159,10$ \\
$-0,93$ & 8,35 & 2,78 & 3,71 & 2,78 & $-0,93$ & 6,55
\end{tabular}

ensaio

$\begin{array}{rrrrrrr}-0,93 & 8,35 & 2,78 & 3,71 & 2,78 & -0,93 & 6,55 \\ -39,89 & -64,93 & -49,16 & -52,85 & -71,43 & -65,35 & -58,96 \\ -75,14 & -126,16 & -94,62 & -101,99 & -141,00 & -126,04 & -114,18 \\ -111,32 & -188,31 & -141,00 & -151,13 & -210,57 & -184,85 & -167,53 \\ -152,13 & -255,10 & -191,09 & -203,05 & -287,56 & -254,87 & -221,81 \\ -174,39 & -286,64 & -217,06 & -229,94 & -325,60 & -293,15 & -245,21 \\ -190,16 & -324,67 & -243,04 & -255,90 & -363,63 & -332,36 & -264,86 \\ -189,24 & -357,14 & -258,81 & -270,73 & -392,39 & -360,37 & -247,08 \\ -199,44 & -368,27 & -269,94 & -280,93 & -407,23 & -376,24 & -256,44 \\ -217,99 & -395,17 & -293,13 & -302,26 & -440,62 & -411,71 & -247,08 \\ -262,52 & -284,78 & -267,16 & -255,90 & -404,45 & -387,44 & -174,08 \\ -285,71 & -327,45 & -297,77 & -288,35 & -456,39 & -427,59 & -204,96 \\ -301,48 & -360,85 & -321,89 & -312,46 & -489,79 & -464,00 & -221,81 \\ -277,36 & -383,11 & -320,03 & -312,46 & -511,12 & -496,67 & -212,45 \\ -282,00 & -395,17 & -328,38 & -319,87 & -515,76 & -514,41 & -204,96 \\ -297,77 & -424,85 & -350,64 & -342,13 & -546,37 & -541,48 & -217,13 \\ -311,68 & -446,19 & -369,20 & -358,82 & -568,64 & -569,49 & -221,81 \\ -336,73 & -488,86 & -405,37 & -387,56 & -603,88 & -622,71 & -210,58 \\ -269,01 & -480,51 & -366,41 & -355,11 & -542,66 & -593,77 & -154,42 \\ -317,25 & -557,50 & -431,35 & -412,59 & -630,79 & -680,59 & -180,63 \\ -341,37 & -588,12 & -461,96 & -432,99 & -656,76 & -737,54 & -161,91 \\ -335,80 & -543,59 & -441,55 & -399,61 & -618,73 & -747,81 & -79,55 \\ -140,07 & -393,31 & -269,94 & -241,99 & -302,41 & -435,99 & 125,41 \\ -86,27 & -339,51 & -217,99 & -191,92 & -216,14 & -348,23 & 176,89 \\ -52,87 & -338,58 & -200,37 & -178,02 & -186,45 & -316,49 & 195,60 \\ 51,95 & -60,30 & -15,77 & 12,98 & 39,89 & -110,16 & 303,23\end{array}$


Chan 28

ue

Chan 29

ue
Chan 30

Chan 31

ue

ue

0,00
$-57,85$
$-62,52$
$-123,17$
$-176,36$
$-0,93$

Chan 32

ue

0,00

$-68,12$

$-73,72$

$-147,43$

$-210,89$

1,87
Chan 33

ue

0,93

$-89,62$

$-95,23$

$-192,32$

$-295,02$

$-20,54$
Chan 34

ue ensaio

2,78

$-75,14$

$-147,49$

$-219,85$

$-303,33$

$-347,86$

$-398,88$

$-463,81$

$-482,37$

$-551,94$

$-560,29$

$-617,80$

$-666,04$

$-725,40$

$-752,31$

$-794,98$

$-837,65$

$-931,34$

$-899,80$

$-1040,80$

$-1136,34$

$-1185,51$

$-780,13$

$-661,40$

$-622,44$

$-306,12$
0,93

$-56,59$

$-108,53$

$-157,70$

$-210,57$

$-236,54$

$-265,30$

$-291,27$

$-296,84$

$-309,83$

$-284,78$

$-309,83$

$-324,67$

$-323,74$

$-330,24$

$-340,44$

$-347,86$

$-352,50$

$-326,52$

$-340,44$

$-330,24$

$-304,26$

$-256,95$

$-226,34$

$-215,21$

$-35,25$
0,00

$-85,85$

$-170,76$

$-254,74$

$-353,66$

$-409,64$

$-472,16$

$-535,62$

$-555,21$

$-595,34$

$-538,42$

$-610,27$

$-664,39$

$-665,32$

$-695,18$

$-751,17$

$-794,10$

$-888,34$

$-832,35$

$-994,72$

$-1098,30$

$-1088,96$

$-722,24$

$-609,33$

$-570,14$

$-194,09$
$-0,93$

$-62,52$

$-122,24$

$-180,09$

$-243,55$

$-277,14$

$-311,67$

$-335,93$

$-344,33$

$-354,59$

$-307,00$

$-341,53$

$-360,19$

$-340,59$

$-345,26$

$-363,92$

$-369,52$

$-363,92$

$-303,27$

$-331,26$

$-302,33$

$-178,23$

$-60,65$

$-21,46$

$-7,47$

160,50
1,87
$-74,65$
$-146,50$
$-217,42$
$-297,67$
$-342,46$
$-395,65$
$-457,23$
$-474,03$
$-514,16$
$-483,36$
$-539,35$
$-586,94$
$-607,47$
$-636,40$
$-680,25$
$-722,24$
$-822,09$
$-807,16$
$-946,20$
$-1063,77$
$-1153,35$
$-879,01$
$-779,16$
$-746,51$
$-379,78$

$-20,54$

$-96,16$

$-189,52$

$-283,81$

$-404,25$

$-474,27$

$-540,55$

$-590,96$

$-614,30$

$-665,65$

$-643,25$

$-708,60$

$-765,55$

$-785,15$

$-803,82$

$-853,30$

$-896,25$

$-983,07$

$-832,77$

$-950,40$

$-1010,15$

$-974,67$

$-675,92$

$-579,76$

$-554,55$

$-175,52$
0,93

$-92,38$

$-98,91$

$-197,82$

$-291,14$

$-7,47$

$$
\begin{array}{r}
-7,47 \\
-99,85 \\
-195,02 \\
-291,14 \\
-404,05 \\
-462,83 \\
-519,75 \\
-549,61 \\
-571,08 \\
-622,40 \\
-526,29 \\
-590,67 \\
-639,20 \\
-635,46 \\
-655,99 \\
-700,78 \\
-739,97 \\
-822,09 \\
-817,42 \\
-972,32 \\
-1052,57 \\
-1026,44 \\
-663,46 \\
-551,48 \\
-508,56 \\
-149,30
\end{array}
$$


PROT4

Chan 35 Chan 36 Chan 37 Chan 38 Chan 39 Chan 40 Chan 41

ne ne ue ne ue ue ue

\begin{tabular}{|c|c|c|c|c|c|c|}
\hline 0,94 & 0,00 & 1,87 & 0,93 & 0,93 & 0,00 & 0,00 \\
\hline 16,01 & 13,06 & $-82,16$ & $-71,85$ & $-19,61$ & $-15,87$ & $-8,37$ \\
\hline 17,89 & 14,93 & $-93,36$ & $-75,58$ & $-20,54$ & $-15,87$ & $-8,37$ \\
\hline 37,66 & 30,79 & $-185,79$ & $-153,97$ & $-41,08$ & $-30,81$ & $-14,89$ \\
\hline 57,43 & 48,52 & $-279,14$ & $-232,35$ & $-56,95$ & $-44,81$ & $-18,61$ \\
\hline 5,65 & 5,60 & $-30,81$ & $-13,06$ & 3,73 & 0,93 & 0,93 \\
\hline \multicolumn{7}{|l|}{ ensaio } \\
\hline 5,65 & 5,60 & $-30,81$ & $-13,06$ & 3,73 & 0,93 & 0,93 \\
\hline 16,95 & 14,93 & $-91,49$ & $-77,45$ & $-21,47$ & $-16,80$ & $-7,44$ \\
\hline 36,72 & 30,79 & $-178,32$ & $-151,17$ & $-40,14$ & $-30,81$ & $-13,96$ \\
\hline 53,67 & 44,79 & $-267,94$ & $-225,82$ & $-60,68$ & $-46,68$ & $-20,47$ \\
\hline 76,26 & 64,39 & $-379,04$ & $-321,00$ & $-83,09$ & $-63,48$ & $-26,05$ \\
\hline 88,50 & 74,65 & $-455,59$ & $-375,12$ & $-95,23$ & $-73,75$ & $-28,84$ \\
\hline 101,68 & 86,78 & $-532,15$ & $-425,51$ & $-108,30$ & $-82,16$ & $-31,63$ \\
\hline 111,10 & 96,11 & $-596,57$ & $-459,10$ & $-118,57$ & $-87,76$ & $-35,35$ \\
\hline 115,81 & 100,78 & $-624,57$ & $-478,70$ & $-124,17$ & $-90,56$ & $-36,28$ \\
\hline 127,10 & 111,04 & $-683,39$ & $-526,29$ & $-136,30$ & $-97,09$ & $-36,28$ \\
\hline 118,63 & 105,44 & $-2600,99$ & $-455,37$ & $-128,84$ & $-89,62$ & $-38,15$ \\
\hline 132,75 & 119,44 & $-2662,61$ & $-505,76$ & $-142,84$ & $-98,96$ & $-38,15$ \\
\hline 144,99 & 128,77 & $-2725,16$ & $-544,02$ & $-156,84$ & $-106,43$ & $-38,15$ \\
\hline 145,93 & 135,30 & $-2750,37$ & $-544,95$ & $-160,58$ & $-107,36$ & $-37,21$ \\
\hline 150,64 & 139,04 & $-2776,51$ & $-561,75$ & $-165,25$ & $-110,16$ & $-37,21$ \\
\hline 161,94 & 149,30 & $-2825,05$ & $-599,07$ & $-176,45$ & $-114,83$ & $-35,35$ \\
\hline 171,36 & 158,63 & $-2871,73$ & $-635,46$ & $-187,65$ & $-120,43$ & $-33,49$ \\
\hline 188,30 & 175,43 & $-2966,03$ & $-714,78$ & $-211,93$ & $-130,70$ & $-26,98$ \\
\hline 176,06 & 142,77 & $-2852,13$ & $-731,58$ & $-199,79$ & $-120,43$ & $-24,19$ \\
\hline 203,37 & 165,16 & $-2957,62$ & $-877,14$ & $-230,60$ & $-137,24$ & $-13,03$ \\
\hline 219,37 & 176,36 & $-3014,57$ & $-956,46$ & $-249,27$ & $-140,97$ & $-2,79$ \\
\hline 216,55 & 167,03 & $-2986,57$ & $-950,86$ & $-249,27$ & $-132,57$ & 1,86 \\
\hline 145,93 & 111,04 & $-2712,09$ & $-675,59$ & $-176,45$ & $-98,03$ & $-17,68$ \\
\hline 122,40 & 92,38 & $-2623,40$ & $-590,67$ & $-154,04$ & $-87,76$ & $-23,26$ \\
\hline 114,86 & 85,85 & $-2599,12$ & $-558,95$ & $-148,44$ & $-84,02$ & $-26,05$ \\
\hline 42,37 & 30,79 & $-2249,96$ & $-276,21$ & $-68,15$ & $-35,48$ & $-29,77$ \\
\hline
\end{tabular}


PROT4

Chan 42 Chan 43 Chan 44 Chan 45 Chan 46 Chan 47 Chan 48

ue ue ne ue ue ue ue

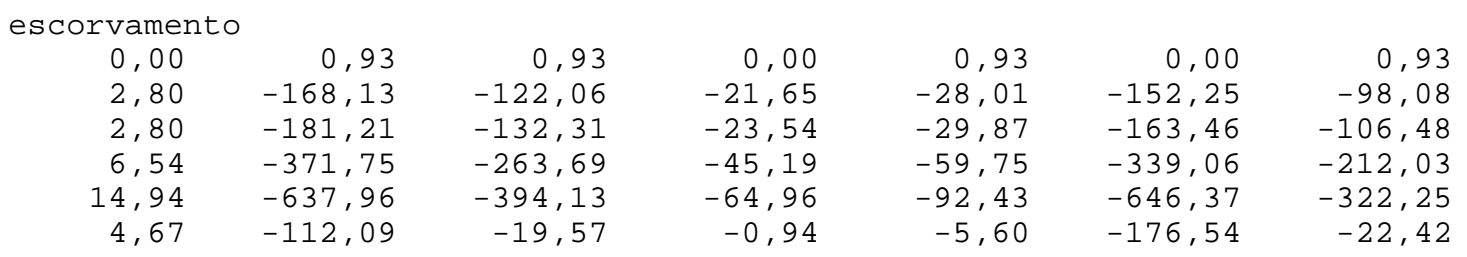

ensaio

$\begin{array}{rrrr}4,67 & -112,09 & -19,57 & -0,94 \\ 2,80 & -183,07 & -131,38 & -24,48 \\ 7,47 & -361,48 & -258,09 & -45,19 \\ 11,21 & -548,29 & -383,88 & -66,85 \\ 22,42 & -913,51 & -532,96 & -93,21 \\ 28,96 & -1257,24 & -616,82 & -110,16 \\ 40,16 & -1795,25 & -700,68 & -128,05 \\ 52,31 & -2517,28 & -760,31 & -146,88 \\ 57,91 & -2788,16 & -789,19 & -153,47 \\ 67,25 & -3385,02 & -813,42 & -164,76 \\ 70,05 & -3618,53 & -719,31 & -160,06 \\ 77,53 & -3803,47 & -804,10 & -172,30 \\ 88,74 & -4430,23 & -864,66 & -183,60 \\ 99,01 & -5029,89 & -850,69 & -186,42 \\ 04,61 & -5354,94 & -877,71 & -193,95 \\ 14,89 & -5812,63 & -938,27 & -201,48 \\ 27,97 & -6479,54 & -992,31 & -209,02 \\ 58,79 & -8076,78 & -1110,65 & -221,26 \\ 61,59 & -8438,26 & -1061,26 & -209,96 \\ 94,28 & -9679,62 & -1228,98 & -223,14 \\ 231,65 & -11411,36 & -1355,70 & -230,67 \\ 255,93 & -12792,83 & -1362,22 & -227,85 \\ 25,11 & -12602,28 & -929,89 & -207,13 \\ 211,10 & -12401,46 & -783,60 & -194,89 \\ 206,43 & -12357,56 & -712,79 & -192,07 \\ 63,46 & -11424,43 & -268,34 & -125,22\end{array}$

$$
\begin{array}{r}
-5,60 \\
-30,81 \\
-59,75 \\
-89,62 \\
-133,50 \\
-162,45 \\
-195,12 \\
-231,53 \\
-243,67 \\
-267,01 \\
-259,54 \\
-281,01 \\
-306,22 \\
-316,49 \\
-328,62 \\
-351,03 \\
-372,50 \\
-419,18 \\
-416,38 \\
-474,27 \\
-520,01 \\
-530,28 \\
-430,39 \\
-396,78 \\
-384,64 \\
-268,87
\end{array}
$$

$-22,42$

$-106,48$

$-207,36$

$-308,24$

$-433,40$

$-503,46$

$-580,05$

$-637,96$

$-664,11$

$-687,46$

$-622,08$

$-687,46$

$-737,90$

$-726,70$

$-748,18$

$-794,88$

$-835,05$

$-909,77$

$-861,20$

$-965,81$

$-1017,19$

$-966,75$

$-620,21$

$-507,19$

$-452,08$

$-107,42$ 
PROT4

Chan 49 Chan 50 Chan 51 Chan 52 Chan 53 Chan 54 Chan 55

ue ue ne ue ue ue ue

\begin{tabular}{crrrrrr} 
escorvamento & \multicolumn{7}{c}{0} & 0,94 & 0,00 \\
1,87 & 0,00 & 0,94 & 0,94 & 0,94 & 0,94 \\
$-40,16$ & $-56,49$ & $-59,32$ & $-64,96$ & $-59,29$ & $-67,76$ & $-34,84$ \\
$-42,97$ & $-62,14$ & $-64,02$ & $-70,61$ & $-63,99$ & $-74,34$ & $-37,66$ \\
$-86,87$ & $-125,22$ & $-128,05$ & $-142,17$ & $-126,10$ & $-148,68$ & $-75,32$ \\
$-121,43$ & $-182,65$ & $-185,48$ & $-208,07$ & $-180,68$ & $-210,79$ & $-107,33$ \\
6,54 & $-0,94$ & $-0,94$ & $-2,82$ & 0,94 & 4,71 & 0,94
\end{tabular}

ensaio

6,54
$-45,77$

$-87,80$

$-128,90$

$-168,13$

$-181,21$

$-198,02$

$-200,82$

$-210,16$

$-226,98$

$-174,67$

$-200,82$

$-223,24$

$-197,09$

$-186,81$

$-212,03$

$-226,04$

$-236,32$

$-207,36$

$-251,26$

$-271,81$

$-321,32$

$-180,27$

$-132,64$

$-113,95$

53,24

$$
\begin{array}{r}
-0,94 \\
-64,02 \\
-125,22 \\
-184,54 \\
-252,33 \\
-293,75 \\
-332,35 \\
-361,54 \\
-373,78 \\
-403,91 \\
-387,90 \\
-427,45 \\
-456,63 \\
-479,23 \\
-499,94 \\
-532,90 \\
-554,55 \\
-612,93 \\
-569,62 \\
-645,88 \\
-682,60 \\
-567,73 \\
-381,31 \\
-315,41 \\
-291,87 \\
-45,19
\end{array}
$$

$-2,82$

$-71,56$

$-140,29$

$-209,02$

$-291,87$

$-345,54$

$-395,44$

$-430,27$

$-443,45$

$-469,82$

$-428,39$

$-474,52$

$-511,24$

$-513,12$

$-531,95$

$-570,56$

$-595,98$

$-634,58$

$-592,21$

$-671,30$

$-708,02$

$-665,65$

$-452,87$

$-376,61$

$-344,59$

$-56,49$
0,94

$-65,87$

$-127,04$

$-185,39$

$-251,26$

$-287,02$

$-326,54$

$-352,89$

$-366,07$

$-395,24$

$-368,89$

$-403,71$

$-436,64$

$-458,29$

$-464,88$

$-496,87$

$-521,34$

$-560,86$

$-530,75$

$-594,74$

$-632,38$

$-619,21$

$-394,30$

$-312,43$

$-276,67$

$-36,70$
4,71

$-76,22$

$-147,74$

$-219,26$

$-293,61$

$-326,54$

$-362,30$

$-383,95$

$-399,00$

$-430,06$

$-392,42$

$-439,47$

$-471,46$

$-491,22$

$-483,70$

$-527,93$

$-548,63$

$-581,56$

$-533,57$

$-614,50$

$-644,61$

$-590,98$

$-271,96$

$-182,56$

$-149,63$

94,10
0,94

$-38,60$

$-74,38$

$-110,16$

$-133,69$

$-145,93$

$-160,06$

$-153,47$

$-161,94$

$-174,18$

$-144,99$

$-164,76$

$-184,54$

$-180,77$

$-241,03$

$-260,80$

$-272,10$

$-289,04$

$-308,82$

$-348,36$

$-364,37$

$-361,54$

$-231,61$

$-189,24$

$-167,59$

$-31,07$ 
PROT4

Chan 56 Chan 57 Chan 58 Chan 59 Chan 60 Chan 61 Chan 62

ue

ue

ue

ue

ue

ue

ue

escorvamento

0,94

1,88

1,88

$-54,61$

$-56,49$

$-73,40$

$-79,99$

$-122,40$

$-160,92$

$-59,32$

$-175,12$

$-231,50$

$-116,75$

$-172,30$

1,88

$-3,77$

0,94

$-71,52$

$-76,22$

$-153,39$

$-220,20$

3,76
0,91
$-51,88$
$-54,61$
110,13
160,19
$-2,73$
0,91

$-30,02$

$-31,84$

$-63,68$

$-88,24$

2,73
0,00

$-58,22$

$-62,77$

$-126,45$

$-183,77$

$-0,91$

ensaio

3,77

$-63,08$

$-122,40$

$-180,77$

$-257,03$

$-297,52$

$-336,12$

$-372,84$

$-386,02$

$-418,03$

$-390,73$

$-426,51$

$-455,69$

$-466,05$

$-408,62$

$-444,39$

$-467,93$

$-515,95$

$-430,27$

$-509,36$

$-547,96$

$-495,24$

$-323,88$

$-262,68$

$-243,85$

1,88

$$
\begin{array}{r}
1,88 \\
-81,87 \\
-159,98 \\
-238,08 \\
-331,25 \\
-381,12 \\
-437,59 \\
-498,75 \\
-519,46 \\
-574,04 \\
-553,33 \\
-607,91 \\
-660,61 \\
-689,78 \\
-683,20 \\
-744,37 \\
-787,65 \\
-885,52 \\
-836,59 \\
-992,80 \\
-1120,78 \\
-1141,49 \\
-543,92 \\
-395,24 \\
-338,78 \\
-79,99
\end{array}
$$

$-3,77$

$-60,26$

$-116,75$

$-170,41$

$-233,50$

$-265,51$

$-301,28$

$-327,65$

$-337,06$

$-355,89$

$-333,30$

$-357,77$

$-376,61$

$-377,55$

$-368,13$

$-388,84$

$-394,49$

$-395,44$

$-372,84$

$-378,49$

$-337,06$

$-260,80$

$-121,46$

$-56,49$

$-28,25$

111,10
3,76

$-78,11$

$-153,39$

$-227,73$

$-313,37$

$-370,77$

$-425,35$

$-466,76$

$-481,81$

$-516,63$

$-479,93$

$-528,87$

$-571,21$

$-592,86$

$-603,21$

$-654,03$

$-685,08$

$-746,25$

$-691,67$

$-809,30$

$-865,76$

$-828,12$

$-524,16$

$-431,00$

$-392,42$

$-80,93$
$-2,73$

$-55,52$

$-107,40$

$-159,28$

$-215,71$

$-250,30$

$-280,33$

$-299,45$

$-307,64$

$-321,29$

$-296,72$

$-321,29$

$-342,23$

$-346,78$

$-349,51$

$-371,35$

$-383,18$

$-398,66$

$-369,53$

$-410,49$

$-422,32$

$-409,58$

$-294,90$

$-250,30$

$-224,81$

$-10,92$

2,73
$-31,84$
$-62,77$
$-92,79$
$-115,54$
$-129,18$
$-138,28$
$-127,36$
$-134,64$
$-146,47$
$-141,01$
$-158,29$
$-172,85$
$-185,59$
$-185,59$
$-198,32$
$-210,15$
$-241,08$
$-228,34$
$-264,73$
$-278,38$
$-275,65$
$-75,51$
$-28,20$
$-16,38$
45,49

$-0,91$

$-64,59$

$-126,45$

$-187,41$

$-259,27$

$-295,66$

$-336,60$

$-377,54$

$-389,37$

$-420,30$

$-370,26$

$-411,20$

$-442,13$

$-438,49$

$-446,68$

$-476,70$

$-498,54$

$-526,74$

$-468,51$

$-551,30$

$-585,87$

$-542,20$

$-409,38$

$-358,44$

$-332,96$

$-46,40$ 
PROT4

Chan 63 Chan 64 Chan 65 Chan 66

\begin{tabular}{|c|c|c|c|}
\hline ue & ue & ue & ue \\
\hline \multicolumn{4}{|c|}{ escorvamento } \\
\hline 0,91 & 0,92 & 1,86 & 0,91 \\
\hline$-56,43$ & $-62,74$ & $-50,14$ & $-69,17$ \\
\hline$-60,98$ & $-66,43$ & $-51,07$ & $-75,54$ \\
\hline$-121,96$ & $-133,78$ & $-102,14$ & $-152,91$ \\
\hline$-178,39$ & $-190,06$ & $-140,21$ & $-222,99$ \\
\hline$-2,73$ & 2,77 & & 1,82 \\
\hline \multicolumn{4}{|l|}{ ensaio } \\
\hline$-2,73$ & 2,77 & 5,57 & 1,82 \\
\hline$-60,98$ & $-67,35$ & $-52,93$ & $-76,45$ \\
\hline$-120,14$ & $-131,94$ & $-101,21$ & $-152,00$ \\
\hline$-179,30$ & $-195,60$ & $-148,57$ & $-228,45$ \\
\hline$-244,84$ & $-261,11$ & $-194,99$ & $-321,29$ \\
\hline$-283,97$ & $-296,17$ & $-215,42$ & $-370,44$ \\
\hline$-327,66$ & $-333,07$ & $-236,78$ & $-426,87$ \\
\hline$-374,99$ & $-363,52$ & $-248,85$ & $-487,85$ \\
\hline$-387,73$ & $-369,05$ & $-253,49$ & $-508,79$ \\
\hline$-416,86$ & $-383,82$ & $-259,06$ & $-564,31$ \\
\hline$-390,46$ & $-345,99$ & $-233,06$ & $-539,73$ \\
\hline$-427,78$ & $-384,74$ & $-248,85$ & $-603,45$ \\
\hline$-462,37$ & $-407,81$ & $-246,99$ & $-667,16$ \\
\hline$-478,75$ & $-411,50$ & $-233,99$ & $-712,67$ \\
\hline$-487,85$ & $-411,50$ & $-223,78$ & $-722,68$ \\
\hline$-520,62$ & $-436,41$ & $-224,71$ & $-773,65$ \\
\hline$-550,66$ & $-445,63$ & $-211,71$ & $-832,81$ \\
\hline$-613,46$ & $-457,63$ & $-160,64$ & $-985,72$ \\
\hline$-585,24$ & $-398,58$ & $-128,14$ & $-942,94$ \\
\hline$-683,54$ & $-454,86$ & $-72,43$ & $-1182,32$ \\
\hline$-747,25$ & $-452,09$ & 70,57 & $-1458,10$ \\
\hline$-746,34$ & $-401,35$ & 400,20 & $-1988,73$ \\
\hline$-533,36$ & $-194,68$ & 4966,76 & $-16077,33$ \\
\hline$-457,82$ & $-137,47$ & 4546,13 & $-12230,93$ \\
\hline$-427,78$ & $-116,25$ & 4571,20 & $-11520,99$ \\
\hline$-140,17$ & 87,65 & 4184,93 & $-11449,09$ \\
\hline
\end{tabular}

